UNIVERSIDADE DE SÃO PAULO

FACULDADE DE ADMINISTRAÇÃO, ECONOMIA E CONTABILIDADE DEPARTAMENTO DE CONTABILIDADE E ATUÁRIA

PROGRAMA DE PÓS-GRADUAÇÃo EM CONTABILIDADE E CONTROLADORIA

DETERMINAÇÃO DA PERDA DE CRÉDITO POR MEIO DE MODELOS ESTRUTURAIS: APLICAÇÃO DA ABORDAGEM DE IMPLIED MARKET LOSS GIVEN DEFAULT

Cristiana Gobbi Macedo

Orientador: Prof. Dr. Luiz Paulo Lopes Fávero 
Prof. Dr. Marco Antonio Zago

Reitor da Universidade de São Paulo

Prof. Dr. Reinaldo Guerreiro

Diretor da Faculdade de Economia, Administração e Contabilidade.

Prof. Dr. Edgard Bruno Cornachione Jr.

Chefe do Departamento de Contabilidade e Atuária

Prof ${ }^{a}$ Dr. Andson Braga de Aguiar

Coordenador do Programa de Pós- Graduação em Controladoria e Contabilidade. 


\title{
DETERMINAÇÃO DA PERDA DE CRÉDITO POR MEIO DE MODELOS ESTRUTURAIS: APLICAÇÃO DA ABORDAGEM DE IMPLIED MARKET LOSS GIVEN DEFAULT
}

\begin{abstract}
Dissertação apresentada ao Departamento de Contabilidade e Atuária da Faculdade de Administração, Economia e Contabilidade da Universidade de São Paulo, como parte dos requisitos para obtenção do título de Mestre em Ciências.
\end{abstract}

Orientador: Prof. Dr. Luiz Paulo Lopes Fávero

Versão Corrigida

(versão original disponível na Unidade que aloja o Programa)

São Paulo

2014 
FICHA CATALOGRÁFICA

Elaborada pela Seção de Processamento Técnico do SBD/FEA/USP

\section{Macedo, Cristiana Gobbi}

Determinação da perda de crédito por meio de modelos estruturais: aplicação da abordagem de Implied Market Loss Given Default / Cristiana Gobbi Macedo. -- São Paulo, 2014.

$88 \mathrm{p}$.

Dissertação (Mestrado) - Universidade de São Paulo, 2014.

Orientador: Luiz Paulo Lopes Fávero.

1. Crédito 2. Risco 3. Modelos estruturais 4. Implied Market Loss Given Default. I. Universidade de São Paulo. Faculdade de Economia, Administração e Contabilidade. II. Título. 


\section{Para Arcinio Luiz Gobbi.}




\section{AGRADECIMENTOS}

Agradeço a Deus que tem me dado força e iluminação durante toda a minha vida e em especial neste período.

Aos meus pais, Octávio e Maria de Lourdes, e meu irmão, Eduardo, por sempre estarem presentes e pelo apoio nos bons e maus momentos da vida.

Aos professores do programa de pós-graduação: Iran Siqueira Lima, Reinaldo Guerreiro, Adriana Backx, Maria Aparecida Gouvêa e Bruno Salotti.

Aos amigos que fiz durante o mestrado: Patrícia Victório, Bianca Cotrim, Erika Pena, Carolina Guerra e Souza, Ademir Borbolatto, Marcelo Cunha de Souza, Samantha Telles e Rafael Sasso. Ao pessoal do programa de pós-graduação em Administração: Natalia Zaniboni, Ivan Ferraz, Nelson Yoshida, Gleriane Ferreira e Marcel dos Santos Cabral. Obrigada por todos os momentos: aqueles em que foram meus professores, aqueles em que me ofereceram um ombro amigo e aqueles em que simplesmente rimos juntos. Desejo a vocês muito sucesso em suas jornadas.

Ao pessoal da Secretaria de pós-graduação do FEA5 (obrigada Luciene!), da Secretaria de pós-graduação de Contabilidade e à equipe da biblioteca da FEA por sempre serem tão prestativos e gentis.

A Josiane da Silva Lereno (Josi, você salvou minha vida!).

A minha banca, pelas preciosas contribuições que fizeram ao trabalho.

Ao meu orientador.

A todos muito obrigada! 
"Things will get worse before they get better" Margaret Thatcher 


\section{RESUMO}

Em busca da adequação aos requisitos apresentados pelo Acordo de Basiléia, as instituições financeiras estão despendendo esforços para o desenvolvimento de mensurações e processos. Neste contexto se insere o desenvolvimento de modelos quantitativos para às organizações que pretendem se candidatar à abordagem avançada. $\mathrm{O}$ problema de pesquisa propõe mensurar o parâmetro de perda de crédito, ou loss given default, em situações em que não existam eventos de inadimplência observados. A literatura a respeito indica a utilização de modelos estruturais para estes cenários: o modelo proposto por Merton (1974) ou suas derivações são largamente empregados na determinação da probabilidade de perdas (probability of default - em inglês) e perdas de credito (loss given default - em inglês). Nesta metodologia a solução é encontrada de maneira implícita, por meio de preços de títulos e ações. Este trabalho aplica o modelo de Merton e verifica implicações deste uso para o calculo da perda de credito, neutra ao risco e implícita, em empresas listadas na Bolsa de Valores de São Paulo (Bovespa). O público foi selecionado no período de dezembro de 2006 a junho de 2013 e, informações como preço e quantidade de ações e valor da dívida contábil foram coletadas. Os principais resultados encontrados, de modo similar a de outros autores, mostram que: (i) a perda de crédito é maior em momentos de instabilidade financeira, como observado em 2008, época em que os preços dos ativos possuíram alta volatilidade, (ii) o maturity, ou duration, utilizado possui grande peso nos valores de perda de crédito: maturity maior, recuperação menor e (iii) quanto maior o peso da dívida contábil no valor da empresa, menor a volatilidade da própria.

Palavras-chave: Risco, Crédito, Modelos Estruturais, Implied Market Loss Given Default. 


\begin{abstract}
In an effort to comply with the Basel Agreement requirements, financial institutions have engaged in developing their own measures and processes. Within that context, quantitative models are being developed for organizations seeking an advanced approach. The researchrelated problem aims to estimate the credit loss parameter, loss given default, in situations where events of default are not observed. Literature in that respect indicates the utilization of structural models in such scenarios: the model proposed by Merton (1974) or its derivations are widely employed in determining the probability of default and loss given default. In this methodology the solution is found in an implied manner through the price of bonds and equities. This work applies the Merton model and verifies the implications of its use in calculating loss given default, risk neutral and implicit, in companies listed on the São Paulo Stock Exchange (Bovespa). The target populations in the period from December 2006 to June 2013 and such data as stock price, number of outstanding shares and debt book value have been collected. The main results found, in a manner very similar to other authors, demonstrate that: (i) the loss given default is greater at moments of financial instability, as observed in 2008, a time at which asset prices showed high volatility, (ii) the maturity, or duration, has a great influence on loss given default: higher the maturity, lower the recovery, and as well (iii) higher the book's value debt weight on firm value, the lower is the firm's value volatility.
\end{abstract}

Key words: Credit, Risk, Structural Models, Implied Market Loss Given Default 


\section{SUMÁRIO}

1. INTRODUÇÃO ........................................................................................................................................... 5

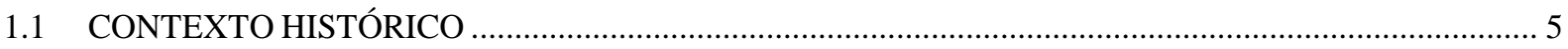

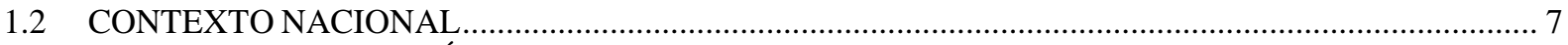

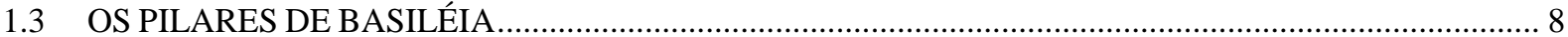

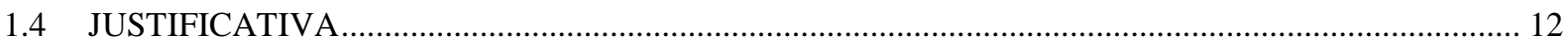

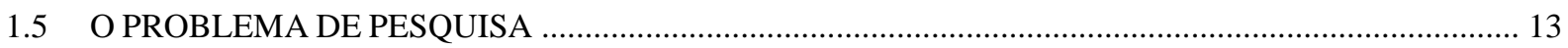

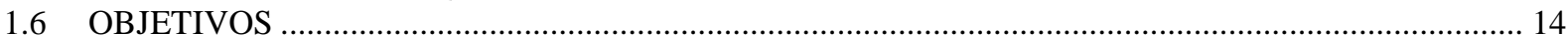

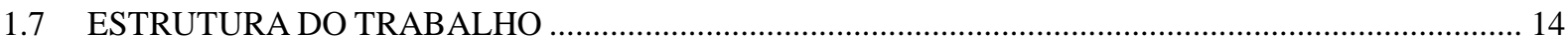

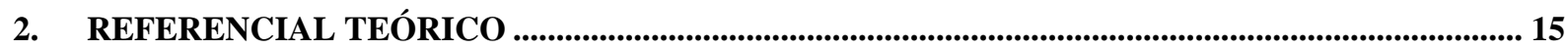

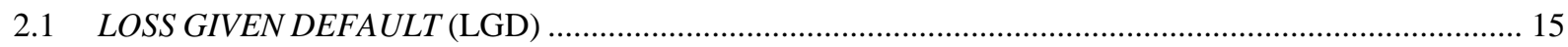

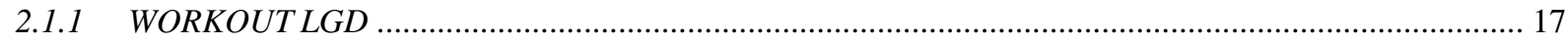

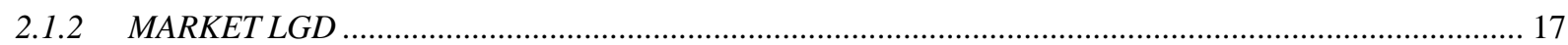

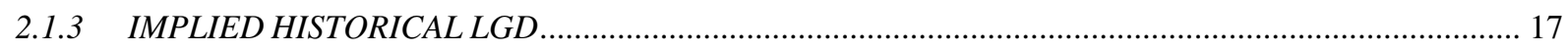

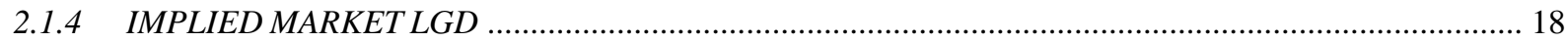

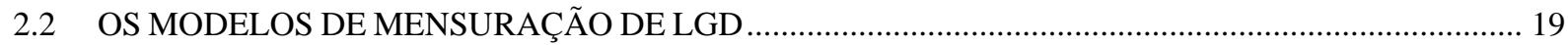

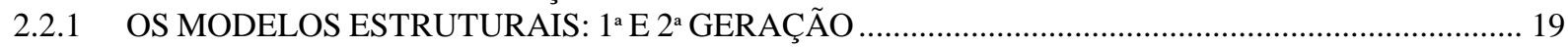

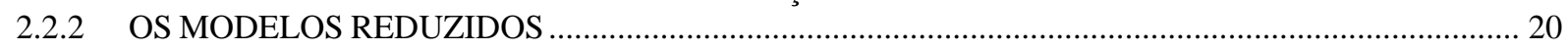

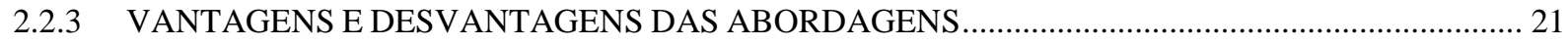

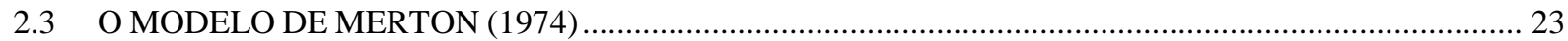

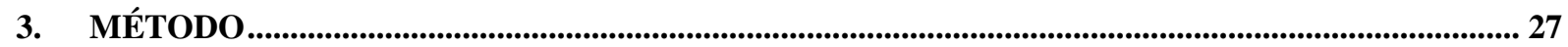

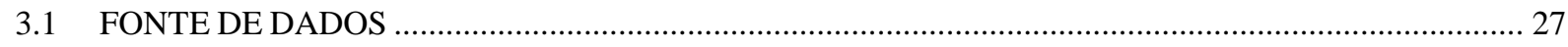

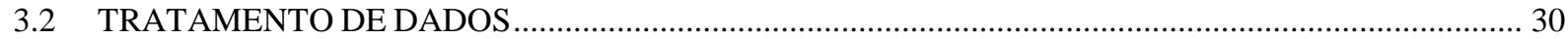

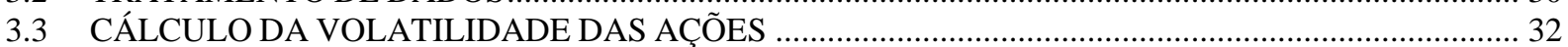

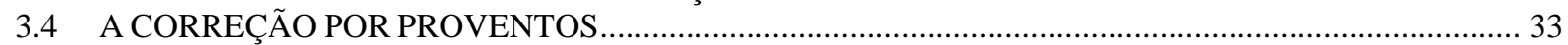

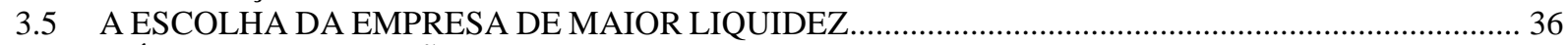

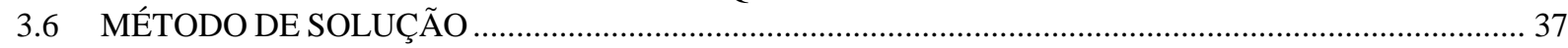

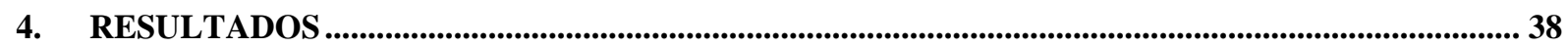

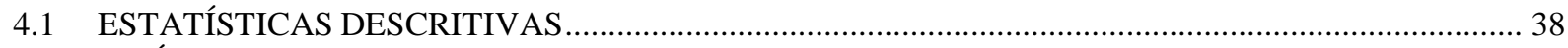

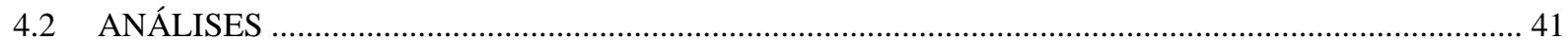

5. CONCLUSÕES, LIMITAÇÕES E POSSÍVEIS EXTENSÕES........................................................ 49

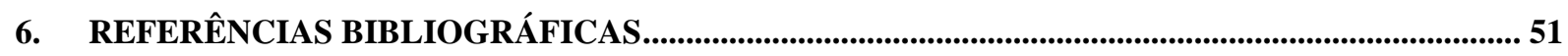

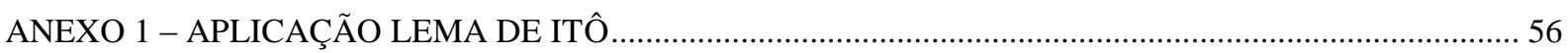

ANEXO 2 - DESENVOLVIMENTO DA FORMULAÇÃO DE MERTON PARA V (FIRM VALUE) .............. 57

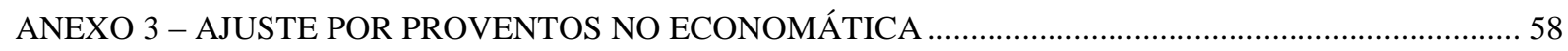

ANEXO 4 - TABELAS DO RESULTADO DE SELEÇÃO POR LIQUIDEZ ……………………………….... 59

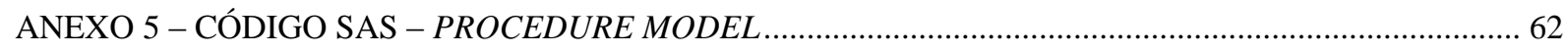

ANEXO 6 - GRÁFICOS DE LGD AO LONGO DO TEMPO PARA CADA EMPRESA DA MODELAGEM 63

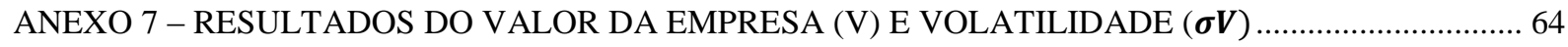




\section{LISTA DE SIGLAS}

BIS Bank for Internacional Settlements

G-10 Grupo dos 11 países mais industrializados do mundo: Alemanha, Bélgica, Canadá,

Estados Unidos, França, Itália, Japão, Países Baixos, Reino Unido, Suécia e Suíça.

LGD Loss Given Default

IMLGD Implied Market Loss Given Default

PD Probability of Default

EAD Exposure at Default

BACEN Banco Central do Brasil

FEBRABAN Federação Brasileira dos Bancos

CETIP Central de Custódia e Liquidação Financeira de Títulos

BCBS Basel Committee on Banking Supervision

CMN Conselho Monetário Nacional

BC Banco Central

BCB Banco Central do Brasil

CEBS Committee of European Banking Supervisors

EL Expected Loss

RMV Recovery of Market Value

ILGD Implied Loss Given Default

RR Recovery Rate

CD Certificates of Deposit 


\section{LISTA DE FIGURAS}

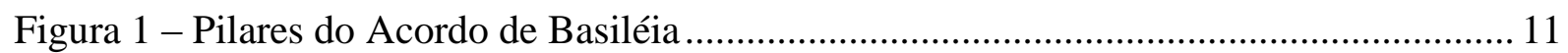

Figura 2 - Contexto do problema de pesquisa. .................................................................. 13

Figura 3 - Distribuição da LGD por Categoria do Tomador de Crédito [Adaptado Querci

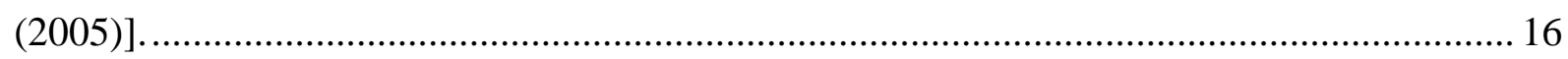

Figura 4 - Procedimento de Limpeza e Criação da Base de Modelagem................................. 30

Figura 5 - Quantidade de empresas por setor na base de modelagem................................... 38

Figura 6 - Comportamento das volatilidades das ações por data base. .................................. 41

Figura 7 - Média das medidas do modelo para a volatilidade de 3 meses. .............................. 42

Figura 8 - Média das medidas do modelo para a volatilidade de 6 meses. .............................. 44

Figura 9 - Média das medidas do modelo para a volatilidade de 12 meses. ........................... 45

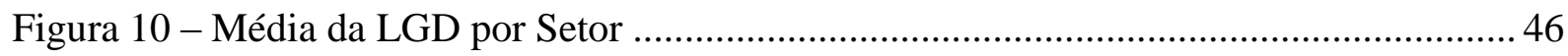




\section{LISTA DE QUADROS E TABELAS}

Quadro 1 - Vantagens e Desvantagens das Abordagens de Mensuração de LGD. 21

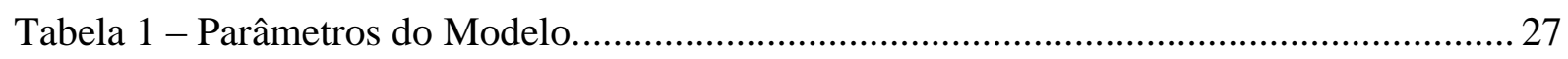

Tabela 2 - Seleção das informações no Economática........................................................... 28

Quadro 2 - Resumo dos tipos de tratamentos realizados na base de dados............................ 31

Tabela 3 - Ajuste por Proventos realizados na Quantidade de Ações. .................................... 34

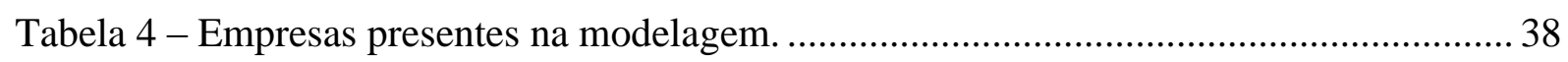

Tabela 5 - Análise descritiva das variáveis E (equity) e F (dívida) ....................................... 39

Tabela 6 - Descritiva Estatística da volatilidade de 3 meses................................................ 40

Tabela 7 - Descritiva Estatística da volatilidade de 6 meses................................................ 40

Tabela 8 - Descritiva Estatística da volatilidade de 12 meses............................................. 40

Tabela 9 - Descritivas do Valor de Volume Negociado por Empresa e Percentual em relação à

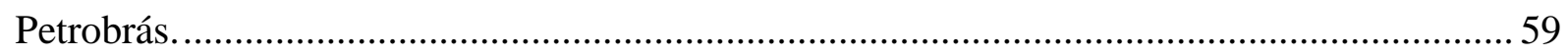

Tabela 10 - Descritivas do Percentual de Volume Negociado por Empresa............................ 60 


\section{INTRODUÇÃO}

\subsection{CONTEXTO HISTÓRICO}

A década de 70 foi marcada pela volatilidade ocasionada pelo término do sistema de câmbio fixo. Este sistema, determinado pelo acordo de Bretton Woods em 1944, previa que os países adotassem políticas monetárias que mantivessem a taxa de câmbio a um determinado valor indexado ao dólar. O valor do dólar, por sua vez, estaria ligado ao ouro.

No começo da década de 70, os EUA abandonaram esse sistema, caracterizando um período em que o mercado teve dificuldades em administrar a moeda, uma aceleração do quadro inflacionário e na elevação da taxa básica de juros. Nesse cenário, as instituições financeiras passaram a aplicar maiores taxas em seus empréstimos para manter suas margens e se viram estimuladas a buscar novas alternativas de ativos mais arriscados com alto retorno e isentos de controle regulatório (Leite et al., 2011).

Segundo o autor Amaral (2009), inúmeras crises são percebidas durante todo o século $\mathrm{XX}$ e, menores no período antes e durante o período de Bretton Woods. O referido autor, também cita que é possível concluir, por um trabalho dos autores Klingebiel e Caprio $(2003)^{1}$., que "a maior parte destas crises bancárias foram internas”, indicando a necessidade por uma supervisão e regulamentação das instituições financeiras.

Em meio a este cenário o BIS - Bank for Internacional Settlements promoveu um comitê, formado pelos responsáveis pela supervisão bancária dos países integrantes do G-10, em 1975 com "a intenção de promover o entendimento e a qualidade da supervisão bancária no mundo" (BCBS,2013a).

Como produto dos diversos encontros entre os países membros desde a sua instituição, em 1988, é firmado o Acordo de Basiléia I, que define três conceitos, a saber: Capital Regulatório, que é o montante de capital próprio alocado para cobertura de riscos, considerando parâmetros definidos pelo regulador; Fatores de Ponderação de Risco de Ativos, onde a exposição ao risco de crédito dos ativos é ponderada por diferentes pesos e Índice Mínimo de Capital, o coeficiente do valor do capital regulatório pelos ativos ponderados ao risco deve ser maior igual a $8 \%$.

Desde 1988 este acordo veio, progressivamente, sendo introduzido em outros países além dos membros do G-10. O acordo não tem a intenção de ser estático, pelo contrário sua

\footnotetext{
${ }^{1}$ Os autores realizaram um extenso trabalho de levantamento dos países que sofreram episódios de insolvência bancária a partir de 1970. Há uma apresentação da descrição da crise e, para os casos disponíveis, a perda estimada no evento.
} 
intenção é acompanhar as inovações e mudanças que o mercado e as instituições financeiras proporcionam.

A partir de 1999 o comitê começou a trabalhar em melhorias no primeiro acordo firmado em 1988, e em junho de 2006 foi firmado o novo acordo nomeado Acordo de Basiléia II composto por três pilares: capital mínimo requerido, que procurou seguir e expandir as regras do acordo de 1988; revisão supervisória da adequação de capital e dos processos internos; e forte disciplina de mercado e encorajamento de boas práticas bancárias (BCBS, 2013a).

Entre as mudanças do segundo acordo em relação ao primeiro estão: a inserção da medida de risco operacional, uma categoria específica para tratar a disciplina de mercado e, também, a abordagem metodológica para o cálculo dos requisitos mínimos de capital. No primeiro acordo a abordagem era única, padronizada. Já o segundo acordo permite a escolha entre a abordagem padronizada, na qual os parâmetros são definidos pelo órgão regulador, ou uma abordagem avançada, na qual as instituições desenvolvem modelos internamente para definirem os parâmetros.

Contudo, no final do ano de 2008, quando nem todas as instituições haviam se consolidado nos padrões do acordo de 2006, culminou a crise nos Estados Unidos, conhecida como "Crise dos subprimes", que abalou todo o sistema financeiro mundial em um efeito dominó.

Analisando as experiências advindas desta crise, os países em que esta teve maior efeito, o acordo sofreu algumas modificações a fim sempre de garantir o bom funcionamento e a solidez do mercado.

Em setembro do ano de 2011 foi apresentado o acordo de Basiléia III. Este novo acordo aumenta as exigências de capital das instituições, reforçando os requisitos de capitais e, introduzindo requisitos sobre liquidez e alavancagem. Basicamente, o capital mínimo requerido que era de $8 \%$ será elevado para $10,5 \%$ até o final de 2019 , segundo a aplicação do Capital Conservation Buffer. O acordo introduz também o Countercyclical Capital Buffer, que variará de 0\% a 2,5\% (BCBS, 2013b). O intuito destas determinações é que as instituições constituam um "colchão", uma reserva, nos momentos bons para fazer frente às situações de recessão.

As instituições, portanto, devem adequar seus sistemas para atender as necessidades dos Acordos, principalmente as instituições que optarem por aderir à abordagem avançada. Nesta abordagem é necessária readequação de sistemas para tornar as informações mais aderentes à realidade dos negócios, aperfeiçoando o cálculo dos parâmetros, de acordo com a formação de sua carteira. 


\subsection{CONTEXTO NACIONAL}

O Brasil foi uma das economias em que o impacto da "Crise do subprimes" não tomou grandes proporções. É fato que, em uma economia globalizada como a dos dias atuais, o impacto foi sentido principalmente ao longo do ano de 2008. Segundo matéria da revista Veja (2008, 15 de outubro), a Bolsa de Valores de São Paulo (Bovespa) havia sofrido cinco circuits breakers $^{2}$ até a metade do mês de outubro.

Contudo, apesar dos reflexos sentidos, a economia brasileira enfrentou bem a crise. Segundo o autor Barfield (2011), além do Brasil, os países da Ásia em geral, Austrália, Rússia, Canadá e África do Sul são alguns exemplos de economias que saíram ilesas da crise.

Segundo o BACEN (2013), o Brasil é um país com uma regulação conservadora e "o nosso SFN não tinha e não tem as características que levaram à crise financeira global (pouco capital, provisões insuficientes, alavancagem excessiva, ativos de grande complexidade) ". O mesmo autor complementa ainda que para os esforços relativos à Basiléia III : "o SFN como um todo terá capital superior aos valores exigidos".

É sabido que o Brasil já trabalhava com um percentual de PR/PRE ${ }^{3}$ de $11 \%$, segundo Resolução do CMN no 3.490, de 29 de agosto de 2007, e Circular do BC n 3.360, de 12 de setembro de 2007, enquanto os demais países trabalhavam com $8 \%$.

Visto este cenário o BACEN manteve o cronograma internacional para implantação de Basiléia III, ainda que as instituições estivessem em processo de desenvolvimento dos requisitos do acordo de Basiléia II, porque, o Acordo de Basileia III não substitui o Acordo de Basileia II, mas sim o aprimora e complementa, portanto os esforços para o alcance dos requistos do Acordo III necessitam do atendimento do Acordo II e do I.

Os novos conceitos introduzidos do Acordo I para o Acordo II foram mais onerosos do ponto de vista de implementação operacional do que as introduções feitas do Acordo II para o III. O acordo II insere o contexto do risco operacional, da necessidade de criação de processos seguros, bem mapeados, exigindo grandes esforços tecnológicos. Já o acordo III exige maior esforço financeiro por parte das Instituições, pois exige considerável aumento nas resevas necessárias frente às épocas de crise.

\footnotetext{
${ }^{2}$ Circuit Breaker é o nome dado a um mecanismo ativado pela Bolsa para interromper o pregão devido a grandes quedas.

${ }^{3}$ PR- Patrimônio de Referência e PRE - Patrimônio de Referência Exigido. A razão PR/PRE mede o quanto do patrimônio da empresa está acima do mínimo exigido pelo órgão regulador, portanto o quanto a empresa tem de patrimônio para cobrir riscos de suas operações ativas.
} 
A adoção das regras de Basiléia III, assim como as de Basiléia II, foi sempre precedida de vastos estudos sobre o cenário brasileiro sob a luz do Acordo. Segundo FEBRABAN (2013): "A adoção das regras de Basiléia III no País foi precedida de estudos detalhados, conduzidos pelas áreas técnicas do BCB, e também de um longo e amplo processo de consulta pública”. $\mathrm{O}$ resultado destes estudos foi um conjunto de normativos com o objetivo de guiar as instituições no seu processo de adequação às normas.

No cronograma de Basiléia III para o Brasil, as datas de entrega segundo a Resolução ${ }^{\circ}$ 4.193 do BACEN, tem como previsão de completude de todos os requisitos o final do ano de 2019.

\subsection{OS PILARES DE BASILÉIA}

O Acordo de Basiléia se apoia nos chamados três pilares:

\section{O Pilar 1.}

Este pilar trata da exigência do Capital Mínimo. Este pilar envolve a quantificação dos riscos de crédito, risco de mercado e risco operacional.

O risco de crédito segundo Sicsú (2010): "pode ser avaliado de forma subjetiva ou medido de forma objetiva utilizando metodologia quantitativa. A avaliação subjetiva, apesar de incorporar a experiência do analista, não quantifica o risco de crédito". No Acordo, a abordagem para o risco de crédito pode ser: padrão, na qual o órgão regulador determina os valores dos parâmetros e, avançada em que a instituição desenvolve seus métodos para determinação dos parâmetros. O risco de crédito, em qualquer que seja a abordagem, se mensura por meio de três parâmetros: PD (probability of default), LGD (loss given default), pela EAD (exposure at default). Para a determinação do capital requerido é necessário, ainda, a introdução do conceito de M (maturity).

PD (probability of default): segundo Schuermann (2004) a probabilidade de default ${ }^{4}$ é definida como a probabilidade da ocorrência de inadimplência de um tomador de crédito no horizonte de um ano. Segundo BCBS (2005, p.96), o default é definido:

\footnotetext{
${ }^{4}$ Default é a inadimplência, o não cumprimento da obrigação.
} 
"A ocorrência do default é considerada quando ou o credor ou uma dívida em particular se enquadra em um ou mais eventos a seguir:

- O banco considera que a obrigação provavelmente não será paga em sua totalidade,

- A obrigação possui atrasos materiais em mais de 90 dias. "'grifos próprios]

O documento de 2005, ainda acrescenta que os elementos, os quais caracterizam o evento como "provável”, são: a operação entra no estágio de não accrual; ou o banco realiza uma conta de provisão devido ao declínio perceptível da qualidade de crédito; ou o banco vende a obrigação; ou, ainda, o banco concede renegociação.

EAD (exposure at default): exposição no default, ou seja, o montante da operação no momento do default.

M (maturity): prazo médio da operação, duration. Segundo Hull (2005), o duration é o tempo médio, ponderado pelo valor dos fluxos de recebimento, que se espera receber o pagamento.

LGD (loss given default): definida como a perda dada ao default, ou como 1 - a taxa de recuperação. Segundo Schuermann (2004), a perda dada ao default inclui três tipos de perda: a perda do principal, o custo de "carregamento" da operação e as despesas com cobranças.

O mesmo autor cita que existem três abordagens para o cálculo deste parâmetro:

- Market LGD: observada a partir dos preços de mercado de bonds em default, ou empréstimos ativos no mercado que acabaram de entrar em default;

- Workout LGD: estimada através de fluxos de caixa, resultado do processo de recuperação da operação;

- Implied Market LGD: esta metodologia deriva do risco de preço de bonds (que não estão em default), utilizando de um modelo teórico de pricing.

O CEBS (2006), também acrescenta a abordagem de Implied Historical LGD, que assim como a Implied Market LGD, não se baseia diretamente em instrumentos em default. Porto (2011), explica que este método para a determinação da LGD é permitido, segundo BCBS (2005, parágrafo 465), para carteira de varejo e se baseia na fórmula de perda esperada (expected loss - EL) determinada pelo produto dos parâmetros EAD, PD e LGD.

O risco de mercado, segundo Jorion (2003, pg. 14), advém “dos movimentos dos níveis e volatilidades dos preços de mercado". Segundo o Acordo de Basiléia, para o risco de mercado a abordagem também pode ser a padrão e a avançada. 
O risco operacional, segundo BCBS (2005, p.140): "é definido como o risco de perdas resultante da inadequação ou falha dos processos internos, pessoas e sistemas ou por eventos externos (incluindo o risco legal)", define-se, então, como a parte do risco relacionada com perdas de sistemas inadequados e falhas humanas. $\mathrm{O}$ acordo descreve os tratamentos a serem adotados para a mensuração deste risco que, também, assim como os demais já descritos possui a abordagem padrão e avançada. A mensuração padronizada deste risco é feita pela medição da receita bruta ("gross income"), que, segundo o Acordo, serve como uma boa proxy para determinação da escala operacional e, por conseguinte, da exposição em determinada linha operacional.

Portanto, pode-se dizer, que o Pilar 1 é quantitativo, isto é, transcreve os riscos aos quais uma instituição está sujeita (crédito, mercado e operacional) em números, a fim de construir um capital mínimo, assegurando a solvência em situações adversas.

\section{O Pilar 2.}

Pilar que trata da supervisão bancária. Segundo BCBS (2005), este pilar se apoia em quatro princípios chaves:

Principio 1: Os bancos devem ter um processo para avaliar a adequação do seu capital global com relação ao seu perfil de risco e uma estratégia para manutenção dos seus níveis de capital.

Principio 2: Os supervisores devem rever e avaliar a estratégia e a adequação do capital interno, assim como suas habilidades de monitorar e assegurar sua observância com a relação de capital regulatório. Devem, também, tomar ações cabíveis caso os resultados não sejam satisfatórios.

Principio 3: Os supervisores devem esperar que os bancos operem acima do mínimo de capital regulatório exigido e ter a habilidade de exigir que os bancos mantenham o capital acima deste mínimo.

Principio 4: Os supervisores devem procurar intervir nos estágios iniciais, para prevenir que o capital fique abaixo do mínimo, para suportar as características de risco 
de um banco e, devem exigir uma rápida ação caso o capital não seja mantido ou restaurado.

O segundo Pilar do Acordo assegura o acompanhamento rigoroso do órgão supervisor responsável e, este acompanhamento, exige que o mesmo tenha papel ativo junto às instituições, com a finalidade de garantir o bom funcionamento do sistema financeiro como um todo.

\section{O Pilar 3.}

Pilar que trata da disciplina de mercado. Este último pilar trata do disclosure das informações, descreve uma série de pontos importantes como tratamento e apresentação das informações pertinentes e, novamente, do papel crucial do órgão supervisor junto aos bancos para o cumprimento das normas.

Os três pilares juntos perseguem a intenção de manter a solidez das instituições, com intuito de que essas consigam passar por momentos de crises sem sofrerem grandes impactos. A figura 1 ilustra, resumidamente, o objetivo de cada um dos três pilares dentro do Acordo de Basiléia.

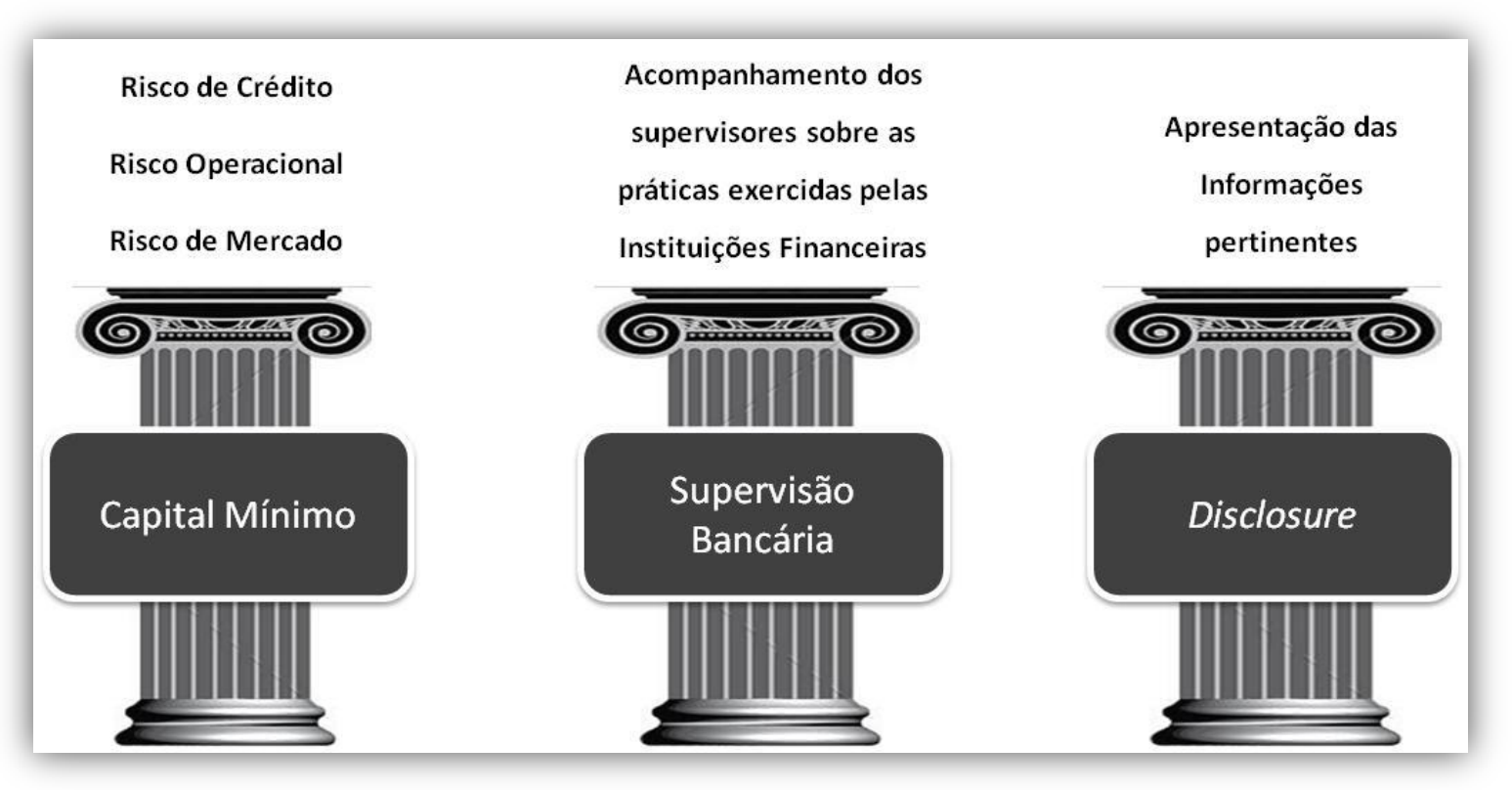

Figura 1 - Pilares do Acordo de Basiléia 


\subsection{JUSTIFICATIVA}

As instituições financeiras deverão até 2019 atender os requisitos do Novo Acordo de Basiléia III, e, para isso, precisarão atentar em percorrer as exigências contidas nos três pilares de Basiléia, devendo adequar seus processos, sua estrutura, seus sistemas, seus disclosures.

O risco de crédito, inserido no Pilar 1, pode ser quantificado pelas orientações da abordagem avançada. Nesta escolha, as instituições serão responsáveis pelo desenvolvimento de seus modelos para mensuração quantitativa dos parâmetros necessários ao cálculo de capital mínimo.

Segundo Querci (2005): “avaliações empíricas de loss given default são relativamente recentes", as instituições financeiras já possuíam modelos de mensuração de probabilidade de inadimplência (ou default como apresentado anteriormente), este conceito já era conhecido antes da introdução do Novo Acordo, contudo, a mensuração do parâmetro de LGD, ou seja, de perda dada à inadimplência, surgiu por meio do próprio Acordo, portanto, os estudos no tema são bem mais recentes do que os para determinação da PD.

Sob este contexto, o presente trabalho se propõe a estudar um modelo teórico para predição da LGD por meio dos preços de ativos adimplentes, metodologia determinada Implied Market LGD.

A motivação surgiu das seguintes indagações:

- Qual o comportamento e peculiaridades deste tipo de abordagem?

- Quais são as características: vantagens, desvantagens e limitações de uso deste tipo de metodologia? 


\subsection{O PROBLEMA DE PESQUISA}

O problema de pesquisa segundo Martins e Theóphilo (2009) “origina-se da inquietação, da dúvida, da hesitação, da perplexidade, da curiosidade sobre uma questão não resolvida". Somado a isso, as indagações introduzidas no tópico anterior (1.4 Justificativa), este trabalho propõe elucidar as indagações relativas à aplicação da Implied Market LGD para empresas no cenário brasileiro. Dentro do contexto de Basiléia, o problema está inserido no Pilar 1, risco de crédito, na abordagem de modelos avançados para o parâmetro LGD conforme ilustrado na figura 2 .

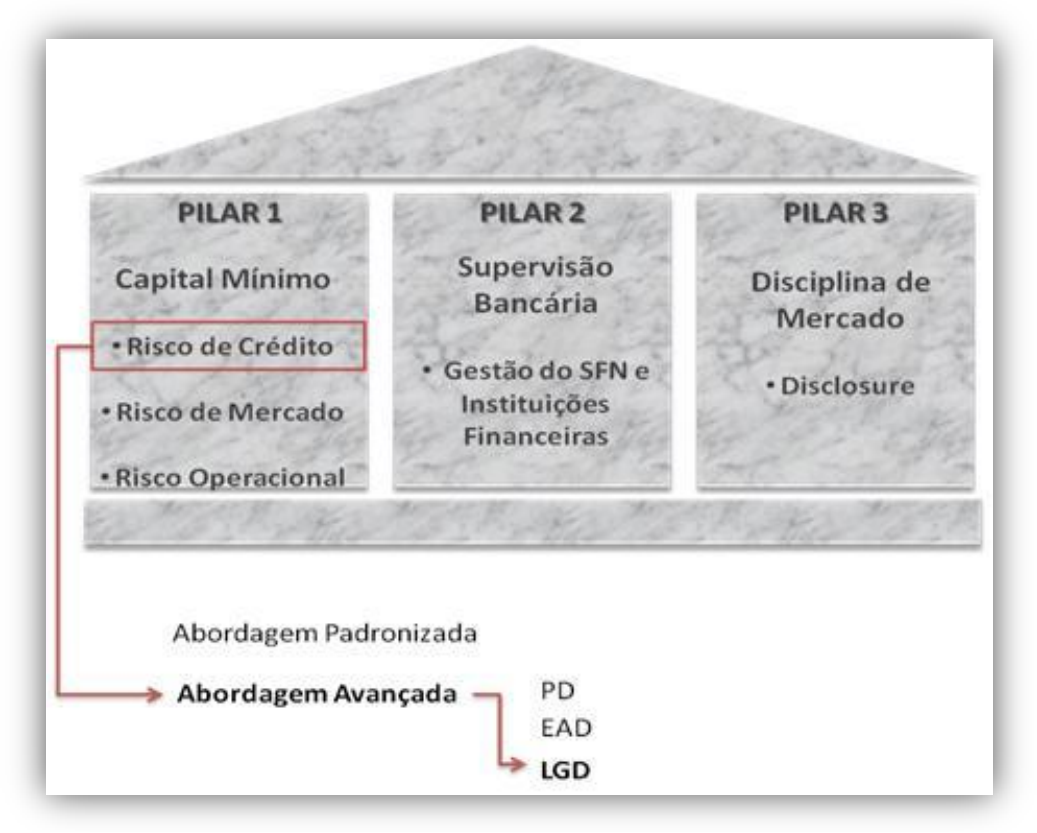

Figura 2 - Contexto do problema de pesquisa.

A formulação do problema de pesquisa é: Quais as implicações da utilização do modelo estrutural de Merton na determinação de perdas em crédito? 


\subsection{OBJETIVOS}

O estudo tem a intenção de elucidar os seguintes pontos:

- Averiguar o comportamento do modelo de Implied Market LGD para companhias brasileiras em períodos de "stress" e períodos de crescimento;

- Avaliar a sensibilidade dos parâmetros do modelo e seus impactos na determinação da perda de crédito;

- Verificar os prós e contras da utilização deste modelo para o cálculo da LGD;

\subsection{ESTRUTURA DO TRABALHO}

O trabalho está estruturado da seguinte maneira: o segundo tópico - referencial teórico que apresentará o conceito de LGD, suas abordagens metodológicas e com mais profundidade a metodologia alvo de estudo. O terceiro tópico descreverá a metodologia utilizada para operacionalização da pesquisa. O quarto tópico exibirá os resultados obtidos. O quinto tópico apresentará as conclusões, as limitações e as possíveis extensões do trabalho. 


\section{REFERENCIAL TEÓRICO}

\subsection{LOSS GIVEN DEFAULT (LGD)}

Loss Given Default, ou a perda dada ao default, é o percentual da dívida que não será recuperada após o não cumprimento. Segundo BCBS (2005), “a definição de perda usada na estimativa da LGD é a perda econômica. Quando se mensura a perda econômica, todos os fatores relevantes são levados em conta", portanto, não basta simplesmente identificar as taxas de recuperação da obrigação, mas, também, devem ser inclusos os custos incorridos.

Segundo Schuermann (2004), existem quatro estágios que a empresa em dificuldades enfrenta:

(1) o primeiro é o estágio do último pagamento. O autor denomina de LCP (last cash paid),

(2) o segundo é a inadimplência, que ocorre algum tempo depois do último pagamento. Conforme definido pelo BCBS (2005, p.96), ocorre 90 dias depois do último pagamento.Por outro lado o autor acrescenta que em títulos de dívida (bonds), esse evento ocorre seis meses depois do último pagamento, isso porque, este título de dívida, paga cupons semestrais ao detentor então, portanto o evento de default será identificado no "não pagamento" do próximo cupom;

(3) Falência, cerca de um ano mais tarde do evento de default. A empresa pode estar em não cumprimento e não declarar falência, caso haja negociação com seus credores;

(4) Emergência, este estado, segundo Schuermann (2004), é consequência da liquidação da empresa.

A LGD é mensurada após o evento classificado como (2), (3) ou (4) e, vale ressaltar, que após o evento (2), inadimplência, pode ocorrer a recuperação da empresa por meio do pagamento de suas dividas junto aos credores e caso isto ocorra o, evento (3), falência, não é atingido.

Schuermann (2004) e diversos outros autores como Querci (2005), Renault \& Scaillet (2004) citam a forma da distribuição das taxas de recuperação, e por consequência da LGD, $(\mathrm{RR} \text { - recovery rate })^{5}$ é uma bimodal ${ }^{6}$ com picos em torno de 0 e 1 , o que significa dizer que uma vez dado o default, dois eventos irão prevalecer na recuperação: a recuperação quase total, ou seja, a obrigação será paga e, a não recuperação total, no caso em que o montante da

\footnotetext{
${ }^{5}$ Lembrar que a relação de taxa de recuperação, do inglês recovery rate e LGD é dado por LGD=1-RR.

${ }^{6}$ A distribuição bimodal é uma distribuição com duas modas, ou seja, com dois picos de valores mais frequentes.
} 
obrigação é perdido. A figura 3 apresenta a forma da distribuição bimodal da LGD apresentada por Querci (2005). Outros autores como Chen e Wang (2013) e Grunert e Weber (2009) também citam que este tipo de distribuição é encontrada para as taxa de recuperação.

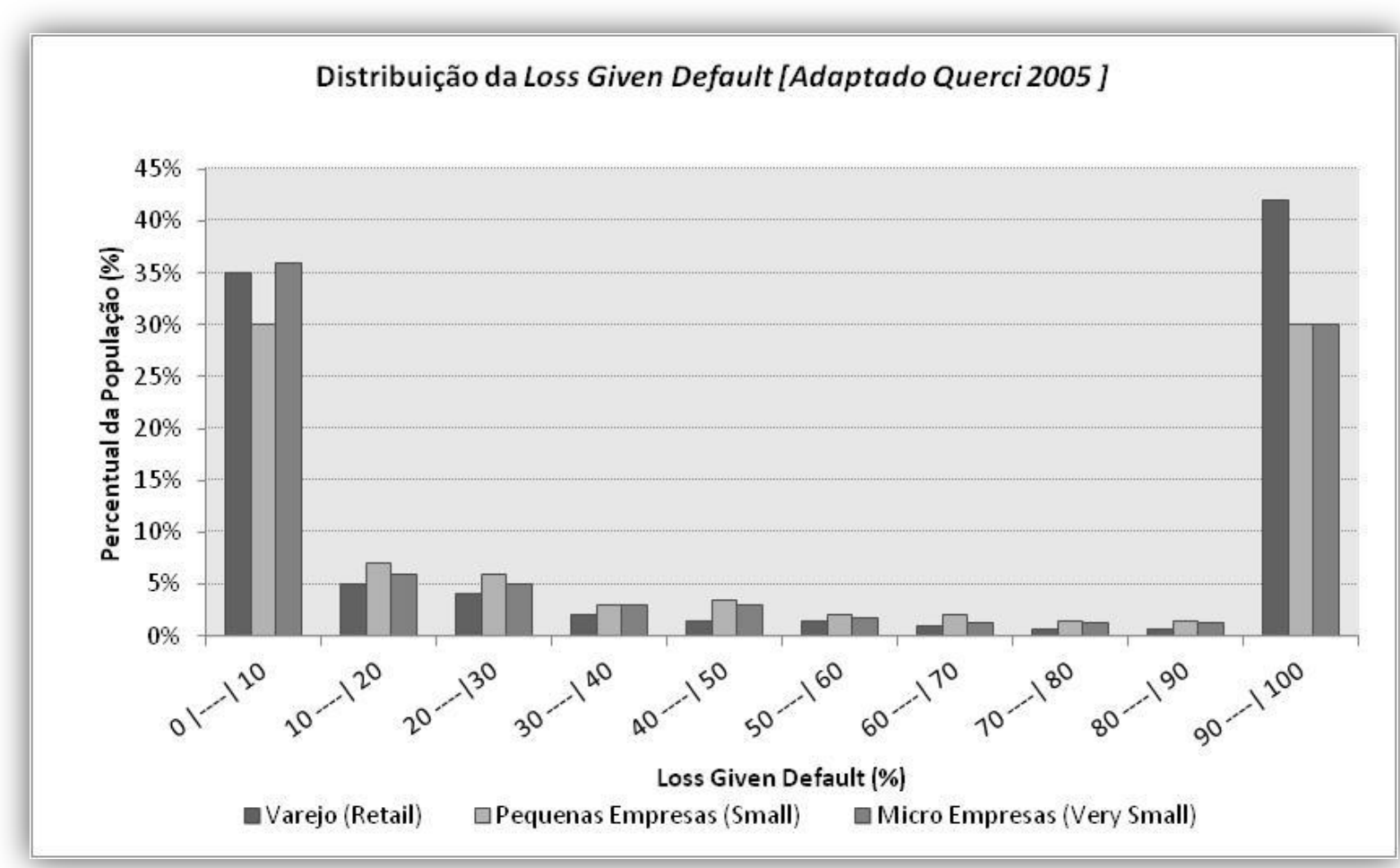

Figura 3 - Distribuição da LGD por Categoria do Tomador de Crédito [Adaptado Querci (2005)].

Segundo CEBS (2006), no seu documento entitulado "Guidelines of the implementation, validation and assessment of Advanced Measurement (AMA) and Internal Rating Based (IRB) Approaches", os supervisores não determinam nenhuma técnica para a estimação da LGD, isso fica a critério de cada instituição, contudo, a instituição deve provar que a técnica utilizada produz boas estimativas e, ainda, deve justificar também as suposições utilizadas. O documento adiciona que as estimativas não podem ser puramente baseadas em considerações julgamentais.

Ainda segundo o CEBS (2006), e conforme já citado, existem quatro maneiras de se estimar a LGD, a saber: LGD Workout, Market LGD, Implied Market LGD e Implied Historical LGD. Este último acrescentará à abordagem de Schuermann (2004) o conceito de Implied Historical LGD. 
Nos próximos tópicos serão descritos estes conceitos mais aprofundadamente, segundo os autores Schuermann (2004) e Porto (2011).

\subsubsection{WORKOUT LGD}

CEBS (2006, parágrafo 277) afirma: "In the Workout LGD technique, the cash flows resulting from the workout and/ or collections process, properly discounted, are calculated." Nesta técnica é calculado o fluxo de caixa descontado dos recebimentos da operação para determinar o valor perdido desta por conta da inadimplência.

Além dos recebimentos todos os custos incorridos no processo de cobrança são inclusos no fluxo de caixa. Neste método é necessário acesso a base de dados que contenham informações de pagamentos de clientes e respectivos custos de cobrança.

\subsubsection{MARKET LGD}

Schuermann (2004) descreve que este método mensura a LGD através dos preços negociados no mercado de títulos e empréstimos. Segundo ele, o preço de mercado já reflete a expectativa dos investidores na recuperação, isso porque o preço é o valor presente esperado pelo mercado para a eventual recuperação. Esta abordagem também é citada por Madan et.al. (2006) e Seidler (2008) que definem como sendo a diferença entre o preço do instrumento antes e depois o default, modelagem também conhecida como RMV-Recovery of Market Value.

\subsubsection{IMPLIED HISTORICAL LGD}

Segundo Porto (2011), o cálculo da Implied Martket LGD muito se assemelha ao cálculo do LGD Workout. Todavia são consideradas além das operações inadimplentes, as operações adimplentes, conforme a equação a seguir:

$$
E L=E A D \times P D \times L G D
$$

A equação (1) define a perda esperada (EL, do inglês expected loss). Este é o produto dos parâmetros EAD, PD e LGD. A equação (1) pode ser reescrita em termos de LGD que seria a razão entre a perda esperada (EL) e, a exposição ponderada multiplicada pela probabilidade de default (EAD*PD). 
Segundo autor, o cálculo da implied historical LGD para um portfólio é dado determinando-se a perda esperada. Esta, por sua vez, pode ser determinada por uma razão entre exposição de ativos em default, subtraídos dos fluxos de pagamentos de recuperação deduzidos de seus custos e, o produto de EAD*PD do portfólio.

$\mathrm{O}$ produto se dá pela exposição de todos os ativos (em default e não default) ponderados pela taxa de default do mesmo. Esta taxa de default será a quantidade de ativos em default sobre ativos total.

A fórmula final é apresentada a seguir:

$$
I L G D_{t 0}=\frac{\sum_{i=1}^{D}\left[E A D_{i}-\left(\sum_{j=1}^{J_{i}} R_{i, j}-\sum_{k=1}^{K J_{i}} P_{i, j}\right)\right]}{\sum_{i=1}^{N} E A D_{i}(D / N)}
$$

Em que,

$I L G D_{t 0}$ é o valor do parâmetro de LGD no tempo zero,

$E A D_{i}$ é a exposição no momento do default,

$R_{i, j}$ é a representação dos fluxos de pagamento,

$P_{i, j}$ é a representação dos fluxos de custos, taxas,

D é o numero total de ativos em default,

$\mathrm{N}$ é o número de ativos totais.

\subsubsection{IMPLIED MARKET LGD}

Schuermann (2004), Seidler (2008) e Moody’s (2011) caracterizam este método como aquele que mensura a LGD por meio de preço de títulos de dívidas "bons" (não em default) utilizando de um modelo de apreçamento teórico.

O ponto de partida para esta metodologia é o modelo de Merton (1974) que deriva do modelo de apreçamento de opções de Black and Scholes (1973). Posteriormente a Merton, diversos outros autores agregaram suas contribuições à abordagem de 1974: Black and Cox (1976) adicionaram a estrutura de capital e subordinação de dívidas, Geske (1977), o qual adicionou pagamento de juros, e segundo Jacobs (2011), alguns outros autores estudaram a limitação da aplicação destes modelos teóricos.

Altman et. al. (2004) expõe que o estudo inicial foi estendido para o que se denominou modelos de segunda geração: este modelo parte da consideração que o default pode ocorrer em qualquer instante de tempo da "vida" do ativo e não somente no maturity como inicialmente proposto pela abordagem de Merton. 
Seidler (2008) propõe um estudo a partir da abordagem de Merton que considera a distribuição/ pagamento de dividendos antes do maturity.

\subsection{OS MODELOS DE MENSURAÇÃO DE LGD}

\subsubsection{OS MODELOS ESTRUTURAIS: $1^{\mathrm{a}}$ E $2^{\mathrm{a}}$ GERAÇÃO}

Altman et. al. (2004) apresentam um trabalho de revisão da literatura sobre os modelos para taxas de recuperação. Este trabalho detalha o primórdio do cálculo de PD e RR desde o modelo de Merton (1974) até as variações que foram introduzidas por outros estudiosos.

Conforme anteriormente exposto, existem basicamente, dentre as diversas metodologias, duas formas de se observar a LGD (ou por complementaridade a taxa de recuperação RR): a primeira é utilizar dados passados, históricos e, a partir destes dados, que possuem informações de eventos de default e não default, estimar um percentual que se ajusta à população estudada, determinando-se a PD e LGD.

Esta forma é denominada pela literatura como "ex-post", porque estima os parâmetros a partir de dados já ocorridos, ou seja, posterior ao seu acontecimento: acredita-se que o comportamento futuro será similar ao ocorrido no passado.

A segunda forma estima os parâmetros projetando o futuro, e assim sendo, o estudo é alicerçado baseia-se em dados de eventos adimplentes. A literatura denomina como "ex-ante", estima os parâmetros a partir de dados em que o evento não ocorreu.

O cálculo é implícito e dele surge a implied market LGD, a determinação da LGD por meio de dados de mercado e de maneira implícita.

Os modelos da chamada primeira geração são baseados no modelo de Merton de 1974 e basicamente determinam o default da seguinte maneira: o evento ocorre quando o valor dos ativos é menor que o valor das obrigações.

Alguns autores que desenvolveram seus modelos a partir de flexibilizações do modelo de Merton (1974) e podem ser enquadrados nos modelos de $1^{a}$ geração são: Black and Cox (1976), Geske (1977) e Vasicek (1984). Este último incorporou a segregação de dívidas de curto e longo prazo.

Os modelos estruturais de segunda geração também derivam do modelo de Merton, contudo, flexibilizam a premissa dos modelos de primeira geração que o default só ocorre na maturidade do título. Nestes modelos, portanto, o default pode ocorrer em qualquer período 
entre a emissão do título e sua maturidade e, ainda, ocorre quando o valor dos ativos rompe um valor/ barreira específico.

Os modelos de segunda geração também partem do pressuposto de determinar o parâmetro de PD e LGD a partir de dados de eventos não default.

Entre os autores na abordagem de segunda geração é possível citar o trabalho de Longstaff e Schwartz (1995) e Hull e White (1995).

\subsubsection{OS MODELOS REDUZIDOS}

Os modelos reduzidos diferem-se dos modelos estruturais porque não condicionam o default ao valor da empresa, ou seja, o default não depende da estrutura de capital da empresa. Estes modelos assumem que a taxa de recuperação (RR) é independente da probabilidade de default (PD).

Segundo Seidler (2008), estes modelos "simplesmente assumem que o default é possível e é ocasionado por alguma variável exógena aleatória", ou seja, assumem que o default ocorre de maneira aleatória.

Altman et. al. (2004) corrobora: "podem acomodar defaults que ocorrem de maneira repentina", Segundo ele, os autores desta vertente tratam o default como um evento de Poisson $^{7}$.

Altman et. al. (2004), ainda, cita como autores desta linha: Litterman e Iben (1991), Madan e Unal (1998), Duffie (1998), Lando (1998).

Os autores Madan e Unal (1998) utilizam instrumentos denominados CD - certificates of deposit para a modelagem da PD é uma abordagem "ex-ante" e o momento em que o default ocorre é incerto, aleatório.

O estudo de Duffie (1998) baseia-se no comportamento estocástico das taxas de defaultable bonds. O default é determinado por um processo de Poisson. Lando (1998) também sugere que o default segue um processo de Poisson.

Seidler (2008) atenta para o fato de que estes modelos reduzidos adotam como premissa a independência da PD e LGD gera uma restrição conceitual: “... default $e$ recuperação são modelados independentemente da estrutura da empresa, com a clara falta de intuição econômica por trás do evento de default.". A questão da independência entre os dois parâmetros pode decorrer do fato de que não importando qual a dimensão da "chance"

\footnotetext{
${ }^{7}$ A distribuição de Poisson quantifica probabilidades cujos eventos são independentes e em intervalos contínuos de tempo.
} 
(PD) da empresa inadimplir, a recuperação irá depender da capacidade desta de honrar sua dívida: a empresa pode inadimplir e, ainda assim, ter alta recuperação, efetuando seus pagamentos. Por outro lado, a capacidade de recuperação está intimamente ligada à estrutura e saúde financeira da empresa, assim como a capacidade de inadimplir, então os dois parâmetros, intuitivamente, estão vinculados à estrutura financeira da empresa, o que é defendido por Seidler.

\subsubsection{VANTAGENS E DESVANTAGENS DAS ABORDAGENS}

O quadro 1 resume as vantagens e desvantagens das abordagens para a determinação da LGD sob a ótica da abordagem "ex-ante" e "ex-post", permeando também as restrições das diversas vertentes de modelos: $1^{\mathrm{a}}, 2^{\mathrm{a}}$ geração e modelos reduzidos.

Quadro 1 - Vantagens e Desvantagens das Abordagens de Mensuração de LGD.

\begin{tabular}{|c|c|c|c|c|}
\hline Abordagem & $\begin{array}{c}\text { Mensuração } \\
\text { LGD }\end{array}$ & Modelos & Vantagens & Desvantagens \\
\hline 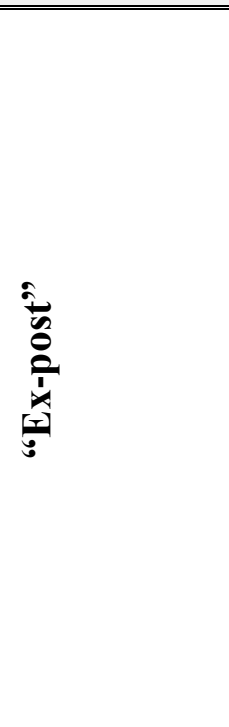 & LGD Workout & $\begin{array}{l}\text { Fluxo de } \\
\text { Caixa } \\
\text { Descontado }\end{array}$ & $\begin{array}{lr}\text { 1) Mensuração } & \text { de } \\
\text { todos os parâmetros } \\
\text { envolvidos } & \text { na } \\
\text { recuperação; } & \\
\text { 2) Estimativa } & \text { mais } \\
\text { aderente a } & \text { realidade } \\
\text { do } & \text { negócio; } \\
\text { 3) } & \text { Benefício } \\
\text { adicional: } & \text { melhor } \\
\text { entendimento } & \text { do } \\
\text { processo } & \text { de } \\
\text { recuperação } & \end{array}$ & 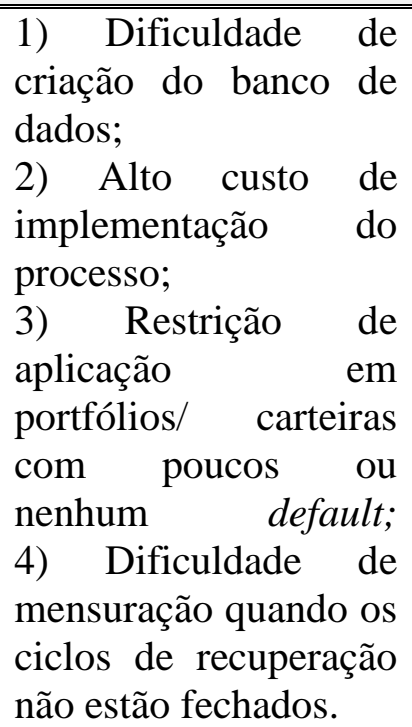 \\
\hline
\end{tabular}




\begin{tabular}{|c|c|c|c|c|}
\hline & Market LGD & $\begin{array}{l}\text { Modelos } \\
\text { estruturais }\end{array}$ & $\begin{array}{l}\text { 1) O preço de } \\
\text { mercado já contempla } \\
\text { o valor recuperável } \\
\text { do ativo; } \\
\text { 2) Simplificação e } \\
\text { disponibilidade de } \\
\text { dados de mercado; } \\
\text { 3) Conhecimento do } \\
\text { comportamento dos } \\
\text { ativos em momentos } \\
\text { de default, maior } \\
\text { conhecimento das } \\
\text { condições. }\end{array}$ & 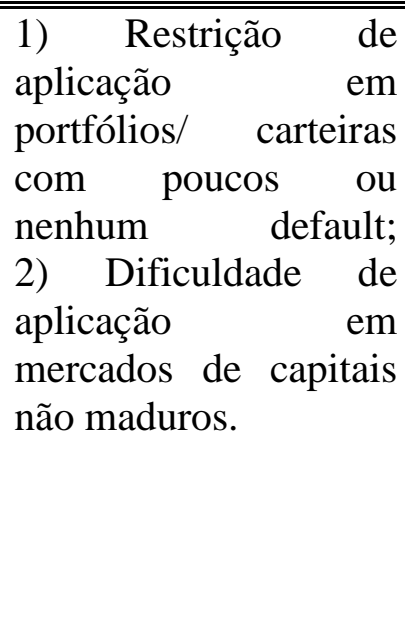 \\
\hline 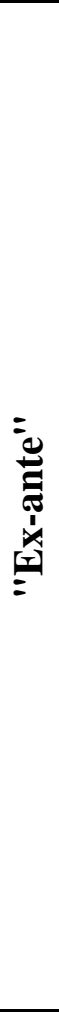 & $\begin{array}{l}\text { Implied Market } \\
\text { LGD }\end{array}$ & $\begin{array}{l}\text { Modelos } \\
\text { Estruturais } \\
\text { e } \\
\text { Reduzidos }\end{array}$ & $\begin{array}{l}\text { 1) Maior quantidade e } \\
\text { histórico de dados } \\
\text { disponíveis; } \\
\text { 2) Simplificação de } \\
\text { processos; } \\
\text { 3) Aplicação em } \\
\text { carteiras com pouco } \\
\text { ou nenhum default. }\end{array}$ & 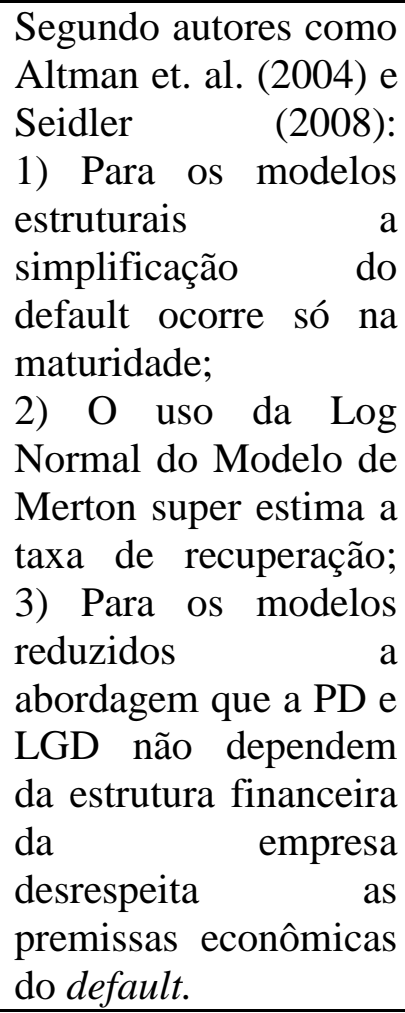 \\
\hline
\end{tabular}

Conforme evidenciado no quadro 1, cada abordagem "ex-ante" e "ex-post", apresenta vantagens e restrições.

A "ex-post" possui a vantagem de mensurar com precisão cada elemento da recuperação pelo método do fluxo de caixa descontado: todo o fluxo de pagamento para o evento default é determinado, assim como custos. Contudo, a aplicabilidade fica impraticável em carteiras de pouco ou nenhum default (não existe evento "ex-post" a ser dimensionado). Existe, ainda, uma dificuldade quanto a ciclos de recuperação abertos, aqueles em que o processo de cobrança e recuperação ainda não foi finalizado. 
A "ex-ante" é uma alternativa nas carteiras de pouco ou nenhum default, uma vez que a mensuração parte de dados em que nenhum evento de inadimplência foi observado. Todavia conforme observado por alguns autores, as mensurações nem sempre são realistas, devido à simplificação dos modelos estruturais e reduzidos de mercado.

Sob a ótica proposta, para este referido trabalho, a abordagem aplicável será a "exante", uma vez que este estudo tratará de um conjunto de empresas adimplentes, que não há evento de default e, determinar para estas, um dos parâmetros do cálculo necessários para o cálculo de capital regulatório: a LGD, ou a perda dado o evento de default.

\subsection{O MODELO DE MERTON (1974)}

Merton (1974) parte das seguintes suposições baseando-se no modelo de precificação de Black and Scholes (1973):

S1. Não há custos de transações, taxas ou problemas com a indivisibilidade do ativo.

S2. Existe um numero suficiente de investidores com níveis de riquezas comparáveis que cada investidor acredita que ele pode comprar e vender tanto de um ativo quanto queira no valor de mercado.

S3. Existe um mercado de troca para empréstimos em uma mesma taxa de juros.

S4. É permitida short-sales de todos os ativos.

S5. Compra e venda de ativos (trading) acontece continuamente no horizonte de tempo.

S6. A condição do teorema de Modigliani-Miller que o valor da empresa independe de sua estrutura de capital é respeitada.

S7. A estrutura a termo é "flat" e conhecida.

S8. A dinâmica para o valor da firma no tempo é descrita pelo processo estocástico do tipo difuso.

$$
d V=(\alpha V-C) d t+\sigma V d z
$$

A equação (3) acima designa uma equação diferencial estocástica denominada movimento geométrico Browniano.

Em que,

dV é a variação diferencial do valor da empresa,

V é o valor da empresa,

$\boldsymbol{\alpha}$ é a taxa de retorno esperada da empresa por unidade de tempo,

C é o montante em dinheiro pago por unidade de tempo para acionistas ou credores (seja por meio de dividendos ou cupons), 
dt é a variação diferencial do tempo,

$\boldsymbol{\sigma}$ representa o desvio padrão do retorno da empresa por unidade de tempo,

dz é o termo estocástico.

O termo estocástico, representado por $d z$, possui algumas peculiaridades, segundo Ross (1996, pg.356):

1. Possui distribuição normal com média zero;

2. Os incrementos são independentes e estacionários.

A equação (3) pode ser reescrita em termos do valor do título de dívida. Uma vez que o valor deste título está intrinsecamente ligado ao valor da empresa ao longo do tempo, segundo função $\mathrm{Y}=\mathrm{F}(\mathrm{V}, \mathrm{t})$, a equação (3) toma a forma:

$$
d Y=\left(\alpha_{Y} Y-C_{Y}\right) d t+\sigma_{Y} Y d z_{Y}
$$

Aplicando o Lema de Itô ${ }^{8}$ se obtêm:

$$
d Y=\left[\frac{1}{2} \sigma^{2} V^{2} \frac{\partial^{2} F}{\partial V^{2}}+(\alpha V-C) \frac{\partial F}{\partial V}+\frac{\partial F}{\partial t}\right] d t+\sigma V \frac{\partial F}{\partial V} d z
$$

Considerando-se um portfólio de três ativos: a empresa, o título de dívida e um ativo livre de risco, conforme formulação apresentada por Merton (1973, pg.164), considerando um ambiente sem risco e sem arbitragem, a seguinte formulação é alcançada ${ }^{9}$ :

$$
\frac{1}{2} \sigma^{2} V^{2} \frac{\partial^{2} F}{\partial V^{2}}+r V \frac{\partial F}{\partial V}-r F+\frac{\partial F}{\partial t}=0
$$

O termo $C_{Y}$ é zero por não haver pagamento de cupons. Para resolver a equação (6) é necessário ainda utilizar o valor da empresa, V, que é aproximadamente a soma da sua estrutura de dívida, F, e o valor de suas ações, E. As condições de contorno, sendo $\tau=\mathrm{T}-\mathrm{t}$ (o tempo até o vencimento), então são:

$$
\mathrm{F}(0, \tau)=\mathrm{E}(0, \tau)=0 \text { e } \mathrm{F}(\mathrm{V}, \tau) \leq \mathrm{V}
$$

As condições de contorno a respeito da dívida, F, e das ações, E, limitam o valor mínimo a zero porque estas não podem ter valores negativos.

A segunda condição, condição inicial, é que a dívida, F, possui valor menor ou igual ao valor da empresa, $\mathrm{V}$.

Os credores na maturidade (vencimento) do título recebem o valor de face, $\mathrm{F}$ ou o valor remanescente da empresa, $\mathrm{V}$, portanto tem-se:

$$
\mathrm{F}(\mathrm{V}, 0)=\min [\mathrm{V}, \mathrm{F}]
$$

Segundo Merton (1974) substituindo por $F$ a seguinte expressão $F(V, \tau)=V-E(V, \tau)$ na equação (6) e nas condições em (7), obtêm-se a equação em função de E:

\footnotetext{
${ }^{8} \mathrm{O}$ desenvolvimento desta equação encontra-se no Anexo 1.

${ }^{9} \mathrm{O}$ desenvolvimento desta equação encontra-se no Anexo 2.
} 


$$
\frac{1}{2} \sigma^{2} V^{2} \frac{\partial^{2} E}{\partial V^{2}}+r V \frac{\partial E}{\partial V}-r E+\frac{\partial E}{\partial t}=0
$$

As mesmas condições de contorno em (7) são mantidas e a condição inicial para este caso é:

$$
\mathrm{E}(\mathrm{V}, 0)=\operatorname{Max}[0, \mathrm{~V}-\mathrm{F}]
$$

A condição (10) significa que no vencimento o valor da ação é o maior entre zero (o acionista/ shareholder não recebe nada) e o valor da empresa menos o valor de face (o que equivale dizer que os acionistas/ shareholders recebem o residual da dívida depois dos credores).

Aplicando a formulação de Black and Scholes para as equações (9) e (10) tem-se:

$$
E(V, \tau)=V \phi\left(d_{1}\right)-F e^{-r \tau} \phi\left(d_{2}\right)
$$

Sendo:

$$
\begin{gathered}
d 1=\frac{\ln \frac{V}{F}+\left(r+\frac{1}{2} \sigma_{V}^{2}\right) \tau}{\sigma_{V} \sqrt{\tau}} \\
d 2=d 1-\sigma_{V} \sqrt{\tau}=\frac{\ln \frac{V}{F}+\left(r-\frac{1}{2} \sigma_{V}^{2}\right) \tau}{\sigma_{V} \sqrt{\tau}}
\end{gathered}
$$

O símbolo $\phi($.$) representa a distribuição normal padrão acumulada. Segundo Hull$ (2005, pag. 300) esta função $\phi($.$) representa a probabilidade de que a variável com$ distribuição normal padrão seja menor que d1 ou d2. O mesmo autor acrescenta ainda que, quanto maior o valor do termo $\mathrm{V}$ se torna muito grande, tanto $\mathrm{d} 1$ quanto $\mathrm{d} 2$ também se tornam grandes e então $\phi(d 1)$ e $\phi(d 2)$ se aproximam de 1 e analogamente $\phi(-d 2)$ e $\phi(-d 1)$ aproximam-se de zero.

Segundo Seidler (2008) e Cerezo et. al. (2011) a PD pode ser extraída do modelo de Merton quando o valor da empresa $\mathrm{V}$ estiver abaixo do valor da dívida $\mathrm{F}$ no vencimento $\mathrm{T}$ :

$$
P D=\operatorname{Pr}\left(V_{T} \leq F\right)
$$

Segundo Cerezo et. al. (2011) o valor da empresa segue uma distribuição log-normal, portanto $\ln _{V_{T}}$ segue uma distribuição normal com média $l n_{V_{0}}+\left(\mathrm{r}-\frac{1}{2} \sigma_{\mathrm{V}}^{2}\right) \mathrm{T}$ e variância $\sigma_{\mathrm{V}}{ }^{2} \mathrm{~T}$, com isso a probabilidade de default neutra ao risco, é dada por:

$$
P D=\phi\left(-d_{2}\right)
$$

Segundo Seidler (2008) a taxa de recuperação ${ }^{10}$ é dada por:

$$
R R=E\left(\frac{V_{T}}{F} \mid V_{T}<F\right)=\frac{1}{F} E\left(V_{T} \mid V_{T}<F\right)
$$

Significa dizer que a recuperação é dada pela razão do valor da firma no maturity, pela dívida.

\footnotetext{
${ }^{10}$ Para maiores esclarecimentos das deduções das equações 16, 17 e 18 consultar Seidler (2008).
} 
E ainda:

$$
E\left(V_{T} \mid V_{T}<F\right)=V_{0} e^{r T} \frac{\phi\left(-d_{1}\right)}{\phi\left(-d_{2}\right)}
$$

Portanto a taxa de recuperação neutra ao risco é dada pela expressão:

$$
R R=E\left(\frac{V_{T}}{F} \mid V_{T}<F\right)=\frac{V_{0}}{F} e^{r T} \frac{\phi\left(-d_{1}\right)}{\phi\left(-d_{2}\right)}
$$

Como é sabido a LGD $=1-\mathrm{RR}$, portanto a partir da eq. 18 determina-se a LGD. Vale ressaltar que: (a) a formulação dada a taxa de recuperação não inclui custos de liquidação e (b) a taxa de recuperação real pode ser obtida pelas mesmas formulações bastando substituir a taxa livre de risco (r) pela taxa de retorno esperado. Os autores Cerezo et. al. (2011) utilizaram a taxa de crescimento do PIB como proxy para a taxa de retorno esperado das companhias de seu estudo.

A solução para este problema pode ser obtida por meio da equação (11), contudo nesta equação existem duas incógnitas a serem determinadas: o valor da empresa, V e sua volatilidade, $\sigma \mathrm{V}$. É necessário um conjunto de duas equações para a solução do problema.

A próxima equação é obtida a partir da consideração que o valor das ações de uma empresa é função de seus ativos. Conforme Merton (1974, pg. 5), tem-se a seguinte relação:

$$
\sigma_{E} E=\sigma_{V} V \frac{\partial E}{\partial V}
$$

Segundo Seidler (2008) o termo $\frac{\partial E}{\partial V}$ igual à $\phi\left(d_{1}\right)$, portanto a equação (19) toma a seguinte forma:

$$
\sigma_{E} E=\sigma_{V} V \phi\left(d_{1}\right)
$$

Utilizando-se das equações (11) e (20) o problema em questão possui solução. Determinando-se os valores da empresa, $\mathrm{V}$ e sua volatilidade, $\sigma_{\mathrm{v}}$ é possível determinar o valor da LGD pela equação (18).

A tabela 1 apresenta os parâmetros envolvidos na modelagem, assim como sua forma de obtenção. 
Tabela 1 - Parâmetros do Modelo.

\begin{tabular}{|c|c|c|c|}
\hline Termos & Mensuração & Obtenção & I/O \\
\hline$\sigma_{V}$ & $\begin{array}{l}\text { Volatilidade do Valor da } \\
\text { Empresa }\end{array}$ & Determinado Modelo & Output \\
\hline$\sigma_{E}$ & $\begin{array}{l}\text { Volatilidade do Valor das } \\
\text { Ações }\end{array}$ & $\begin{array}{c}\text { Desvio padrão dos retornos históricos } \\
\text { das ações. }\end{array}$ & Input \\
\hline$\phi(\mathrm{d} 2)$ & $\begin{array}{l}\text { Distribuição Normal } \\
\text { Padrão Acumulada }\end{array}$ & $\frac{\ln \frac{V}{F}+\left(r-\frac{1}{2}{\sigma_{V}}^{2}\right) \tau}{\sigma_{V} \sqrt{\tau}}$ & Input/ Output \\
\hline$\phi(\mathrm{d} 1)$ & $\begin{array}{l}\text { Distribuição Normal } \\
\text { Padrão Acumulada }\end{array}$ & $\frac{\ln \frac{V}{F}+\left(r+\frac{1}{2}{\sigma_{V}}^{2}\right) \tau}{\sigma_{V} \sqrt{\tau}}$ & Input/ Output \\
\hline $\mathrm{F}$ & Valor Contábil da Dívida & $\begin{array}{c}\text { Valor Histórico: Balanços Patrimoniais } \\
\text { (Passivo Circulante + Passivo Não } \\
\text { Circulante) }\end{array}$ & Input \\
\hline$\tau$ & Maturity & Realizado com 1 e 5 anos & Input \\
\hline $\mathrm{r}$ & Taxa Livre de Risco & $\begin{array}{c}\text { Valor determinado pela curva de juros } \\
\text { pré-fixada. Fonte CETIP } \\
\end{array}$ & Input \\
\hline V & Valor da Empresa & Determinado Modelo & Output \\
\hline $\mathrm{E}$ & Valor das Ações & $\begin{array}{c}\text { Valor Histórico: (PU Fechamento x } \\
\text { Quantidade Ações) }\end{array}$ & Input \\
\hline
\end{tabular}

\section{MÉTODO}

\subsection{FONTE DE DADOS}

As empresas selecionadas, por meio do Economática, foram aquelas que possuíam ações negociadas na bolsa de São Paulo (Bovespa) no período histórico de dezembro 2006 até junho de 2013. A abordagem segundo Merton proporciona o cálculo do parâmetro de LGD a qualquer atualização nos valores das cotações das ações e do termo da dívida, portanto, é possível acompanhar, a cada momento de tempo, a predição deste parâmetro. O horizonte de tempo foi escolhido de modo a contemplar o período pré-crise de 2008, o período critico e um momento posterior.

A seleção foi realizada com os seguintes filtros: 1. O filtro de listagem na Bovespa, 2. O filtro do período de dezembro de 2006 a junho de 2013, 3. O filtro de "Ativo" nas empresas $^{11}$, 4. O filtro para apresentação dos valores em moeda local: R\$.

\footnotetext{
${ }^{11}$ Este filtro é aplicado com a finalidade de excluir empresas que apresentam descontinuação nas suas séries históricas
} 
As informações coletadas e a forma de coleta no Economática são destacadas na tabela 2.

Tabela 2 - Seleção das informações no Economática.

\begin{tabular}{||l|l|l||}
\hline \multicolumn{2}{||}{ Informação } & \multicolumn{2}{c||}{ Tela de Coleta } & Análise \\
\hline \hline Nome da Empresa & Base de Dados/ Cadastro da Empresa & Análise \\
\hline Setor Economática e NAICS & Base de Dados/ Cadastro da Empresa & Chave \\
\hline ISIN da Empresa & Base de Dados/ Cadastro da Empresa & Análise \\
\hline Passivo Circulante & $\begin{array}{l}\text { Base de Dados/ Demonstrativos Financeiros. } \\
\text { Modo: Matrixx }\end{array}$ & Análise \\
\hline Passivo Não Circulante & $\begin{array}{l}\text { Base de Dados/ Demonstrativos Financeiros. } \\
\text { Modo: Matrixx }\end{array}$ & Análise \\
\hline Cotação de Fechamento & Base de Dados/ Cotações. Modo: Matrixx & Análise \\
\hline Quantidade de Ações & $\begin{array}{l}\text { Base de Dados/ Demonstrativos Financeiros. } \\
\text { Modo: Matrixx }\end{array}$ & \\
\hline \hline
\end{tabular}

A informação “Cotação de Fechamento", para as empresas selecionadas, foi ajustada por "proventos". Esta opção no Economática resulta em um valor ajustado por oscilações devido à: bonificações, dividendos, desdobramentos, grupamentos, cisões e subscrições. Este ajuste por proventos permite que os valores sejam comparáveis ao longo do histórico de análise, não havendo assim descontinuidades na série.

A informação "Quantidade de Ações" foi ajustada por proventos posteriormente, após obter a base final para modelagem. Após determinado o universo das empresas a ser considerado na modelagem, o ajuste por proventos, no horizonte considerado, foi realizado através de notas de mercado no site de cada empresa ou no site da $\mathrm{CVM}^{13}$.

As informações de "Passivo Circulante" e "Passivo Não Circulante" apresentam-se na forma trimestral, por terem sido consideradas informações advindas de balanços e balancetes.

Para o parâmetro "r" que representa a taxa livre de risco foi considerado o valor da taxa de juros da curva pré-fixada fornecida pela CETIP ${ }^{14}$.

\footnotetext{
${ }^{12}$ O Modo Matrixx permite que o usuário selecione o histórico do parâmetro por data de referência, com a opção de utilizar as empresas previamente selecionadas na tela "Screening"

${ }^{13}$ Site da CVM no link "Participantes do Mercado" e posteriormente no link "Companhias Abertas", ou ainda, no site de RI das empresas.

${ }^{14}$ Informação disponível no site: www.cetip.com.br em estatísticas e depois em DI.
} 
Esta taxa pré-fixada é obtida com base das operações de depósito interfinanceiro - DI. As operações entre os bancos do mercado financeiro formam a taxa referencial. A metodologia da CETIP apura diariamente esta taxa, que representa o custo básico da captação bancária.

Quanto à utilização da curva pré-fixada para taxa livre de risco, os autores Silveira et. al. (2002) argumentam citando autores como Copeland et. al. (1995), que a melhor estimativa para uma taxa livre de risco seria o retorno de um portfólio com beta igual a zero. Silveira et. al.(2002) a obtenção de tal portfólio, se daria quando os retornos do mesmo fossem não correlacionados com demais ativos da economia.

O estudo de 2002 revela que o retorno da Caderneta de Poupança e dos CDI se mostraram boas medidas para taxa livre de risco.

O trabalho acrescenta, por último, que apesar de nos Estados Unidos serem utilizados títulos públicos como aproximações para taxa livre de risco, no Brasil a utilização do título CBond gera alguns problemas: primeiro porque é incorporado o valor de pagamento pelo risco de default no título e, segundo, porque este título apresenta correlação com outros ativos da economia.

O termo $\tau$ o "Maturity" será trabalhado com valores de 1e 5 anos.

O autor Seidler (2008) utiliza o horizonte de 5 anos para o maturity. Ele afirma que é comum na academia agrupar a dívida de curto e longo prazo e ponderar o duration ou maturity por cada um dos grupos: os autores Dalianedis e Geske (2001) utilizaram um ano para dívida de curto prazo e 10 anos para dívida de longo prazo. A correta ponderação do duration exigiria uma análise da estrutura da dívida de cada empresa e a realização de tal método necessita de uma apuração minuciosa de cada informe financeiro divulgado para cada empresa escolhida, um procedimento manual e oneroso, contudo, mais assertivo.

Já os autores Bharath e Shumway (2008) e Duan et.al. (2003) argumentam que a utilização de um maturity de 1 ano. Os últimos autores defendem que uma vez que a cada ano, com a publicação das informações contábeis ao mercado, os acionistas tomam suas decisões de manter ou não suas posições, pode-se dizer que existe um pseudo maturity de 1 ano.

Uma vez coletados e determinados os parâmetros necessários ao cálculo do modelo, fez-se necessária a mineração dos dados, ou a limpeza da base de empresas não elegíveis ao cálculo: desconsiderando empresas com informações faltantes ou aquelas que não são alvo do estudo.

A figura 4 abaixo apresenta de maneira ilustrativa como foram realizados filtros à base coletada no Economática. 


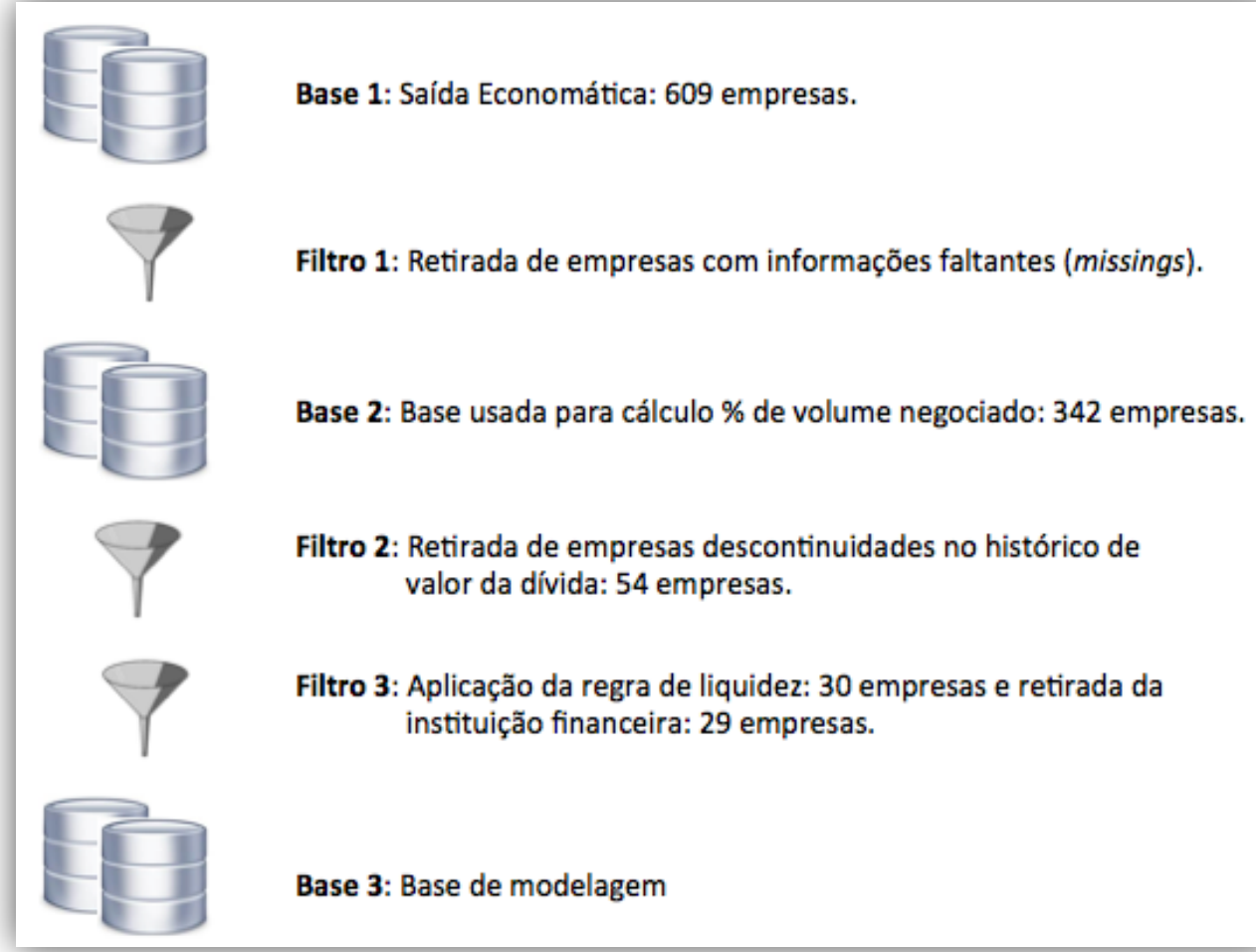

Figura 4 - Procedimento de Limpeza e Criação da Base de Modelagem.

A seleção inicial continha 609 empresas, porém algumas empresas foram excluídas da base por não apresentarem o valor contábil da divida no horizonte de tempo, ou por não apresentarem ações com considerável grau de liquidez, ou ainda apresentarem descontinuações em suas séries históricas que não foram possíveis de ser tratadas.

No universo selecionado de 609 empresas, apenas 342 empresas apresentavam valores de divida contábil e valor de ações no período analisado, destas 342 empresas apenas 54 empresas apresentaram dados de passivo sem descontinuações no horizonte de tempo analisado. Após selecionar as empresas com ações de maior liquidez foram obtidas 30 empresas e no final a base contou com 29 empresas. Esta diferença de uma empresa foi devido à retirada da Itaúsa da análise: instituições financeiras não foram consideradas no estudo devido ao seu método de contabilização ser distinto das demais empresas, podendo ocasionar análises enviesadas.

\subsection{TRATAMENTO DE DADOS}

O tratamento da base de dados e a modelagem foram realizados no software SAS. A quadro 2 a seguir sumariza todos os tratamentos e considerações feitas à base coletada no Economática. 
Quadro 2 - Resumo dos tipos de tratamentos realizados na base de dados.

\begin{tabular}{|c|c|c|c|}
\hline Variável & Descrição & Tratamento & Motivo \\
\hline $\begin{array}{c}\text { PU de } \\
\text { Fechamento }\end{array}$ & $\begin{array}{c}\text { PU de } \\
\text { Fechamento } \\
\text { formará a } \\
\text { variável E } \\
\text { (equity) }\end{array}$ & $\begin{array}{l}\text { Criação de uma data de } \\
\text { tolerância para o valor da } \\
\text { cotação: é a data do final do } \\
\text { mês subtraída de } 5 \text { dias } \\
\text { úteis. }\end{array}$ & $\begin{array}{l}\text { A data do passivo é sempre } \\
\text { no último dia do mês, } \\
\text { contudo pode ser que não } \\
\text { seja um dia útil ou, ainda, } \\
\text { não tenha havido negociação } \\
\text { das ações da respectiva } \\
\text { empresa neste dia. }\end{array}$ \\
\hline $\begin{array}{l}\text { Quantidade } \\
\text { de Ações }\end{array}$ & $\begin{array}{l}\text { Quantidade de } \\
\text { Ações formará a } \\
\text { variável E } \\
\text { (equity) }\end{array}$ & $\begin{array}{l}\text { Correção dos valores } \\
\text { históricos por proventos } \\
\text { através de informações de } \\
\text { mercado }\end{array}$ & $\begin{array}{l}\text { Ajuste de desdobramento de } \\
\text { ações, grupamento } \\
\text { coversão de ações na } \\
\text { migração para novo } \\
\text { mercado }^{15} \text { conforme } \\
\text { cálculo realizado pelo } \\
\text { Economática e abordado no } \\
\text { Anexo 3. }\end{array}$ \\
\hline $\begin{array}{l}\text { Passivo } \\
\text { Contábil }\end{array}$ & $\begin{array}{l}\text { Somatório de } \\
\text { Passivo } \\
\text { Circulante e } \\
\text { Passivo Não } \\
\text { Circulante } \\
\text { forma o termo } \\
\text { de dívida }\end{array}$ & $\begin{array}{l}\text { Retirada de empresas que } \\
\text { possuíam valores faltantes } \\
\text { (missings) no horizonte } \\
\text { estudado. }\end{array}$ & $\begin{array}{l}\text { Sem o termo de dívida não é } \\
\text { possível determinar o valor } \\
\text { da empresa e sua volatilidade } \\
\text { e consequentemente não é } \\
\text { possível determinar a LGD }\end{array}$ \\
\hline Empresas & $\begin{array}{c}\text { Empresas } \\
\text { consideradas na } \\
\text { modelagem }\end{array}$ & $\begin{array}{l}\text { 1) Retiradas Instituições } \\
\text { Financeiras; } \\
\text { 2) Retiradas Empresas com } \\
\text { ações com pouca liquidez. }\end{array}$ & $\begin{array}{l}\text { 1) A contabilização destas } \\
\text { empresas é diferenciada das } \\
\text { demais, podendo acarretar } \\
\text { vieses no cálculo; } \\
\text { 2) Empresas com ações de } \\
\text { pouca liquidez também } \\
\text { podem acarretar em vieses } \\
\text { nas análises e comparações. }\end{array}$ \\
\hline
\end{tabular}

\footnotetext{
${ }^{15}$ Somente a empresa TIM sofreu migração para Novo Mercado, durante histórico em junho de 2011.
} 


\begin{tabular}{|c|c|c|c|}
\hline Ação & $\begin{array}{l}\text { Ação que } \\
\text { representa o } \\
\text { valor do equity } \\
\text { da empresa }\end{array}$ & $\begin{array}{l}\text { Caso uma empresa } \\
\text { possuísse ações ordinárias e } \\
\text { preferenciais, optou-se por } \\
\text { manter a ação mais líquida } \\
\text { para representar o E (equity) } \\
\text { da empresa. }\end{array}$ & $\begin{array}{l}\text { A ação com maior volume de } \\
\text { negociação é a que melhor } \\
\text { representará o valor da } \\
\text { empresa sem gerar vieses. }\end{array}$ \\
\hline $\begin{array}{l}\text { Volatilidade } \\
\text { da Ação }\end{array}$ & $\begin{array}{l}\text { Parâmetro do } \\
\text { Modelo }\end{array}$ & $\begin{array}{l}\text { O valor encontrado para a } \\
\text { volatilidade da ação é diária, } \\
\text { este valor foi anualizado } \\
\text { multiplicando pela raiz } \\
\text { quadrada de } 252(\mathrm{du}) \text {. }\end{array}$ & $\begin{array}{l}\text { Este tratamento é necessário } \\
\text { para equalização de unidades } \\
\text { na fómula. O maturity é dado } \\
\text { em anos, a taxa livre de risco } \\
\text { é dada em anos, portanto a } \\
\text { volatilidade deve ser } \\
\text { apresentada em anos. }\end{array}$ \\
\hline $\begin{array}{c}\text { Valor da } \\
\text { Divida (B) } \\
\text { e Ações (E) }\end{array}$ & $\begin{array}{l}\text { Parâmetros do } \\
\text { modelo }\end{array}$ & $\begin{array}{l}\text { Os valores foram divididos } \\
\text { por milhão. }\end{array}$ & 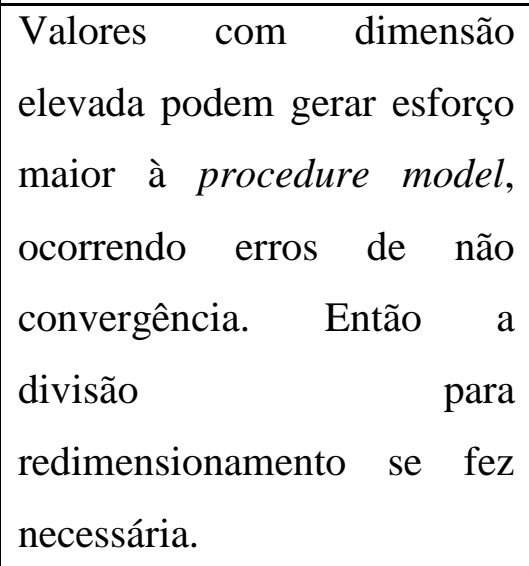 \\
\hline
\end{tabular}

\subsection{CÁLCULO DA VOLATILIDADE DAS AÇÕES}

A volatilidade das ações por meio de dados históricos é determinada pelo desvio padrão dos seus retornos contínuos diários, conforme equação abaixo descrita por Hull (2005, pg.296):

$$
\sigma=\sqrt{\frac{1}{n-1} \sum_{i=1}^{n}\left(\mu_{i}-\bar{\mu}\right)^{2}}
$$

O termo $\mu_{i}$ é o retorno no ponto observado, o termo $\bar{\mu}$ é o termo do retorno médio do período observado e n é o número de observações. 
O retorno por sua vez, é definido pelo logaritmo natural da cotação de fechamento da ação no ponto i observado, contra a cotação de fechamento em i-1, segundo a seguinte equação:

$$
\mu=\ln \left(\frac{P_{i}}{P_{i-1}}\right)
$$

O cálculo da volatilidade foi construído por meio das cotações diárias das ações de cada empresa candidata a modelagem (as empresas restantes após as seleções descritas no final do item 3.1).

Foram escolhidos três períodos para mensurar a volatilidade: 3 meses, 6 meses e 12 meses anteriores a data base. Segundo Hull (2005, pg. 296) a escolha por 90 e 180 dias é razoável, pois prioriza os preços mais recentes. Segundo o autor, a escolha por horizontes longos de tempo podem conter valores que distorcem o comportamento de previsão do futuro. $\mathrm{O}$ autor, contudo, observa que a utilização de mais dados produz melhores resultados.

Minardi et. al. (2006) utilizaram um horizonte de 12 meses anteriores à data de observação.

A volatilidade foi calculada no software SAS por meio da procedure proc expand este procedimento realiza diversos tipos de cálculos em janelas móveis. Optou-se, então, pela estatística do desvio padrão em janelas móveis de períodos estipulados: 3 meses, 6 meses e 12 meses.

Uma vez que o valor retornado do desvio padrão é o valor do retorno diário, este valor foi multiplicado pela raiz quadrada de 252 dias úteis para obter-se seu valor anualizado.

\subsection{A CORREÇÃO POR PROVENTOS}

A correção por proventos foi utilizada para a coleta de cotação das ações no Economática: esta opção é fornecida pelo próprio software para as informações da janela Cotações e Indicadores Financeiros, porém, a informação de quantidade de ações foi proveniente da janela Demonstrativo Financeiro e o ajuste por proventos foi realizado posteriormente à coleta, corrigido manualmente, consultando o site de RI - Relações com Investidores das 29 empresas selecionadas.

Os ajustes por provento realizado pelo Economática são determinados multiplicando-se os valores de cotação por um fator de ajuste, este fator realiza um tipo diferente de cálculo, dependendo do tipo de provento.

O Anexo 3 contempla todos os ajustes por proventos realizados no Economática. 
A tabela 3 apresenta todos os ajustes feitos à série histórica de quantidade de ações das empresas.

Tabela 3 - Ajuste por Proventos realizados na Quantidade de Ações.

\begin{tabular}{|c|c|c|c|}
\hline Empresa & $\begin{array}{c}\text { Tipo de } \\
\text { Provento }\end{array}$ & Proporção & Fonte e Data do Evento \\
\hline $\begin{array}{l}\text { Lojas } \\
\text { Americanas }\end{array}$ & Grupamento & $100: 1$ & $\begin{array}{l}\text { Acessado em } 20 \text { de novembro de } 2013 \text { em: } \\
\text { http://ri.lasa.com.br/noticias/ultimas- } \\
\text { noticias?fato-relevante-grupamento-de- } \\
\text { acoes\&id=5303 } \\
\text { Data: } \mathbf{2 5 / 0 6 / 2 0 0 7}\end{array}$ \\
\hline $\begin{array}{l}\text { Grupo Pão } \\
\text { de Açúcar }\end{array}$ & Grupamento & 500:1 & $\begin{array}{l}\text { Acessado em } 20 \text { de novembro de } 2013 \text { em: } \\
\text { http://rigpa.grupopaodeacucar.com.br/grupop } \\
\text { aodeacucar/web/arquivos/GPA_AGE_20070 } \\
\text { 730a_port.pdf } \\
\text { Data: 30/07/2007 }\end{array}$ \\
\hline OI & Grupamento & 1000:1 & $\begin{array}{l}\text { Acessado em } 20 \text { de novembro de } 2013 \text { em: } \\
\text { http://v4oi.infoinvest.com.br/ptb/5300/AA_B } \\
\text { TM_Grupamento_10.04.07P.pdf } \\
\text { Data: 10/04/2007 }\end{array}$ \\
\hline Light & Grupamento & 1000:1 & $\begin{array}{l}\text { Acessado em } 20 \text { de novembro de } 2013 \text { em: } \\
\text { http://ri.light.com.br/ptb/341/2007\%2011\%2 } \\
\text { 030\%20Fim\%20Prazo\%20Ajuste.pdf } \\
\text { Data: 30/11/2007 }\end{array}$ \\
\hline Comgás & Grupamento & 100:1 & $\begin{array}{l}\text { Acessado em } 23 \text { de novembro de } 2013 \text { em: } \\
\text { http://ri.comgas.com.br/Assembleias.aspx?Id } \\
\text { Canal=ZJ/j4/AZSW6+lnsIu2XLjw== } \\
\text { Data: } \mathbf{2 9 / 0 8 / 2 0 0 7}\end{array}$ \\
\hline Cemig & Grupamento & 500:1 & $\begin{array}{l}\text { Acessado em } 23 \text { de novembro de } 2013 \text { em: } \\
\text { http://cemig.infoinvest.com.br/ptb/3048/AVI } \\
\text { SO\%20AOS\%20ACIONISTAS_260407_por } \\
\text {.pdf } \\
\text { Data: } \mathbf{2 6 / 0 4 / 2 0 0 7}\end{array}$ \\
\hline AmBev & Grupamento & 100:1 & Acessado em 23 de novembro de 2013 em: \\
\hline
\end{tabular}




\begin{tabular}{|c|c|c|c|}
\hline & & & $\begin{array}{l}\text { http://ri.ambev.com.br/arquivos/Ambev_Avis } \\
\text { o_20070629_port.pdf } \\
\text { Data: 01/08/2007 }\end{array}$ \\
\hline AES Tiete & Grupamento & $250: 1$ & $\begin{array}{l}\text { Acessado em } 23 \text { de novembro de } 2013 \text { em: } \\
\text { http://aestiete.riweb.com.br/Show.aspx?IdMa } \\
\text { teria=EbQ6N1+iFewMm/z/KOMx5A== } \\
\text { Data: } \mathbf{2 6 / 0 2 / 2 0 0 8}\end{array}$ \\
\hline TIM & Grupamento & 1000:1 & $\begin{array}{l}\text { Acessado em } 23 \text { de novembro de } 2013 \text { em: } \\
\text { http://siteempresas.bovespa.com.br/consbov/ } \\
\text { ArquivosExibe.asp?site=\&protocolo=120027 } \\
\text { Data: } \mathbf{3 0 / 0 5 / 2 0 0 7}\end{array}$ \\
\hline Copel & Grupamento & 1000:1 & $\begin{array}{l}\text { Acessado em } 23 \text { de novembro de } 2013 \text { em: } \\
\text { http://www.copel.com/hpcopel/root/sitearqui } \\
\text { vos2.nsf/arquivos/acoes4_07port/\$FILE/acoe } \\
\text { s4_07.pdf } \\
\text { Data: } \mathbf{0 2 / 0 7 / 2 0 0 7}\end{array}$ \\
\hline $\mathrm{AmBev}$ & Desdobramento & $1: 5$ & $\begin{array}{l}\text { Acessado em } 26 \text { de novembro de } 2013 \text { em: } \\
\text { http://ri.ambev.com.br/conteudo_pt.asp?cont } \\
\text { a=28\&id=158941\&tipo=43194\&idioma=0 } \\
\text { Data:17/10/2010 }\end{array}$ \\
\hline $\mathrm{CSN}$ & Desdobramento & $1: 3$ & $\begin{array}{l}\text { Acessado em } 26 \text { de novembro de } 2013 \text { em: } \\
\text { http://www.mzweb.com.br/csn/web/conteudo } \\
\text { _pt.asp?idioma=0\&tipo=1435\&conta=28\&id } \\
=24835 \\
\text { Data: } 22 / 01 / 2008\end{array}$ \\
\hline $\mathrm{CSN}$ & Desdobramento & $1: 2$ & $\begin{array}{l}\text { Acessado em } 26 \text { de novembro de } 2013 \text { em: } \\
\text { http://www.mzweb.com.br/csn/web/conteudo } \\
\text { _pt.asp?idioma=0\&tipo=1435\&conta=28\&id } \\
=81705 \\
\text { Data: } \mathbf{2 5 / 0 3 / 2 0 1 0}\end{array}$ \\
\hline$\overline{\mathrm{CCR}}$ & Desdobramento & $1: 4$ & $\begin{array}{l}\text { Acessado em } 26 \text { de novembro de } 2013 \text { em: } \\
\text { http://ri.ccr.com.br/grupoccr/web/conteudo_p } \\
\text { t.asp?idioma=0\&conta=28\&tipo=47179 }\end{array}$ \\
\hline
\end{tabular}




\begin{tabular}{|c|c|c|c|}
\hline & & & Data: $25 / 11 / 2011$ \\
\hline Souza Cruz & Desdobramento & $1: 5$ & $\begin{array}{l}\text { Acessado em } 26 \text { de novembro de } 2013 \text { em: } \\
\text { http://www.souzacruz.com.br/group/sites/SO } \\
\text { U_7UVF24.nsf/vwPagesWebLive/DO8EBP } \\
\text { R6?opendocument\&SKN=1 } \\
\text { Data: } \mathbf{2 2 / 0 2 / 2 0 1 1}\end{array}$ \\
\hline Petrobrás & Desdobramento & $1: 2$ & $\begin{array}{l}\text { Acessado em } 26 \text { de novembro de } 2013 \mathrm{em} \text { : } \\
\text { http://www.investidorpetrobras.com.br/pt/go } \\
\text { vernanca/assembleias/24-de-marco-de-2008- } \\
\text { ata-da-assembleia-geral-extraordinaria.htm } \\
\text { Data: } \mathbf{2 5 / 0 4 / 2 0 0 8}\end{array}$ \\
\hline TIM & $\begin{array}{l}\text { Migração Novo } \\
\text { Mercado }\end{array}$ & $\begin{array}{l}0,8406: 1 \\
\text { (ações } \\
\text { preferenciais } \\
\text { para } \\
\text { ordinárias) }\end{array}$ & $\begin{array}{l}\text { Acessado em } 26 \text { de novembro de } 2013 \text { em: } \\
\text { http://ri.tim.com.br/Show.aspx?IdMateria=3+ } \\
\text { V/SxacqVtSqJr0wsozkg== } \\
\text { Data: } \mathbf{0 5 / 0 5 / 2 0 1 1}\end{array}$ \\
\hline
\end{tabular}

Após estas correções, a série histórica de quantidade de ações para as empresas listadas na tabela 3, não possuíam mais descontinuidades que ocasionariam vieses no número do valor do Equity (E).

\subsection{A ESCOLHA DA EMPRESA DE MAIOR LIQUIDEZ}

Uma empresa pode possuir mais de um ativo (ação) negociado em bolsa. Dessa forma, para o cálculo do valor do Equity (E), foram escolhidos apenas os ativos de ações de maior liquidez, isso porque ativos com pouco volume de negociação podem não oferecer estimativas precisas e os valores podem levar a interpretações errôneas.

A escolha dos ativos de maior liquidez foi feita com base no volume de negociação, assim como os autores Kanandani e Minardi (2013) que usaram o volume de negociação como critério de desempate quando havia mais de uma classe de ação para dada empresa.

Os autores Cerezo et. al. (2011) optaram por selecionar os ativos que compunham o IGBC, ou Índice General de la Bolsa de Valores de Colombia, esta escolha segundo os autores já determinaria as empresas com maior bursatilidade, com ativos com maior transação no mercado. 
O procedimento adotado para seleção das empresas foi escolher aquelas com um percentual de volume negociado acima de $0,1 \%$ na data base e com pelo menos $1 \%$ de volume de negociação em relação à Petrobrás (empresa com maior volume de negociação).

O percentual de volume negociado foi calculado utilizando todas as empresas que passaram pelo primeiro filtro, segundo figura 4 na seção 3.1 deste documento. O percentual de volume negociado de uma empresa é dado pelo volume negociado da empresa pelo volume total negociado por todas as empresas em uma mesma data.

As tabelas que contêm, respectivamente, o percentual em relação à Petrobrás e os percentuais de volume negociado se apresentam no anexo 4 deste documento, são as tabelas 9 e 10 .

Após a aplicação deste procedimento foram obtidas 30 empresas conforme pode ser observado pelas tabelas 9 e 10 do Anexo 4. A empresa Itaúsa foi retirada por se tratar de uma instituição financeira que não fará parte do estudo.

\subsection{MÉTODO DE SOLUÇÃO}

O tratamento da base de dados e a modelagem foram realizados no software SAS. A solução do sistema de equações foi atingida utilizando a procedure model ${ }^{16}$ do referido software segundo sugerido pelas notas 22779 do site do support $\mathrm{SAS}^{17}$.

A procedure model utiliza o método iterativo de Newton para solução do sistema de equações não lineares. Para cada observação da base de dados o cálculo é realizado até a convergência ${ }^{18}$ ser atingida. Esta convergência é dada pelo erro medido entre o valor da iteração realizada no momento e o valor da iteração do momento anterior, quando o erro atinge o valor de convergência, é considerado que a resposta foi encontrada. Este procedimento é repetido para cada linha da base de dados.

O conjunto de dados dispostos por empresa e data base, assim, terá, calculado para cada safra de referência, o valor de V (valor da empresa) e DV (volatilidade do valor da empresa). Uma vez determinadas estas duas incógnitas, os valores dos parâmetros RR e LGD, assim como PD, são facilmente determinados conforme as equações 15 e 18 .

\footnotetext{
${ }^{16}$ Além da procedure model, a procedure FCMP do SAS também é utilizada para solução de equações.

${ }^{17}$ A nota 22779 se encontra no link http://support.sas.com/kb/22/779.html

${ }^{18}$ A convergência atingida pela procedure neste modelo foi de $1.10^{-8}$
} 


\section{RESULTADOS}

\subsection{ESTATÍSTICAS DESCRITIVAS}

A base final de modelagem contou com 29 empresas conforme a tabela 4. Classificando setorialmente as empresas, a maior frequência é no setor de energia elétrica, seguido pelos setores de comércio, siderurgia/ metalurgia, telecomunicações e veículos, conforme apresentado na figura 5 .

Tabela 4 - Empresas presentes na modelagem.

\begin{tabular}{||l|l|l||}
\hline \multicolumn{2}{|c|}{ EMPRESAS } \\
\hline Braskem & AmBev & OI \\
\hline CCR & Gerdau Metais & Pão de Açúcar \\
\hline Comgás & Gol & Petrobrás \\
\hline Cemig & Guararapes & Marcopolo \\
\hline Copel & Klabin & Randon Participações \\
\hline Souza Cruz & Lojas Americanas & Suzano Papel \\
\hline Siderúrgica Nacional & Light & Tractebel \\
\hline Embraer & Natura & TIM Participações \\
\hline AES Tiete & Net & Usiminas \\
\hline Gerdau & & Telefônica Brasil \\
\hline \hline
\end{tabular}

Os setores de menor frequência foram: o de alimentos e bebidas, representado somente pela AmBev, o setor químico, representado pela Braskem e o setor têxtil, representado pela Guararapes.

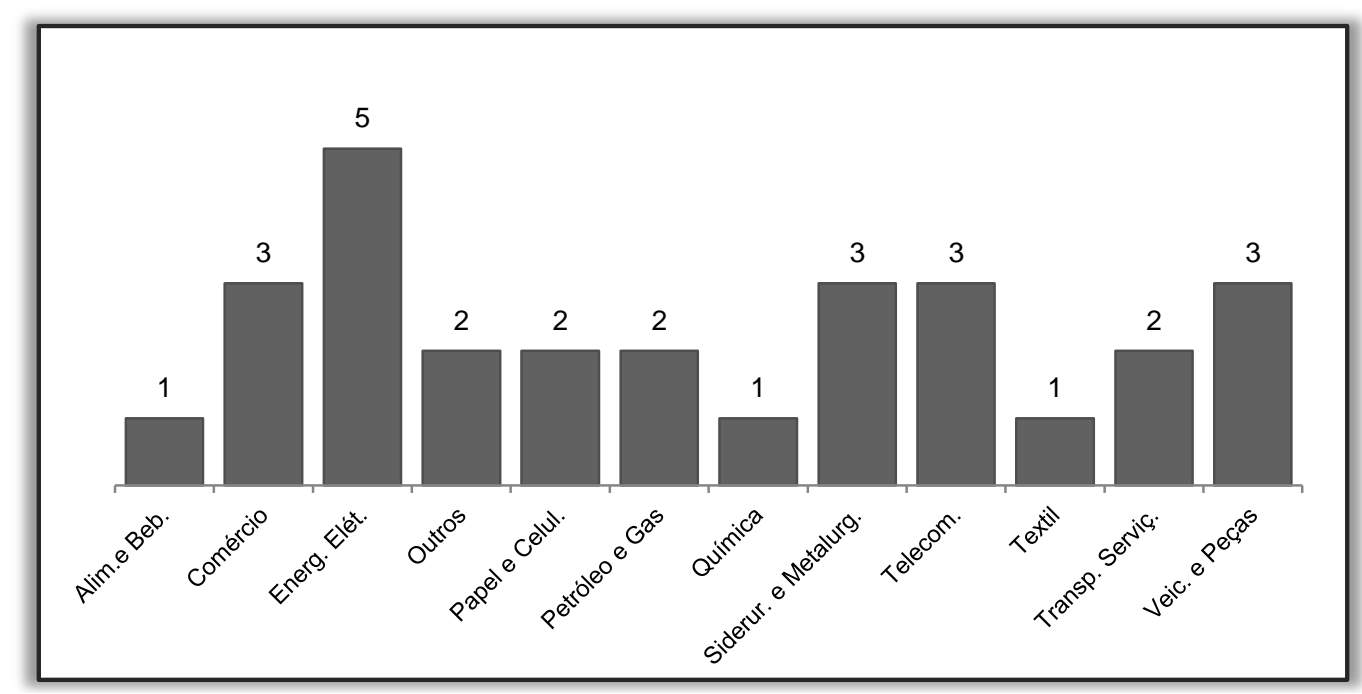

Figura 5 - Quantidade de empresas por setor na base de modelagem.

As estatísticas descritivas para as variáveis Equity (E) e Dívida (F) se apresentam na tabela 5. Estas duas varáveis input do modelo para o cálculo do valor da empresa (V). 
Tabela 5 - Análise descritiva das variáveis E (equity) e F (dívida).

\begin{tabular}{|c|c|c|c|c|c|c|}
\hline Empresa & Variável & $\mathbf{N}$ & Média* & $\begin{array}{c}\text { Desvio } \\
\text { Padrão* }\end{array}$ & Mínimo* & Máximo* \\
\hline \multirow{2}{*}{ AmBev } & $\bar{E}$ & 198 & 12.3466623 & 8.4712803 & 3.646452 & 29.561011 \\
\hline & $\mathrm{F}$ & 198 & 17.388288 & 2.5832446 & 12.40661 & 24.235952 \\
\hline \multirow{2}{*}{ Braskem } & $\mathrm{E}$ & 198 & 4.090289 & 1.3280869 & 1.404307 & 7.4229954 \\
\hline & $\mathrm{F}$ & 198 & 19.7718679 & 7.9082854 & 10.32599 & 35.740333 \\
\hline \multirow{2}{*}{ CCR } & $\mathrm{E}$ & 198 & 14.4091368 & 8.7480751 & 3.754031 & 34.8017669 \\
\hline & $\mathrm{F}$ & 198 & 5.843827 & 3.3342638 & 2.034308 & 11.600175 \\
\hline \multirow{2}{*}{ Comgás } & $\mathrm{E}$ & 198 & 0.8079184 & 0.2933677 & 0.325813 & 1.515852 \\
\hline & $\mathrm{F}$ & 198 & 2.5047203 & 0.7135957 & 1.182506 & 4.121056 \\
\hline \multirow{2}{*}{ Cemig } & $\mathrm{E}$ & 198 & 4.6107666 & 3.0343804 & 1.069673 & 12.9179854 \\
\hline & $\mathrm{F}$ & 198 & 18.0607226 & 4.7540188 & 10.27801 & 28.728899 \\
\hline \multirow{2}{*}{ Copel } & $\mathrm{E}$ & 198 & 3.47028 & 1.1076859 & 1.314934 & 5.4974671 \\
\hline & $\mathrm{F}$ & 198 & 5.7355998 & 1.3065105 & 4.450994 & 8.900971 \\
\hline \multirow{2}{*}{ Souza Cruz } & $\mathrm{E}$ & 198 & 18.8714671 & 13.1461294 & 4.967431 & 45.3866301 \\
\hline & $\mathrm{F}$ & 198 & 2.1958197 & 0.7758769 & 1.14541 & 4.069045 \\
\hline \multirow{2}{*}{$\begin{array}{c}\text { Siderúrgica } \\
\text { Nacional }\end{array}$} & $\mathrm{E}$ & 198 & 20.740334 & 9.6370236 & 6.052084 & 40.3814921 \\
\hline & $\mathrm{F}$ & 198 & 26.4978442 & 9.2292824 & 17.09948 & 45.814124 \\
\hline \multirow{2}{*}{ Embraer } & $\mathrm{E}$ & 198 & & 3.5486119 & & 14.9302324 \\
\hline & $\mathrm{F}$ & 198 & 11.3066315 & 1.5675965 & 8.763257 & 15.365145 \\
\hline \multirow{2}{*}{ AES Tiete } & $\mathrm{E}$ & 198 & 2.3109586 & 1.0869648 & 0.728034 & 4.4182003 \\
\hline & $\mathrm{F}$ & 198 & 1.9628741 & 0.1899321 & 1.602662 & 2.414914 \\
\hline \multirow{2}{*}{ Gerdau } & $\mathrm{E}$ & 198 & 14.4761555 & 7.3877795 & 1.74513 & 31.9701817 \\
\hline & $\mathrm{F}$ & 198 & 21.4816519 & 6.1229688 & 9.679973 & 34.006936 \\
\hline \multirow{2}{*}{$\begin{array}{l}\text { Gerdau } \\
\text { Metais }\end{array}$} & $\mathrm{E}$ & 198 & 4.8890789 & 2.5942915 & 0.628087 & 12.3044413 \\
\hline & $\mathrm{F}$ & 198 & 22.7809713 & 6.8860418 & 9.561071 & 35.778999 \\
\hline \multirow{2}{*}{ Gol } & $\mathrm{E}$ & 198 & 2.8415418 & 1.6227542 & 0.594638 & 6.1361251 \\
\hline & $\mathrm{F}$ & 198 & 4.7587487 & 2.7581151 & 0.44392 & 8.989597 \\
\hline \multirow{2}{*}{ Guararapes } & $\mathrm{E}$ & 198 & 2.157 & 0.8344738 & 0.46 & 3.7486081 \\
\hline & F & 198 & 0.8355325 & 0.4034775 & 0.438832 & 1.713743 \\
\hline \multirow{2}{*}{ Klabin } & $\mathrm{E}$ & 198 & 3.1294237 & 1.5735334 & 1.384559 & 7.7263904 \\
\hline & $\mathrm{F}$ & 198 & 5.7525619 & 2.1345382 & 2.184705 & 9.037665 \\
\hline \multirow{2}{*}{$\begin{array}{c}\text { Lojas } \\
\text { Americanas }\end{array}$} & $\mathrm{E}$ & 198 & 4.8061992 & 2.3910343 & 1.312479 & 10.7286781 \\
\hline & $\mathrm{F}$ & 198 & 5.6695785 & 2.4121136 & 2.033094 & 10.516821 \\
\hline \multirow{2}{*}{ Light } & $\mathrm{E}$ & 198 & 3.0713225 & 1.3727975 & 0.353208 & 5.2336264 \\
\hline & $\mathrm{F}$ & 198 & 6.8364869 & 0.9902727 & 5.370526 & 9.935824 \\
\hline \multirow{2}{*}{ Natura } & $\mathrm{E}$ & 198 & 11.4283825 & 6.2293899 & 0.879065 & 24.1798409 \\
\hline & $\mathrm{F}$ & 198 & 1.7894424 & 1.1322322 & 0.565029 & 4.848726 \\
\hline \multirow{2}{*}{ Net } & $\mathrm{E}$ & 198 & 4.5314861 & 1.4867723 & 1.427787 & 7.312128 \\
\hline & $\mathrm{F}$ & 198 & 3.5232766 & 1.427297 & 1.568454 & 6.390104 \\
\hline \multirow{2}{*}{ OI } & $\mathrm{E}$ & 198 & 2.8914151 & 1.8332551 & 1.048295 & 7.9799792 \\
\hline & $\mathrm{F}$ & 198 & 20.1396341 & 17.3184047 & 9.023962 & 57.824084 \\
\hline \multirow{2}{*}{$\begin{array}{l}\text { Pão de } \\
\text { Açúcar }\end{array}$} & $\mathrm{E}$ & 198 & 7.6622955 & 4.2499615 & 2.782133 & 17.2948779 \\
\hline & $\mathrm{F}$ & 198 & 12.648356 & 7.0597092 & 5.764344 & 24.328283 \\
\hline \multirow{2}{*}{ Petrobrás } & $\mathrm{E}$ & 198 & 96.0060807 & 30.8573636 & 9.046946 & 145.302758 \\
\hline & $\mathrm{F}$ & 198 & 181.224742 & 87.9612351 & 89.00545 & 409.002115 \\
\hline Marcopolo & $\mathrm{E}$ & 198 & 0.5319558 & 0.5874158 & 0.026881 & 1.9741357 \\
\hline
\end{tabular}




\begin{tabular}{clccccc}
\hline \hline & F & 198 & 1.6213661 & 0.5939919 & 0.646074 & 2.733694 \\
Randon & E & 198 & 1.0828328 & 0.5792231 & 0.282777 & 1.9961048 \\
Part. & F & 198 & 1.4562129 & 0.7283654 & 0.590476 & 3.105809 \\
Suzano & E & 198 & 2.952875 & 1.2082825 & 1.124677 & 5.927592 \\
Papel & F & 198 & 8.8049312 & 3.2197366 & 3.714708 & 15.786056 \\
Tractebel & E & 198 & 12.0612607 & 5.101645 & 2.960041 & 21.9257559 \\
& F & 198 & 5.0727482 & 1.7938803 & 2.368927 & 7.945309 \\
TIM Part. & E & 198 & 16.9845269 & 5.9485515 & 3.388571 & 27.1469841 \\
& F & 198 & 7.271582 & 2.6937362 & 0.901799 & 12.276107 \\
Usiminas & E & 198 & 4.4291482 & 2.5789811 & 0.658539 & 10.6149257 \\
Telefônica & F & 198 & 11.1075998 & 2.3398018 & 7.662007 & 14.743 \\
BR & F & 198 & 15.6695919 & 10.9154116 & 6.295124 & 37.7444903 \\
\hline \hline
\end{tabular}

* Valores em Bilhões de R\$

A tabela 5 apresenta as métricas de média, desvio padrão, máximo e mínimo valor observado para cada uma das empresas consideradas na modelagem. Essas métricas são feitas para todo o período de modelagem: de dezembro de 2006 a junho de 2013.

É possível perceber que para a maioria das empresas a média no período do valor contábil da dívida é superior à média do valor do equity.

As tabelas 6, 7 e 8 possuem as estatísticas descritivas para as volatilidades de 3 meses, 6 meses e 12 meses respectivamente. Nestas tabelas é possível observar que a volatilidade de 12 meses possui o valor levemente superior, porém com variância menor, já a volatilidade de 3 meses possui média menor com maior variância.

Tabela 6 - Descritiva Estatística da volatilidade de 3 meses.

\begin{tabular}{cccc}
\hline \hline Média & Mediana & Desvio Padrão & Variância \\
0.366066 & 0.339863 & 0.1415 & 0.02001 \\
\hline \hline
\end{tabular}

Tabela 7 - Descritiva Estatística da volatilidade de 6 meses.

\begin{tabular}{cccc}
\hline \hline Média & Mediana & Desvio Padrão & Variância \\
0.373204 & 0.352669 & 0.13115 & 0.01702 \\
\hline \hline
\end{tabular}

Tabela 8 - Descritiva Estatística da volatilidade de 12 meses.

\begin{tabular}{cccc}
\hline \hline Média & Mediana & Desvio Padrão & Variância \\
0.381238 & 0.359361 & 0.1187 & 0.01409 \\
\hline \hline
\end{tabular}

A figura 6 ilustra o comportamento das volatilidades das ações no horizonte de tempo: a volatilidade de 3 meses é mais suscetível a impactos recentes do mercado, isso porque 
considera as safras mais recentes para o cálculo, o impacto é acentuado e pontual. Já para a volatilidade de 12 meses ocorre um abrandamento do impacto, contudo o pico se prolonga por um horizonte maior que a volatilidade de 3 meses. Pelo fato da volatilidade de 3 meses capturar os impactos com maior intensidade, é intuitivo que esta medida gerará resultados mais altos para a LGD.

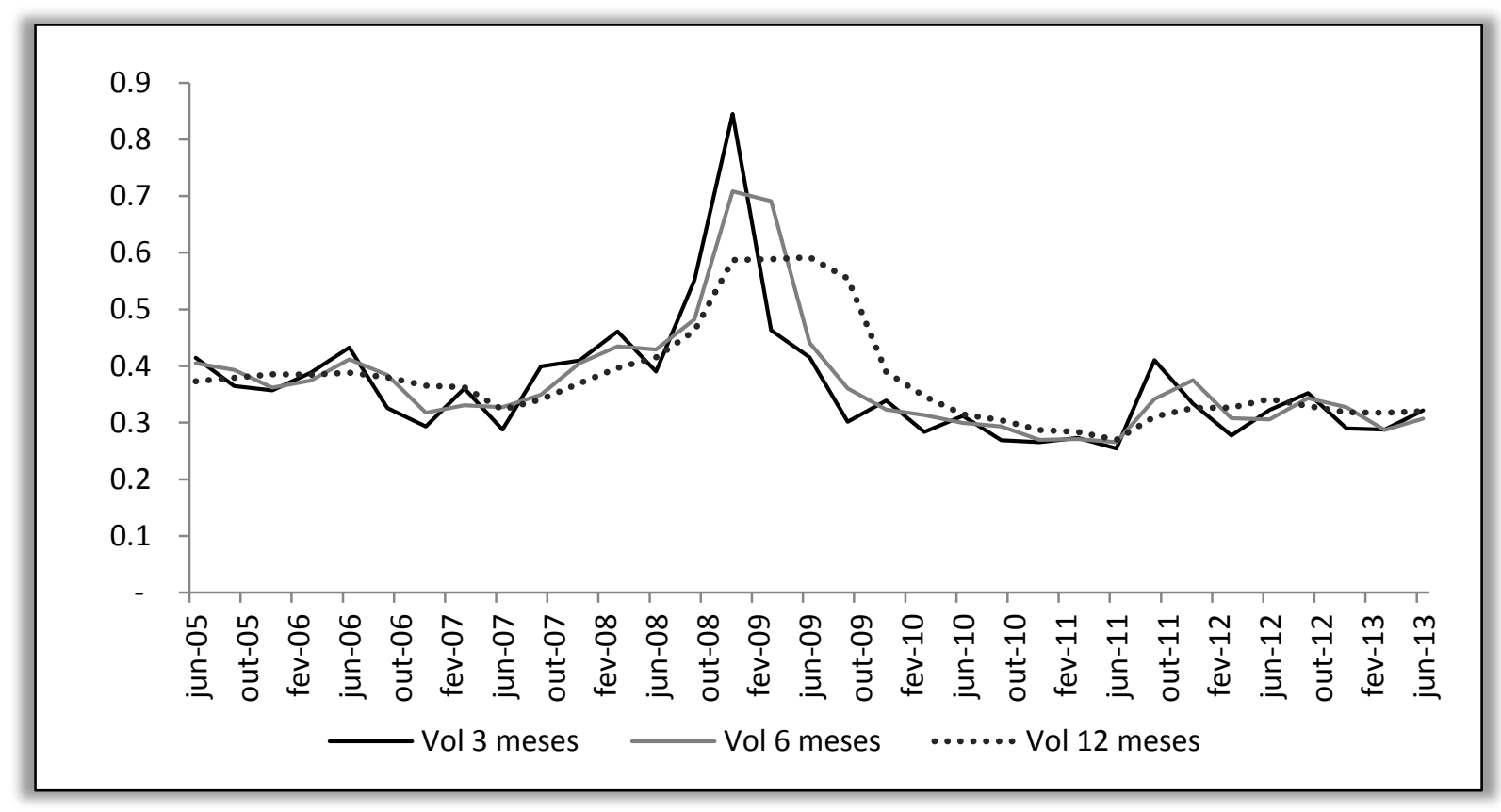

Figura 6 - Comportamento das volatilidades das ações por data base.

\subsection{ANÁLISES}

A barreira de default no modelo proposto por Merton é atingida quando o valor da empresa (enterprise value) fica abaixo do valor do passivo, no caso representado pela dívida contábil. Assim sendo, é de se esperar que em tempos de maior instabilidade financeira, onde os valores das ações possuem grande oscilação e degradação, que os parâmetros como a probabilidade de default - PD e a perda dada ao default - LGD possuam valores elevados.

Observando o horizonte de tempo de 2006 a 2013, espera-se que o período de 2008 ocorra valores acentuados de PD e LGD e uma degradação do enterprise value (V) em relação ao passivo, uma vez que este ano foi acometido pela instabilidade de diversos mercados resultado da crise dos subprimes.

As figuras 7, 8 e 9 apresentam os parâmetros do modelo para volatilidade de 3 meses, 6 meses e 12 meses respectivamente. Nestas figuras são apresentadas as métricas para o maturity de 1 ano e de 5 anos. 


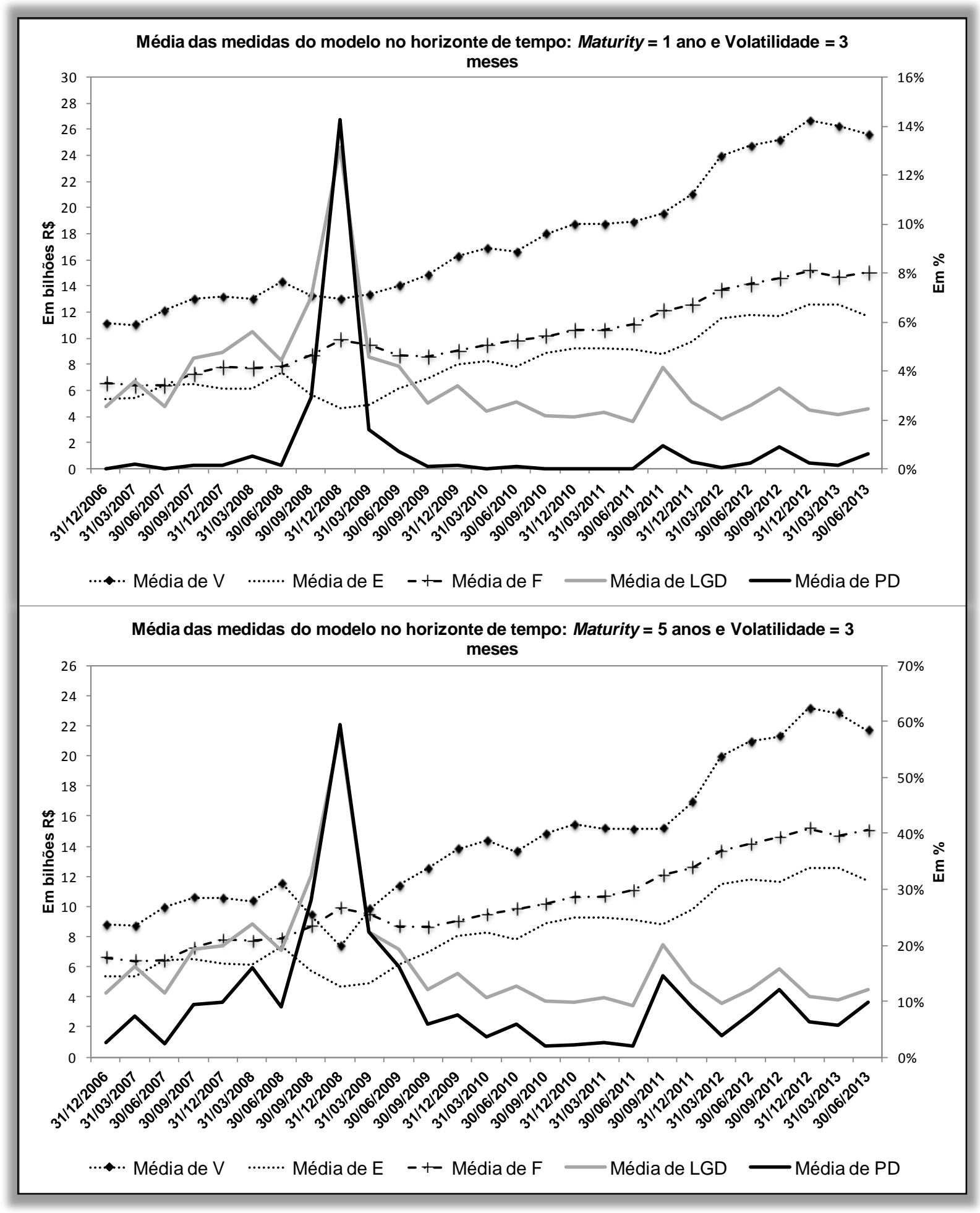

Figura 7 - Média das medidas do modelo para a volatilidade de 3 meses.

Na figura 7 observa-se um pico para a LGD e a PD, em ambos gráficos, no período de dezembro de 2008, época que a crise do subprimes surtiu seus efeitos nos mercados em nível global. Neste mesmo ponto, observa-se ainda, que o valor das ações, representado pelo E (equity) possui uma desvalorização significativa, ao passo que a dívida, representada pelo $\mathrm{F}$, 
apresenta um ligeiro aumento, estes movimentos resultam em uma desvalorização do valor da empresa, representado por $\mathrm{V}$, e aumenta a probabilidade de default (PD) e de perda dada a inadimplência (LGD).

Observando o horizonte de tempo posterior à crise, tanto o valor das ações como a dívida possuem tendências de crescimento. $\mathrm{O}$ valor da empresa (V) também atinge valores altos, a PD possui valores bem reduzidos e a LGD possui um patamar controlado. Além disso, confrontado os dois gráficos da figura 7, observa-se que para o maturity de 5 anos os valores de PD e LGD são maiores que para o maturity de 1 ano, o que pode sugerir que dívidas com duration mais curto possuem perdas menores que as dívidas com duration maior: este fato é intuitivo, quanto maior o período da dívida e um maior período de cobrança menores as chances de recuperação do valor.

$\mathrm{Na}$ figura 8 um comportamento parecido com os gráficos da volatilidade de 3 meses é observado: no mesmo momento do tempo, em dezembro de 2008, ocorre uma perturbação positiva, um aumento, nas tendências de PD e LGD. Contudo, observa-se que, ao passo que com a volatilidade de 3 meses esse pulso é intenso, na volatilidade de 6 meses ele é amenizado, mostrando um grafismo parecido ao da figura 6 que apresenta os comportamentos das volatilidades propriamente ditas. Portanto, pode-se dizer que as métricas de LGD e PD são sensíveis ao valor da volatilidade das ações: em momentos de grandes oscilações seus valores tendem a aumentar na proporção da variação das volatilidades.

Similarmente às figuras 7 e 8 , a figura 9 também apresenta um pico na safra de dezembro de 2008, contudo mais suavizado que o observado nas volatilidades de 3 e 6 meses. Analogamente também às figuras 7 e 8 observa-se uma melhora dos parâmetros de PD e LGD após este período e uma crescente valorização do valor da empresa (V). 


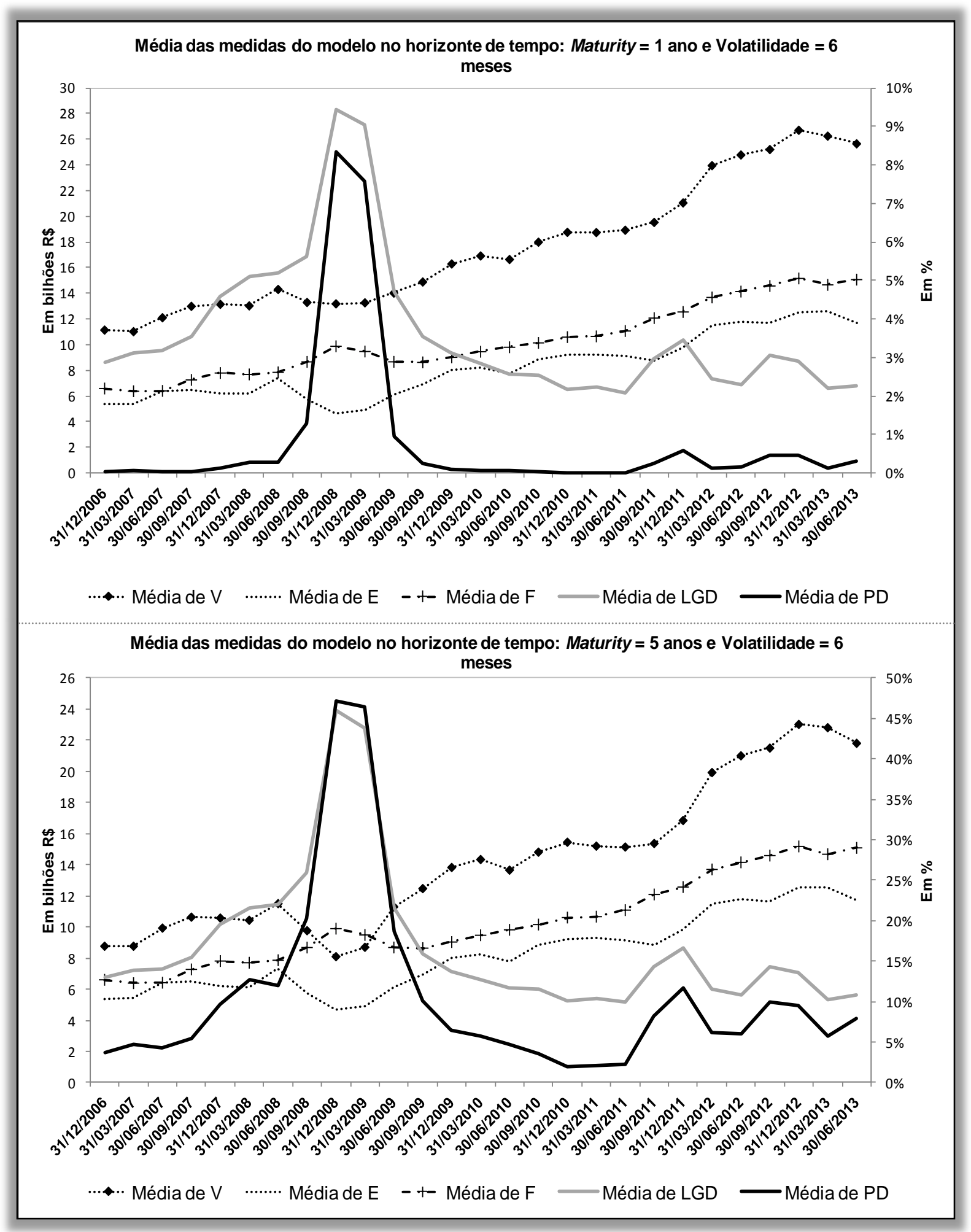

Figura 8 - Média das medidas do modelo para a volatilidade de 6 meses. 


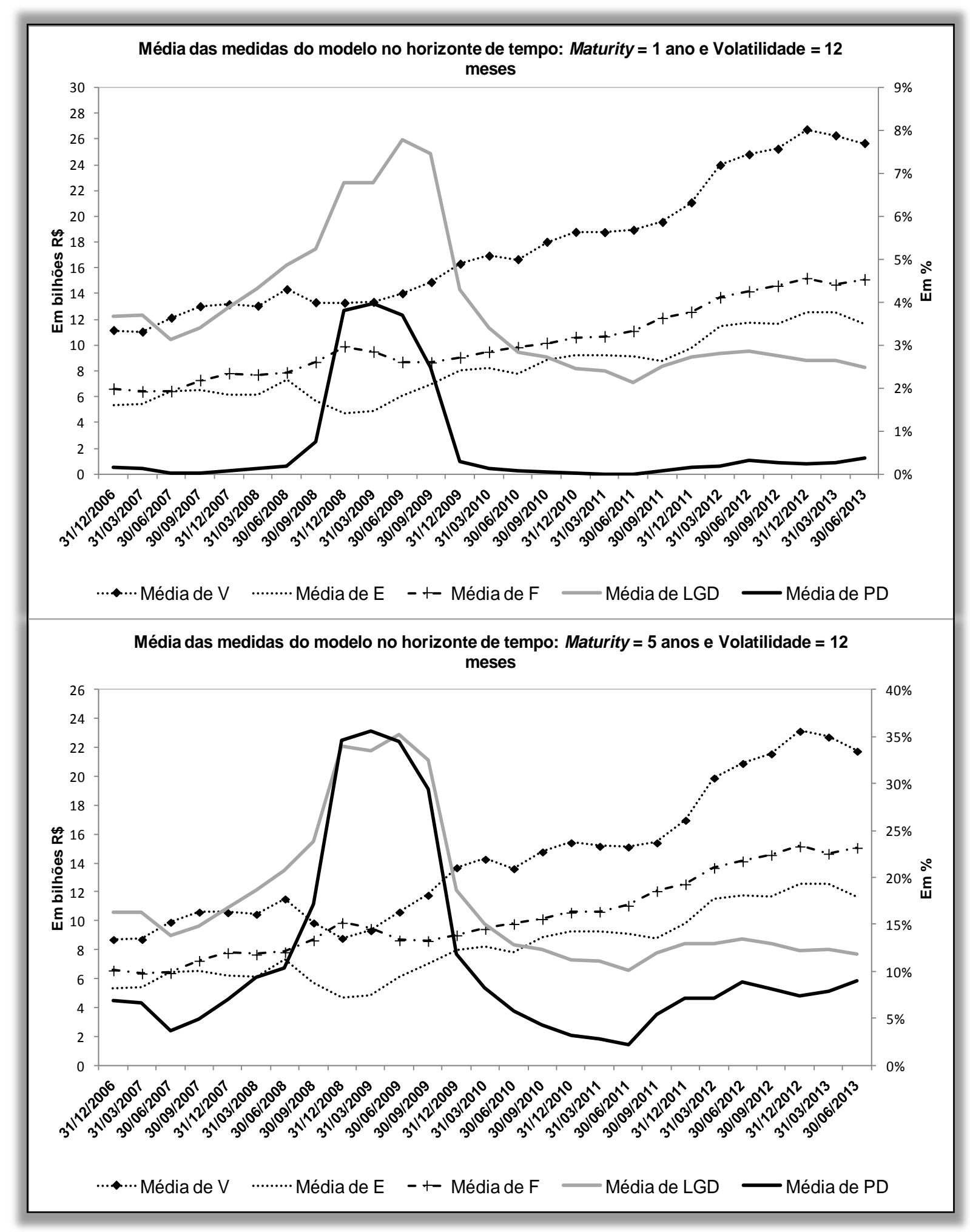

Figura 9 - Média das medidas do modelo para a volatilidade de 12 meses.

A análise setorial para esta população é frágil: observando a tabela 4, existem muitos setores com uma ou duas empresas apenas, portanto qualquer extrapolação feita para o setor pode ser imprudente. A figura 10 apresenta a média da LGD nos setores. 
O setor com maior LGD média é o setor de transporte e serviços, isso tanto para o maturity de 1 ano como para o de 5 anos, porém este setor é formado por apenas duas empresas, e o menor foi o de Alimentos e Bebidas, com sua única representante, a AmBev.

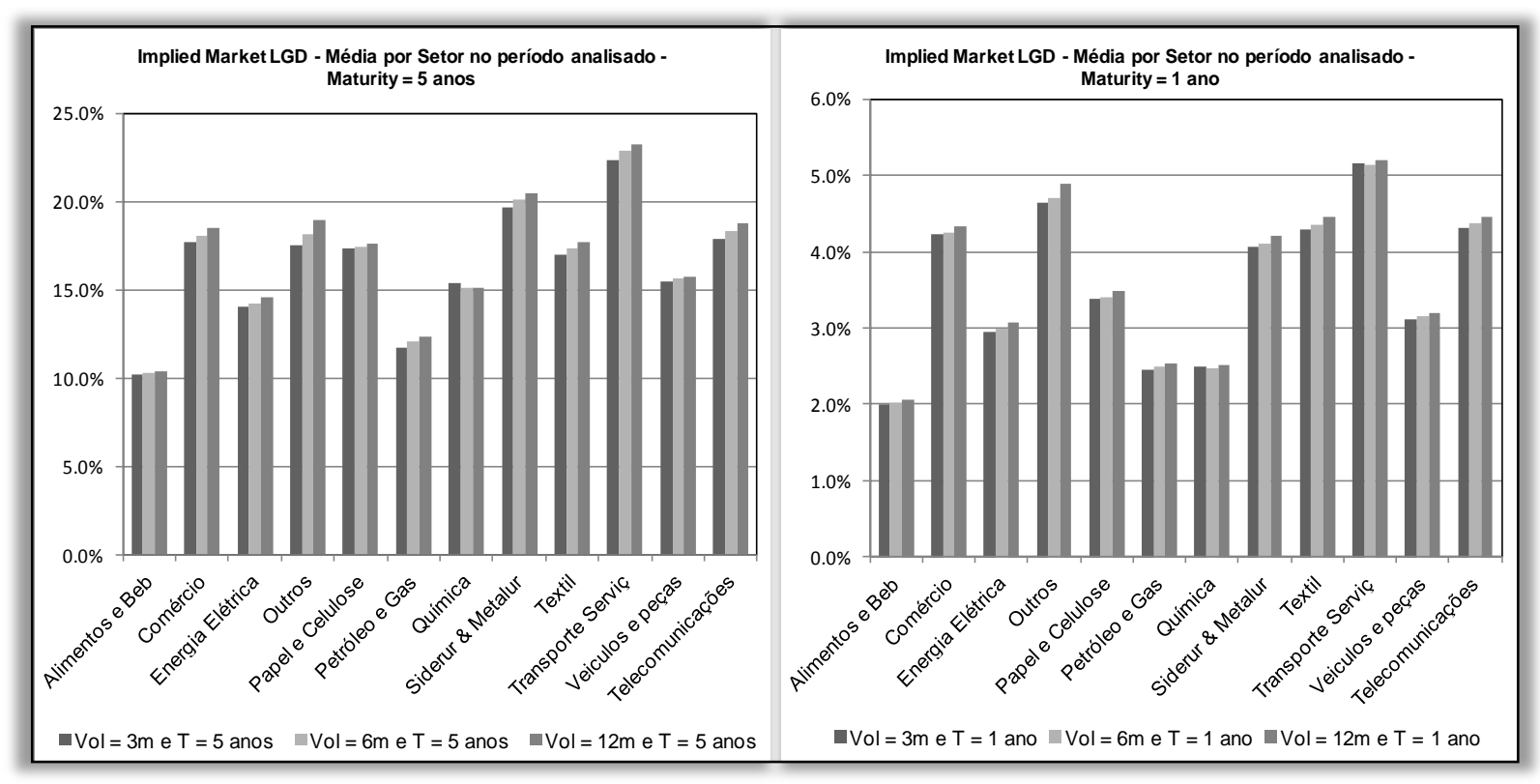

Figura 10 - Média da LGD por Setor

Uma vez que não há empresas suficientes em cada um dos setores para uma comparação setorial robusta, a melhor comparação é feita pelas empresas individualmente. $\mathrm{O}$ anexo 6 apresenta gráficos da LGD no horizonte de tempo para cada uma das empresas presentes na modelagem.

Os gráficos deste anexo mostram que o comportamento de todas as empresas é similar ao longo do tempo, sendo que algumas possuem um patamar de LGD levemente mais elevado que outras.

$\mathrm{O}$ anexo 7 possui uma tabela com os valores dos parâmetros valor da empresa (V) e sua volatilidade, para cada uma das volatilidades e maturity.

Os valores apresentados para as estimativas de Loss Given Default, pela abordagem do Implied Market, mostraram-se satisfatórios. Os valores aqui encontrados para o maturity de 1 ano e volatilidade de 12 meses, são similares aos valores encontrados pelos autores Cerezo et. al. (2011). O trabalho deles utiliza uma volatilidade de 12 meses e, apesar de não explicitar, parece considerar um maturity de 1 ano. As taxas de recuperações neutras ao risco encontradas foram em torno de $90 \%$, resultando em LGD na casa dos $10 \%$ aplicando o modelo de Merton para o mercado colombiano.

Seilder (2008) obteve valores de LGD no patamar dos 30\% - 40\%, principalmente (salvo alguns poucos casos), aplicando também uma variação do modelo de Merton para o 
mercado de Praga. Os valores encontrados aqui apresentados de LGD para um mesmo maturity são menores, no momento pós-crise, que os apresentados por este autor. Comparando, todavia, as premissas utilizadas existem diferenças consideráveis em cada estudo: as métricas dos parâmetros aqui apresentados correspondem às neutras ao risco, ou seja, para determinação de PD e LGD foi considerada a taxa livre de risco; o cálculo de volatilidade foi utilizado a fórmula de desvio padrão utilizando janelas móveis de 3, 6 e 12 meses e pagamento de dividendos não foram considerados, diferentemente de Seidler (2008), que utilizou um modelo GARCH para determinação da volatilidade das ações e considerou o pagamento de dividendos nas estimativas e inseriu também um fator de custo para a taxa de recuperação, incrementando os valores de perda.

Vale ressaltar ainda, o trabalho realizado por Seidler (2008), a análise de sensibilidade. $\mathrm{O}$ autor cita que quanto maior a volatilidade das ações, maior será a LGD. Este fato foi observado principalmente no período de 2008, segundo a figura 6 o pico de volatilidade das ações é exatamente neste período e coincide com o pico de LGD nas figuras 7, 8 e 9. O autor também elucida um fato importante, segundo ele "quando a alavancagem (razão entre a dívida sobre o valor da empresa - F/V) aumenta, o peso das ações (equity E) no valor da empresa (V) diminui, diminuindo assim a volatilidade da empresa".

$\mathrm{Na}$ tabela do anexo 7, que apresenta os valores de $\mathrm{V}$ e $\sigma_{V}$ para as volatilidades e maturity considerados, é possível observar que os valores de $\sigma_{V}$ são menores que os valores médios da volatilidades apresentados nas tabelas 6,7 e 8 . Observa-se também pela tabela 5 que o valor da dívida (F) é para a maioria das empresas, maior que o valor das ações (equity E), indícios de alta alavancagem e, por consequência, menores volatilidades da empresa.

Completando a análise, soma-se a todo o exposto, o fato de que o gráfico apresentado na figura 9, que utiliza da volatilidade de 12 meses, apresenta resultados menos sensíveis a perturbações de mercado, evidenciando que a utilização de uma janela maior para a volatilidade, confere resultados mais robustos. A volatilidade que Hull (2005) sugere é indicada para risco de mercado em que a visão de curto prazo é favorecida para predição dos preços e comportamento do mercado. Contudo, tratando-se do risco de crédito o objetivo é obter modelos estáveis e predição em horizontes de tempo maior que o risco de mercado.

Através de todo o exposto até este ponto, pode-se afirmar que haja vista a necessidade de se adequarem às exigências do acordo de Basiléia, as instituições financeiras estão despendendo esforços para desenvolverem modelos quantitativos para mensuração dos parâmetros necessários ao cálculo de capital regulatório. 
A importância de métricas aderentes à suas carteiras e, ao mesmo tempo, que gerem estimativas reais e não sub ou superestimadas, reside no fato que este cálculo determina a quantia de capital que os bancos deverão provisionar para suas reservas. Quanto melhores as estimativas, mais assertivo será o provisionamento e melhor será esse valor se comparado às estimativas determinada pela abordagem padronizada.

Sob esta ótica, a escolha da metodologia que melhor se encaixa a realidade da carteira de ativos da instituição é determinante nos resultados obtidos. Na literatura existem diversos trabalhos relacionados ao cálculo de probabilidade de default (PD) tanto para carteiras com default observado quanto para carteiras onde se observa pouco ou nenhum default.

Para o parâmetro de loss given default (LGD) a grande maioria da literatura a respeito trata de cálculos onde se parte da mensuração de recuperação após a observância do evento de default, e poucos são os trabalhos que abordam o cálculo para carteiras onde este evento não é encontrado.

Os trabalhos existentes para esta abordagem partem de modelos estruturais, a maioria a partir do modelo de Merton ou de variações deste modelo, nos quais os parâmetros de PD e LGD podem ser determinados de maneira implícita através dos preços de mercado dos ativos e da dívida de uma empresa. A barreira de default nestes modelos é atingida quando o valor da empresa é inferior ao valor de suas dívidas. O valor da empresa é função do valor da divida e do valor de ações e como o valor das ações possui atualização diária este modelo atualiza seus valores a cada nova atualização do valor de ações no mercado.

Respondendo, assim, a pergunta de pesquisa feita no item 1.5 deste documento, podese concluir que como qualquer outra metodologia a abordagem do cálculo da LGD por modelos estruturais possui vantagens e limitações: como vantagens principais este modelo oferece o cálculo de dois parâmetros - PD e LGD - sem que haja a necessidade de obter uma população com eventos de default observados, outra grande vantagem reside no fato de que os parâmetros podem ser atualizados com uma frequência diária. As limitações principais residem principalmente nas premissas de adaptação do modelo: o valor da dívida normalmente utilizado é o valor contábil ao invés do valor de títulos de divida.

Diversos autores utilizam esta premissa porque somente a utilização de títulos de dividas não representa o valor da dívida da empresa na sua forma plena, outra premissa normalmente adotada é o valor do maturity, alguns autores defendem o valor de 1 ano, outros utilizam valores que ponderem melhor a passivo de curto e longo prazo, contudo o fato é que cada empresa tem uma estrutura de dívida diferente e generalizações acabam por resultarem em estimativas não precisas. 
Ainda que flexibilizações sejam feitas, os resultados obtidos mostraram-se satisfatórios: observaram-se valores maiores de PD e LGD na época de crise e valores menores em épocas posteriores a essa. Esta técnica, portanto, é uma alternativa para determinação de perda de crédito em portfólios que não existam eventos de inadimplência observados.

\section{CONCLUSÕES, LIMITAÇÕES E POSSÍVEIS EXTENSÕES}

Como desfecho das análises deste método de cálculo para perda de crédito, a principal conclusão a ser feita é que o uso deste modelo deve ser condicionado, estritamente de preferência, a cenários que não existam eventos de inadimplência observáveis e depois de outras metodologias mais robustas conhecidas serem descartadas.

As flexibilizações feitas ao modelo de forma a torná-lo operacionalizável e até mesmo àquelas que são realizadas para simplificar a coleta e tratamento das informações, acabam por deixar o modelo frágil.

A concepção original de Merton previa a utilização de título de divida e ações. Substituir os títulos, que são sujeitos às influências e oscilações de mercado, pela dívida contábil, que não é afetada diretamente por estes movimentos, surge algumas inquietações: um termo está extremamente suscetível a grandes oscilações e o outro é praticamente fixo, portanto, em épocas de crise, o valor da divida terá maior participação no valor da empresa (pois certamente o valor das ações terá sofrido degradações significativas), em períodos de expansão o valor das ações terá maior participação no valor da empresa.

A respeito da dívida pode-se dizer que o crédito é concedido analisando uma série de fatores individuais da estrutura da empresa: sua participação e solidez no mercado, sua capacidade de honrar dívidas, seus projetos, o relacionamento que esta enquanto cliente mantém com seu banco. É evidente que em épocas de crise, a oferta de crédito será reduzida e por consequência, afetará a dívida da empresa, mas o ponto é que a concessão de crédito dependerá mais da companhia em questão do que das oscilações de mercado. A conclusão é que, enquanto as ações sofrem muito com as oscilações de mercado, as dívidas sofrem pouco.

Apesar de tantas restrições, vale lembrar que, as instituições financeiras para candidatarem-se à metodologia avançada, precisam ter todo seu portfólio "coberto" por modelos quantitativos. Considerando que a maior parte do portfólio de um banco comercial é composta pelo crédito do varejo, $\mathrm{PF}$ e $\mathrm{PJ}$, os quais possuem grande volume de operações e consequentemente uma quantidade considerável de eventos de default enquadrados nas 
definições do Acordo, pode-se dizer que uma expressiva massa da carteira será submetida a modelos robustos e adequados a sua realidade própria de crédito.

A metodologia de cálculo implícita pode ser aplicada a uma pequena parte da carteira, que possui baixíssimos índices de inadimplência históricos, a ponto de não ser possível em um horizonte de tempo considerável ter um evento sequer observado.

Do ponto de vista das instituições financeiras a candidatura à abordagem avançada é mais atrativa, os modelos quantitativos desenvolvidos fornecem parâmetros mais ajustados e menores que o da abordagem padronizada, resultando assim em um Índice de Basiléia menor, o qual afetará em última instancia, às práticas exercidas por tal instituição perante o mercado. Portanto é necessário que os modelos quantitativos sejam robustos e ajustados à realidade de sua instituição, mas que sem que haja excesso de conservadorismo desnecessário.

As limitações deste trabalho incluem: a utilização do passivo com a conta de "dividendos a pagar"; o valor do maturity que foi padronizado e não representa a real estrutura de dívida da empresa; os valores de LGD calculados foram neutros ao risco e, a mensuração da volatilidade se deu pela fórmula da variância.

Como possíveis extensões para este trabalho são sugeridas: (a) um estudo de sensibilidade teórico para os parâmetros do modelo através de simulação, identificando quais variáveis possuem maior impacto no resultado e a sinergia entre os parâmetros; (b) o desenvolvimento de um backtesting neste tipo de abordagem, (c) utilizar valores da estrutura da dívida contida em informes financeiros para compor o maturity, levando em conta as diferentes senioridades dos títulos de dívida, segregando-os em níveis de senioridades, (d) identificar soluções para tratar/ considerar no modelo as empresas que não possuem liquidez suficiente, ou seja, as empresas que possuem pouco volume de negociação de ações, (e) utilizar outras medidas para determinação da volatilidade das ações, utilizando-se de uma janela maior (12 meses), mas ponderando as últimas observações de preços. 


\section{REFERÊNCIAS BIBLIOGRÁFICAS}

Altman, E., Resti, A., \& Sironi, A. (2004). Default recovery rates in credit risk modelling: a review of the literature and empirical evidence. Economic Notes, vol. 33, $\mathrm{n}^{\mathrm{o}} 2$, pgs. 183 208.

Amaral, L. (2009). Crises financeiras: história e actualidade. Revista de Relações Internacionais (R: I), pgs. 119-138. Recuperado em 25 de março de 2013: http://www.scielo.oces.mctes.pt/scielo.php?pid=S164591992009000300009\&script=S ci_arttext

Bacen, (2013). Discurso do diretor de Regulação do Sistema Financeiro, Luiz Pereira da Silva, na divulgação sobre a implantação no Brasil do Acordo de Basiléria III. Recuperado em 08 de maio de 2013: http://www.bcb.gov.br/pec/appron/apres/Discurso_Luiz_Pereira_Basileia_1-32012.pdf

Barfield, R. (2011). A Practitioner's Guide to Basel III and Beyond. PricewaterhouseCoopers. Recuperado em 08 de maio de 2013: http://www.pwc.com/en_GX/gX/financial-services/pdf/Introduction-and chaptersfinal.pdf

BCBS, Basel Committee on Banking Supervision (2005). International Convergence of Capital Measurement and Capital Standards. Recuperado em 08 de maio de 2013 em: http://www.bis.org/publ/bclbs107.htm

BCBS, Basel Committee on Banking Supervision (2013a). History of the Basel Committee and its Membership. Recuperado em 08 de maio de 2013 em: http://www.bis.org/bcbs/history.pdf

BCBS, Basel Committee on Banking Supervision (2013b). Annex2: Phase-in Arrangements. Recuperado em 09 de maio de 2013 em: http://www.bis.org/bchs/basel3/basel3_phase_in_arrangements.pdf.

Bharath, S. T., \& Shumway, T. (2008). Forecasting default with the Merton distance to default model. Review of Financial Studies, vol. 21, n 3, pgs. 1339-1369.

Black, F., \& Cox, J. C. (1976). Valuing Corporate Securities: Some effects of Bond Indenture Provisions. The Journal of Finance, vol. 31, $\mathrm{n}^{\mathrm{o}}$ 2,pgs. 351-367. 
Black, F., \& Scholes, M. (1973). The pricing of options and corporate liabilities. The journal of political economy, pgs. 637-654.

CEBS, Committee of European Banking Supervisors. (2006, April 4). Guidelines on the implementation, validation and assessment of Advanced Mensurament (AMA) and Internal Ratings Based (IRB) Approaches. Recuperado em 09 de maio de 2013 em: http://www.eba.europa.eu/-/guidelines-on-the-implementation-validation-andassessment-of-advanced-measurement-ama-and-internal-ratings-based-irbapproach-1

Cerezo, E. C., Bielsa, M. C., \& Ramón, M. C. (2011). Medición del riesgo de crédito mediante modelos estructurales: una aplicación al mercado colombiano. Cuadernos de Administración, vol 24, nº42.

Chen, R., \& Wang, Z. (2013). Curve Fitting of the Corporate Recovery Rates: The Comparison of Beta Distribution Estimation and Kernel Density Estimation. PloS one, vol. $8, \mathrm{n}^{\mathrm{o}} 7$, e68238.

Copeland, T; Koller, T e Murrin, J (1995). Valuation : Measuring and Managing the Value of Companies. McKinsey \& Company Inc.

Delianedis, G., \& Geske, R. (2001). The components of Corporate Creditspreads: Default, Recovery, Tax, Jumps, Liquity, and Martket Factors. Anderson Graduate School of Management, UCLA, $\mathrm{n}^{\circ} 1025$

Duan, J. C., Gauthier, G., Simonato, J. G., \& Zaanoun, S. (2003). Maximum likelihood estimation of structural credit spread models-deterministic and stochastic interest rates. Working paper, University of Toronto, Toronto, Canada.

Duffie, D. (1998). Defaultable term structure models with fractional recovery of par. Graduate School of Business, Stanford University.

Febraban - Federação Brasileira de Bancos (2013, 1 de março). Basiléia III reforça posição de destaque do Brasil. Recuperado em 08 de maio de 2013 em: http://www.febraban.org.br/Noticias1.asp?id_texto=1961\&id_pagina=60\&palavra $=$

Geske, R. (1977). The valuation of corporate liabilities as compound options. Journal of Financial and Quantitative Analysis, vol 12, nº4, pgs 541-552. 
Grunert, J., \& Weber, M. (2009). Recovery rates of commercial lending: Empirical evidence for German companies. Journal of Banking \& Finance, vol. 33, nº 3, pgs. 505513.

Hull, J. C. (2005). Fundamentos dos mercados futuros e de opções: manual de soluções. Bolsa de Mercadorias \& Futuros.

Hull, J., \& White, A. (1995). The impact of default risk on the prices of options and other derivative securities. Journal of Banking \& Finance, vol. 19, $\mathrm{n}^{\mathbf{0}}$ 2, pgs. 299-322.

Jacobs Jr, M. (2011). An option theoretic model for ultimate loss given default with systematic recovery risk and stochastic returns on defaulted debt. BIS Working Papers, $\mathrm{n}^{\mathrm{o}} 58$

Jorion, P. (2003). Value at risk: nova fonte de referência para o controle do risco de mercado. Bolsa de Mercadorias \& Futuros, $2^{a}$ edição.

Kanandani, F. H., Minardi, A. M. A. F. (2013). Modelos Estruturais antecipam alteração de rating de crédito de agências? Insper Working Paper: 314/2013.

Klingebiel, D., \& Caprio, G. (2003). Episodes of systemic and borderline financial crises, In World Bank Research Dataset, 2003. Recuperado em 25 de março de 2013 em: http://econ.worldbank.org

Lando, D. (1998). On Cox processes and credit risky securities. Review of Derivatives research, vol. 2, $n^{o}$ 2-3, pgs 99-120.

Leite,V. K.S., Cavalcanti Filho, F. P., B. D. M., \& Cordeiro, A. D. (2011). Do fim de Bretton Woods à crise do Sub-prime: a securitização como solução e causa de duas crises financeiras, IV Encontro Internacional da Associação Keynesiana Brasileira.

Litterman, R. B., \& Iben, T. (1991). Corporate bond valuation and the term structure of credit spreads. The journal of portfolio management, vol. 17, $\mathrm{n}^{\circ} 3$, pgs 52-64.

Longstaff, F. A., \& Schwartz, E. S. (1995). A simple approach to valuing risky fixed and floating rate debt. The Journal of Finance, vol.50, n 3, pgs 789-819. 
Madan, D., Bakshi, G., \& Zhang, F. X. (2006). Understanding the role of recovery in default risk models: Empirical comparisons and implied recovery rates. FDIC Center for Financial Research, Working Paper, nº 06

Madan, D. B., \& Unal, H. (1998). Pricing the Risks of Default, Review of derivatives Research, Boston, vol 2, pgs 121-160

Martins, G. A., Theóphilo, C.R. (2009). Metodologia da Investigação Científica para Ciências Sociais Aplicadas. São Paulo: Atlas, 2ed.

Merton, R. C. (1973). Theory of rational option pricing. The Bell Journal of Economics and Management Science, pgs 141-183.

Merton, R. C. (1974). On the pricing of corporate debt: The risk structure of interest rates. The Journal of Finance, vol 29, n 2, pgs 449-470.

Minardi, A. M. A. F., Sanvicente, A. Z., \& Artes, R. (2006). Determinação de Rating de Crédito de Unidades de Negócios Visando Estimar o Custo de Capital de Terceiros. 30o Encontro da ANPAD.

Moddy'S. (2011). Overcoming challenges in PD/ LGD modelling in the absence of high quality and rich data. Recuperadoo em 09 de maio de 2013 em: http://www.moodysanalytics.com/ /media/Insight/Regulatory/Basel-II/ThoughtLeadership/2011/2011-01-02-Overcomingchallenges-PDLGD-modelling.ashx

Porto, R. (2011). A brief note on implied historical lgd. The Journal of Credit Risk, vol 7, $\mathrm{n}^{\circ}$ 2, pgs 73-81.

Querci, F. (2005). Loss given default on a medium-sized Italian bank's loans: an empirical exercise. European Financial Management Association, 2005 Annual Meetings, Milan, Italy.

Renault, O., \& Scaillet, O. (2004). On the way to recovery: A nonparametric bias free estimation of recovery rate densities. Journal of Banking \& Finance, vol. 28, n 12, pgs. 2915-2931.

Ross, S. (1996). Stochastic Processes. John Wiley \& Sons, 2 edição. 
Seidler, J. (2008). Implied Market Loss Given Default: structural-model approach. Charles University Prague, Faculty of Social Sciences, Institute of Economic Studies, no 2008/26

Schuermann, T. (2004). What do we know about loss given default? The Wharton Financial Intitucion Center, Working Paper no 04-01

Sicsú, A.L. (2010). Credit Scoring Desenvovimento - Implantação - Acompanhamento. São Paulo: editora Blucher.

Silveira, H. P. D., Famá, R., \& Barros, L. A. B. D. C. (2002). Conceito de taxa livre de risco e sua aplicação no capital asset pricing model-um estudo exploratório para o mercado brasileiro, II Encontro Brasileiro de Finanças, Rio de Janeiro.

Vasicek, O. A. (1984). Credit valuation, KMV Corporation.

Veja, Revista Veja online (2008, 15 de outubro). Bovespa cai 11,39\%. Dólar sobe e fecha em $R \$$ 2,16. Recuperado em 08 de maio de 2013 em: http://veja.abril.com.br/noticia/brasil/bovespa-opera-forte-queda-dolar-volta-subir. 


\section{ANEXO 1 - Aplicação Lema de Itô}

Utilizando-se a expansão em séries de Taylor de segunda ordem para a derivada em relação ao preço da empresa (representada por $\mathrm{V})$ :

$$
\boldsymbol{d} \boldsymbol{Y}=\frac{\partial F}{\partial V} \boldsymbol{d V}+\frac{\mathbf{1}}{\mathbf{2}} \frac{\partial^{2} F}{\partial V^{2}}(\boldsymbol{d V})^{2}+\frac{\partial F}{\partial t} \boldsymbol{d t}
$$

Substituindo a equação (3) na equação acima:

$$
\boldsymbol{d} \boldsymbol{Y}=\frac{\partial F}{\partial V}[(\alpha V-C) d t+\sigma V d z]+\frac{\mathbf{1}}{\mathbf{2}} \frac{\partial^{2} F}{\partial V^{2}}[(\alpha V-C) d t+\sigma V d z]^{2}+\frac{\partial F}{\partial t} \boldsymbol{d t}
$$

Desenvolvendo o termo quadrático:

$$
\begin{aligned}
\boldsymbol{d} \boldsymbol{Y}=\frac{\partial F}{\partial V}[(\alpha V & -C) d t+\sigma V d z] \\
& +\frac{\mathbf{1}}{\mathbf{2}} \frac{\partial^{2} F}{\partial V^{2}}\left[(\alpha V-C)^{2} d t^{2}+2(\alpha V-C) \sigma V d t d z+\sigma^{2} V^{2} d z^{2}\right]+\frac{\partial F}{\partial t} \boldsymbol{d t}
\end{aligned}
$$

Segundo Itô quando $d t \rightarrow 0$, temos que os termos $d t^{2}$ e $d t d z$ são zero. Portanto a equação simplifica-se à:

$$
\boldsymbol{d} \boldsymbol{Y}=\frac{\partial F}{\partial V}[(\alpha V-C) d t+\sigma V d z]+\frac{\mathbf{1}}{\mathbf{2}} \frac{\partial^{2} F}{\partial V^{2}}\left[\sigma^{2} V^{2} d z^{2}\right]+\frac{\partial F}{\partial t} \boldsymbol{d t}
$$

Ainda segundo Itô $d z^{2}=d t$. Portanto:

$$
\boldsymbol{d} \boldsymbol{Y}=\frac{\partial F}{\partial V}[(\alpha V-C) d t+\sigma V d z]+\frac{\mathbf{1}}{\mathbf{2}} \frac{\partial^{2} F}{\partial V^{2}}\left[\sigma^{2} V^{2} d t\right]+\frac{\partial F}{\partial t} \boldsymbol{d t}
$$

Rearranjando os termos da equação obtemos a equação (5):

$$
\boldsymbol{d} \boldsymbol{Y}=\left[\frac{\mathbf{1}}{\mathbf{2}} \frac{\partial^{2} F}{\partial V^{2}} \sigma^{2} V^{2}+\frac{\partial F}{\partial V}(\alpha V-C)+\frac{\partial F}{\partial t}\right] \boldsymbol{d} \boldsymbol{t}+\frac{\partial F}{\partial V} \sigma V d z
$$




\section{ANEXO 2 - Desenvolvimento da Formulação de Merton para V (Firm Value)}

Segundo Merton (1974, pg.5), temos que ao comparar a eq. 4 com eq. 5:

$$
\begin{gathered}
\boldsymbol{\alpha}_{\boldsymbol{Y}} \boldsymbol{Y}=\boldsymbol{\alpha}_{\boldsymbol{Y}} \boldsymbol{F}=\frac{\mathbf{1}}{\mathbf{2}} \frac{\partial^{2} F}{\partial V^{2}} \sigma^{2} V^{2}+\frac{\partial F}{\partial V}(\alpha V-C)+\frac{\partial F}{\partial t}+\boldsymbol{C}_{\boldsymbol{Y}} \\
\boldsymbol{\sigma}_{\boldsymbol{Y}} \boldsymbol{Y}=\boldsymbol{\sigma}_{\boldsymbol{Y}} \boldsymbol{F}=\frac{\partial F}{\partial V} \sigma V
\end{gathered}
$$

Substituindo as equações acima na igualdade da situação sem arbitragem e sem risco Merton (1974, pg.6):

$$
\frac{\alpha-r}{\sigma}=\frac{\alpha_{Y}-r}{\sigma_{Y}}
$$

Temos:

$$
\begin{aligned}
& \frac{\boldsymbol{\alpha}-\boldsymbol{r}}{\boldsymbol{\sigma}}=\frac{\frac{\left[\frac{1}{2} \frac{\partial^{2} F}{\partial V^{2}} \sigma^{2} V^{2}+\frac{\partial F}{\partial V}(\alpha V-C)+\frac{\partial F}{\partial t}+\boldsymbol{C}_{\boldsymbol{Y}}\right]-\boldsymbol{r} \boldsymbol{F}}{\boldsymbol{F}}}{\frac{\partial F}{\partial V} \sigma V} \\
& \frac{\boldsymbol{\alpha}-\boldsymbol{r}}{\boldsymbol{\sigma}}=\frac{\left[\frac{\mathbf{1}}{\mathbf{2}} \frac{\partial^{2} F}{\partial V^{2}} \sigma^{2} V^{2}+\frac{\partial F}{\partial V}(\alpha V-C)+\frac{\partial F}{\partial t}+\boldsymbol{C}_{\boldsymbol{Y}}\right]-\boldsymbol{r} \boldsymbol{F}}{\frac{\partial F}{\partial V} \sigma V} \\
& \frac{\boldsymbol{\alpha}-\boldsymbol{r}}{\boldsymbol{\sigma}} * \frac{\partial F}{\partial V} \sigma V=\left[\frac{\mathbf{1}}{\mathbf{2}} \frac{\partial^{2} F}{\partial V^{2}} \sigma^{2} V^{2}+\frac{\partial F}{\partial V}(\alpha V-C)+\frac{\partial F}{\partial t}+\boldsymbol{C}_{\boldsymbol{Y}}\right]-\boldsymbol{r} \boldsymbol{F} \\
& \frac{\partial F}{\partial V} V \alpha-\frac{\partial F}{\partial V} V r=\frac{\mathbf{1}}{\mathbf{2}} \frac{\partial^{2} F}{\partial V^{2}} \sigma^{2} V^{2}+\frac{\partial F}{\partial V} \alpha V-\frac{\partial F}{\partial V} C+\frac{\partial F}{\partial t}+\boldsymbol{C}_{\boldsymbol{Y}}-\boldsymbol{r} \boldsymbol{F} \\
& \mathbf{0}=\frac{\mathbf{1}}{\mathbf{2}} \frac{\partial^{2} F}{\partial V^{2}} \sigma^{2} V^{2}+(\boldsymbol{r} \boldsymbol{V}-\boldsymbol{C}) \frac{\partial F}{\partial V}+\frac{\partial F}{\partial t}+\boldsymbol{C}_{\boldsymbol{Y}}-\boldsymbol{r} \boldsymbol{F}
\end{aligned}
$$

Considerando o não pagamento de cupons temos que os termos $\mathrm{C}$ e $\boldsymbol{C}_{\boldsymbol{Y}}$ são zero:

$$
\mathbf{0}=\frac{\mathbf{1}}{\mathbf{2}} \frac{\partial^{2} F}{\partial V^{2}} \sigma^{2} V^{2}+\boldsymbol{r} \boldsymbol{V} \frac{\partial F}{\partial V}+\frac{\partial F}{\partial t}-\boldsymbol{r} \boldsymbol{F}
$$

Portanto se obtêm a equação (6). 


\section{ANEXO 3 - Ajuste por Proventos no Economática}

Segundo o Economática (2013) existem acontecimentos na base acionária que levam à descontinuidades nos preços das ações, contudo são alterações que não refletem reais valorizações e desvalorizações de mercado.

O Economática determina um fator de ajuste, o qual é multiplicado pelas cotações a fim de ajustar os valores. Para cada evento o fator de ajuste possui uma fórmula, conforme especificado a seguir:

Dividendo: $\quad F=1-\frac{D}{P u}$

Bonificação: $F=\frac{1}{1+b}$

Desdobramento: $F=\frac{1}{d}$

Redução de Capital: $F=\frac{1}{1-r}$

Grupamento: $F=g$

Subscrição: $F=\frac{P u+s * S}{(1+S) * P u}$

Cissão: $F=\frac{1-c}{100}$

Em que,

$\mathrm{F}=$ Fator de ajuste

$\mathrm{D}=$ Valor do dividendo

$\mathrm{Pu}=$ Preço Original da Ação

$\mathrm{b}=$ Quantidade de ações novas recebidas para cada ação possuída

d = Quantidade de ações novas que substituirão cada ação antiga

$\mathrm{r}=$ Quantidade de ações canceladas para cada ação possuída

$\mathrm{g}=$ Quantidade de ações antigas que serão substituídas por cada nova ação

$\mathrm{S}=$ Preço de subscrição

$\mathrm{S}=$ Quantidade de ações novas ofertadas por cada ação possuída

$\mathrm{c}=$ Porcentagem que a parte cindida representava no mercado antes da cissão 


\section{ANEXO 4 - Tabelas do Resultado de Seleção por Liquidez}

A tabela 9 a seguir apresenta as estatísticas para o volume de negociação para cada empresa no período estudado, a última coluna apresenta o valor do percentual do volume negociado da empresa em relação ao maior volume negociado que é o da Petrobrás.

Tabela 9 - Descritivas do Valor de Volume Negociado por Empresa e Percentual em relação à Petrobrás.

\begin{tabular}{|c|c|c|c|c|c|c|c|}
\hline \multicolumn{8}{|c|}{ Volume Negociado (Valor Absoluto) } \\
\hline Empresa & Ativo & N Obs. & Média & $\begin{array}{l}\text { Desvio } \\
\text { Padrão }\end{array}$ & Mínimo & Máximo & $\begin{array}{c}\text { \% relação } \\
\text { PETR4 }\end{array}$ \\
\hline AmBev & ABEV3 & 39 & 10,781 & 11,130 & 63 & 47,166 & $2 \%$ \\
\hline AES Elpa & AELP3 & 38 & 157 & 216 & 5 & 1,071 & $0 \%$ \\
\hline Alpargatas & ALPA4 & 38 & 2,662 & 3,154 & 4 & 11,200 & $1 \%$ \\
\hline Amazônia & BAZA3 & 38 & 389 & 1,085 & 2 & 6,291 & $0 \%$ \\
\hline Bardella & BDLL4 & 38 & 294 & 744 & 5 & 3,879 & $0 \%$ \\
\hline Brasmotor & BMTO4 & 39 & 125 & 360 & 1 & 2,240 & $0 \%$ \\
\hline Braskem & BRKM5 & 38 & 22,603 & 13,841 & 5,202 & 61,265 & $5 \%$ \\
\hline Ampla Energ. & CBEE3 & 39 & 22 & 47 & - & 234 & $0 \%$ \\
\hline CCR SA & CCRO3 & 39 & 35,453 & 36,179 & 824 & 145,632 & $8 \%$ \\
\hline Celpe & CEPE5 & 38 & 52 & 105 & 1 & 575 & $0 \%$ \\
\hline Cesp & CESP3 & 23 & 207 & 296 & 2 & 1,205 & $0 \%$ \\
\hline Comgás & CGAS5 & 38 & 4,114 & 3,679 & 183 & 20,904 & $1 \%$ \\
\hline Grazziotin & CGRA4 & 39 & 653 & 2,602 & 1 & 16,232 & $0 \%$ \\
\hline Cemig & CMIG4 & 38 & 51,372 & 24,700 & 9,617 & 109,421 & $12 \%$ \\
\hline Coelce & COCE5 & 39 & 1,926 & 1,747 & 31 & 7,386 & $0 \%$ \\
\hline Copel & CPLE6 & 38 & 23,051 & 16,016 & 4,267 & 84,540 & $5 \%$ \\
\hline Souza Cruz & CRUZ3 & 39 & 20,395 & 17,190 & 1,589 & 71,938 & $5 \%$ \\
\hline Sid Nacional & CSNA3 & 38 & 76,240 & 49,154 & 14,863 & 209,729 & $18 \%$ \\
\hline Coteminas & CTNM4 & 38 & 949 & 993 & 9 & 4,750 & $0 \%$ \\
\hline Embraer & EMBR3 & 38 & 19,433 & 18,501 & 1,075 & 94,075 & $4 \%$ \\
\hline Estrela & ESTR4 & 38 & 235 & 818 & - & 4,970 & $0 \%$ \\
\hline Forja Taurus & FJTA4 & 38 & 525 & 1,186 & 17 & 7,229 & $0 \%$ \\
\hline Fras-Le & FRAS4 & 38 & 164 & 270 & 1 & 1,338 & $0 \%$ \\
\hline AES Tiete & GETI4 & 30 & 9,613 & 6,811 & 850 & 29,617 & $2 \%$ \\
\hline Gerdau & GGBR4 & 38 & 82,558 & 43,979 & 17,927 & 160,459 & $19 \%$ \\
\hline Gerdau Met. & GOAU4 & 37 & 24,747 & 14,849 & 4,171 & 79,829 & $6 \%$ \\
\hline Gol & GOLL4 & 37 & 21,168 & 24,206 & 350 & 141,224 & $5 \%$ \\
\hline Guararapes & GUAR3 & 38 & 3,160 & 3,466 & 2 & 11,692 & $1 \%$ \\
\hline Ideiasnet & IDNT3 & 37 & 1,510 & 2,153 & 1 & 10,331 & $0 \%$ \\
\hline Inepar & INEP4 & 38 & 851 & 959 & 11 & 4,030 & $0 \%$ \\
\hline Itaúsa & ITSA4 & 38 & 74,610 & 55,489 & 5,241 & 234,533 & $17 \%$ \\
\hline J B Duarte & JBDU4 & 38 & 92 & 195 & 1 & 1,113 & $0 \%$ \\
\hline Klabin S/A & KLBN4 & 39 & 14,084 & 14,110 & 844 & 45,323 & $3 \%$ \\
\hline Lojas Americ & LAME4 & 38 & 24,378 & 15,569 & 769 & 63,298 & $6 \%$ \\
\hline Light S/A & LIGT3 & 38 & 12,209 & 12,812 & 85 & 62,635 & $3 \%$ \\
\hline Mangels Indl & MGEL4 & 38 & 308 & 1,137 & - & 7,087 & $0 \%$ \\
\hline Natura & NATU3 & 38 & 29,246 & 24,209 & 1,311 & 87,949 & $7 \%$ \\
\hline Net & NETC4 & 38 & 21,198 & 21,557 & 26 & 110,449 & $5 \%$ \\
\hline
\end{tabular}




\begin{tabular}{cccccccc}
\hline \hline Oi & OIBR4 & $\mathbf{3 8}$ & $\mathbf{1 6 , 8 3 9}$ & $\mathbf{1 2 , 6 2 4}$ & $\mathbf{4 , 6 2 5}$ & $\mathbf{6 2 , 3 5 1}$ & $\mathbf{4 \%}$ \\
P.Acucar-Cbd & PCAR4 & $\mathbf{3 9}$ & $\mathbf{3 6 , 2 5 7}$ & $\mathbf{4 7 , 1 2 5}$ & $\mathbf{3 , 0 1 3}$ & $\mathbf{2 6 3 , 8 1 2}$ & $\mathbf{8 \%}$ \\
Petrobras & PETR4 & $\mathbf{3 9}$ & $\mathbf{4 3 5 , 1 0 8}$ & $\mathbf{2 5 8 , 7 8 5}$ & $\mathbf{3 6 , 4 9 9}$ & $\mathbf{1 , 1 4 7 , 4 1 1}$ & $\mathbf{1 0 0 \%}$ \\
Pro Metalurg & PMET6 & 38 & 15 & 34 & - & 202 & $0 \%$ \\
Marcopolo & POMO4 & $\mathbf{3 8}$ & $\mathbf{6 , 7 7 2}$ & $\mathbf{9 , 4 6 7}$ & $\mathbf{9 4}$ & $\mathbf{4 3 , 3 4 2}$ & $\mathbf{2 \%}$ \\
Randon Part & RAPT4 & $\mathbf{3 8}$ & $\mathbf{6 , 5 9 9}$ & $\mathbf{6 , 9 3 4}$ & $\mathbf{2 6 9}$ & $\mathbf{3 0 , 1 5 2}$ & $\mathbf{2 \%}$ \\
M G Poliest & RHDS3 & 38 & 180 & 602 & - & 3,705 & $0 \%$ \\
Sanepar & SAPR4 & 38 & 291 & 453 & - & 2,663 & $0 \%$ \\
Sao Carlos & SCAR3 & 38 & 838 & 1,400 & 1 & 6,651 & $0 \%$ \\
Saraiva Livr & SLED4 & 38 & 1,793 & 1,448 & 24 & 6,028 & $0 \%$ \\
Suzano Papel & SUZB5 & $\mathbf{3 9}$ & $\mathbf{1 4 , 0 8 1}$ & $\mathbf{1 1 , 7 0 3}$ & $\mathbf{1 5 0}$ & $\mathbf{4 4 , 4 4 1}$ & $\mathbf{3 \%}$ \\
Tractebel & TBLE3 & $\mathbf{3 9}$ & $\mathbf{1 2 , 8 9 0}$ & $\mathbf{1 0 , 0 4 4}$ & $\mathbf{6 6}$ & $\mathbf{4 6 , 8 5 3}$ & $\mathbf{3 \%}$ \\
Tim Part S/A & TIMP3 & $\mathbf{3 9}$ & $\mathbf{1 5 , 4 8 7}$ & $\mathbf{1 9 , 9 8 9}$ & $\mathbf{3 2 2}$ & $\mathbf{8 7 , 9 8 5}$ & $\mathbf{4 \%}$ \\
Tectoy & TOYB4 & 38 & 137 & 281 & - & 1,081 & $0 \%$ \\
Usiminas & USIM5 & $\mathbf{3 9}$ & $\mathbf{9 3 , 8 8 9}$ & $\mathbf{6 9 , 0 4 2}$ & $\mathbf{2 0 , 5 2 3}$ & $\mathbf{4 2 5 , 9 4 4}$ & $\mathbf{2 2 \%}$ \\
Telef. Brasil & VIVT4 & $\mathbf{3 8}$ & $\mathbf{1 8 , 4 6 4}$ & $\mathbf{2 5 , 1 4 3}$ & $\mathbf{1 , 3 1 8}$ & $\mathbf{8 7 , 4 0 9}$ & $\mathbf{4 \%}$ \\
\hline \hline
\end{tabular}

A tabela 10 a seguir apresenta as estatísticas para o percentual volume de negociação para cada empresa no período estudado.

Tabela 10 - Descritivas do Percentual de Volume Negociado por Empresa.

\begin{tabular}{ccccccc}
\hline \hline & \multicolumn{5}{c}{ Percentual do Volume Negociado } & \\
Empresa & Ativo & N Obs. & Média & $\begin{array}{c}\text { Desvio } \\
\text { padrão }\end{array}$ & Mínimo & Máximo \\
\hline \hline Ambev & ABEV3 & $\mathbf{3 9}$ & $\mathbf{0 . 3 3}$ & $\mathbf{0 . 3}$ & $\mathbf{0}$ & $\mathbf{1 . 5}$ \\
AES Elpa & AELP3 & 38 & 0.01 & 0 & 0 & 0.1 \\
Alpargatas & ALPA4 & 38 & 0.08 & 0.1 & 0 & 0.4 \\
Amazonia & BAZA3 & 38 & 0.01 & 0 & 0 & 0.1 \\
Bardella & BDLL4 & 38 & 0.01 & 0 & 0 & 0.2 \\
Brasmotor & BMTO4 & 39 & 0 & 0 & 0 & 0.1 \\
Braskem & BRKM5 & $\mathbf{3 8}$ & $\mathbf{1 . 2 8}$ & $\mathbf{1 . 8}$ & $\mathbf{0 . 2}$ & $\mathbf{9}$ \\
Ampla Energ & CBEE3 & 39 & 0 & 0 & - & 0 \\
CCR SA & CCRO3 & $\mathbf{3 9}$ & $\mathbf{0 . 9 1}$ & $\mathbf{0 . 5}$ & $\mathbf{0 . 1}$ & $\mathbf{2 . 5}$ \\
Celpe & CEPE5 & 38 & 0 & 0 & 0 & 0 \\
Cesp & CESP3 & 23 & 0.01 & 0 & 0 & 0 \\
Comgas & CGAS5 & $\mathbf{3 8}$ & $\mathbf{0 . 2}$ & $\mathbf{0 . 2}$ & $\mathbf{0}$ & $\mathbf{0 . 7}$ \\
Grazziotin & CGRA4 & 39 & 0.03 & 0.2 & 0 & 1 \\
Cemig & CMIG4 & $\mathbf{3 8}$ & $\mathbf{2 . 1 4}$ & $\mathbf{1 . 6}$ & $\mathbf{0 . 4}$ & $\mathbf{6 . 7}$ \\
Coelce & COCE5 & 39 & 0.06 & 0 & 0 & 0.2 \\
Copel & CPLE6 & $\mathbf{3 8}$ & $\mathbf{0 . 9 5}$ & $\mathbf{1}$ & $\mathbf{0 . 2}$ & $\mathbf{5}$ \\
Souza Cruz & CRUZ3 & $\mathbf{3 9}$ & $\mathbf{0 . 5 7}$ & $\mathbf{0 . 3}$ & $\mathbf{0 . 2}$ & $\mathbf{1 . 8}$ \\
Sid Nacional & CSNA3 & $\mathbf{3 8}$ & $\mathbf{3 . 0 8}$ & $\mathbf{2 . 7}$ & $\mathbf{0 . 7}$ & $\mathbf{1 5 . 2}$ \\
Coteminas & CTNM4 & 38 & 0.07 & 0.1 & 0 & 0.4 \\
Embraer & EMBR3 & $\mathbf{3 8}$ & $\mathbf{0 . 5 1}$ & $\mathbf{0 . 3}$ & $\mathbf{0 . 1}$ & $\mathbf{1 . 5}$ \\
Estrela & ESTR4 & 38 & 0.01 & 0 & - & 0.1 \\
Forja Taurus & FJTA4 & 38 & 0.02 & 0 & 0 & 0.2 \\
Fras-Le & FRAS4 & 38 & 0 & 0 & 0 & 0 \\
AES Tiete & GETI4 & $\mathbf{3 0}$ & $\mathbf{0 . 2 7}$ & $\mathbf{0 . 2}$ & $\mathbf{0 . 1}$ & $\mathbf{0 . 7}$ \\
Gerdau & GGBR4 & $\mathbf{3 8}$ & $\mathbf{2 . 9 1}$ & $\mathbf{1 . 7}$ & $\mathbf{1}$ & $\mathbf{9 . 2}$ \\
Gerdau Met & GOAU4 & $\mathbf{3 7}$ & $\mathbf{0 . 9}$ & $\mathbf{0 . 7}$ & $\mathbf{0 . 3}$ & $\mathbf{3 . 6}$ \\
\hline \hline & & & & & & \\
\hline
\end{tabular}




\begin{tabular}{ccccccc}
\hline \hline Gol & GOLL4 & $\mathbf{3 7}$ & $\mathbf{0 . 6 7}$ & $\mathbf{0 . 9}$ & $\mathbf{0 . 1}$ & $\mathbf{4 . 4}$ \\
Guararapes & GUAR3 & $\mathbf{3 8}$ & $\mathbf{0 . 1 2}$ & $\mathbf{0 . 2}$ & $\mathbf{0}$ & $\mathbf{0 . 8}$ \\
Ideiasnet & IDNT3 & 37 & 0.05 & 0.1 & 0 & 0.4 \\
Inepar & INEP4 & 38 & 0.04 & 0.1 & 0 & 0.7 \\
Itausa & ITSA4 & $\mathbf{3 8}$ & $\mathbf{2 . 1}$ & $\mathbf{0 . 7}$ & $\mathbf{0 . 8}$ & $\mathbf{3 . 5}$ \\
J B Duarte & JBDU4 & 38 & 0 & 0 & 0 & 0 \\
Klabin S/A & KLBN4 & $\mathbf{3 9}$ & $\mathbf{0 . 4 3}$ & $\mathbf{0 . 3}$ & $\mathbf{0 . 1}$ & $\mathbf{1 . 7}$ \\
Lojas Americ & LAME4 & $\mathbf{3 8}$ & $\mathbf{0 . 7 8}$ & $\mathbf{0 . 6}$ & $\mathbf{0 . 1}$ & $\mathbf{3}$ \\
Light S/A & LIGT3 & $\mathbf{3 8}$ & $\mathbf{0 . 3 1}$ & $\mathbf{0 . 3}$ & $\mathbf{0}$ & $\mathbf{1 . 3}$ \\
Mangels Indl & MGEL4 & 38 & 0.04 & 0.2 & - & 1.2 \\
Natura & NATU3 & $\mathbf{3 8}$ & $\mathbf{0 . 8 2}$ & $\mathbf{0 . 5}$ & $\mathbf{0 . 2}$ & $\mathbf{2 . 5}$ \\
Net & NETC4 & $\mathbf{3 8}$ & $\mathbf{1 . 2 3}$ & $\mathbf{1 . 4}$ & $\mathbf{0}$ & $\mathbf{4 . 7}$ \\
Oi & OIBR4 & $\mathbf{3 8}$ & $\mathbf{0 . 8 2}$ & $\mathbf{0 . 9}$ & $\mathbf{0 . 1}$ & $\mathbf{4}$ \\
P.Acucar-Cbd & PCAR4 & $\mathbf{3 9}$ & $\mathbf{0 . 9 9}$ & $\mathbf{1}$ & $\mathbf{0 . 3}$ & $\mathbf{6}$ \\
Petrobras & PETR4 & $\mathbf{3 9}$ & $\mathbf{1 4 . 0 2}$ & $\mathbf{5 . 8}$ & $\mathbf{4 . 9}$ & $\mathbf{3 0 . 1}$ \\
Pro Metalurg & PMET6 & 38 & 0 & 0 & - & 0 \\
Marcopolo & POMO4 & $\mathbf{3 8}$ & $\mathbf{0 . 1 7}$ & $\mathbf{0 . 2}$ & $\mathbf{0}$ & $\mathbf{0 . 8}$ \\
Randon Part & RAPT4 & $\mathbf{3 8}$ & $\mathbf{0 . 1 7}$ & $\mathbf{0 . 1}$ & $\mathbf{0}$ & $\mathbf{0 . 6}$ \\
M G Poliest & RHDS3 & 38 & 0.01 & 0 & - & 0.1 \\
Sanepar & SAPR4 & 38 & 0.01 & 0 & - & 0.1 \\
Sao Carlos & SCAR3 & 38 & 0.03 & 0.1 & 0 & 0.4 \\
Saraiva Livr & SLED4 & 38 & 0.05 & 0 & 0 & 0.2 \\
Suzano Papel & SUZB5 & $\mathbf{3 9}$ & $\mathbf{0 . 4 3}$ & $\mathbf{0 . 5}$ & $\mathbf{0}$ & $\mathbf{2 . 7}$ \\
Tractebel & TBLE3 & $\mathbf{3 9}$ & $\mathbf{0 . 3 5}$ & $\mathbf{0 . 3}$ & $\mathbf{0}$ & $\mathbf{1 . 5}$ \\
Tim Part S/A & TIMP3 & $\mathbf{3 9}$ & $\mathbf{0 . 4 3}$ & $\mathbf{0 . 6}$ & $\mathbf{0}$ & $\mathbf{3 . 5}$ \\
Tectoy & TOYB4 & 38 & 0 & 0 & - & 0 \\
Usiminas & USIM5 & $\mathbf{3 9}$ & $\mathbf{3 . 6 6}$ & $\mathbf{2 . 5}$ & $\mathbf{0 . 7}$ & $\mathbf{1 0 . 3}$ \\
Telef Brasil & VIVT4 & $\mathbf{3 8}$ & $\mathbf{0 . 4 6}$ & $\mathbf{0 . 4}$ & $\mathbf{0}$ & $\mathbf{1 . 5}$ \\
\hline \hline & & & & & \\
\hline
\end{tabular}




\section{ANEXO 5 - Código SAS - procedure model}

Abaixo se encontra o código SAS que resolve o sistema de duas equações pelo algoritmo de Newton.

Estimar valores iniciais para V e DV é necessário para atingir a convergência, conforme apresentado na nota explicativa do site de suporte do SAS em http://support.sas.com/kb/22/779.html.

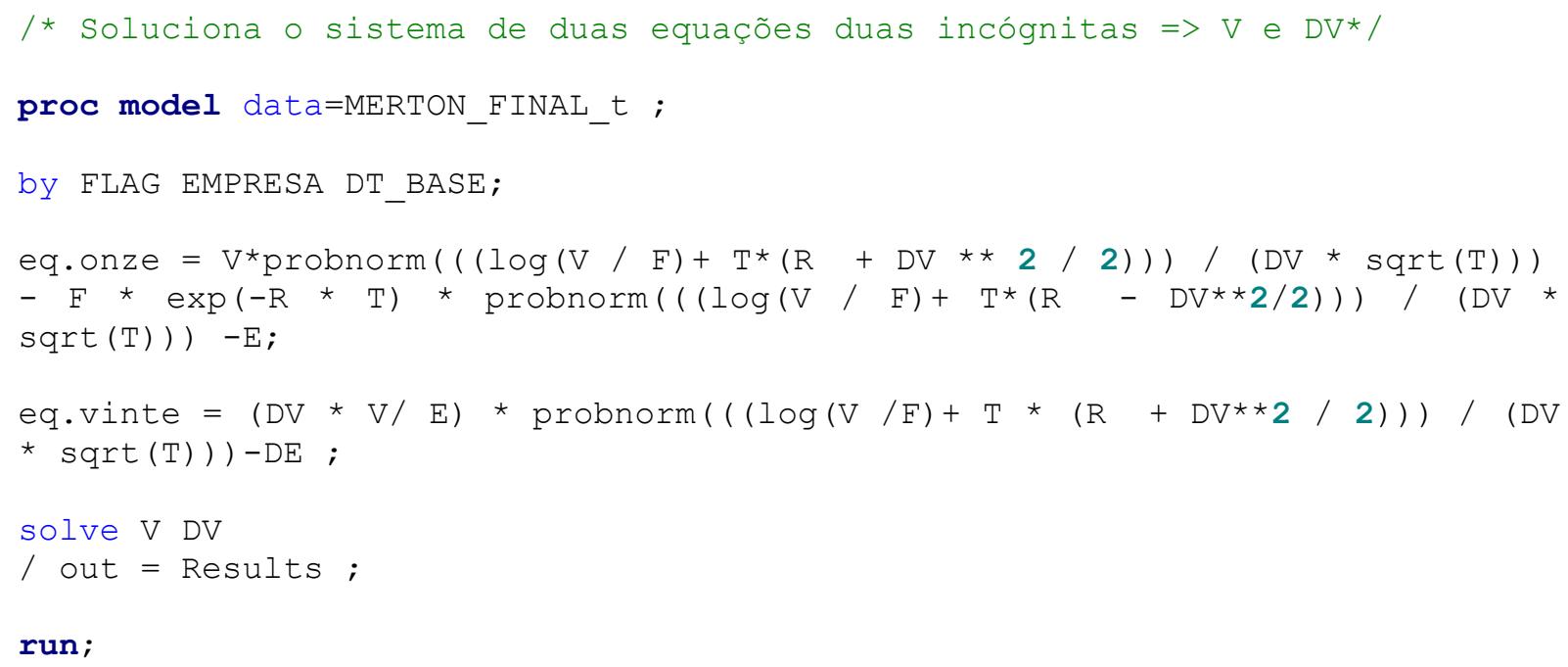




\section{ANEXO 6 - Gráficos de LGD ao longo do tempo para cada empresa da modelagem}

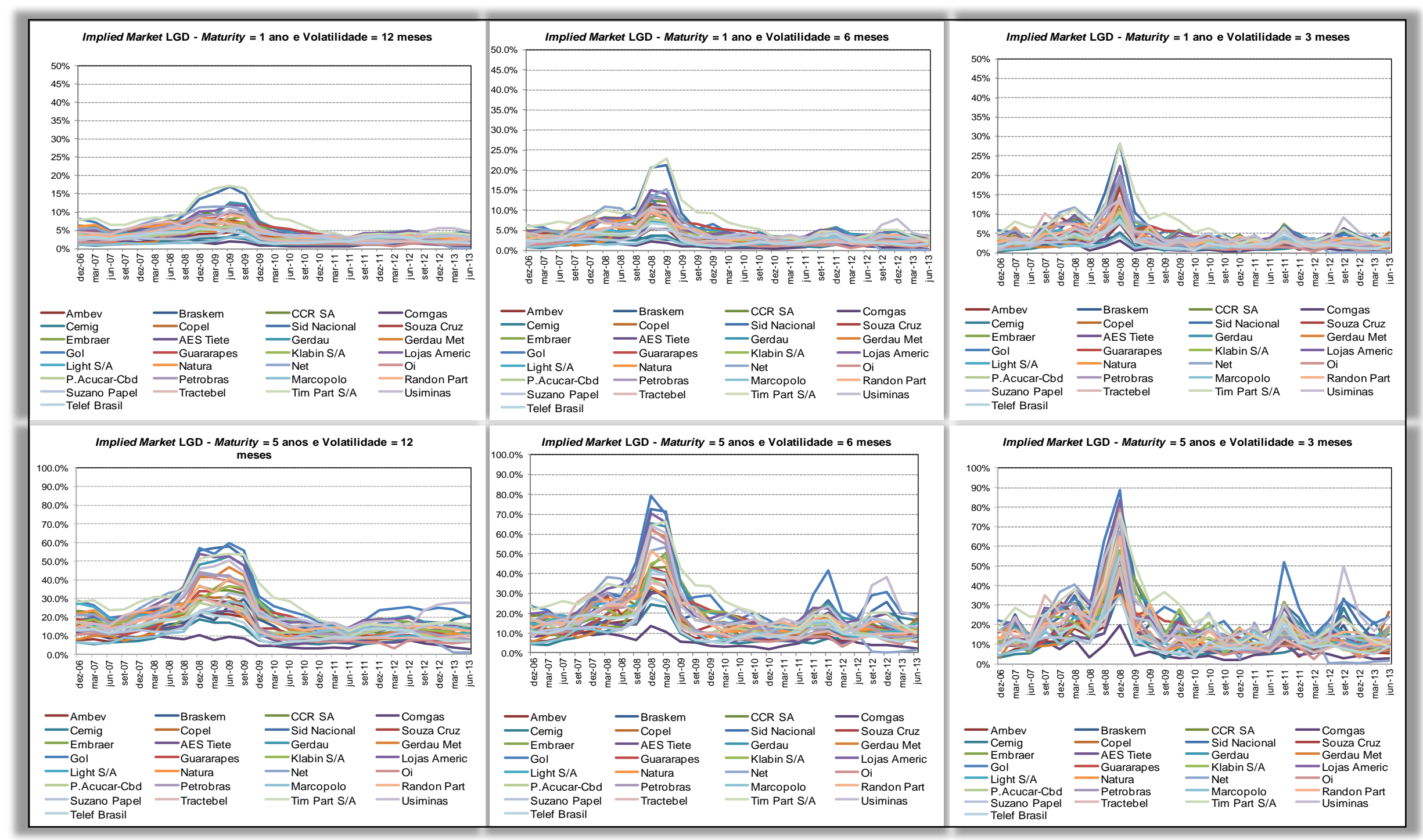


ANEXO 7 - Resultados do Valor da Empresa $(V)$ e volatilidade $\left(\sigma_{V}\right)$

\begin{tabular}{|c|c|c|c|c|c|c|c|c|c|c|c|c|c|c|c|c|c|c|c|}
\hline \multirow{3}{*}{ 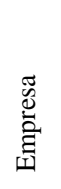 } & \multirow{3}{*}{ Data Base } & \multicolumn{6}{|c|}{ бe 3 meses } & \multicolumn{6}{|c|}{ бe 6 meses } & \multicolumn{6}{|c|}{ бe 12 meses } \\
\hline & & \multicolumn{3}{|c|}{$\tau=1$ ano } & \multicolumn{3}{|c|}{$\tau=5$ anos } & \multicolumn{3}{|c|}{$\tau=1$ ano } & \multicolumn{3}{|c|}{$\tau=5$ anos } & \multicolumn{3}{|c|}{$\tau=1$ ano } & \multicolumn{3}{|c|}{$\tau=5$ anos } \\
\hline & & $\mathbf{V}^{*}$ & $\sigma d$ & LGD & $\mathbf{V}^{*}$ & $\sigma d$ & LGD & $\mathbf{V}^{*}$ & $\sigma d$ & LGD & $\mathbf{V}^{*}$ & $\sigma d$ & LGD & $\mathbf{V}^{*}$ & $\sigma d$ & LGD & $\mathbf{V}^{*}$ & $\sigma d$ & LGD \\
\hline \multirow{32}{*}{ 离 } & jun- 05 & 14.24 & 0.06 & $1.3 \%$ & 8.45 & 0.11 & $8.0 \%$ & 14.24 & 0.07 & $1.6 \%$ & 8.44 & 0.12 & $9.8 \%$ & 14.24 & 0.06 & $1.3 \%$ & 8.45 & 0.11 & $8.0 \%$ \\
\hline & set-05 & 14.98 & 0.05 & $0.7 \%$ & 9.20 & 0.08 & $4.3 \%$ & 14.98 & 0.06 & $1.0 \%$ & 9.20 & 0.10 & $6.3 \%$ & 14.98 & 0.07 & $1.3 \%$ & 9.19 & 0.11 & $7.8 \%$ \\
\hline & dez-05 & 15.84 & 0.07 & $1.4 \%$ & 10.11 & 0.12 & $8.3 \%$ & 15.84 & 0.06 & $1.1 \%$ & 10.11 & 0.10 & $6.4 \%$ & 15.84 & 0.07 & $1.4 \%$ & 10.11 & 0.12 & $8.4 \%$ \\
\hline & mar-06 & 15.59 & 0.08 & $1.6 \%$ & 10.41 & 0.12 & $8.7 \%$ & 15.59 & 0.08 & $1.5 \%$ & 10.41 & 0.12 & $8.5 \%$ & 15.59 & 0.07 & $1.3 \%$ & 10.41 & 0.11 & $7.5 \%$ \\
\hline & jun-06 & 15.42 & 0.10 & $2.6 \%$ & 10.52 & 0.16 & $13.6 \%$ & 15.42 & 0.09 & $2.1 \%$ & 10.55 & 0.14 & $11.1 \%$ & 15.42 & 0.08 & $1.6 \%$ & 10.56 & 0.12 & $8.7 \%$ \\
\hline & set-06 & 18.70 & 0.06 & $1.0 \%$ & 12.88 & 0.08 & $5.5 \%$ & 18.70 & 0.08 & $1.7 \%$ & 12.86 & 0.12 & $9.5 \%$ & 18.70 & 0.08 & $1.6 \%$ & 12.86 & 0.11 & $8.6 \%$ \\
\hline & dez-06 & 19.70 & 0.05 & $0.7 \%$ & 13.95 & 0.07 & $4.2 \%$ & 19.70 & 0.06 & $1.0 \%$ & 13.95 & 0.09 & $5.6 \%$ & 19.70 & 0.07 & $1.5 \%$ & 13.94 & 0.10 & $7.8 \%$ \\
\hline & mar-07 & 19.73 & 0.08 & $1.4 \%$ & 14.32 & 0.11 & $7.6 \%$ & 19.73 & 0.07 & $1.1 \%$ & 14.33 & 0.09 & $6.2 \%$ & 19.73 & 0.08 & $1.6 \%$ & 14.32 & 0.11 & $8.3 \%$ \\
\hline & jun-07 & 22.09 & 0.08 & $1.6 \%$ & 16.52 & 0.11 & $8.1 \%$ & 22.09 & 0.08 & $1.5 \%$ & 16.52 & 0.11 & $7.9 \%$ & 22.09 & 0.08 & $1.3 \%$ & 16.52 & 0.10 & $6.9 \%$ \\
\hline & set-07 & 22.92 & 0.10 & $2.3 \%$ & 17.30 & 0.14 & $11.4 \%$ & 22.92 & 0.09 & $1.9 \%$ & 17.33 & 0.12 & $9.7 \%$ & 22.92 & 0.08 & $1.6 \%$ & 17.34 & 0.11 & $8.0 \%$ \\
\hline & dez-07 & 22.93 & 0.10 & $2.3 \%$ & 17.18 & 0.13 & $11.4 \%$ & 22.93 & 0.10 & $2.2 \%$ & 17.18 & 0.13 & $11.1 \%$ & 22.93 & 0.09 & $1.8 \%$ & 17.21 & 0.12 & $9.2 \%$ \\
\hline & mar-08 & 22.15 & 0.13 & $3.7 \%$ & 16.56 & 0.19 & $18.0 \%$ & 22.15 & 0.12 & $3.1 \%$ & 16.66 & 0.17 & $15.0 \%$ & 22.15 & 0.11 & $2.5 \%$ & 16.72 & 0.15 & $12.3 \%$ \\
\hline & jun-08 & 20.19 & 0.10 & $2.7 \%$ & 14.49 & 0.15 & $14.2 \%$ & 20.19 & 0.11 & $3.0 \%$ & 14.45 & 0.16 & $15.6 \%$ & 20.20 & 0.10 & $2.6 \%$ & 14.52 & 0.14 & $13.3 \%$ \\
\hline & set-08 & 21.45 & 0.12 & $3.5 \%$ & 14.72 & 0.19 & $18.9 \%$ & 21.45 & 0.11 & $3.2 \%$ & 14.80 & 0.17 & $16.8 \%$ & 21.45 & 0.11 & $3.0 \%$ & 14.84 & 0.17 & $15.7 \%$ \\
\hline & dez- 08 & 23.10 & 0.19 & $7.8 \%$ & 13.46 & 0.39 & $45.3 \%$ & 23.17 & 0.15 & $5.3 \%$ & 14.77 & 0.27 & $30.9 \%$ & 23.19 & 0.12 & $4.1 \%$ & 15.32 & 0.21 & $23.1 \%$ \\
\hline & mar-09 & 23.90 & 0.10 & $2.5 \%$ & 17.46 & 0.14 & $13.2 \%$ & 23.88 & 0.15 & $5.4 \%$ & 16.40 & 0.26 & $29.8 \%$ & 23.89 & 0.13 & $4.1 \%$ & 17.00 & 0.20 & $22.1 \%$ \\
\hline & jun-09 & 24.24 & 0.09 & $1.8 \%$ & 19.16 & 0.11 & $8.7 \%$ & 24.24 & 0.10 & $2.3 \%$ & 19.11 & 0.13 & $11.2 \%$ & 24.23 & 0.14 & $4.4 \%$ & 18.63 & 0.21 & $21.5 \%$ \\
\hline & set-09 & 25.03 & 0.07 & $1.1 \%$ & 20.29 & 0.09 & $5.6 \%$ & 25.03 & 0.08 & $1.5 \%$ & 20.28 & 0.10 & $7.4 \%$ & 25.02 & 0.15 & $4.3 \%$ & 19.91 & 0.20 & $20.1 \%$ \\
\hline & dez-09 & 26.95 & 0.11 & $2.4 \%$ & 22.18 & 0.14 & $10.9 \%$ & 26.95 & 0.10 & $1.8 \%$ & 22.20 & 0.12 & $8.6 \%$ & 26.95 & 0.12 & $2.4 \%$ & 22.17 & 0.14 & $11.1 \%$ \\
\hline & mar-10 & 25.86 & 0.09 & $1.7 \%$ & 21.23 & 0.12 & $8.1 \%$ & 25.86 & 0.10 & $2.0 \%$ & 21.22 & 0.13 & $9.3 \%$ & 25.86 & 0.10 & $1.9 \%$ & 21.22 & 0.12 & $8.9 \%$ \\
\hline & jun-10 & 26.37 & 0.09 & $1.3 \%$ & 21.28 & 0.11 & $6.7 \%$ & 26.37 & 0.10 & $1.6 \%$ & 21.28 & 0.12 & $7.6 \%$ & 26.37 & 0.10 & $1.7 \%$ & 21.28 & 0.12 & $8.3 \%$ \\
\hline & set-10 & 29.59 & 0.08 & $1.1 \%$ & 23.80 & 0.10 & $5.7 \%$ & 29.59 & 0.09 & $1.2 \%$ & 23.80 & 0.11 & $6.1 \%$ & 29.59 & 0.10 & $1.7 \%$ & 23.80 & 0.13 & $8.2 \%$ \\
\hline & dez-10 & 32.38 & 0.11 & $1.7 \%$ & 26.73 & 0.14 & $8.2 \%$ & 32.38 & 0.11 & $1.5 \%$ & 26.73 & 0.13 & $7.4 \%$ & 32.38 & 0.11 & $1.6 \%$ & 26.73 & 0.13 & $7.8 \%$ \\
\hline & $\operatorname{mar}-11$ & 30.13 & 0.13 & $2.2 \%$ & 24.36 & 0.15 & $10.2 \%$ & 30.13 & 0.12 & $2.0 \%$ & 24.36 & 0.15 & $9.4 \%$ & 30.13 & 0.11 & $1.6 \%$ & 24.37 & 0.13 & $7.9 \%$ \\
\hline & jun-11 & 31.48 & 0.10 & $1.4 \%$ & 25.74 & 0.13 & $6.6 \%$ & 31.48 & 0.12 & $1.8 \%$ & 25.74 & 0.15 & $8.7 \%$ & 31.48 & 0.12 & $1.7 \%$ & 25.74 & 0.14 & $8.2 \%$ \\
\hline & set-11 & 36.29 & 0.14 & $2.7 \%$ & 29.57 & 0.18 & $12.1 \%$ & 36.29 & 0.12 & $2.0 \%$ & 29.58 & 0.15 & $9.3 \%$ & 36.29 & 0.12 & $2.0 \%$ & 29.58 & 0.15 & $9.5 \%$ \\
\hline & dez-11 & 40.54 & 0.08 & $0.7 \%$ & 34.12 & 0.09 & $3.7 \%$ & 40.54 & 0.12 & $1.8 \%$ & 34.12 & 0.15 & $8.4 \%$ & 40.54 & 0.12 & $1.9 \%$ & 34.12 & 0.15 & $8.6 \%$ \\
\hline & mar-12 & 41.99 & 0.13 & $1.7 \%$ & 36.73 & 0.15 & $7.9 \%$ & 41.99 & 0.11 & $1.2 \%$ & 36.73 & 0.13 & $5.9 \%$ & 41.99 & 0.13 & $1.7 \%$ & 36.73 & 0.15 & $8.0 \%$ \\
\hline & jun-12 & 45.21 & 0.14 & $2.1 \%$ & 39.79 & 0.16 & $9.4 \%$ & 45.21 & 0.13 & $1.9 \%$ & 39.79 & 0.15 & $8.6 \%$ & 45.21 & 0.13 & $1.9 \%$ & 39.79 & 0.15 & $8.5 \%$ \\
\hline & set-12 & 45.46 & 0.13 & $1.8 \%$ & 40.56 & 0.14 & $8.1 \%$ & 45.46 & 0.13 & $1.9 \%$ & 40.56 & 0.15 & $8.7 \%$ & 45.46 & 0.12 & $1.6 \%$ & 40.56 & 0.13 & $7.3 \%$ \\
\hline & dez-12 & 52.18 & 0.11 & $1.4 \%$ & 46.73 & 0.12 & $6.3 \%$ & 52.18 & 0.12 & $1.6 \%$ & 46.72 & 0.13 & $7.3 \%$ & 52.18 & 0.12 & $1.7 \%$ & 46.72 & 0.14 & $7.8 \%$ \\
\hline & mar-13 & 47.11 & 0.12 & $1.4 \%$ & 42.78 & 0.13 & $6.7 \%$ & 47.11 & 0.12 & $1.4 \%$ & 42.78 & 0.13 & $6.5 \%$ & 47.11 & 0.14 & $1.8 \%$ & 42.78 & 0.15 & $8.2 \%$ \\
\hline
\end{tabular}




\begin{tabular}{|c|c|c|c|c|c|c|c|c|c|c|}
\hline \multirow{34}{*}{ 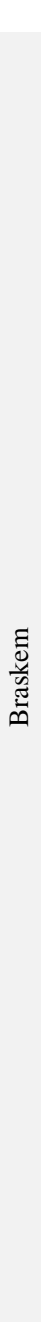 } & jun-13 & 46.61 & 0.16 & $2.6 \%$ & 41.96 & 0.18 & $11.2 \%$ & 46.61 & 0.14 & $2.0 \%$ \\
\hline & jun-05 & 12.75 & 0.13 & $4.0 \%$ & 7.78 & 0.24 & $22.2 \%$ & 12.76 & 0.12 & $3.5 \%$ \\
\hline & set-05 & 13.09 & 0.18 & $5.6 \%$ & 8.25 & 0.30 & $28.6 \%$ & 13.09 & 0.17 & $5.1 \%$ \\
\hline & dez-05 & 12.86 & 0.11 & $2.9 \%$ & 8.15 & 0.18 & $16.0 \%$ & 12.86 & 0.13 & $3.8 \%$ \\
\hline & mar-06 & 12.55 & 0.09 & $2.1 \%$ & 8.07 & 0.14 & $12.0 \%$ & 12.55 & 0.09 & $2.4 \%$ \\
\hline & jun-06 & 12.20 & 0.09 & $2.4 \%$ & 7.84 & 0.14 & $13.8 \%$ & 12.20 & 0.08 & $2.1 \%$ \\
\hline & set-06 & 12.84 & 0.09 & $2.9 \%$ & 8.29 & 0.16 & $17.4 \%$ & 12.84 & 0.09 & $2.6 \%$ \\
\hline & dez-06 & 13.51 & 0.07 & $1.7 \%$ & 9.18 & 0.11 & $9.7 \%$ & 13.51 & 0.09 & $2.4 \%$ \\
\hline & mar-07 & 13.13 & 0.12 & $4.3 \%$ & 8.67 & 0.22 & $25.3 \%$ & 13.13 & 0.10 & $3.0 \%$ \\
\hline & jun-07 & 14.82 & 0.07 & $1.6 \%$ & 10.52 & 0.10 & $8.5 \%$ & 14.82 & 0.10 & $3.0 \%$ \\
\hline & set-07 & 15.12 & 0.11 & $3.2 \%$ & 11.07 & 0.17 & $16.5 \%$ & 15.12 & 0.10 & $2.5 \%$ \\
\hline & dez-07 & 16.58 & 0.08 & $2.1 \%$ & 11.80 & 0.12 & $11.7 \%$ & 16.58 & 0.08 & $2.4 \%$ \\
\hline & mar-08 & 16.94 & 0.11 & $3.7 \%$ & 11.77 & 0.19 & $20.9 \%$ & 16.95 & 0.10 & $3.0 \%$ \\
\hline & jun- 08 & 16.73 & 0.09 & $2.8 \%$ & 11.55 & 0.15 & $15.7 \%$ & 16.73 & 0.10 & $3.2 \%$ \\
\hline & set- 08 & 17.21 & 0.10 & $3.7 \%$ & 10.42 & 0.21 & $25.7 \%$ & 17.22 & 0.09 & $3.0 \%$ \\
\hline & dez- 08 & 18.10 & 0.09 & $4.4 \%$ & 7.62 & 0.33 & $50.0 \%$ & 18.17 & 0.07 & $3.1 \%$ \\
\hline & mar-09 & 18.16 & 0.04 & $1.4 \%$ & 11.74 & 0.08 & $11.2 \%$ & 18.13 & 0.06 & $2.6 \%$ \\
\hline & jun-09 & 17.91 & 0.07 & $2.7 \%$ & 12.20 & 0.15 & $20.4 \%$ & 17.92 & 0.06 & $2.4 \%$ \\
\hline & set- 09 & 18.50 & 0.08 & $2.6 \%$ & 13.75 & 0.13 & $14.5 \%$ & 18.49 & 0.09 & $3.2 \%$ \\
\hline & dez-09 & 20.20 & 0.09 & $2.6 \%$ & 15.28 & 0.13 & $14.2 \%$ & 20.20 & 0.09 & $2.8 \%$ \\
\hline & mar-10 & 21.00 & 0.05 & $1.3 \%$ & 15.99 & 0.07 & $6.6 \%$ & 21.00 & 0.07 & $1.8 \%$ \\
\hline & jun-10 & 27.19 & 0.05 & $1.3 \%$ & 19.34 & 0.07 & $7.4 \%$ & 27.19 & 0.05 & $1.1 \%$ \\
\hline & set-10 & 27.55 & 0.06 & $1.3 \%$ & 19.88 & 0.08 & $7.0 \%$ & 27.55 & 0.06 & $1.5 \%$ \\
\hline & dez-10 & 28.18 & 0.07 & $1.6 \%$ & 20.61 & 0.10 & $8.4 \%$ & 28.18 & 0.07 & $1.5 \%$ \\
\hline & mar-11 & 28.21 & 0.06 & $1.3 \%$ & 20.25 & 0.09 & $7.1 \%$ & 28.21 & 0.07 & $1.5 \%$ \\
\hline & jun-11 & 28.68 & 0.09 & $2.1 \%$ & 20.39 & 0.12 & $11.2 \%$ & 28.68 & 0.08 & $1.7 \%$ \\
\hline & set-11 & 28.66 & 0.10 & $3.6 \%$ & 18.18 & 0.20 & $25.0 \%$ & 28.69 & 0.08 & $2.6 \%$ \\
\hline & dez-11 & 28.83 & 0.08 & $2.7 \%$ & 19.18 & 0.15 & $18.4 \%$ & 28.83 & 0.08 & $2.9 \%$ \\
\hline & mar-12 & 31.65 & 0.06 & $1.9 \%$ & 22.73 & 0.10 & $11.4 \%$ & 31.65 & 0.07 & $2.3 \%$ \\
\hline & jun-12 & 33.84 & 0.06 & $1.7 \%$ & 25.09 & 0.09 & $10.1 \%$ & 33.84 & 0.06 & $1.7 \%$ \\
\hline & set-12 & 34.93 & 0.08 & $2.9 \%$ & 25.52 & 0.15 & $19.5 \%$ & 34.94 & 0.07 & $2.3 \%$ \\
\hline & dez-12 & 34.73 & 0.05 & $1.3 \%$ & 27.18 & 0.07 & $7.1 \%$ & 34.73 & 0.06 & $2.0 \%$ \\
\hline & mar-13 & 35.83 & 0.05 & $1.4 \%$ & 27.92 & 0.07 & $7.8 \%$ & 35.83 & 0.05 & $1.4 \%$ \\
\hline & jun-13 & 38.75 & 0.05 & $1.3 \%$ & 29.79 & 0.07 & $6.8 \%$ & 38.75 & 0.05 & $1.4 \%$ \\
\hline \multirow{6}{*}{ 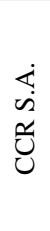 } & jun-05 & 5.43 & 0.22 & $3.6 \%$ & 4.51 & 0.26 & $14.9 \%$ & 5.43 & 0.22 & $3.9 \%$ \\
\hline & set-05 & 6.27 & 0.20 & $3.1 \%$ & 5.31 & 0.24 & $12.7 \%$ & 6.27 & 0.21 & $3.4 \%$ \\
\hline & dez-05 & 6.95 & 0.21 & $2.9 \%$ & 6.08 & 0.24 & $11.8 \%$ & 6.95 & 0.21 & $2.9 \%$ \\
\hline & mar-06 & 7.56 & 0.38 & $8.5 \%$ & 6.70 & 0.43 & $29.8 \%$ & 7.56 & 0.31 & $5.8 \%$ \\
\hline & jun-06 & 6.85 & 0.35 & $7.7 \%$ & 6.03 & 0.40 & $27.9 \%$ & 6.85 & 0.35 & $7.9 \%$ \\
\hline & set-06 & 8.34 & 0.27 & $5.0 \%$ & 7.42 & 0.31 & $19.4 \%$ & 8.34 & 0.32 & $6.5 \%$ \\
\hline
\end{tabular}

\begin{tabular}{|c|c|c|c|c|c|c|c|c|}
\hline 41.96 & 0.16 & $8.9 \%$ & 46.61 & 0.14 & $1.8 \%$ & 41.96 & 0.15 & $8.3 \%$ \\
\hline 7.84 & 0.21 & $19.3 \%$ & 12.76 & 0.12 & $3.2 \%$ & 7.86 & 0.20 & $17.8 \%$ \\
\hline 8.31 & 0.28 & $26.0 \%$ & 13.10 & 0.14 & $3.9 \%$ & 8.41 & 0.23 & $20.3 \%$ \\
\hline 8.06 & 0.22 & $21.1 \%$ & 12.86 & 0.12 & $3.6 \%$ & 8.09 & 0.21 & $19.9 \%$ \\
\hline 8.05 & 0.15 & $13.5 \%$ & 12.55 & 0.11 & $3.2 \%$ & 7.98 & 0.19 & $18.1 \%$ \\
\hline 7.87 & 0.13 & $12.2 \%$ & 12.20 & 0.09 & $2.6 \%$ & 7.81 & 0.15 & $15.4 \%$ \\
\hline 8.35 & 0.15 & $15.2 \%$ & 12.84 & 0.08 & $2.3 \%$ & 8.39 & 0.13 & $13.3 \%$ \\
\hline 9.11 & 0.14 & $13.8 \%$ & 13.51 & 0.08 & $2.2 \%$ & 9.13 & 0.13 & $12.6 \%$ \\
\hline 8.96 & 0.16 & $17.1 \%$ & 13.13 & 0.10 & $2.9 \%$ & 8.98 & 0.16 & $16.4 \%$ \\
\hline 10.34 & 0.16 & $16.5 \%$ & 14.82 & 0.09 & $2.7 \%$ & 10.38 & 0.15 & $15.0 \%$ \\
\hline 11.16 & 0.14 & $12.9 \%$ & 15.12 & 0.11 & $3.1 \%$ & 11.10 & 0.16 & $15.6 \%$ \\
\hline 11.76 & 0.13 & $13.0 \%$ & 16.58 & 0.09 & $2.6 \%$ & 11.72 & 0.14 & $14.3 \%$ \\
\hline 11.98 & 0.15 & $16.4 \%$ & 16.95 & 0.09 & $2.5 \%$ & 12.07 & 0.14 & $13.9 \%$ \\
\hline 11.45 & 0.17 & $18.4 \%$ & 16.73 & 0.10 & $2.9 \%$ & 11.54 & 0.15 & $16.1 \%$ \\
\hline 10.76 & 0.17 & $20.0 \%$ & 17.22 & 0.08 & $2.7 \%$ & 10.89 & 0.15 & $17.2 \%$ \\
\hline 9.28 & 0.21 & $32.8 \%$ & 18.20 & 0.05 & $2.2 \%$ & 10.28 & 0.14 & $20.9 \%$ \\
\hline 10.32 & 0.17 & $27.7 \%$ & 18.15 & 0.05 & $1.9 \%$ & 11.19 & 0.12 & $18.2 \%$ \\
\hline 12.46 & 0.13 & $17.1 \%$ & 17.90 & 0.08 & $3.3 \%$ & 11.69 & 0.18 & $26.0 \%$ \\
\hline 13.44 & 0.16 & $19.5 \%$ & 18.47 & 0.12 & $4.5 \%$ & 12.63 & 0.23 & $29.5 \%$ \\
\hline 15.23 & 0.14 & $15.1 \%$ & 20.20 & 0. & $3.4 \%$ & 14.98 & 0.16 & $19.0 \%$ \\
\hline 15.89 & 0.10 & $9.7 \%$ & 21.00 & 0.08 & $2.7 \%$ & 15.60 & 0.13 & $15.2 \%$ \\
\hline 19.38 & 0.07 & $6.5 \%$ & 27.19 & 0.06 & $1.6 \%$ & 19.23 & 0.09 & $9.5 \%$ \\
\hline 19.84 & 0.09 & $8.4 \%$ & 27.55 & 0.07 & $1.7 \%$ & 19.80 & 0.10 & $9.5 \%$ \\
\hline 20.62 & 0.09 & $8.1 \%$ & 28.18 & 0.07 & $1.7 \%$ & 20.60 & 0.10 & $9.0 \%$ \\
\hline 20.23 & 0.10 & $8.0 \%$ & 28.21 & 0.07 & $1.6 \%$ & 20.22 & 0.10 & $8.8 \%$ \\
\hline 20.45 & 0.11 & $9.2 \%$ & 28.68 & 0.08 & $1.7 \%$ & 20.45 & 0.11 & $9.1 \%$ \\
\hline 19.06 & 0.14 & $16.2 \%$ & 28.69 & 0.06 & $1.9 \%$ & 19.42 & 0.11 & $11.1 \%$ \\
\hline 18.96 & 0.16 & $20.3 \%$ & 28.84 & 0.06 & $2.0 \%$ & 19.71 & 0.11 & $12.7 \%$ \\
\hline 22.44 & 0.12 & $14.5 \%$ & 31.65 & 0.07 & $2.3 \%$ & 22.44 & 0.12 & $14.4 \%$ \\
\hline 25.08 & 0.09 & $10.3 \%$ & 33.84 & 0.07 & $2.2 \%$ & 24.65 & 0.11 & $14.1 \%$ \\
\hline 26.29 & 0.11 & $14.4 \%$ & 34.94 & 0.07 & $2.2 \%$ & 26.39 & 0.11 & $13.7 \%$ \\
\hline 26.62 & 0.10 & $12.1 \%$ & 34.73 & 0.05 & $1.8 \%$ & 26.83 & 0.09 & $10.4 \%$ \\
\hline 27.93 & 0.07 & $7.7 \%$ & 35.82 & 0.06 & $1.8 \%$ & 27.65 & 0.09 & $10.3 \%$ \\
\hline 29.72 & 0.07 & $7.7 \%$ & 38.75 & 0.06 & $1.9 \%$ & 29.41 & 0.09 & $10.7 \%$ \\
\hline 4.51 & 0.27 & $15.7 \%$ & 5.43 & 0.24 & $4.3 \%$ & 4.51 & 0.28 & $17.2 \%$ \\
\hline 5.31 & 0.25 & $13.7 \%$ & 6.27 & 0.22 & $3.7 \%$ & 5.31 & 0.26 & $14.8 \%$ \\
\hline 6.08 & 0.24 & $11.8 \%$ & 6.95 & 0.23 & $3.4 \%$ & 6.08 & 0.26 & $13.7 \%$ \\
\hline 6.72 & 0.35 & $21.7 \%$ & 7.56 & 0.27 & $4.5 \%$ & 6.72 & 0.30 & $17.5 \%$ \\
\hline 6.03 & 0.40 & $28.4 \%$ & 6.85 & 0.29 & $5.5 \%$ & 6.04 & 0.33 & $21.0 \%$ \\
\hline 7.42 & 0.36 & $24.1 \%$ & 8.34 & 0.31 & $6.1 \%$ & 7.42 & 0.34 & $22.8 \%$ \\
\hline
\end{tabular}




\begin{tabular}{|c|c|c|c|c|c|c|c|c|c|c|c|c|c|c|c|c|c|c|}
\hline dez-06 & 10.52 & 0.28 & $4.3 \%$ & 9.72 & 0.30 & $16.8 \%$ & 10.52 & 0.30 & $4.8 \%$ & 9.71 & 0.32 & $18.6 \%$ & 10.52 & 0.34 & $6.3 \%$ & 9.71 & 0.37 & $23.2 \%$ \\
\hline mar-07 & 10.42 & 0.31 & $5.5 \%$ & 9.57 & 0.34 & $20.8 \%$ & 10.42 & 0.30 & $5.1 \%$ & 9.57 & 0.32 & $19.6 \%$ & 10.42 & 0.32 & $6.0 \%$ & 9.57 & 0.35 & $22.3 \%$ \\
\hline jun-07 & 12.66 & 0.27 & $3.8 \%$ & 11.93 & 0.29 & $15.1 \%$ & 12.66 & 0.30 & $4.6 \%$ & 11.93 & 0.32 & $17.9 \%$ & 12.66 & 0.31 & $4.6 \%$ & 11.93 & 0.32 & $17.9 \%$ \\
\hline set- 07 & 13.71 & 0.34 & $5.8 \%$ & 12.88 & 0.36 & $21.9 \%$ & 13.71 & 0.31 & $4.8 \%$ & 12.88 & 0.33 & $18.7 \%$ & 13.71 & 0.31 & $4.9 \%$ & 2.88 & 0.33 & $8.9 \%$ \\
\hline dez-07 & 10.82 & 0.37 & $7.6 \%$ & 9.97 & 0.40 & $27.4 \%$ & 10.82 & 0.36 & $7.2 \%$ & 9.97 & 0.39 & $26.4 \%$ & 10.82 & 0.31 & $5.8 \%$ & 9.98 & 0.34 & $21.8 \%$ \\
\hline mar-08 & 10.70 & 38 & $8.8 \%$ & 9.74 & 43 & $31.0 \%$ & 10.70 & 37 & $8.1 \%$ & 9.75 & .41 & $29.2 \%$ & 10.70 & 0.33 & $6.7 \%$ & 9.77 & .36 & $4.8 \%$ \\
\hline jun-08 & 12.67 & 36 & $7.4 \%$ & 11.62 & 40 & $26.8 \%$ & 12.67 & 38 & $8.1 \%$ & 11.62 & .42 & $28.8 \%$ & 12.67 & .37 & $7.6 \%$ & 11.62 & .40 & $7.5 \%$ \\
\hline set- 08 & 11.50 & 0.28 & $5.7 \%$ & 10.08 & 32 & $22.0 \%$ & 11.50 & 30 & $6.3 \%$ & 10.08 & .34 & $23.9 \%$ & 11.50 & .32 & $7.3 \%$ & 0.06 & .37 & $27.2 \%$ \\
\hline dez-08 & 11.74 & 0.54 & $18.3 \%$ & 9.45 & 0.69 & $57.9 \%$ & 11.77 & 0.42 & $12.4 \%$ & 9.80 & 0.52 & $42.9 \%$ & 11.77 & 0.37 & $10.2 \%$ & 9.91 & 0.45 & $6.5 \%$ \\
\hline nar-09 & 11.20 & 0.24 & $5.4 \%$ & 9.59 & 0.28 & $21.4 \%$ & 11.19 & 0.39 & $12.1 \%$ & 9.25 & 0.49 & $43.4 \%$ & 11.19 & 33 & $9.2 \%$ & 9.44 & 40 & $4.4 \%$ \\
\hline jun-09 & 14.88 & 0.30 & $6.6 \%$ & 13.48 & 0.34 & $24.9 \%$ & 14.88 & 0.29 & $6.2 \%$ & 13. & 0.32 & $23.5 \%$ & 14.88 & 8 & $9.7 \%$ & 13. & 43 & $34.3 \%$ \\
\hline set -09 & 15.69 & 0.19 & $3.0 \%$ & 14.15 & 0.21 & $12.7 \%$ & 15.69 & 0.24 & $4.8 \%$ & 14.14 & 0.27 & $19.0 \%$ & 15.69 & 0.35 & $9.0 \%$ & 13.97 & 0.40 & $32.8 \%$ \\
\hline dez-09 & 20.66 & 0.24 & $4.2 \%$ & 19.02 & 26 & $16.8 \%$ & 20.66 & 0.22 & $3.6 \%$ & 19.02 & 0.24 & $14.7 \%$ & 20.66 & 0.27 & $5.1 \%$ & 19.00 & 0.29 & $19.9 \%$ \\
\hline mar-10 & 21.46 & 0.21 & $3.4 \%$ & 19.53 & .23 & $14.1 \%$ & 21.46 & 22 & $3.8 \%$ & 19.53 & .24 & $15.6 \%$ & 21.46 & .24 & $4.4 \%$ & 19.52 & .26 & $17.7 \%$ \\
\hline jun-10 & 20.99 & 0.19 & $3.0 \%$ & 18.70 & 21 & $12.6 \%$ & 20.99 & 19 & $3.2 \%$ & 18.70 & 0.22 & $13.3 \%$ & 20.99 & 0.20 & $3.4 \%$ & 18.70 & .23 & $14.1 \%$ \\
\hline set-10 & 24.08 & 0.18 & $2.5 \%$ & 21.69 & 0.20 & $10.7 \%$ & 24.08 & 0.19 & $2.8 \%$ & 21.69 & 0.21 & $11.7 \%$ & 24.08 & 0.21 & $3.3 \%$ & 21.69 & 0.23 & $3.7 \%$ \\
\hline dez-10 & 27.13 & 0.24 & $4.6 \%$ & 24.11 & 0.27 & $18.3 \%$ & 27.13 & 0.21 & $3.5 \%$ & & 0.23 & $14.5 \%$ & 27.13 & 0.20 & $3.3 \%$ & 12 & 0.23 & $14.0 \%$ \\
\hline mar-11 & 27.32 & 0.16 & $2.2 \%$ & 24.09 & 0.18 & $9.6 \%$ & 27.32 & 0.21 & $3.4 \%$ & 24.09 & 0.23 & $14.3 \%$ & 27.32 & 0.1 & $3.0 \%$ & 24.09 & 22 & $12.8 \%$ \\
\hline jun-11 & 26.90 & 0.16 & $2.1 \%$ & 23.62 & 0.18 & $9.2 \%$ & 26.90 & 0.16 & $2.1 \%$ & 23.62 & 0.18 & $9.2 \%$ & 26.90 & 0.19 & $2.9 \%$ & 23.62 & 0.21 & 12.29 \\
\hline set-11 & 28.69 & 0.23 & $4.0 \%$ & 25.41 & .26 & $16.4 \%$ & 28.69 & 0.20 & $3.0 \%$ & 25.42 & 0.22 & $12.7 \%$ & 28.69 & 0.20 & $3.2 \%$ & 25.42 & 0.23 & $13.4 \%$ \\
\hline dez-11 & 28.66 & 0.18 & $2.5 \%$ & 25.62 & 20 & $10.7 \%$ & 28.66 & .20 & $3.1 \%$ & 25.61 & 0.22 & $13.1 \%$ & 28.66 & 0.18 & $2.6 \%$ & 25.62 & .20 & 11.29 \\
\hline mar-12 & 33.00 & 0.20 & $2.9 \%$ & 30.22 & 0.22 & $12.4 \%$ & 33.00 & 0.20 & $2.7 \%$ & 30.22 & 0.21 & $11.6 \%$ & 33.00 & 0.20 & $2.9 \%$ & 30.22 & 0.22 & $12.1 \%$ \\
\hline jun-12 & 36.29 & 0.23 & $3.6 \%$ & 33.60 & 25 & $14.9 \%$ & 36.29 & 0.22 & $3.3 \%$ & 33.60 & 0.23 & $13.6 \%$ & 36.29 & 0.21 & $3.2 \%$ & 33.60 & .23 & $13.4 \%$ \\
\hline set-12 & 40.95 & 0.23 & $3.7 \%$ & 38.20 & 0.25 & $15.2 \%$ & 40.95 & 0.23 & $3.6 \%$ & 38.20 & 0.25 & $14.9 \%$ & 40.95 & 0.21 & $3.2 \%$ & 38.20 & 0.23 & $13.4 \%$ \\
\hline dez-12 & 43.17 & 0.14 & $1.4 \%$ & 40.71 & & $6.3 \%$ & 43.17 & 0.20 & $2.5 \%$ & 40. & 0.21 & $10.9 \%$ & 43.17 & 0.21 & $2.9 \%$ & 40.70 & 22 & $12.1^{\circ}$ \\
\hline mar-13 & 43.48 & 19 & $2.0 \%$ & 41.36 & 19 & $8.9 \%$ & 43.48 & 0.17 & $1.7 \%$ & 41.36 & 0.1 & $7.4 \%$ & 43.48 & 0.21 & $2.7 \%$ & 41.36 & 0.22 & $11.4^{\circ}$ \\
\hline jun-13 & 38.73 & 19 & $2.4 \%$ & 36.43 & 21 & $10.4 \%$ & 38.73 & 0.19 & $2.3 \%$ & 36.43 & 0.20 & $9.7 \%$ & 38.73 & 0.20 & $2.4 \%$ & 36.43 & 0.21 & 10.5 \\
\hline jun-05 & 1.30 & 0.11 & $3.2 \%$ & 0.75 & 0.20 & $19.4 \%$ & 1.30 & 0.11 & $3.2 \%$ & 0.75 & 0.20 & $19.8 \%$ & 1.30 & 0.10 & $2.8 \%$ & 0.76 & 0.18 & $16.8 \%$ \\
\hline set-05 & 1.51 & 0.10 & $2.8 \%$ & 0.89 & 18 & $16.8 \%$ & 1.51 & 0.11 & $3.2 \%$ & 0.89 & 0.20 & $19.1 \%$ & 1.51 & 0.11 & $3.0 \%$ & 0.89 & 0.19 & $18.0 \%$ \\
\hline dez-05 & 1.80 & 0.07 & $1.9 \%$ & 1.07 & 0.13 & $12.1 \%$ & 1.80 & 0.08 & $2.3 \%$ & 1.06 & 0.15 & $14.4 \%$ & 1.80 & 0.09 & $2.6 \%$ & 1.06 & 0.16 & $16.1 \%$ \\
\hline mar-06 & 1.84 & 0.09 & $2.2 \%$ & 1.17 & 0.14 & $12.6 \%$ & 1.84 & 0.09 & $2.2 \%$ & 1.17 & 0.14 & $12.7 \%$ & 1.84 & 0.10 & $2.7 \%$ & 1.16 & 0.16 & $15.5 \%$ \\
\hline jun-06 & 1.83 & 0.09 & $2.7 \%$ & & & $15.4 \%$ & & & $2.4^{\circ}$ & & & $13.7 \%$ & 1.83 & & $2.4 \%$ & 1. & 15 & $14.1 \%$ \\
\hline set- 06 & 1.94 & 0.06 & $1.2 \%$ & & & $6.8 \%$ & & & & & & $11.2 \%$ & & & $\%$ & 1. & 13 & 11.79 \\
\hline dez-06 & 2.25 & 0.08 & $1.7 \%$ & 1.57 & 0.11 & $9.4 \%$ & 2.25 & 0.07 & $1.5 \%$ & 1.57 & 0.10 & $8.2 \%$ & 2.25 & 0.09 & $2.1 \%$ & 1.56 & 0.13 & 11.29 \\
\hline mar-07 & 2.29 & 0.08 & $1.7 \%$ & 1.65 & 0.11 & $9.0 \%$ & 2.29 & 0.08 & $1.7 \%$ & 1.65 & 0.11 & $8.9 \%$ & 2.29 & 0.09 & $2.0 \%$ & 1.65 & 0.13 & $10.6 \%$ \\
\hline jun-07 & 2.54 & 0.09 & $1.9 \%$ & 1.87 & 0.12 & $9.9 \%$ & 2.54 & 0.09 & $1.8 \%$ & 1.87 & 0.12 & $9.4 \%$ & 2.54 & 0.08 & $1.7 \%$ & 1.88 & 0.11 & $8.8 \%$ \\
\hline set-07 & 2.62 & 0.10 & $2.3 \%$ & 1.95 & 0.13 & $11.7 \%$ & 2.62 & 0.09 & $2.1 \%$ & 1.95 & 0.13 & $10.6 \%$ & 2.62 & 0.09 & $1.9 \%$ & 1.95 & 0.12 & $9.6 \%$ \\
\hline dez-07 & 2.55 & 0.07 & $1.5 \%$ & & & $7.7 \%$ & 2.55 & 0.08 & $1.8 \%$ & 1.88 & 0.11 & $9.1 \%$ & 2.55 & 0.08 & $1.7 \%$ & 1.88 & 0.11 & $9.0 \%$ \\
\hline Ir-08 & 2.92 & 0.10 & $2.5 \%$ & 2.14 & 0.14 & $12.7 \%$ & 2.92 & 0.08 & $1.9 \%$ & 2.14 & 0.12 & $10.0 \%$ & 2.92 & 0.08 & $1.9 \%$ & 2.14 & 0.12 & $10.0^{c}$ \\
\hline jun-08 & 3.07 & 0.04 & $0.5 \%$ & 2.22 & 0.06 & $3.2 \%$ & 3.07 & 0.08 & $1.6 \%$ & 2.22 & 0.11 & $8.6 \%$ & 3.07 & 0.08 & $1.7 \%$ & 2.22 & 0.11 & $9.0^{\circ}$ \\
\hline
\end{tabular}




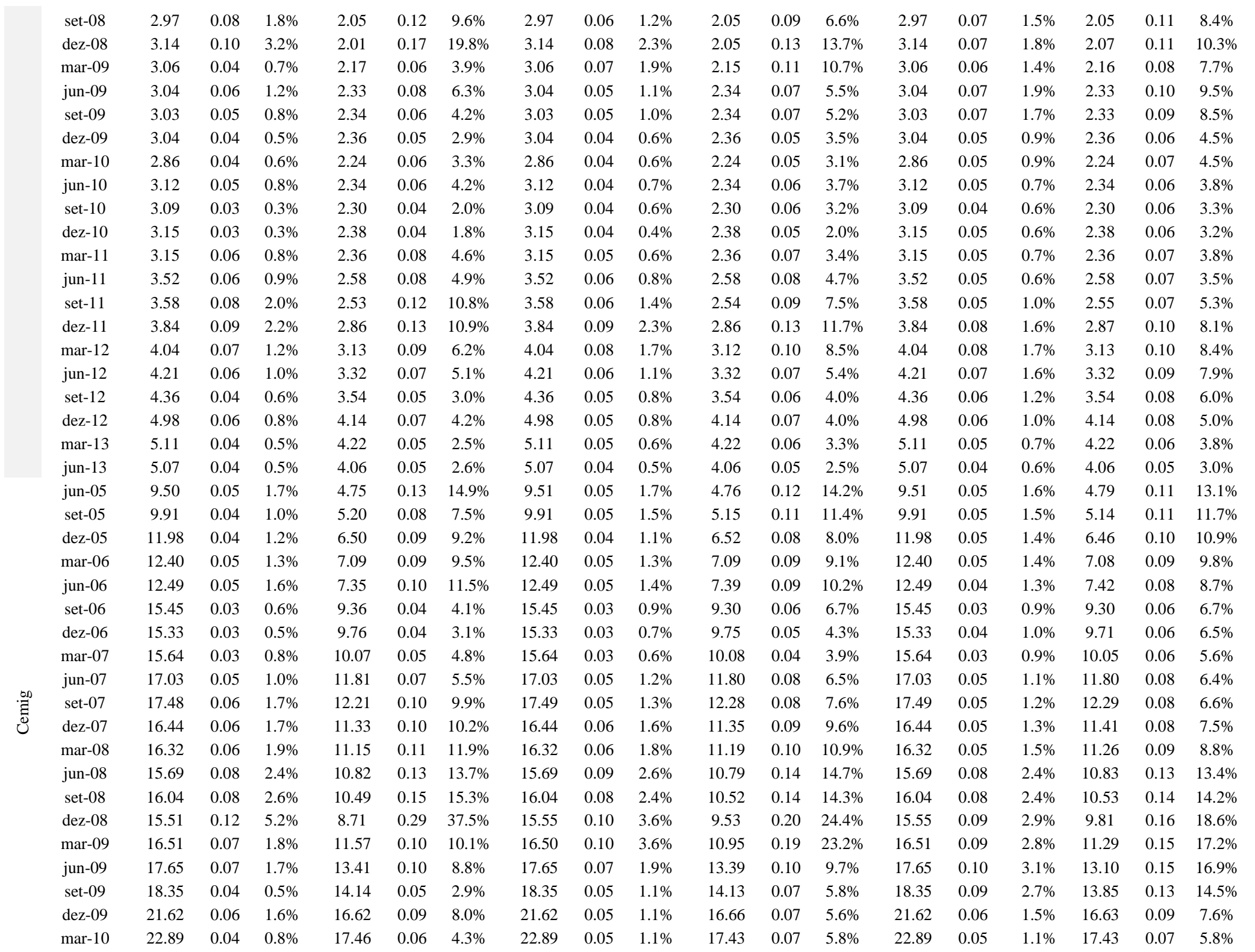




\begin{tabular}{|c|c|c|c|c|c|c|c|c|c|c|c|c|c|c|c|c|c|c|}
\hline jun-10 & 23.65 & 0.05 & $1.0 \%$ & 17.36 & 0.07 & $5.3 \%$ & 23.65 & 0.05 & $0.9 \%$ & 17.37 & 0.07 & $5.0 \%$ & 23.65 & 0.05 & $1.0 \%$ & 17.36 & 0.07 & $5.3 \%$ \\
\hline set-10 & 24.11 & 0.05 & $1.1 \%$ & 17.49 & 0.07 & $5.9 \%$ & 24.11 & 0.05 & $1.0 \%$ & 17.50 & 0.07 & $5.6 \%$ & 24.11 & 0.05 & $1.1 \%$ & 17.49 & 0.08 & $6.1 \%$ \\
\hline dez-10 & 24.98 & 0.05 & $1.1 \%$ & 18.08 & 0.08 & $6.1 \%$ & 24.98 & 0.05 & $1.1 \%$ & 18.08 & 0.07 & $5.9 \%$ & 24.98 & 0.05 & $1.0 \%$ & 18.09 & 0.07 & $5.5 \%$ \\
\hline mar-11 & 25.84 & 0.05 & $1.0 \%$ & 18.43 & 0.08 & $5.7 \%$ & 25.84 & 0.06 & $1.1 \%$ & 18.43 & 0.08 & $6.2 \%$ & 25.84 & 0.06 & $1.1 \%$ & 18.43 & 0.08 & $6.2 \%$ \\
\hline jun-11 & 26.64 & 0.05 & $0.9 \%$ & 18.86 & 0.07 & $5.0 \%$ & 26.64 & 0.05 & $1.0 \%$ & 18.86 & 0.08 & $5.5 \%$ & 26.64 & 0.06 & $1.1 \%$ & 18.85 & 0.08 & $6.1 \%$ \\
\hline set-11 & 26.79 & 0.05 & $1.1 \%$ & 18.77 & 0.08 & $5.9 \%$ & 26.79 & 0.05 & $0.9 \%$ & 18.78 & 0.07 & $5.0 \%$ & 26.79 & 0.05 & $1.0 \%$ & 18.77 & 0.07 & $5.5 \%$ \\
\hline dez-11 & 30.02 & 0.07 & $1.5 \%$ & 21.87 & 0.09 & $7.8 \%$ & 30.02 & 0.06 & $1.3 \%$ & 21.88 & 0.09 & $7.1 \%$ & 30.02 & 0.06 & $1.1 \%$ & 21.90 & 0.08 & $6.2 \%$ \\
\hline mar-12 & 32.39 & 0.06 & $1.0 \%$ & 25.05 & 0.08 & $5.5 \%$ & 32.39 & 0.07 & $1.4 \%$ & 25.04 & 0.09 & $7.1 \%$ & 32.39 & 0.07 & $1.3 \%$ & 25.04 & 0.09 & $6.7 \%$ \\
\hline jun-12 & 35.59 & 0.09 & $1.7 \%$ & 29.12 & 0.11 & $8.3 \%$ & 35.59 & 0.09 & $1.5 \%$ & 29.13 & 0.11 & $7.4 \%$ & 35.59 & 0.09 & $1.7 \%$ & 29.12 & 0.11 & $8.2 \%$ \\
\hline set-12 & 32.02 & 0.15 & $5.4 \%$ & 24.13 & 0.24 & $28.7 \%$ & 32.04 & 0.12 & $3.5 \%$ & 25.38 & 0.17 & $17.7 \%$ & 32.05 & 0.09 & $2.5 \%$ & 25.79 & 0.13 & $12.2 \%$ \\
\hline dez-12 & 35.88 & 0.09 & $2.6 \%$ & 29.08 & 0.13 & $12.5 \%$ & 35.87 & 0.12 & $3.9 \%$ & 28.30 & 0.18 & $20.3 \%$ & 35.88 & 0.10 & $2.6 \%$ & 29.05 & 0.13 & $12.9 \%$ \\
\hline mar-13 & 26.63 & 0.16 & $4.7 \%$ & 21.89 & 0.21 & $21.6 \%$ & 26.63 & 0.14 & $3.9 \%$ & 22.12 & 0.19 & $17.8 \%$ & 26.63 & 0.15 & $4.2 \%$ & 22.05 & 0.19 & $19.0 \%$ \\
\hline jun-13 & 27.14 & 0.11 & $2.3 \%$ & 22.76 & 0.14 & $10.4 \%$ & 27.14 & 0.15 & $3.7 \%$ & 22.60 & 0.19 & $16.6 \%$ & 27.14 & 0.17 & $4.6 \%$ & 22.43 & 0.22 & $20.4 \%$ \\
\hline jun-05 & 5.17 & 0.11 & $3.6 \%$ & 2.99 & 0.22 & $21.6 \%$ & 5.17 & 0.11 & $3.4 \%$ & 3.00 & 0.21 & $20.7 \%$ & 5.17 & 0.11 & $3.2 \%$ & 3.01 & 0.20 & $19.4 \%$ \\
\hline set-05 & 5.68 & 0.12 & $3.2 \%$ & 3.50 & 0.20 & $17.6 \%$ & 5.68 & 0.12 & $3.5 \%$ & 3.49 & 0.21 & $19.5 \%$ & 5.68 & 0.13 & $3.8 \%$ & 3.48 & 0.23 & $21.3 \%$ \\
\hline dez-05 & 6.21 & 0.12 & $3.4 \%$ & 3.88 & 0.20 & $19.3 \%$ & 6.21 & 0.11 & $3.0 \%$ & 3.89 & 0.19 & $17.1 \%$ & 6.21 & 0.12 & $3.4 \%$ & 3.88 & 0.20 & $19.1 \%$ \\
\hline mar-06 & 6.53 & 0.12 & $3.0 \%$ & 4.38 & 0.18 & $15.9 \%$ & 6.53 & 0.13 & $3.4 \%$ & 4.36 & 0.20 & $17.8 \%$ & 6.53 & 0.13 & $3.6 \%$ & 4.36 & 0.20 & $18.6 \%$ \\
\hline jun-06 & 6.08 & 0.14 & $4.1 \%$ & 4.18 & 0.22 & $20.8 \%$ & 6.08 & 0.13 & $3.6 \%$ & 4.20 & 0.20 & $18.3 \%$ & 6.08 & 0.13 & $3.5 \%$ & 4.21 & 0.20 & $18.0 \%$ \\
\hline set-06 & 6.66 & 0.13 & $3.1 \%$ & 4.83 & 0.18 & $15.0 \%$ & 6.66 & 0.14 & $3.8 \%$ & 4.80 & 0.21 & $18.5 \%$ & 6.66 & 0.14 & $3.8 \%$ & 4.80 & 0.21 & $18.3 \%$ \\
\hline dez-06 & 7.15 & 0.11 & $2.6 \%$ & 5.24 & 0.16 & $12.9 \%$ & 7.15 & 0.12 & $2.8 \%$ & 5.23 & 0.17 & $13.9 \%$ & 7.15 & 0.13 & $3.2 \%$ & 5.22 & 0.18 & $15.9 \%$ \\
\hline mar-07 & 6.44 & 0.11 & $2.2 \%$ & 4.84 & 0.15 & $11.0 \%$ & 6.44 & 0.11 & $2.4 \%$ & 4.83 & 0.15 & $12.0 \%$ & 6.44 & 0.13 & $3.1 \%$ & 4.82 & 0.18 & $15.1 \%$ \\
\hline jun-07 & 7.46 & 0.14 & $2.8 \%$ & 5.96 & 0.18 & $13.0 \%$ & 7.46 & 0.14 & $2.7 \%$ & 5.96 & 0.17 & $12.5 \%$ & 7.46 & 0.15 & $3.1 \%$ & 5.95 & 0.19 & $14.2 \%$ \\
\hline set-07 & 7.32 & 0.18 & $4.9 \%$ & 5.72 & 0.24 & $22.1 \%$ & 7.32 & 0.16 & $3.9 \%$ & 5.76 & 0.21 & $17.6 \%$ & 7.32 & 0.14 & $3.3 \%$ & 5.78 & 0.19 & $15.2 \%$ \\
\hline dez-07 & 7.19 & 0.13 & $3.1 \%$ & 5.60 & 0.17 & $14.6 \%$ & 7.19 & 0.15 & $3.9 \%$ & 5.57 & 0.20 & $18.1 \%$ & 7.19 & 0.13 & $3.2 \%$ & 5.60 & 0.18 & $14.8 \%$ \\
\hline mar-08 & 7.27 & 0.17 & $4.6 \%$ & 5.67 & 0.23 & $21.0 \%$ & 7.27 & 0.16 & $3.9 \%$ & 5.70 & 0.21 & $17.8 \%$ & 7.27 & 0.15 & $3.8 \%$ & 5.70 & 0.20 & $17.2 \%$ \\
\hline jun-08 & 7.60 & 0.16 & $3.8 \%$ & 6.03 & 0.21 & $16.8 \%$ & 7.60 & 0.18 & $4.4 \%$ & 6.01 & 0.23 & $19.3 \%$ & 7.60 & 0.18 & $4.4 \%$ & 6.01 & 0.23 & $19.2 \%$ \\
\hline set- 08 & 7.05 & 0.22 & $7.3 \%$ & 5.08 & 0.34 & $33.0 \%$ & 7.05 & 0.19 & $5.4 \%$ & 5.20 & 0.27 & $24.8 \%$ & 7.05 & 0.17 & $4.6 \%$ & 5.24 & 0.24 & $21.3 \%$ \\
\hline dez-08 & 6.90 & 0.31 & $12.4 \%$ & 4.35 & 0.54 & $55.1 \%$ & 6.93 & 0.25 & $9.4 \%$ & 4.66 & 0.42 & $43.6 \%$ & 6.94 & 0.20 & $6.7 \%$ & 4.91 & 0.32 & $31.7 \%$ \\
\hline mar-09 & 6.76 & 0.14 & $3.5 \%$ & 5.25 & 0.19 & $16.1 \%$ & 6.75 & 0.24 & $8.7 \%$ & 4.87 & 0.38 & $39.6 \%$ & 6.76 & 0.21 & $6.6 \%$ & 5.07 & 0.30 & $30.4 \%$ \\
\hline jun-09 & 7.16 & 0.16 & $3.7 \%$ & 5.90 & 0.19 & $16.4 \%$ & 7.16 & 0.16 & $3.7 \%$ & 5.90 & 0.19 & $16.4 \%$ & 7.16 & 0.23 & $7.2 \%$ & 5.70 & 0.31 & $31.0 \%$ \\
\hline set-09 & 7.93 & 0.09 & $1.3 \%$ & 6.65 & 0.11 & $6.2 \%$ & 7.93 & 0.13 & $2.6 \%$ & 6.64 & 0.16 & $11.6 \%$ & 7.93 & 0.22 & $6.3 \%$ & 6.49 & 0.28 & $27.0 \%$ \\
\hline dez-09 & 8.64 & 0.13 & $2.4 \%$ & 7.37 & 0.15 & $10.6 \%$ & 8.64 & 0.12 & $1.9 \%$ & 7.37 & 0.14 & $8.7 \%$ & 8.64 & 0.15 & $3.1 \%$ & 7.36 & 0.18 & $13.4 \%$ \\
\hline mar-10 & 9.28 & 0.09 & $1.3 \%$ & 7.80 & 0.11 & $6.3 \%$ & 9.28 & 0.11 & $1.8 \%$ & 7.80 & 0.13 & $8.3 \%$ & 9.28 & 0.12 & $2.2 \%$ & 7.80 & 0.14 & $10.1 \%$ \\
\hline jun-10 & 9.30 & 0.11 & $1.7 \%$ & 7.65 & 0.13 & $8.1 \%$ & 9.30 & 0.10 & $1.5 \%$ & 7.65 & 0.12 & $7.2 \%$ & 9.30 & 0.11 & $1.7 \%$ & 7.65 & 0.13 & $8.2 \%$ \\
\hline set-10 & 9.68 & 0.10 & $1.6 \%$ & 7.84 & 0.12 & $7.6 \%$ & 9.68 & 0.10 & $1.7 \%$ & 7.84 & 0.13 & $8.0 \%$ & 9.68 & 0.10 & $1.7 \%$ & 7.84 & 0.13 & $8.2 \%$ \\
\hline dez-10 & 10.77 & 0.11 & $1.8 \%$ & 8.73 & 0.13 & $8.8 \%$ & 10.77 & 0.11 & $1.8 \%$ & 8.73 & 0.13 & $8.4 \%$ & 10.77 & 0.10 & $1.6 \%$ & 8.73 & 0.13 & $7.8 \%$ \\
\hline mar-11 & 11.04 & 0.10 & $1.4 \%$ & 8.87 & 0.12 & $7.0 \%$ & 11.04 & 0.11 & $1.6 \%$ & 8.87 & 0.13 & $7.9 \%$ & 11.04 & 0.11 & $1.7 \%$ & 8.87 & 0.13 & $8.0 \%$ \\
\hline jun-11 & 10.91 & 0.09 & $1.2 \%$ & 8.62 & 0.11 & $5.9 \%$ & 10.91 & 0.09 & $1.3 \%$ & 8.62 & 0.11 & $6.4 \%$ & 10.91 & 0.10 & $1.5 \%$ & 8.62 & 0.13 & $7.5 \%$ \\
\hline set-11 & 10.28 & 0.11 & $2.2 \%$ & 7.96 & 0.14 & $10.5 \%$ & 10.28 & 0.09 & $1.6 \%$ & 7.96 & 0.12 & $8.0 \%$ & 10.28 & 0.09 & $1.6 \%$ & 7.96 & 0.12 & $7.8 \%$ \\
\hline dez-11 & 11.09 & 0.11 & $1.9 \%$ & 8.85 & 0.14 & $9.2 \%$ & 11.09 & 0.11 & $2.1 \%$ & 8.85 & 0.14 & $10.1 \%$ & 11.09 & 0.10 & $1.7 \%$ & 8.86 & 0.13 & $8.2 \%$ \\
\hline
\end{tabular}




\begin{tabular}{|c|c|c|c|c|c|c|c|c|c|c|c|c|c|c|c|c|c|c|}
\hline mar-12 & 11.57 & 0.10 & $1.5 \%$ & 9.56 & 0.12 & $7.3 \%$ & 11.57 & 0.11 & $1.8 \%$ & 9.56 & 0.13 & $8.3 \%$ & 11.57 & 0.11 & $1.8 \%$ & 9.56 & 0.13 & $8.5 \%$ \\
\hline jun-12 & 11.99 & 0.13 & $2.5 \%$ & 10.13 & 0.16 & $11.3 \%$ & 11.99 & 0.12 & $2.0 \%$ & 10.13 & 0.14 & $9.4 \%$ & 11.99 & 0.12 & $2.1 \%$ & 10.13 & 0.14 & $9.7 \%$ \\
\hline set-12 & 10.72 & 0.12 & $2.5 \%$ & 9.02 & 0.14 & $11.3 \%$ & 10.72 & 0.11 & $2.4 \%$ & 9.02 & 0.14 & $10.9 \%$ & 10.72 & 0.10 & $2.0 \%$ & 9.03 & 0.12 & $9.1 \%$ \\
\hline dez-12 & 12.08 & 0.10 & $2.2 \%$ & 10.08 & 0.12 & $10.3 \%$ & 12.08 & 0.10 & $2.2 \%$ & 10.08 & 0.12 & $10.2 \%$ & 12.08 & 0.09 & $1.9 \%$ & 10.10 & 0.11 & $8.9 \%$ \\
\hline mar-13 & 12.00 & 0.09 & $1.9 \%$ & 10.01 & 0.11 & $8.7 \%$ & 12.00 & 0.09 & $2.0 \%$ & 10.00 & 0.12 & $9.5 \%$ & 12.00 & 0.10 & $2.1 \%$ & 10.00 & 0.12 & $9.7 \%$ \\
\hline jun-13 & 11.78 & 0.16 & $5.3 \%$ & 9.10 & 0.24 & $26.6 \%$ & 11.79 & 0.13 & $3.6 \%$ & 9.42 & 0.17 & $17.4 \%$ & 11.79 & 0.11 & $2.8 \%$ & 9.51 & 0.14 & $13.5 \%$ \\
\hline jun-05 & 6.47 & 0.26 & $4.1 \%$ & 5.73 & 0.29 & $15.7 \%$ & 6.47 & 0.25 & $3.7 \%$ & 5.73 & 0.28 & $14.6 \%$ & 6.47 & 0.22 & $3.1 \%$ & 5.73 & 0.25 & $12.2 \%$ \\
\hline set- 05 & 6.33 & 0.25 & $3.7 \%$ & 5.59 & 0.28 & $14.5 \%$ & 6.33 & 0.25 & $3.8 \%$ & 5.59 & 0.28 & $14.9 \%$ & 6.33 & 0.24 & $3.4 \%$ & 5.59 & 0.27 & $13.5 \%$ \\
\hline dez-05 & 7.22 & 0.23 & $3.7 \%$ & 6.27 & 0.27 & $14.9 \%$ & 7.22 & 0.23 & $3.7 \%$ & 6.27 & 0.27 & $15.0 \%$ & 7.22 & 0.23 & $3.8 \%$ & 6.27 & 0.27 & $15.0 \%$ \\
\hline mar-06 & 8.22 & 0.28 & $4.9 \%$ & 7.31 & 0.31 & $18.7 \%$ & 8.22 & 0.26 & $4.3 \%$ & 7.31 & 0.29 & $16.7 \%$ & 8.22 & 0.25 & $4.1 \%$ & 7.31 & 0.29 & $16.1 \%$ \\
\hline jun-06 & 7.78 & 0.34 & $6.6 \%$ & 7.06 & 0.38 & $24.2 \%$ & 7.78 & 0.32 & $5.7 \%$ & 7.06 & 0.35 & $21.4 \%$ & 7.78 & 0.29 & $4.7 \%$ & 7.06 & 0.31 & $18.2 \%$ \\
\hline set-06 & 8.12 & 0.26 & $3.9 \%$ & 7.46 & 0.29 & $15.3 \%$ & 8.12 & 0.31 & $5.2 \%$ & 7.46 & 0.34 & $19.8 \%$ & 8.12 & 0.29 & $4.7 \%$ & 7.46 & 0.32 & $18.2 \%$ \\
\hline dez-06 & 9.48 & 0.26 & $4.1 \%$ & 8.67 & 0.29 & $16.3 \%$ & 9.48 & 0.26 & $4.0 \%$ & 8.67 & 0.28 & $15.8 \%$ & 9.48 & 0.29 & $4.9 \%$ & 8.67 & 0.32 & $18.8 \%$ \\
\hline mar-07 & 10.00 & 0.30 & $4.3 \%$ & 9.43 & 0.32 & $16.8 \%$ & 10.00 & 0.29 & $4.0 \%$ & 9.43 & 0.31 & $15.8 \%$ & 10.00 & 0.31 & $4.6 \%$ & 9.43 & 0.33 & $17.8 \%$ \\
\hline jun-07 & 10.95 & 0.28 & $3.7 \%$ & 10.42 & 0.30 & $14.7 \%$ & 10.95 & 0.29 & $3.9 \%$ & 10.42 & 0.31 & $15.5 \%$ & 10.95 & 0.29 & $3.8 \%$ & 10.42 & 0.30 & $15.2 \%$ \\
\hline set- 07 & 11.22 & 0.36 & $5.2 \%$ & 10.84 & 0.38 & $19.9 \%$ & 11.22 & 0.33 & $4.3 \%$ & 10.84 & 0.34 & $17.0 \%$ & 11.22 & 0.32 & $4.0 \%$ & 10.84 & 0.33 & $15.9 \%$ \\
\hline dez-07 & 11.92 & 0.47 & $9.3 \%$ & 11.37 & 0.49 & $32.1 \%$ & 11.92 & 0.41 & $7.3 \%$ & 11.38 & 0.43 & $26.3 \%$ & 11.92 & 0.36 & $5.6 \%$ & 11.38 & 0.37 & $21.3 \%$ \\
\hline mar-08 & 11.34 & 0.41 & $6.7 \%$ & 10.91 & 0.42 & $24.7 \%$ & 11.34 & 0.45 & $8.0 \%$ & 10.90 & 0.46 & $28.3 \%$ & 11.34 & 0.39 & $6.2 \%$ & 10.91 & 0.41 & $23.2 \%$ \\
\hline jun-08 & 11.26 & 0.30 & $3.6 \%$ & 10.85 & 0.31 & $14.3 \%$ & 11.26 & 0.36 & $5.1 \%$ & 10.85 & 0.37 & $19.6 \%$ & 11.26 & 0.39 & $6.0 \%$ & 10.85 & 0.41 & $22.3 \%$ \\
\hline set- 08 & 11.52 & 0.40 & $6.1 \%$ & 11.10 & 0.42 & $22.3 \%$ & 11.52 & 0.36 & $5.0 \%$ & 11.10 & 0.38 & $19.1 \%$ & 11.52 & 0.41 & $6.4 \%$ & 11.10 & 0.43 & $23.3 \%$ \\
\hline dez-08 & 11.52 & 0.68 & $16.8 \%$ & 10.90 & 0.73 & $49.9 \%$ & 11.52 & 0.55 & $11.6 \%$ & 10.96 & 0.58 & $37.7 \%$ & 11.52 & 0.46 & $8.6 \%$ & 10.97 & 0.48 & $29.8 \%$ \\
\hline mar-09 & 12.05 & 0.31 & $4.1 \%$ & 11.54 & 0.32 & $16.3 \%$ & 12.05 & 0.52 & $11.0 \%$ & 11.51 & 0.55 & $36.6 \%$ & 12.05 & 0.44 & $8.0 \%$ & 11.53 & 0.46 & $28.5 \%$ \\
\hline jun-09 & 15.42 & 0.28 & $3.6 \%$ & 14.87 & 0.29 & $14.5 \%$ & 15.42 & 0.28 & $3.6 \%$ & 14.87 & 0.29 & $14.5 \%$ & 15.42 & 0.43 & $7.9 \%$ & 14.86 & 0.45 & $28.3 \%$ \\
\hline set-09 & 17.51 & 0.24 & $2.4 \%$ & 17.00 & 0.25 & $10.3 \%$ & 17.51 & 0.25 & $2.7 \%$ & 17.00 & 0.26 & $11.1 \%$ & 17.51 & 0.42 & $6.9 \%$ & 17.00 & 0.43 & $25.5 \%$ \\
\hline dez- 09 & 16.43 & 0.31 & $4.2 \%$ & 15.92 & 0.32 & $16.7 \%$ & 16.43 & 0.28 & $3.3 \%$ & 15.92 & 0.29 & $13.7 \%$ & 16.43 & 0.28 & $3.4 \%$ & 15.92 & 0.29 & $14.1 \%$ \\
\hline mar-10 & 18.65 & 0.25 & $3.0 \%$ & 17.95 & 0.26 & $12.3 \%$ & 18.65 & 0.28 & $3.6 \%$ & 17.95 & 0.29 & $14.7 \%$ & 18.65 & 0.27 & $3.4 \%$ & 17.95 & 0.28 & $14.0 \%$ \\
\hline jun-10 & 19.82 & 0.18 & $1.4 \%$ & 19.16 & 0.19 & $6.0 \%$ & 19.82 & 0.22 & $2.1 \%$ & 19.16 & 0.23 & $8.9 \%$ & 19.82 & 0.26 & $2.7 \%$ & 19.16 & 0.26 & $11.4 \%$ \\
\hline set-10 & 24.71 & 0.23 & $2.0 \%$ & 24.02 & 0.23 & $8.5 \%$ & 24.71 & 0.21 & $1.7 \%$ & 24.02 & 0.21 & $7.2 \%$ & 24.71 & 0.26 & $2.5 \%$ & 24.02 & 0.26 & $10.5 \%$ \\
\hline dez-10 & 26.44 & 0.18 & $1.2 \%$ & 25.70 & 0.18 & $5.4 \%$ & 26.44 & 0.21 & $1.6 \%$ & 25.70 & 0.21 & $7.1 \%$ & 26.44 & 0.22 & $1.8 \%$ & 25.70 & 0.22 & $7.7 \%$ \\
\hline mar-11 & 25.75 & 0.24 & $2.3 \%$ & 24.93 & 0.25 & $9.5 \%$ & 25.75 & 0.21 & $1.8 \%$ & 24.93 & 0.22 & $7.4 \%$ & 25.75 & 0.21 & $1.7 \%$ & 24.93 & 0.22 & $7.3 \%$ \\
\hline jun-11 & 29.65 & 0.26 & $2.5 \%$ & 28.83 & 0.27 & $10.3 \%$ & 29.65 & 0.25 & $2.3 \%$ & 28.83 & 0.26 & $9.7 \%$ & 29.65 & 0.23 & $2.0 \%$ & 28.83 & 0.24 & $8.3 \%$ \\
\hline set-11 & 28.90 & 0.32 & $3.7 \%$ & 28.15 & 0.33 & $14.9 \%$ & 28.90 & 0.30 & $3.1 \%$ & 28.15 & 0.30 & $12.7 \%$ & 28.90 & 0.26 & $2.4 \%$ & 28.15 & 0.26 & $10.0 \%$ \\
\hline dez-11 & 34.56 & 0.23 & $1.7 \%$ & 33.87 & 0.23 & $7.4 \%$ & 34.56 & 0.28 & $2.7 \%$ & 33.87 & 0.29 & $11.2 \%$ & 34.56 & 0.27 & $2.5 \%$ & 33.87 & 0.27 & $10.2 \%$ \\
\hline mar-12 & 43.15 & 0.22 & $1.7 \%$ & 42.32 & 0.22 & $7.1 \%$ & 43.15 & 0.22 & $1.7 \%$ & 42.32 & 0.23 & $7.3 \%$ & 43.15 & 0.26 & $2.4 \%$ & 42.32 & 0.27 & $10.0 \%$ \\
\hline jun-12 & 45.91 & 0.25 & $2.4 \%$ & 45.00 & 0.26 & $10.0 \%$ & 45.91 & 0.23 & $2.0 \%$ & 45.00 & 0.24 & $8.7 \%$ & 45.91 & 0.26 & $2.4 \%$ & 45.00 & 0.26 & $10.3 \%$ \\
\hline set-12 & 44.10 & 0.25 & $2.4 \%$ & 43.18 & 0.25 & $10.3 \%$ & 44.10 & 0.25 & $2.4 \%$ & 43.18 & 0.25 & $10.3 \%$ & 44.10 & 0.23 & $2.1 \%$ & 43.18 & 0.24 & $9.2 \%$ \\
\hline $\operatorname{dez}-12$ & 48.90 & 0.24 & $2.1 \%$ & 48.05 & 0.24 & $9.1 \%$ & 48.90 & 0.25 & $2.2 \%$ & 48.05 & 0.25 & $9.7 \%$ & 48.90 & 0.24 & $2.1 \%$ & 48.05 & 0.24 & $9.2 \%$ \\
\hline mar-13 & 48.10 & 0.19 & $1.3 \%$ & 47.17 & 0.19 & $5.9 \%$ & 48.10 & 0.21 & $1.7 \%$ & 47.17 & 0.21 & $7.4 \%$ & 48.10 & 0.23 & $2.1 \%$ & 47.17 & 0.24 & $8.9 \%$ \\
\hline jun-13 & 44.31 & 0.18 & $1.2 \%$ & 43.46 & 0.18 & $5.3 \%$ & 44.31 & 0.18 & $1.2 \%$ & 43.46 & 0.19 & $5.5 \%$ & 44.31 & 0.22 & $1.7 \%$ & 43.46 & 0.22 & $7.6 \%$ \\
\hline
\end{tabular}




\begin{tabular}{|c|c|c|c|c|c|c|c|c|c|c|c|c|c|c|c|c|c|c|}
\hline jun-05 & 20.34 & 0.13 & $3.8 \%$ & 12.32 & 0.23 & $21.6 \%$ & 20.34 & 0.12 & $3.5 \%$ & 12.37 & 0.21 & $19.6 \%$ & 20.34 & 0.11 & $3.1 \%$ & 12.42 & 0.20 & $17.6 \%$ \\
\hline set-05 & 22.43 & 0.14 & $3.6 \%$ & 14.56 & 0.22 & $18.6 \%$ & 22.43 & 0.15 & $4.2 \%$ & 14.50 & 0.24 & $21.3 \%$ & 22.43 & 0.14 & $3.8 \%$ & 14.54 & 0.23 & $19.6 \%$ \\
\hline dez-05 & 22.69 & 0.13 & $3.5 \%$ & 4.85 & 0.21 & $18.4 \%$ & 22.69 & 0.13 & $3.5 \%$ & 14.85 & 0.21 & $18.4 \%$ & 22.69 & 0.13 & $3.7 \%$ & 14.83 & 0.22 & $19.3 \%$ \\
\hline mar-06 & 25.54 & 0.19 & $5.3 \%$ & 8.25 & 0.28 & $24.3 \%$ & 25.54 & 0.18 & $4.8 \%$ & 8.31 & 0.26 & $22.2 \%$ & 25.54 & 0.18 & $4.8 \%$ & 18.31 & 0.26 & $22.2 \%$ \\
\hline jun-06 & 27.60 & 0.19 & $5.3 \%$ & 20.08 & 0.27 & $24.1 \%$ & 27.60 & 0.19 & $5.3 \%$ & 20.08 & 0.27 & $24.1 \%$ & 27.60 & 0.18 & $4.7 \%$ & 20.16 & 0.25 & $21.8 \%$ \\
\hline set- 06 & 26.51 & 0.14 & $3.4 \%$ & 9.55 & 0.20 & $16.3 \%$ & 26.51 & 0.16 & $4.3 \%$ & 9.45 & 0.23 & $20.1 \%$ & 26.51 & 0.16 & $4.4 \%$ & 19.43 & 0.23 & $20.7 \%$ \\
\hline dez-06 & 27.64 & 0.12 & $2.4 \%$ & 0.83 & 0.16 & $11.7 \%$ & 7.64 & 0.13 & $3.1 \%$ & 0.79 & 0.18 & $14.6 \%$ & 27.64 & 0.15 & $4.0 \%$ & 20.69 & 0.21 & $8.6 \%$ \\
\hline mar-07 & 31.91 & 0.21 & $5.6 \%$ & 4.97 & 0.28 & $24.2 \%$ & 1.91 & 0.18 & $4.2 \%$ & 5.16 & 0.23 & $18.5 \%$ & 31.91 & 0.18 & $4.5 \%$ & 25.12 & 0.24 & $9.9 \%$ \\
\hline jun-07 & 33.13 & 0.16 & $3.1 \%$ & 27.23 & 0.20 & $13.8 \%$ & 33.13 & 0.20 & $4.5 \%$ & 27.15 & 0.25 & $19.2 \%$ & 33.13 & 0.19 & $4.1 \%$ & 27.18 & 0.23 & $17.6 \%$ \\
\hline set-07 & 38.02 & 0.22 & $4.6 \%$ & 2.46 & 0.26 & $19.0 \%$ & 8.02 & 0.20 & $4.0 \%$ & 32.49 & 0.24 & $16.6 \%$ & 38.02 & 0.21 & $4.3 \%$ & 32.48 & 0.25 & $17.9 \%$ \\
\hline dez-07 & 45.81 & 0.26 & $6.1 \%$ & 39.36 & 0.31 & $23.7 \%$ & 45.81 & 0.24 & $5.2 \%$ & 39.44 & 0.28 & $20.9 \%$ & 45.81 & 0.23 & $5.1 \%$ & 39.45 & 0.28 & $0.3 \%$ \\
\hline mar-08 & 49.78 & 0.37 & $9.8 \%$ & 43.45 & 0.44 & $35.1 \%$ & 49.78 & 0.33 & $8.1 \%$ & 43.71 & 0.38 & $29.8 \%$ & 49.78 & 0.28 & $6.2 \%$ & 43.90 & 0.33 & $23.9 \%$ \\
\hline jun-08 & 55.29 & 0.27 & $5.2 \%$ & 49.20 & 0.30 & $20.4 \%$ & 55.29 & 0.34 & $7.8 \%$ & 49.04 & 0.38 & $28.4 \%$ & 55.29 & 0.31 & $6.6 \%$ & 49.13 & 0.35 & $24.6 \%$ \\
\hline set-08 & 40.15 & 0.44 & $15.6 \%$ & 30.32 & 0.61 & $54.6 \%$ & 40.26 & 0.35 & $10.9 \%$ & 31.68 & 0.46 & $41.1 \%$ & 40.27 & 0.31 & $9.3 \%$ & 32.08 & 0.41 & $35.8 \%$ \\
\hline dez- 08 & 35.74 & 0.59 & $28.3 \%$ & 19.77 & 1.03 & $83.1 \%$ & 36.72 & 0.46 & $20.7 \%$ & 21.83 & 0.80 & $72.7 \%$ & 37.31 & 0.34 & $13.5 \%$ & 24.66 & 0.57 & $55.7 \%$ \\
\hline mar-09 & 42.09 & 0.31 & $10.5 \%$ & 31.92 & 0.44 & $42.9 \%$ & 41.41 & 0.50 & $21.2 \%$ & 27.08 & 0.79 & $71.3 \%$ & 41.90 & 0.39 & $15.1 \%$ & 29.74 & 0.60 & $57.3 \%$ \\
\hline jun-09 & 44.45 & 0.26 & $6.7 \%$ & 38.33 & 0.31 & $26.2 \%$ & 44.44 & 0.32 & $9.3 \%$ & 37.68 & 0.39 & $35.3 \%$ & 44.26 & 0.47 & $17.0 \%$ & 34.79 & 0.64 & $58.0 \%$ \\
\hline set-09 & 51.98 & 0.18 & $3.2 \%$ & 45.72 & 0.20 & $13.7 \%$ & 51.98 & 0.22 & $4.9 \%$ & 45.58 & 0.26 & $20.0 \%$ & 51.87 & 0.44 & $15.0 \%$ & 42.29 & 57 & $52.1 \%$ \\
\hline dez- 09 & 53.34 & 0.20 & $3.9 \%$ & 47.01 & 0.22 & $16.0 \%$ & 53.34 & 0.19 & $3.5 \%$ & 47.03 & 0.21 & $14.8 \%$ & 53.34 & 0.27 & $7.0 \%$ & 46.58 & 0.32 & $26.9 \%$ \\
\hline mar-10 & 63.80 & 0.18 & $3.0 \%$ & 56.97 & 0.20 & $12.7 \%$ & 63.80 & 0.20 & $3.5 \%$ & 56.95 & 0.22 & $14.7 \%$ & 63.80 & 0.22 & $4.5 \%$ & 56.89 & 0.25 & $18.1 \%$ \\
\hline jun-10 & 55.56 & 0.20 & $4.3 \%$ & 47.18 & 0.24 & $18.0 \%$ & 55.56 & 0.18 & $3.7 \%$ & 47.23 & 0.22 & $15.7 \%$ & 55.56 & 0.18 & $3.6 \%$ & 47.24 & 0.21 & $15.4 \%$ \\
\hline set-10 & 61.73 & 0.14 & $2.2 \%$ & 52.24 & 0.16 & $10.1 \%$ & 61.73 & 0.17 & $3.4 \%$ & 52.20 & 0.21 & $14.5 \%$ & 61.73 & 0.17 & $3.3 \%$ & 52.20 & 0.21 & $14.4 \%$ \\
\hline dez-10 & 58.14 & 0.13 & $2.0 \%$ & 48.79 & 0.15 & $9.2 \%$ & 58.14 & 0.13 & $2.1 \%$ & 48.79 & 0.16 & $9.7 \%$ & 58.14 & 0.16 & $2.9 \%$ & 48.77 & 0.19 & $12.7 \%$ \\
\hline mar-11 & 59.52 & 0.12 & $2.0 \%$ & 48.96 & 0.15 & $9.2 \%$ & 59.52 & 0.13 & $2.0 \%$ & 48.96 & 0.15 & $9.5 \%$ & 59.52 & 0.15 & $2.7 \%$ & 48.95 & 0.18 & $12.0 \%$ \\
\hline jun-11 & 51.69 & 0.09 & $1.2 \%$ & 40.90 & 0.11 & $6.0 \%$ & 51.69 & 0.10 & $1.5 \%$ & 40.90 & 0.13 & $7.5 \%$ & 51.69 & 0.11 & $1.8 \%$ & 40.90 & 0.14 & $8.7 \%$ \\
\hline set-11 & 50.67 & 0.19 & $6.3 \%$ & 36.69 & 0.29 & $30.2 \%$ & 50.70 & 0.14 & $3.8 \%$ & 37.97 & 0.20 & $18.4 \%$ & 50.70 & 0.12 & $2.8 \%$ & 38.26 & 0.16 & $13.4 \%$ \\
\hline dez-11 & 52.96 & 0.16 & $4.9 \%$ & 39.76 & 0.23 & $23.4 \%$ & 52.95 & 0.17 & $5.5 \%$ & 39.35 & 0.26 & $26.5 \%$ & 52.97 & 0.13 & $3.5 \%$ & 40.40 & 0.18 & $16.8 \%$ \\
\hline mar-12 & 57.00 & 0.10 & $2.1 \%$ & 45.61 & 0.13 & $10.2 \%$ & 56.99 & 0.14 & $3.7 \%$ & 45.24 & 0.19 & $17.0 \%$ & 56.99 & 0.15 & $3.8 \%$ & 45.18 & 0.19 & $17.7 \%$ \\
\hline jun-12 & 51.16 & 0.08 & $1.9 \%$ & 40.68 & 0.11 & $9.2 \%$ & 51.16 & 0.09 & $1.9 \%$ & 40.68 & 0.11 & $9.3 \%$ & 51.15 & 0.12 & $3.4 \%$ & 40.10 & 0.16 & $16.5 \%$ \\
\hline set-12 & 52.74 & 0.17 & $6.4 \%$ & 39.10 & 0.28 & $33.5 \%$ & 52.81 & 0.13 & $4.2 \%$ & 41.64 & 0.19 & $21.1 \%$ & 52.82 & 0.12 & $3.6 \%$ & 42.17 & 0.17 & $17.6 \%$ \\
\hline dez-12 & 53.24 & 0.14 & $4.2 \%$ & 42.82 & 0.19 & $20.6 \%$ & 53.22 & 0.15 & $5.1 \%$ & 41.93 & 0.23 & $25.6 \%$ & 53.25 & 0.12 & $3.6 \%$ & 43.32 & 0.17 & $17.1 \%$ \\
\hline mar-13 & 53.57 & 0.08 & $2.4 \%$ & & 0.12 & $11.9 \%$ & 53.57 & 0.09 & $2.8 \%$ & 42.52 & 0.14 & $14.6 \%$ & 53.57 & 0.10 & $3.1 \%$ & 42.30 & 0.14 & $16.0 \%$ \\
\hline jun-13 & 50.61 & 0.06 & $1.7 \%$ & 38.94 & 0.09 & $9.1 \%$ & 50.61 & 0.06 & $1.7 \%$ & 38.92 & 0.09 & $9.3 \%$ & 50.61 & 0.07 & $2.4 \%$ & 38.17 & 0.12 & $14.3 \%$ \\
\hline jun-05 & 10.73 & 0.10 & $2.5 \%$ & 6.41 & 0.17 & $15.0 \%$ & 10.73 & 0.11 & $3.4 \%$ & 6.35 & 0.21 & $19.9 \%$ & 10.73 & 0.10 & $2.7 \%$ & 6.41 & 0.17 & $15.6 \%$ \\
\hline set-05 & 11.48 & 0.09 & $2.1 \%$ & 7.04 & 0.15 & $12.4 \%$ & 11.48 & 0.10 & $2.4 \%$ & 7.03 & 0.16 & $13.8 \%$ & 11.48 & 0.11 & $2.9 \%$ & 7.01 & 0.18 & $16.3 \%$ \\
\hline dez-05 & 13.74 & 0.09 & $2.2 \%$ & 8.53 & 0.15 & $12.6 \%$ & 13.74 & 0.08 & $2.0 \%$ & 8.54 & 0.14 & $11.6 \%$ & 13.74 & 0.10 & $2.7 \%$ & 8.49 & 0.17 & $15.5 \%$ \\
\hline mar-06 & 13.28 & 0.12 & $3.3 \%$ & 8.68 & 0.19 & $17.7 \%$ & 13.28 & 0.11 & $2.9 \%$ & 8.71 & 0.17 & $15.7 \%$ & 13.28 & 0.10 & $2.6 \%$ & 8.73 & 0.16 & $14.2 \%$ \\
\hline jun-06 & 22.42 & 0.18 & $3.7 \%$ & 17.83 & 0.23 & $16.0 \%$ & 22.42 & 0.20 & $4.2 \%$ & 17.81 & 0.25 & $18.1 \%$ & 22.42 & 0.18 & $3.8 \%$ & 17.82 & 0.23 & $16.5 \%$ \\
\hline set-06 & 23.86 & 0.17 & $3.1 \%$ & & 0.21 & $13.9 \%$ & & 0.17 & $3.3 \%$ & 19.32 & 0.21 & $14.5 \%$ & 23.86 & 0.19 & $3.9 \%$ & 19.31 & 0.24 & $16.8 \%$ \\
\hline dez-06 & 23.66 & 0.15 & $2.3 \%$ & 19.69 & 0.18 & $10.5 \%$ & 23.66 & 0.16 & $2.7 \%$ & 19.69 & 0.19 & $12.1 \%$ & 23.66 & 0.19 & $3.5 \%$ & 19.68 & 0.22 & $15.2 \%$ \\
\hline
\end{tabular}




\begin{tabular}{|c|c|c|c|c|c|c|c|c|c|c|c|c|c|c|c|c|c|c|}
\hline mar-07 & 23.89 & 0.15 & $2.3 \%$ & 20.32 & 0.18 & $10.2 \%$ & 23.89 & 0.15 & $2.3 \%$ & 20.32 & 0.18 & $10.2 \%$ & 23.89 & 0.18 & $2.9 \%$ & 20.32 & 0.21 & $12.7 \%$ \\
\hline dez-07 & 22.18 & 0.17 & $3.0 \%$ & 18.89 & 0.20 & $13.0 \%$ & 22.18 & 0.20 & $4.1 \%$ & 18.87 & 0.24 & $17.2 \%$ & 22.18 & 0.17 & $3.0 \%$ & 18.89 & 0.20 & $12.9 \%$ \\
\hline jun-08 & 15.88 & 0.13 & $2.7 \%$ & 12.42 & 0.17 & $12.8 \%$ & 15.88 & 0.13 & $2.8 \%$ & 12.42 & 0.17 & $13.0 \%$ & 15.88 & 0.14 & $3.1 \%$ & 12.41 & 0.18 & $14.3 \%$ \\
\hline set-08 & 19.00 & 0.24 & $7.4 \%$ & 14.17 & 0.34 & $32.2 \%$ & 19.01 & 0.20 & $5.6 \%$ & 14.42 & 0.28 & $24.6 \%$ & 19.01 & 0.17 & $4.1 \%$ & 14.55 & 0.23 & $18.7 \%$ \\
\hline dez-08 & 19.01 & 0.25 & $11.0 \%$ & 10.89 & 0.51 & $55.7 \%$ & 19.10 & 0.21 & $8.3 \%$ & 11.88 & 0.40 & $43.8 \%$ & 19.15 & 0.16 & $5.3 \%$ & 12.89 & 0.27 & $28.3 \%$ \\
\hline set-09 & 16.90 & 0.15 & $3.8 \%$ & 13.81 & 0.19 & $16.9 \%$ & 16.90 & 0.18 & $5.4 \%$ & 13.60 & 0.25 & $24.1 \%$ & 16.88 & 0.25 & $8.8 \%$ & 12.82 & 0.37 & $39.2 \%$ \\
\hline dez-09 & 16.26 & 0.14 & $3.6 \%$ & 13.30 & 0.18 & $16.2 \%$ & 16.26 & 0.15 & $3.7 \%$ & 13.29 & 0.19 & $16.5 \%$ & 16.26 & 0.20 & $6.2 \%$ & 12.91 & 0.28 & $27.9 \%$ \\
\hline mar-10 & 16.87 & 0.11 & $1.9 \%$ & 14.01 & 0.13 & $8.9 \%$ & 16.87 & 0.13 & $2.9 \%$ & 13.97 & 0.16 & $13.2 \%$ & 16.87 & 0.17 & $4.7 \%$ & 13.83 & 0.22 & $20.5 \%$ \\
\hline jun-10 & 15.28 & 0.10 & $1.7 \%$ & 12.29 & 0.12 & $8.1 \%$ & 15.28 & 0.10 & $1.8 \%$ & 12.29 & 0.13 & $8.7 \%$ & 15.28 & 0.13 & $2.8 \%$ & 12.26 & 0.16 & $13.1 \%$ \\
\hline set- 10 & 16.57 & 0.16 & $3.4 \%$ & 13.59 & 0.20 & $15.0 \%$ & 16.57 & 0.14 & $2.7 \%$ & 13.61 & 0.17 & $12.2 \%$ & 16.57 & 0.15 & $3.0 \%$ & 13.60 & 0.18 & $13.2 \%$ \\
\hline dez-10 & 16.04 & 0.12 & $1.9 \%$ & 13.31 & 0.14 & $8.9 \%$ & 16.04 & 0.15 & $2.8 \%$ & 13.30 & 0.18 & $12.3 \%$ & 16.04 & 0.14 & $2.4 \%$ & 13.30 & 0.16 & $10.9 \%$ \\
\hline jun-12 & 21.37 & 0.12 & $2.3 \%$ & 17.98 & 0.14 & $10.4 \%$ & 21.37 & 0.12 & $2.3 \%$ & 17.98 & 0.14 & $10.4 \%$ & 21.37 & 0.17 & $4.0 \%$ & 17.88 & 0.20 & $17.5 \%$ \\
\hline set-12 & 21.44 & 0.15 & $3.4 \%$ & 18.39 & 0.18 & $14.6 \%$ & 21.44 & 0.14 & $2.8 \%$ & 18.42 & 0.16 & $12.5 \%$ & 21.44 & 0.14 & $3.0 \%$ & 18.42 & 0.17 & $13.1 \%$ \\
\hline dez-12 & 22.11 & 0.15 & $3.1 \%$ & 19.25 & 0.17 & $13.6 \%$ & 22.11 & 0.15 & $3.3 \%$ & 19.24 & 0.18 & $14.1 \%$ & 22.11 & 0.14 & $2.9 \%$ & 19.26 & 0.16 & $12.4 \%$ \\
\hline mar-13 & 25.72 & 0.14 & $2.6 \%$ & 22.59 & 0.16 & $11.4 \%$ & 25.72 & 0.15 & $3.0 \%$ & 22.58 & 0.17 & $12.8 \%$ & 25.72 & 0.15 & $3.0 \%$ & 22.58 & 0.18 & $13.1 \%$ \\
\hline jun-13 & 28.34 & 0.20 & $4.5 \%$ & 24.66 & 0.23 & $18.7 \%$ & 28.34 & 0.17 & $3.6 \%$ & 24.73 & 0.20 & $15.2 \%$ & 28.34 & 0.17 & $3.6 \%$ & 24.73 & 0.20 & $15.2 \%$ \\
\hline jun-05 & 2.19 & 0.11 & $2.7 \%$ & 1.39 & 0.18 & $14.6 \%$ & 2.19 & 0.12 & $3.1 \%$ & 1.38 & 0.20 & $16.6 \%$ & 2.19 & 0.11 & $2.6 \%$ & 1.39 & 0.18 & $14.3 \%$ \\
\hline set-05 & 2.33 & 0.08 & $1.4 \%$ & 1.52 & 0.13 & $8.0 \%$ & 2.33 & 0.11 & $2.4 \%$ & 1.52 & 0.17 & $12.6 \%$ & 2.33 & 0.11 & $2.6 \%$ & 1.52 & 0.18 & $13.7 \%$ \\
\hline dez-05 & 2.67 & 0.12 & $2.8 \%$ & 1.77 & 0.18 & $14.6 \%$ & 2.67 & 0.11 & $2.3 \%$ & 1.78 & 0.16 & $12.3 \%$ & 2.67 & 0.12 & $2.8 \%$ & 1.77 & 0.18 & $14.5 \%$ \\
\hline mar-06 & 2.80 & 0.16 & $4.2 \%$ & 1.96 & 0.24 & $20.5 \%$ & 2.80 & 0.15 & $3.6 \%$ & 1.97 & 0.21 & $17.7 \%$ & 2.80 & 0.13 & $3.1 \%$ & 1.97 & 0.19 & $15.2 \%$ \\
\hline jun-06 & 2.53 & 0.14 & $3.5 \%$ & 1.83 & 0.20 & $17.0 \%$ & 2.53 & 0.15 & $3.9 \%$ & 1.83 & 0.22 & $18.7 \%$ & 2.53 & 0.14 & $3.2 \%$ & 1.83 & 0.19 & $15.6 \%$ \\
\hline set-06 & 2.77 & 0.13 & $2.8 \%$ & 2.08 & 0.18 & $13.3 \%$ & 2.77 & 0.14 & $3.3 \%$ & 2.08 & 0.19 & $15.3 \%$ & 2.77 & 0.15 & $3.6 \%$ & 2.08 & 0.21 & $16.6 \%$ \\
\hline dez-06 & 3.00 & 0.11 & $1.8 \%$ & 2.31 & 0.14 & $8.8 \%$ & 3.00 & 0.12 & $2.2 \%$ & 2.31 & 0.15 & $10.4 \%$ & 3.00 & 0.15 & $3.2 \%$ & 2.31 & 0.19 & $14.9 \%$ \\
\hline
\end{tabular}




\begin{tabular}{|c|c|c|c|c|c|c|c|c|c|c|c|c|c|c|c|c|c|c|}
\hline dez- 08 & 3.33 & 0.30 & $10.4 \%$ & 2.44 & 0.45 & $42.5 \%$ & 3.33 & 0.24 & $7.0 \%$ & 2.54 & 0.33 & $29.8 \%$ & 3.33 & 0.20 & $5.0 \%$ & 2.58 & 0.26 & $22.0 \%$ \\
\hline mar-09 & 3.46 & 0.18 & $3.7 \%$ & 2.88 & 0.22 & $15.8 \%$ & 3.46 & 0.28 & $7.8 \%$ & 2.83 & 0.35 & $31.0 \%$ & 3.46 & 0.22 & $5.5 \%$ & 2.87 & 0.28 & $22.7 \%$ \\
\hline jun-09 & 3.76 & 0.19 & $3.4 \%$ & 3.32 & 0.21 & $14.5 \%$ & 3.76 & 0.19 & $3.6 \%$ & 3.32 & 0.22 & $15.1 \%$ & 3.76 & 0.26 & $6.0 \%$ & 3.30 & 0.30 & $23.4 \%$ \\
\hline set-09 & 3.82 & 0.11 & $1.2 \%$ & 3.38 & 0.12 & $5.8 \%$ & 3.82 & 0.15 & $2.3 \%$ & 3.38 & 0.17 & $10.0 \%$ & 3.82 & 0.24 & $5.5 \%$ & 3.36 & 0.28 & $21.7 \%$ \\
\hline dez-09 & 4.00 & 0.10 & $1.1 \%$ & 3.54 & 0.12 & $5.4 \%$ & 4.00 & 0.11 & $1.2 \%$ & 3.54 & 0.12 & $5.5 \%$ & 4.00 & 0.15 & $2.5 \%$ & 3.54 & 0.18 & $10.8 \%$ \\
\hline mar-10 & 4.24 & 0.11 & $1.5 \%$ & 3.68 & 0.13 & $7.0 \%$ & 4.24 & 0.09 & $1.1 \%$ & 3.68 & 0.11 & $5.1 \%$ & 4.24 & 0.12 & $1.7 \%$ & 3.68 & 0.14 & $7.9 \%$ \\
\hline jun-10 & 4.54 & 0.11 & $1.3 \%$ & 3.90 & 0.13 & $6.2 \%$ & 4.54 & 0.11 & $1.4 \%$ & 3.90 & 0.13 & $6.5 \%$ & 4.54 & 0.10 & $1.2 \%$ & 3.90 & 0.12 & $5.6 \%$ \\
\hline set-10 & 4.95 & 0.12 & $1.7 \%$ & 4.24 & 0.15 & $7.8 \%$ & 4.95 & 0.12 & $1.4 \%$ & 4.24 & 0.13 & $6.8 \%$ & 4.95 & 0.11 & $1.3 \%$ & 4.24 & 0.13 & $6.0 \%$ \\
\hline dez-10 & 5.19 & 0.13 & $1.7 \%$ & 4.49 & 0.15 & $7.9 \%$ & 5.19 & 0.13 & $1.7 \%$ & 4.49 & 0.15 & $7.6 \%$ & 5.19 & 0.12 & $1.5 \%$ & 4.49 & 0.14 & $7.1 \%$ \\
\hline mar-11 & 5.08 & 0.12 & $1.3 \%$ & 4.41 & 0.14 & $6.0 \%$ & 5.08 & 0.12 & $1.4 \%$ & 4.41 & 0.14 & $6.6 \%$ & 5.08 & 0.13 & $1.5 \%$ & 4.41 & 0.14 & $6.7 \%$ \\
\hline jun-11 & 5.31 & 0.11 & $1.1 \%$ & 4.62 & 0.13 & $5.3 \%$ & 5.31 & 0.12 & $1.2 \%$ & 4.62 & 0.13 & $5.6 \%$ & 5.31 & 0.13 & $1.4 \%$ & 4.62 & 0.14 & $6.5 \%$ \\
\hline set-11 & 5.27 & 0.15 & $2.2 \%$ & 4.54 & 0.18 & $9.9 \%$ & 5.27 & 0.13 & $1.7 \%$ & 4.54 & 0.15 & $7.7 \%$ & 5.27 & 0.13 & $1.6 \%$ & 4.54 & 0.15 & $7.2 \%$ \\
\hline dez-11 & 5.89 & 0.10 & $0.9 \%$ & 5.20 & 0.12 & $4.4 \%$ & 5.89 & 0.14 & $1.6 \%$ & 5.20 & 0.16 & $7.4 \%$ & 5.89 & 0.13 & $1.4 \%$ & 5.20 & 0.14 & $6.5 \%$ \\
\hline mar-12 & 5.84 & 0.12 & $1.2 \%$ & 5.28 & 0.13 & $5.4 \%$ & 5.84 & 0.11 & $1.1 \%$ & 5.28 & 0.13 & $5.0 \%$ & 5.84 & 0.13 & $1.4 \%$ & 5.28 & 0.15 & $6.4 \%$ \\
\hline jun-12 & 6.26 & 0.17 & $2.2 \%$ & 5.73 & 0.18 & $9.7 \%$ & 6.26 & 0.15 & $1.7 \%$ & 5.73 & 0.16 & $7.5 \%$ & 6.26 & 0.15 & $1.7 \%$ & 5.73 & 0.16 & $7.5 \%$ \\
\hline set-12 & 5.61 & 0.28 & $6.4 \%$ & 5.07 & 0.31 & $24.5 \%$ & 5.61 & 0.22 & $4.4 \%$ & 5.09 & 0.25 & $17.7 \%$ & 5.61 & 0.18 & $2.8 \%$ & 5.10 & 0.19 & $12.0 \%$ \\
\hline dez-12 & 5.86 & 0.21 & $3.6 \%$ & 5.37 & 0.23 & $15.0 \%$ & 5.86 & 0.25 & $5.1 \%$ & 5.36 & 0.27 & $20.0 \%$ & 5.86 & 0.20 & $3.4 \%$ & 5.37 & 0.22 & $14.1 \%$ \\
\hline mar-13 & 5.54 & 0.19 & $3.5 \%$ & 4.99 & 0.21 & $14.5 \%$ & 5.54 & 0.18 & $3.4 \%$ & 4.99 & 0.20 & $14.1 \%$ & 5.54 & 0.19 & $3.8 \%$ & 4.98 & 0.22 & $15.6 \%$ \\
\hline jun-13 & 5.58 & 0.16 & $2.2 \%$ & 5.06 & 0.17 & $9.7 \%$ & 5.58 & 0.18 & $2.9 \%$ & 5.06 & 0.20 & $12.4 \%$ & 5.58 & 0.21 & $3.9 \%$ & 5.06 & 0.24 & $16.1 \%$ \\
\hline jun-05 & 9.69 & 0.08 & $2.6 \%$ & 5.21 & 0.17 & $18.1 \%$ & 9.69 & 0.07 & $2.3 \%$ & 5.25 & 0.15 & $15.7 \%$ & 9.69 & 0.07 & $2.0 \%$ & 5.29 & 0.14 & $13.5 \%$ \\
\hline set-05 & 11.70 & 0.09 & $2.7 \%$ & 6.68 & 0.17 & $17.0 \%$ & 11.70 & 0.10 & $3.0 \%$ & 6.64 & 0.19 & $19.2 \%$ & 11.70 & 0.09 & $2.7 \%$ & 6.68 & 0.17 & $16.9 \%$ \\
\hline dez-05 & 12.93 & 0.08 & $1.9 \%$ & 7.87 & 0.13 & $11.5 \%$ & 12.93 & 0.09 & $2.4 \%$ & 7.83 & 0.15 & $14.4 \%$ & 12.93 & 0.09 & $2.7 \%$ & 7.80 & 0.17 & $16.3 \%$ \\
\hline mar-06 & 14.24 & 0.10 & $2.5 \%$ & 9.18 & 0.16 & $14.2 \%$ & 14.24 & 0.09 & $2.3 \%$ & 9.20 & 0.15 & $13.0 \%$ & 14.24 & 0.11 & $2.9 \%$ & 9.14 & 0.18 & $16.5 \%$ \\
\hline jun-06 & 17.31 & 0.14 & $4.0 \%$ & 11.97 & 0.22 & $20.1 \%$ & 17.31 & 0.13 & $3.5 \%$ & 12.02 & 0.20 & $17.8 \%$ & 17.31 & 0.13 & $3.4 \%$ & 12.03 & 0.19 & $17.0 \%$ \\
\hline set-06 & 17.06 & 0.11 & $2.6 \%$ & 11.95 & 0.16 & $13.4 \%$ & 17.06 & 0.12 & $3.2 \%$ & 11.89 & 0.18 & $16.3 \%$ & 17.06 & 0.11 & $2.9 \%$ & 11.92 & 0.17 & $15.0 \%$ \\
\hline dez-06 & 18.94 & 0.09 & $1.6 \%$ & 13.83 & 0.12 & $8.3 \%$ & 18.94 & 0.10 & $2.3 \%$ & 13.81 & 0.15 & $11.7 \%$ & 18.94 & 0.12 & $2.9 \%$ & 13.77 & 0.17 & $14.3 \%$ \\
\hline mar-07 & 19.25 & 0.15 & $4.1 \%$ & 14.24 & 0.21 & $19.6 \%$ & 19.25 & 0.12 & $2.9 \%$ & 14.36 & 0.17 & $14.2 \%$ & 19.25 & 0.13 & $3.3 \%$ & 14.33 & 0.18 & $15.7 \%$ \\
\hline jun-07 & 21.56 & 0.13 & $2.6 \%$ & 16.92 & 0.17 & $12.3 \%$ & 21.56 & 0.15 & $3.6 \%$ & 16.87 & 0.20 & $16.4 \%$ & 21.56 & 0.14 & $3.2 \%$ & 16.90 & 0.18 & $14.6 \%$ \\
\hline set-07 & 31.13 & 0.10 & $2.5 \%$ & 23.10 & 0.14 & $12.5 \%$ & 31.13 & 0.09 & $2.2 \%$ & 23.14 & 0.13 & $11.3 \%$ & 31.13 & 0.10 & $2.3 \%$ & 23.12 & 0.13 & $11.7 \%$ \\
\hline dez-07 & 32.19 & 0.12 & $3.1 \%$ & 23.97 & 0.17 & $15.4 \%$ & 32.19 & 0.11 & $2.8 \%$ & 24.03 & 0.16 & $14.1 \%$ & 32.19 & 0.11 & $2.8 \%$ & 24.03 & 0.15 & $13.9 \%$ \\
\hline mar-08 & 32.71 & 0.15 & $4.8 \%$ & 23.90 & 0.23 & $24.1 \%$ & 32.71 & 0.14 & $4.0 \%$ & 24.23 & 0.20 & $19.7 \%$ & 32.72 & 0.12 & $3.2 \%$ & 24.45 & 0.17 & $15.9 \%$ \\
\hline jun- 08 & 55.44 & 0.26 & $6.7 \%$ & 46.02 & 0.32 & $26.6 \%$ & 55.44 & 0.27 & $7.2 \%$ & 45.93 & 0.34 & $28.1 \%$ & 55.44 & 0.24 & $5.8 \%$ & 46.18 & 0.29 & $23.3 \%$ \\
\hline set-08 & 44.40 & 0.29 & $11.2 \%$ & 29.78 & 0.48 & $49.0 \%$ & 44.51 & 0.25 & $8.6 \%$ & 31.25 & 0.39 & $38.9 \%$ & 44.55 & 0.21 & $6.8 \%$ & 32.16 & 0.32 & $31.1 \%$ \\
\hline dez- 08 & 41.12 & 0.38 & $19.0 \%$ & 19.44 & 0.82 & $77.0 \%$ & 41.88 & 0.30 & $13.9 \%$ & 22.20 & 0.63 & $65.3 \%$ & 42.34 & 0.23 & $9.2 \%$ & 25.68 & 0.44 & $48.1 \%$ \\
\hline mar-09 & 39.26 & 0.18 & $6.7 \%$ & 26.34 & 0.32 & $36.5 \%$ & 38.76 & 0.28 & $12.8 \%$ & 21.01 & 0.59 & $63.8 \%$ & 39.11 & 0.22 & $9.3 \%$ & 23.98 & 0.43 & $49.7 \%$ \\
\hline jun-09 & 42.19 & 0.22 & $7.0 \%$ & 33.36 & 0.31 & $30.9 \%$ & 42.18 & 0.24 & $7.9 \%$ & 32.87 & 0.34 & $34.8 \%$ & 42.00 & 0.32 & $12.6 \%$ & 29.92 & 0.51 & $52.8 \%$ \\
\hline set-09 & 42.27 & 0.16 & $3.6 \%$ & 35.77 & 0.20 & $15.6 \%$ & 42.27 & 0.21 & $5.5 \%$ & 35.42 & 0.26 & $23.2 \%$ & 42.16 & 0.34 & $12.2 \%$ & 32.58 & 0.49 & $48.0 \%$ \\
\hline dez-09 & 45.92 & 0.24 & $5.9 \%$ & 39.55 & 0.28 & $23.7 \%$ & 45.92 & 0.21 & $4.9 \%$ & 39.72 & 0.25 & $20.1 \%$ & 45.92 & 0.27 & $7.4 \%$ & 39.19 & 0.33 & $29.2 \%$ \\
\hline mar-10 & 46.03 & 0.16 & $3.1 \%$ & 39.85 & 0.19 & $13.3 \%$ & 46.03 & 0.20 & $4.6 \%$ & 39.72 & 0.24 & $18.9 \%$ & 46.03 & 0.23 & $5.7 \%$ & 39.55 & 0.27 & $22.9 \%$ \\
\hline jun-10 & 41.34 & 0.18 & $4.3 \%$ & 34.23 & 0.23 & $18.3 \%$ & 41.34 & 0.17 & $3.6 \%$ & 34.30 & 0.20 & $15.7 \%$ & 41.34 & 0.18 & $4.2 \%$ & 34.23 & 0.22 & $18.1 \%$ \\
\hline
\end{tabular}




\begin{tabular}{|c|c|c|c|c|c|c|c|c|c|c|c|c|c|c|c|c|c|c|}
\hline set-10 & 40.07 & 0.14 & $2.8 \%$ & 33.03 & 0.18 & $12.6 \%$ & 40.07 & 0.16 & $3.5 \%$ & 32.98 & 0.20 & $15.5 \%$ & 40.07 & 0.17 & $3.9 \%$ & 32.95 & 0.22 & $17.1 \%$ \\
\hline jun-11 & 35.84 & 0.13 & $2.2 \%$ & 28.83 & 0.16 & $10.1 \%$ & 35.84 & 0.14 & $2.7 \%$ & 28.82 & 0.18 & $12.4 \%$ & 35.84 & 0.15 & $3.0 \%$ & 28.81 & 0.19 & $13.6 \%$ \\
\hline dez-11 & 36.98 & 0.18 & $4.6 \%$ & 29.25 & 0.23 & $20.4 \%$ & 36.98 & 0.20 & $5.7 \%$ & 28.99 & 0.27 & $24.9 \%$ & 36.98 & 0.16 & $4.1 \%$ & 29.34 & 0.21 & $18.5 \%$ \\
\hline mar-12 & 40.04 & 0.15 & $3.2 \%$ & 33.39 & 0.18 & $14.0 \%$ & 40.04 & 0.18 & $4.1 \%$ & 33.29 & 0.22 & $17.7 \%$ & 40.04 & 0.18 & $4.5 \%$ & 33.24 & 0.23 & $19.1 \%$ \\
\hline jun-12 & 42.49 & 0.18 & $4.5 \%$ & 35.66 & 0.22 & $19.3 \%$ & 42.49 & 0.16 & $3.8 \%$ & 35.79 & 0.20 & $16.6 \%$ & 42.49 & 0.19 & $4.9 \%$ & 35.58 & 0.24 & $20.8 \%$ \\
\hline set-12 & 44.33 & 0.17 & $3.9 \%$ & 38.31 & 0.20 & $16.6 \%$ & 44.33 & 0.18 & $4.3 \%$ & 38.25 & 0.21 & $18.0 \%$ & 44.33 & 0.18 & $4.2 \%$ & 38.27 & 0.21 & $17.6 \%$ \\
\hline mar-13 & 39.10 & 0.13 & $2.7 \%$ & 33.72 & 0.15 & $11.7 \%$ & 39.10 & 0.13 & $2.5 \%$ & 33.73 & 0.15 & $11.3 \%$ & 39.10 & 0.15 & $3.3 \%$ & 33.65 & 0.18 & $14.5 \%$ \\
\hline jun-13 & 36.84 & 0.14 & $3.4 \%$ & 30.59 & 0.17 & $15.1 \%$ & 36.84 & 0.12 & $2.9 \%$ & 30.67 & 0.15 & $12.9 \%$ & 36.84 & 0.13 & $3.0 \%$ & 30.66 & 0.16 & $13.3 \%$ \\
\hline jun-05 & 8.48 & 0.03 & $1.1 \%$ & 4.09 & 0.08 & $10.4 \%$ & 8.48 & 0.03 & $0.9 \%$ & 4.13 & 0.07 & $8.6 \%$ & 8.48 & 0.03 & $0.8 \%$ & 4.16 & 0.06 & $6.7 \%$ \\
\hline set- 05 & 9.86 & 0.04 & $1.3 \%$ & 4.90 & 0.10 & $11.4 \%$ & 9.86 & 0.04 & $1.4 \%$ & 4.88 & 0.10 & $12.1 \%$ & 9.86 & 0.04 & $1.1 \%$ & 4.93 & 0.08 & $9.6 \%$ \\
\hline dez-05 & 10.73 & 0.03 & $1.0 \%$ & 5.71 & 0.07 & $7.6 \%$ & 10.73 & 0.04 & $1.2 \%$ & 5.68 & 0.08 & $9.4 \%$ & 10.73 & 0.04 & $1.2 \%$ & 5.67 & 0.09 & $9.8 \%$ \\
\hline mar-06 & 11.45 & 0.04 & $1.2 \%$ & 6.48 & 0.08 & $8.4 \%$ & 11.45 & 0.04 & $1.1 \%$ & 6.48 & 0.08 & $8.1 \%$ & 11.45 & 0.05 & $1.4 \%$ & 6.43 & 0.09 & $10.5 \%$ \\
\hline set-07 & 25.32 & 0.05 & $1.5 \%$ & 17.17 & 0.08 & $9.3 \%$ & 25.32 & 0.04 & $1.2 \%$ & 17.26 & 0.07 & $7.6 \%$ & 25.32 & 0.04 & $1.2 \%$ & 17.28 & 0.07 & $7.2 \%$ \\
\hline dez-07 & 26.07 & 0.05 & $1.6 \%$ & 17.83 & 0.09 & $9.8 \%$ & 26.07 & 0.06 & $1.6 \%$ & 17.82 & 0.09 & $10.0 \%$ & 26.07 & 0.05 & $1.6 \%$ & 17.85 & 0.09 & $9.5 \%$ \\
\hline mar-08 & 26.27 & 0.08 & $2.8 \%$ & 17.23 & 0.15 & $19.4 \%$ & 26.27 & 0.07 & $2.2 \%$ & 17.69 & 0.12 & $14.3 \%$ & 26.28 & 0.06 & $1.8 \%$ & 17.91 & 0.10 & $11.4 \%$ \\
\hline jun-08 & 37.66 & 0.15 & $4.6 \%$ & 27.19 & 0.23 & $23.1 \%$ & 37.65 & 0.16 & $5.2 \%$ & 26.93 & 0.25 & $26.0 \%$ & 37.66 & 0.14 & $4.2 \%$ & 27.35 & 0.21 & $21.1 \%$ \\
\hline set-08 & 35.54 & 0.16 & $6.9 \%$ & 19.10 & 0.38 & $46.6 \%$ & 35.65 & 0.13 & $5.1 \%$ & 21.07 & 0.28 & $34.2 \%$ & 35.69 & 0.11 & $4.0 \%$ & 22.14 & 0.22 & $26.3 \%$ \\
\hline dez-08 & 35.12 & 0.19 & $10.9 \%$ & 11.10 & 0.68 & $76.5 \%$ & 35.65 & 0.15 & $7.6 \%$ & 14.25 & 0.49 & $62.2 \%$ & 35.97 & 0.11 & $4.9 \%$ & 18.28 & 0.30 & $41.7 \%$ \\
\hline mar-09 & 33.89 & 0.08 & $3.2 \%$ & 20.70 & 0.19 & $26.4 \%$ & 33.57 & 0.13 & $6.6 \%$ & 14.62 & 0.43 & $58.3 \%$ & 33.79 & 0.10 & $4.7 \%$ & 18.04 & 0.29 & $41.4 \%$ \\
\hline jun-09 & 32.60 & 0.10 & $3.6 \%$ & 23.34 & 0.18 & $21.6 \%$ & 32.58 & 0.11 & $4.2 \%$ & 22.77 & 0.21 & $25.8 \%$ & 32.42 & 0.16 & $7.1 \%$ & 19.20 & 0.36 & $47.0 \%$ \\
\hline set-09 & 30.89 & 0.08 & $2.2 \%$ & 23.81 & 0.12 & $11.2 \%$ & 30.88 & 0.10 & $3.1 \%$ & 23.45 & 0.15 & $16.4 \%$ & 30.76 & 0.17 & $7.1 \%$ & 20.08 & 0.34 & $42.2 \%$ \\
\hline dez-09 & 31.03 & 0.12 & $3.8 \%$ & 23.91 & 0.18 & $19.2 \%$ & 31.03 & 0.11 & $3.2 \%$ & 24.17 & 0.16 & $15.8 \%$ & 31.02 & 0.14 & $4.5 \%$ & 23.53 & 0.21 & $23.3 \%$ \\
\hline mar-10 & 31.80 & 0.09 & $2.2 \%$ & 25.06 & 0.12 & $10.5 \%$ & 31.80 & 0.11 & $3.1 \%$ & 24.84 & 0.15 & $15.1 \%$ & 31.80 & 0.12 & $3.6 \%$ & 24.65 & 0.17 & $17.9 \%$ \\
\hline jun-10 & 29.87 & 0.09 & $2.6 \%$ & 22.08 & 0.14 & $13.5 \%$ & 29.87 & 0.09 & $2.2 \%$ & 22.18 & 0.12 & $11.6 \%$ & 29.87 & 0.09 & $2.6 \%$ & 22.08 & 0.14 & $13.5 \%$ \\
\hline
\end{tabular}




\begin{tabular}{|c|c|c|c|c|c|c|c|c|c|c|c|c|c|c|c|c|c|c|}
\hline jun-12 & 30.78 & 0.08 & $2.4 \%$ & 23.22 & 0.12 & $13.0 \%$ & 30.78 & 0.07 & $2.1 \%$ & 23.36 & 0.11 & $11.1 \%$ & 30.78 & 0.08 & $2.4 \%$ & 23.21 & 0.12 & $13.1 \%$ \\
\hline set-12 & 31.52 & 0.08 & $2.1 \%$ & 24.85 & 0.11 & $10.9 \%$ & 31.52 & 0.08 & $2.3 \%$ & 24.76 & 0.11 & $12.1 \%$ & 31.52 & 0.08 & $2.3 \%$ & 24.76 & 0.11 & $12.0 \%$ \\
\hline dez-12 & 30.85 & 0.06 & $1.5 \%$ & 24.77 & 0.08 & $7.4 \%$ & 30.85 & 0.07 & $1.9 \%$ & 24.66 & 0.09 & $9.5 \%$ & 30.85 & 0.07 & $1.9 \%$ & 24.64 & 0.10 & $9.8 \%$ \\
\hline mar-13 & 29.06 & 0.05 & $1.2 \%$ & 23.15 & 0.07 & $6.0 \%$ & 29.06 & 0.05 & $1.2 \%$ & 23.14 & 0.07 & $6.3 \%$ & 29.06 & 0.06 & $1.7 \%$ & 23.03 & 0.08 & $8.6 \%$ \\
\hline jun-13 & 29.10 & 0.05 & $1.3 \%$ & 22.35 & 0.07 & $7.1 \%$ & 29.10 & 0.05 & $1.2 \%$ & 22.40 & 0.06 & $6.1 \%$ & 29.10 & 0.05 & $1.3 \%$ & 22.35 & 0.07 & $7.1 \%$ \\
\hline jun-05 & 3.10 & 0.36 & $5.7 \%$ & 2.89 & 0.38 & $20.5 \%$ & 3.10 & 0.39 & $6.6 \%$ & 2.89 & 0.42 & $23.4 \%$ & 3.10 & 0.34 & $5.1 \%$ & 2.89 & 0.36 & $18.7 \%$ \\
\hline set- 05 & 3.18 & 0.34 & $5.1 \%$ & 2.99 & 0.37 & $18.6 \%$ & 3.18 & 0.35 & $5.2 \%$ & 2.99 & 0.37 & $19.0 \%$ & 3.18 & 0.36 & $5.6 \%$ & 2.99 & 0.39 & $20.3 \%$ \\
\hline dez-05 & 5.78 & 0.37 & $5.4 \%$ & 5.49 & 0.39 & $19.9 \%$ & 5.78 & 0.36 & $5.3 \%$ & 5.49 & 0.38 & $19.4 \%$ & 5.78 & 0.38 & $5.9 \%$ & 5.49 & 0.41 & $21.3 \%$ \\
\hline mar-06 & 5.22 & 0.44 & $8.0 \%$ & 4.92 & 0.46 & $27.7 \%$ & 5.22 & 0.41 & $7.0 \%$ & 4.92 & 0.43 & $24.9 \%$ & 5.22 & 0.38 & $6.2 \%$ & 4.92 & 0.40 & $22.5 \%$ \\
\hline jun-06 & 7.16 & 0.49 & $10.4 \%$ & 6.68 & 0.52 & $34.6 \%$ & 7.16 & 0.46 & $9.3 \%$ & 6.68 & 0.49 & $31.5 \%$ & 7.16 & 0.40 & $7.5 \%$ & 6.69 & 0.43 & $26.5 \%$ \\
\hline set- 06 & 7.52 & 0.35 & $6.5 \%$ & 6.91 & 0.38 & $23.7 \%$ & 7.52 & 0.41 & $8.6 \%$ & 6.90 & 0.45 & $30.0 \%$ & 7.52 & 0.39 & $8.0 \%$ & 6.90 & 0.43 & $28.2 \%$ \\
\hline dez-06 & 6.70 & 0.31 & $5.8 \%$ & 6.08 & 0.34 & $22.0 \%$ & 6.70 & 0.32 & $6.2 \%$ & 6.08 & 0.36 & $23.2 \%$ & 6.70 & 0.37 & $8.0 \%$ & 6.07 & 0.41 & $28.6 \%$ \\
\hline mar-07 & 7.02 & 0.28 & $5.3 \%$ & 6.29 & 0.32 & $20.5 \%$ & 7.02 & 0.29 & $5.7 \%$ & 6.29 & 0.33 & $21.6 \%$ & 7.02 & 0.33 & $7.2 \%$ & 6.28 & 0.38 & $26.5 \%$ \\
\hline jun-07 & 8.06 & 0.18 & $2.5 \%$ & 7.16 & 0.20 & $10.6 \%$ & 8.06 & 0.22 & $3.8 \%$ & 7.16 & 0.25 & $15.7 \%$ & 8.06 & 0.26 & $5.0 \%$ & 7.15 & 0.29 & $19.7 \%$ \\
\hline set-07 & 6.56 & 0.28 & $7.0 \%$ & 5.59 & 0.33 & $27.0 \%$ & 6.56 & 0.23 & $4.8 \%$ & 5.62 & 0.27 & $19.6 \%$ & 6.56 & 0.23 & $5.1 \%$ & 5.62 & 0.27 & $20.5 \%$ \\
\hline dez-07 & 6.95 & 0.27 & $7.0 \%$ & 5.81 & 0.33 & $27.5 \%$ & 6.95 & 0.26 & $6.6 \%$ & 5.82 & 0.32 & $26.3 \%$ & 6.95 & 0.23 & $5.3 \%$ & 5.85 & 0.27 & $21.4 \%$ \\
\hline mar-08 & 4.78 & 0.26 & $8.0 \%$ & 3.78 & 0.36 & $33.1 \%$ & 4.78 & 0.25 & $7.3 \%$ & 3.81 & 0.33 & $30.2 \%$ & 4.78 & 0.22 & $6.0 \%$ & 3.85 & 0.29 & $25.2 \%$ \\
\hline jun-08 & 4.03 & 0.20 & $6.0 \%$ & 3.01 & 0.29 & $27.6 \%$ & 4.03 & 0.20 & $6.3 \%$ & 3.00 & 0.30 & $28.8 \%$ & 4.03 & 0.19 & $5.8 \%$ & 3.02 & 0.27 & $26.3 \%$ \\
\hline set-08 & 3.69 & 0.27 & $12.6 \%$ & 1.95 & 0.59 & $62.8 \%$ & 3.72 & 0.21 & $8.4 \%$ & 2.25 & 0.41 & $45.8 \%$ & 3.73 & 0.18 & $6.7 \%$ & 2.38 & 0.33 & $36.6 \%$ \\
\hline dez-08 & 5.32 & 0.31 & $19.2 \%$ & 1.39 & 1.01 & $88.9 \%$ & 5.53 & 0.22 & $12.9 \%$ & 1.77 & 0.75 & $79.2 \%$ & 5.67 & 0.15 & $7.4 \%$ & 2.52 & 0.45 & $57.2 \%$ \\
\hline mar-09 & 5.20 & 0.06 & $2.5 \%$ & 3.31 & 0.14 & $19.6 \%$ & 5.11 & 0.14 & $8.2 \%$ & 1.80 & 0.55 & $70.1 \%$ & 5.16 & 0.11 & $5.8 \%$ & 2.34 & 0.38 & $54.2 \%$ \\
\hline jun-09 & 6.11 & 0.10 & $3.8 \%$ & 4.33 & 0.19 & $23.2 \%$ & 6.11 & 0.11 & $4.2 \%$ & 4.25 & 0.21 & $26.2 \%$ & 6.04 & 0.19 & $9.3 \%$ & 3.10 & 0.48 & $59.9 \%$ \\
\hline set-09 & 6.88 & 0.16 & $5.6 \%$ & 5.10 & 0.26 & $29.0 \%$ & 6.88 & 0.16 & $5.4 \%$ & 5.13 & 0.25 & $28.0 \%$ & 6.82 & 0.25 & $10.9 \%$ & 4.22 & 0.49 & $55.6 \%$ \\
\hline dez-09 & 8.40 & 0.19 & $5.6 \%$ & 6.73 & 0.25 & $25.2 \%$ & 8.40 & 0.20 & $6.5 \%$ & 6.64 & 0.29 & $29.1 \%$ & 8.40 & 0.21 & $7.0 \%$ & 6.59 & 0.30 & $31.4 \%$ \\
\hline mar-10 & 8.35 & 0.13 & $3.4 \%$ & 6.70 & 0.17 & $16.0 \%$ & 8.35 & 0.15 & $4.4 \%$ & 6.62 & 0.21 & $20.7 \%$ & 8.35 & 0.17 & $5.5 \%$ & 6.51 & 0.25 & $26.1 \%$ \\
\hline jun-10 & 8.13 & 0.14 & $3.8 \%$ & 6.28 & 0.19 & $18.2 \%$ & 8.13 & 0.13 & $3.6 \%$ & 6.29 & 0.18 & $17.1 \%$ & 8.13 & 0.16 & $4.9 \%$ & 6.19 & 0.23 & $23.5 \%$ \\
\hline set-10 & 8.77 & 0.17 & $4.7 \%$ & 6.80 & 0.23 & $21.8 \%$ & 8.77 & 0.16 & $4.4 \%$ & 6.83 & 0.22 & $20.3 \%$ & 8.77 & 0.17 & $4.6 \%$ & 6.81 & 0.23 & $21.2 \%$ \\
\hline dez-10 & 8.82 & 0.12 & $2.5 \%$ & 6.89 & 0.15 & $12.1 \%$ & 8.82 & 0.14 & $3.6 \%$ & 6.85 & 0.19 & $16.7 \%$ & 8.82 & 0.14 & $3.7 \%$ & 6.84 & 0.19 & $17.5 \%$ \\
\hline mar-11 & 8.25 & 0.11 & $2.7 \%$ & 6.22 & 0.16 & $13.2 \%$ & 8.25 & 0.11 & $2.5 \%$ & 6.23 & 0.15 & $12.5 \%$ & 8.25 & 0.13 & $3.3 \%$ & 6.20 & 0.18 & $16.0 \%$ \\
\hline jun-11 & 8.31 & 0.09 & $1.9 \%$ & 6.05 & 0.12 & $10.0 \%$ & 8.31 & 0.09 & $2.1 \%$ & 6.05 & 0.13 & $11.0 \%$ & 8.31 & 0.10 & $2.6 \%$ & 6.03 & 0.15 & $13.2 \%$ \\
\hline set-11 & 8.06 & 0.15 & $7.0 \%$ & 4.05 & 0.40 & $52.1 \%$ & 8.11 & 0.10 & $4.1 \%$ & 4.97 & 0.23 & $29.7 \%$ & 8.12 & 0.08 & $2.8 \%$ & 5.33 & 0.15 & $18.1 \%$ \\
\hline dez-11 & 9.18 & 0.11 & $4.2 \%$ & 5.89 & 0.22 & $28.5 \%$ & 9.15 & 0.13 & $5.8 \%$ & 5.31 & 0.31 & $41.5 \%$ & 9.18 & 0.10 & $3.6 \%$ & 6.07 & 0.19 & $23.7 \%$ \\
\hline mar-12 & 9.09 & 0.08 & $2.5 \%$ & 6.54 & 0.13 & $14.5 \%$ & 9.09 & 0.09 & $3.3 \%$ & 6.34 & 0.17 & $20.6 \%$ & 9.08 & 0.10 & $3.8 \%$ & 6.19 & 0.19 & $24.7 \%$ \\
\hline jun-12 & 9.39 & 0.07 & $2.9 \%$ & 6.45 & 0.15 & $21.8 \%$ & 9.40 & 0.07 & $2.4 \%$ & 6.68 & 0.13 & $16.8 \%$ & 9.39 & 0.08 & $3.3 \%$ & 6.29 & 0.18 & $25.3 \%$ \\
\hline set-12 & 9.14 & 0.11 & $4.7 \%$ & 6.21 & 0.24 & $32.5 \%$ & 9.15 & 0.11 & $4.3 \%$ & 6.39 & 0.21 & $29.0 \%$ & 9.15 & 0.10 & $3.7 \%$ & 6.62 & 0.18 & $23.9 \%$ \\
\hline dez-12 & 9.44 & 0.11 & $4.3 \%$ & 6.86 & 0.20 & $26.9 \%$ & 9.43 & 0.12 & $4.7 \%$ & 6.67 & 0.23 & $30.8 \%$ & 9.44 & 0.11 & $4.0 \%$ & 6.95 & 0.19 & $25.1 \%$ \\
\hline mar-13 & 9.30 & 0.09 & $3.3 \%$ & 6.96 & 0.16 & $20.6 \%$ & 9.30 & 0.09 & $3.2 \%$ & 6.99 & 0.16 & $19.9 \%$ & 9.30 & 0.10 & $3.8 \%$ & 6.79 & 0.18 & $24.4 \%$ \\
\hline
\end{tabular}




\begin{tabular}{|c|c|c|c|c|c|c|c|c|c|c|c|c|c|c|c|c|c|c|}
\hline jun-05 & 1.20 & 0.18 & $2.6 \%$ & 0.99 & 0.22 & $11.3 \%$ & 1.20 & 0.20 & $3.4 \%$ & 0.99 & 0.25 & $14.0 \%$ & 1.20 & 0.20 & $3.3 \%$ & 0.99 & 0.24 & $13.9 \%$ \\
\hline set-05 & 1.69 & 0.20 & $2.6 \%$ & 1.49 & 0.23 & $10.5 \%$ & 1.69 & 0.21 & $2.8 \%$ & 1.49 & 0.24 & $11.4 \%$ & 1.69 & 0.24 & $3.5 \%$ & 1.49 & 0.27 & $14.0 \%$ \\
\hline dez-05 & 2.43 & 0.28 & $4.7 \%$ & 2.17 & 0.32 & $17.9 \%$ & 2.43 & 0.23 & $3.3 \%$ & 2.17 & 0.26 & $13.0 \%$ & 2.43 & 0.24 & $3.4 \%$ & 2.17 & 0.27 & $13.3 \%$ \\
\hline mar-06 & 3.18 & 0.35 & $5.3 \%$ & 3.00 & 0.37 & $19.7 \%$ & 3.18 & 0.33 & $4.8 \%$ & 3.00 & 0.35 & $18.1 \%$ & 3.18 & 0.28 & $3.6 \%$ & 3.00 & 0.30 & $13.9 \%$ \\
\hline jun-06 & 2.69 & 0.31 & $5.0 \%$ & 2.49 & 0.34 & $18.9 \%$ & 2.69 & 0.33 & $5.4 \%$ & 2.49 & 0.35 & $20.3 \%$ & 2.69 & 0.29 & $4.4 \%$ & 2.49 & 0.31 & $16.9 \%$ \\
\hline set-06 & 2.77 & 0.27 & $3.5 \%$ & 2.60 & 0.28 & $14.0 \%$ & 2.77 & 0.30 & $4.3 \%$ & 2.60 & 0.32 & $16.8 \%$ & 2.77 & 0.31 & $4.8 \%$ & 2.60 & 0.33 & $18.3 \%$ \\
\hline dez-06 & 3.57 & 0.22 & $2.4 \%$ & 3.35 & 0.23 & $10.1 \%$ & 3.57 & 0.26 & $3.4 \%$ & 3.35 & 0.28 & $13.8 \%$ & 3.57 & 0.29 & $4.2 \%$ & 3.35 & 0.31 & $16.4 \%$ \\
\hline mar-07 & 2.94 & 0.24 & $2.9 \%$ & 2.77 & 0.25 & $11.7 \%$ & 2.94 & 0.24 & $2.7 \%$ & 2.77 & 0.25 & $11.2 \%$ & 2.94 & 0.27 & $3.5 \%$ & 2.77 & 0.28 & $14.0 \%$ \\
\hline jun-07 & 3.35 & 0.18 & $1.6 \%$ & 3.18 & 0.19 & $6.9 \%$ & 3.35 & 0.22 & $2.3 \%$ & 3.18 & 0.23 & $9.5 \%$ & 3.35 & 0.25 & $2.9 \%$ & 3.18 & 0.26 & $11.8 \%$ \\
\hline set-07 & 3.04 & 0.24 & $2.9 \%$ & 2.88 & 0.25 & $12.0 \%$ & 3.04 & 0.21 & $2.3 \%$ & 2.88 & 0.22 & $9.7 \%$ & 3.04 & 0.22 & $2.5 \%$ & 2.88 & 0.23 & $10.5 \%$ \\
\hline dez-07 & 2.37 & 0.26 & $4.4 \%$ & 2.17 & 0.29 & $17.2 \%$ & 2.37 & 0.24 & $3.7 \%$ & 2.17 & 0.26 & $15.0 \%$ & 2.37 & 0.22 & $3.1 \%$ & 2.17 & 0.24 & $12.8 \%$ \\
\hline mar-08 & 2.04 & 0.32 & $5.6 \%$ & 1.90 & 0.34 & $21.1 \%$ & 2.04 & 0.30 & $5.0 \%$ & 1.90 & 0.32 & $19.2 \%$ & 2.04 & 0.26 & $3.7 \%$ & 1.90 & 0.27 & $14.9 \%$ \\
\hline jun-08 & 1.84 & 0.34 & $7.1 \%$ & 1.68 & 0.38 & $25.8 \%$ & 1.84 & 0.32 & $6.3 \%$ & 1.68 & 0.36 & $23.6 \%$ & 1.84 & 0.28 & $5.0 \%$ & 1.68 & 0.31 & $19.3 \%$ \\
\hline set-08 & 1.20 & 0.34 & $8.8 \%$ & 1.02 & 0.41 & $32.1 \%$ & 1.20 & 0.32 & $7.9 \%$ & 1.02 & 0.38 & $29.4 \%$ & 1.20 & 0.28 & $6.5 \%$ & 1.03 & 0.34 & $24.8 \%$ \\
\hline dez-08 & 1.09 & 0.37 & $14.0 \%$ & 0.77 & 0.57 & $54.0 \%$ & 1.09 & 0.31 & $10.7 \%$ & 0.80 & 0.46 & $43.4 \%$ & 1.09 & 0.26 & $8.1 \%$ & 0.83 & 0.37 & $33.9 \%$ \\
\hline mar-09 & 0.93 & 0.22 & $5.9 \%$ & 0.76 & 0.28 & $24.8 \%$ & 0.93 & 0.31 & $10.1 \%$ & 0.73 & 0.43 & $40.5 \%$ & 0.93 & 0.27 & $8.4 \%$ & 0.74 & 0.37 & $34.1 \%$ \\
\hline jun-09 & 1.40 & 0.28 & $7.0 \%$ & 1.22 & 0.33 & $27.1 \%$ & 1.40 & 0.28 & $7.0 \%$ & 1.22 & 0.33 & $27.1 \%$ & 1.40 & 0.34 & $9.9 \%$ & 1.20 & 0.41 & $36.6 \%$ \\
\hline set-09 & 1.80 & 0.27 & $5.7 \%$ & 1.63 & 0.30 & $22.0 \%$ & 1.80 & 0.30 & $6.5 \%$ & 1.63 & 0.33 & $24.8 \%$ & 1.80 & 0.37 & $9.6 \%$ & 1.61 & 0.42 & $34.4 \%$ \\
\hline dez-09 & 2.90 & 0.29 & $5.5 \%$ & 2.70 & 0.32 & $21.2 \%$ & 2.90 & 0.30 & $5.6 \%$ & 2.70 & 0.32 & $21.5 \%$ & 2.90 & 0.33 & $6.7 \%$ & 2.70 & 0.35 & $24.8 \%$ \\
\hline mar-10 & 2.51 & 0.26 & $4.3 \%$ & 2.33 & 0.28 & $17.2 \%$ & 2.51 & 0.28 & $5.1 \%$ & 2.33 & 0.30 & $19.9 \%$ & 2.51 & 0.30 & $5.9 \%$ & 2.33 & 0.33 & $22.4 \%$ \\
\hline jun-10 & 2.65 & 0.25 & $4.3 \%$ & 2.43 & 0.28 & $17.2 \%$ & 2.65 & 0.26 & $4.6 \%$ & 2.43 & 0.29 & $18.3 \%$ & 2.65 & 0.28 & $5.3 \%$ & 2.42 & 0.31 & $20.6 \%$ \\
\hline set-10 & 3.43 & 0.23 & $3.4 \%$ & 3.15 & 0.25 & $14.1 \%$ & 3.43 & 0.25 & $3.9 \%$ & 3.15 & 0.27 & $15.6 \%$ & 3.43 & 0.26 & $4.5 \%$ & 3.15 & 0.29 & $17.7 \%$ \\
\hline dez-10 & 3.53 & 0.20 & $3.2 \%$ & 3.15 & 0.22 & $13.3 \%$ & 3.53 & 0.20 & $3.3 \%$ & 3.15 & 0.23 & $13.7 \%$ & 3.53 & 0.22 & $3.9 \%$ & 3.15 & 0.25 & $16.1 \%$ \\
\hline mar-11 & 3.47 & 0.16 & $1.9 \%$ & 3.14 & 0.18 & $8.1 \%$ & 3.47 & 0.19 & $2.5 \%$ & 3.14 & 0.21 & $10.8 \%$ & 3.47 & 0.22 & $3.2 \%$ & 3.14 & 0.24 & $13.2 \%$ \\
\hline jun-11 & 3.64 & 0.19 & $2.6 \%$ & 3.26 & 0.21 & $10.9 \%$ & 3.64 & 0.17 & $2.1 \%$ & 3.26 & 0.19 & $9.1 \%$ & 3.64 & 0.19 & $2.7 \%$ & 3.26 & 0.22 & $11.5 \%$ \\
\hline set-11 & 3.52 & 0.28 & $5.7 \%$ & 3.11 & 0.31 & $22.1 \%$ & 3.52 & 0.23 & $4.1 \%$ & 3.11 & 0.26 & $16.6 \%$ & 3.52 & 0.20 & $3.3 \%$ & 3.11 & 0.23 & $13.8 \%$ \\
\hline dez-11 & 3.85 & 0.20 & $3.6 \%$ & 3.39 & 0.23 & $15.0 \%$ & 3.85 & 0.23 & $4.6 \%$ & 3.38 & 0.27 & $18.6 \%$ & 3.85 & 0.20 & $3.4 \%$ & 3.39 & 0.22 & $14.2 \%$ \\
\hline mar-12 & 3.93 & 0.15 & $1.8 \%$ & 3.55 & 0.16 & $7.8 \%$ & 3.93 & 0.19 & $2.7 \%$ & 3.55 & 0.21 & $11.6 \%$ & 3.93 & 0.21 & $3.4 \%$ & 3.55 & 0.23 & $14.3 \%$ \\
\hline jun-12 & 4.19 & 0.23 & $4.1 \%$ & 3.82 & 0.25 & $16.5 \%$ & 4.19 & 0.19 & $2.9 \%$ & 3.82 & 0.21 & $12.3 \%$ & 4.19 & 0.22 & $3.8 \%$ & 3.82 & 0.24 & $15.6 \%$ \\
\hline set-12 & 4.51 & 0.18 & $2.5 \%$ & 4.17 & 0.19 & $10.7 \%$ & 4.51 & 0.21 & $3.3 \%$ & 4.17 & 0.22 & $13.6 \%$ & 4.51 & 0.20 & $3.0 \%$ & 4.17 & 0.21 & $12.6 \%$ \\
\hline dez-12 & 5.35 & 0.18 & $2.5 \%$ & 4.96 & 0.19 & $10.7 \%$ & 5.35 & 0.19 & $2.7 \%$ & 4.96 & 0.20 & $11.6 \%$ & 5.35 & 0.18 & $2.7 \%$ & 4.96 & 0.20 & $11.4 \%$ \\
\hline mar-13 & 4.81 & 0.18 & $2.4 \%$ & 4.46 & 0.19 & $10.5 \%$ & 4.81 & 0.17 & $2.2 \%$ & 4.46 & 0.18 & $9.7 \%$ & 4.81 & 0.19 & $2.7 \%$ & 4.46 & 0.20 & $11.7 \%$ \\
\hline jun-13 & 4.15 & 0.14 & $1.8 \%$ & 3.76 & 0.15 & $8.1 \%$ & 4.15 & 0.15 & $2.1 \%$ & 3.76 & 0.17 & $9.3 \%$ & 4.15 & 0.16 & $2.3 \%$ & 3.76 & 0.18 & $10.1 \%$ \\
\hline jun-05 & 3.48 & 0.26 & $8.1 \%$ & 2.44 & 0.39 & $34.3 \%$ & 3.48 & 0.22 & $6.1 \%$ & 2.47 & 0.32 & $26.8 \%$ & 3.48 & 0.20 & $5.2 \%$ & 2.48 & 0.29 & $23.0 \%$ \\
\hline set-05 & 3.88 & 0.19 & $4.5 \%$ & 2.84 & 0.27 & $20.2 \%$ & 3.88 & 0.23 & $6.4 \%$ & 2.82 & 0.33 & $27.2 \%$ & 3.88 & 0.21 & $5.4 \%$ & 2.83 & 0.30 & $23.6 \%$ \\
\hline dez-05 & 3.74 & 0.17 & $3.8 \%$ & 2.72 & 0.23 & $17.4 \%$ & 3.74 & 0.18 & $4.1 \%$ & 2.72 & 0.24 & $18.9 \%$ & 3.74 & 0.20 & $5.1 \%$ & 2.71 & 0.28 & $22.8 \%$ \\
\hline mar-06 & 4.12 & 0.17 & $3.9 \%$ & 3.13 & 0.23 & $17.2 \%$ & 4.12 & 0.18 & $3.9 \%$ & 3.12 & 0.23 & $17.4 \%$ & 4.12 & 0.21 & $5.3 \%$ & 3.11 & 0.28 & $22.7 \%$ \\
\hline jun-06 & 4.56 & 0.24 & $7.2 \%$ & 3.42 & 0.34 & $30.5 \%$ & 4.56 & 0.21 & $5.5 \%$ & 3.46 & 0.28 & $23.9 \%$ & 4.56 & 0.19 & $4.9 \%$ & 3.47 & 0.26 & $21.4 \%$ \\
\hline set-06 & 4.47 & 0.14 & $2.7 \%$ & 3.42 & 0.18 & $12.8 \%$ & 4.47 & 0.19 & $4.9 \%$ & 3.39 & 0.26 & $21.8 \%$ & 4.47 & 0.17 & $4.3 \%$ & 3.40 & 0.24 & $19.3 \%$ \\
\hline dez-06 & 5.49 & 0.12 & $2.2 \%$ & 4.21 & 0.15 & $10.4 \%$ & 5.49 & 0.13 & $2.6 \%$ & 4.21 & 0.17 & $12.2 \%$ & 5.49 & 0.16 & $3.8 \%$ & 4.19 & 0.21 & $17.4 \%$ \\
\hline
\end{tabular}




\begin{tabular}{|c|c|c|c|c|c|c|c|c|c|c|c|c|c|c|c|c|c|c|}
\hline mar-07 & 5.94 & 0.18 & $5.0 \%$ & 4.53 & 0.25 & $22.5 \%$ & 5.94 & 0.15 & $3.6 \%$ & 4.57 & 0.20 & $16.5 \%$ & 5.94 & 0.17 & $4.2 \%$ & 4.56 & 0.22 & $18.9 \%$ \\
\hline jun-07 & 6.86 & 0.14 & $3.1 \%$ & 5.40 & 0.18 & $14.0 \%$ & 6.86 & 0.17 & $4.1 \%$ & 5.38 & 0.22 & $18.3 \%$ & 6.86 & 0.15 & $3.3 \%$ & 5.40 & 0.19 & $15.2 \%$ \\
\hline set-07 & 7.47 & 0.19 & $5.4 \%$ & 5.85 & 0.26 & $23.7 \%$ & 7.47 & 0.17 & $4.2 \%$ & 5.91 & 0.22 & $18.8 \%$ & 7.47 & 0.16 & $3.9 \%$ & 5.92 & 0.21 & $17.6 \%$ \\
\hline dez-07 & 7.65 & 0.18 & $5.3 \%$ & 5.88 & 0.25 & $23.9 \%$ & 7.65 & 0.18 & $5.1 \%$ & 5.89 & 0.25 & $23.3 \%$ & 7.65 & 0.16 & $4.5 \%$ & 5.93 & 0.22 & $20.4 \%$ \\
\hline mar-08 & 7.33 & 0.16 & $4.5 \%$ & 5.59 & 0.22 & $20.9 \%$ & 7.33 & 0.16 & $4.7 \%$ & 5.58 & 0.23 & $22.1 \%$ & 7.33 & 0.16 & $4.3 \%$ & 5.60 & 0.22 & $20.1 \%$ \\
\hline jun-08 & 7.26 & 0.13 & $3.1 \%$ & 5.54 & 0.18 & $14.5 \%$ & 7.26 & 0.15 & $3.9 \%$ & 5.52 & 0.21 & $18.2 \%$ & 7.26 & 0.16 & $4.4 \%$ & 5.49 & 0.22 & $20.4 \%$ \\
\hline set-08 & 6.76 & 0.17 & $6.4 \%$ & 4.35 & 0.32 & $35.1 \%$ & 6.76 & 0.14 & $4.4 \%$ & 4.58 & 0.23 & $23.8 \%$ & 6.77 & 0.13 & $4.1 \%$ & 4.60 & 0.22 & $22.3 \%$ \\
\hline dez-08 & 6.75 & 0.21 & $9.8 \%$ & 3.47 & 0.50 & $57.3 \%$ & 6.79 & 0.18 & $7.4 \%$ & 3.87 & 0.38 & $45.1 \%$ & 6.81 & 0.14 & $5.0 \%$ & 4.28 & 0.26 & $30.1 \%$ \\
\hline mar-09 & 6.59 & 0.15 & $6.0 \%$ & 4.05 & 0.31 & $38.9 \%$ & 6.57 & 0.17 & $7.5 \%$ & 3.73 & 0.39 & $48.3 \%$ & 6.60 & 0.13 & $5.3 \%$ & 4.21 & 0.27 & $33.6 \%$ \\
\hline jun-09 & 6.30 & 0.11 & $3.7 \%$ & 4.66 & 0.18 & $20.1 \%$ & 6.30 & 0.14 & $5.1 \%$ & 4.43 & 0.25 & $29.7 \%$ & 6.29 & 0.16 & $6.2 \%$ & 4.23 & 0.30 & $36.6 \%$ \\
\hline set-09 & 6.85 & 0.11 & $3.0 \%$ & 5.41 & 0.15 & $14.3 \%$ & 6.85 & 0.13 & $3.8 \%$ & 5.36 & 0.18 & $18.5 \%$ & 6.84 & 0.19 & $7.0 \%$ & 4.96 & 0.31 & $35.7 \%$ \\
\hline dez-09 & 7.77 & 0.18 & $5.8 \%$ & 6.02 & 0.26 & $27.7 \%$ & 7.78 & 0.15 & $4.5 \%$ & 6.15 & 0.21 & $21.3 \%$ & 7.77 & 0.18 & $5.9 \%$ & 6.01 & 0.26 & $28.0 \%$ \\
\hline mar-10 & 9.15 & 0.11 & $3.0 \%$ & 7.21 & 0.15 & $14.4 \%$ & 9.15 & 0.14 & $4.2 \%$ & 7.09 & 0.20 & $20.6 \%$ & 9.15 & 0.13 & $4.1 \%$ & 7.10 & 0.19 & $20.0 \%$ \\
\hline jun-10 & 8.89 & 0.13 & $4.1 \%$ & 6.59 & 0.20 & $20.9 \%$ & 8.89 & 0.12 & $3.4 \%$ & 6.66 & 0.17 & $17.4 \%$ & 8.89 & 0.12 & $3.7 \%$ & 6.63 & 0.18 & $18.8 \%$ \\
\hline set-10 & 8.98 & 0.06 & $1.0 \%$ & 6.73 & 0.08 & $5.6 \%$ & 8.98 & 0.10 & $2.5 \%$ & 6.68 & 0.14 & $12.8 \%$ & 8.98 & 0.11 & $3.2 \%$ & 6.62 & 0.17 & $16.5 \%$ \\
\hline dez-10 & 9.41 & 0.09 & $2.1 \%$ & 7.18 & 0.13 & $10.2 \%$ & 9.41 & 0.08 & $1.7 \%$ & 7.19 & 0.11 & $8.3 \%$ & 9.41 & 0.11 & $2.8 \%$ & 7.15 & 0.15 & $13.5 \%$ \\
\hline mar-11 & 9.55 & 0.10 & $2.2 \%$ & 7.25 & 0.14 & $10.8 \%$ & 9.55 & 0.10 & $2.1 \%$ & 7.25 & 0.14 & $10.4 \%$ & 9.55 & 0.11 & $2.6 \%$ & 7.24 & 0.16 & $12.8 \%$ \\
\hline jun-11 & 9.28 & 0.09 & $1.9 \%$ & 6.86 & 0.13 & $9.7 \%$ & 9.28 & 0.09 & $1.9 \%$ & 6.86 & 0.13 & $9.8 \%$ & 9.28 & 0.09 & $1.8 \%$ & 6.87 & 0.12 & $9.2 \%$ \\
\hline set-11 & 9.54 & 0.12 & $3.5 \%$ & 6.85 & 0.18 & $18.0 \%$ & 9.55 & 0.10 & $2.5 \%$ & 6.93 & 0.14 & $12.9 \%$ & 9.55 & 0.09 & $2.2 \%$ & 6.95 & 0.13 & $11.3 \%$ \\
\hline dez-11 & 11.26 & 0.13 & $3.3 \%$ & 8.75 & 0.18 & $15.3 \%$ & 11.26 & 0.15 & $3.9 \%$ & 8.72 & 0.20 & $18.0 \%$ & 11.26 & 0.13 & $3.0 \%$ & 8.76 & 0.17 & $14.3 \%$ \\
\hline mar-12 & 11.86 & 0.13 & $2.9 \%$ & 9.50 & 0.16 & $13.6 \%$ & 11.86 & 0.13 & $3.2 \%$ & 9.49 & 0.17 & $14.5 \%$ & 11.86 & 0.13 & $3.2 \%$ & 9.48 & 0.17 & $14.7 \%$ \\
\hline jun-12 & 13.23 & 0.12 & $2.9 \%$ & 10.81 & 0.15 & $13.1 \%$ & 13.23 & 0.12 & $2.9 \%$ & 10.81 & 0.15 & $13.1 \%$ & 13.23 & 0.13 & $3.3 \%$ & 10.78 & 0.17 & $15.0 \%$ \\
\hline set-12 & 14.23 & 0.12 & $2.4 \%$ & 12.07 & 0.14 & $10.9 \%$ & 14.23 & 0.13 & $2.7 \%$ & 12.05 & 0.15 & $12.2 \%$ & 14.23 & 0.13 & $3.0 \%$ & 12.04 & 0.16 & $13.4 \%$ \\
\hline dez-12 & 15.17 & 0.12 & $2.2 \%$ & 13.21 & 0.14 & $10.0 \%$ & 15.17 & 0.13 & $2.5 \%$ & 13.21 & 0.15 & $11.0 \%$ & 15.17 & 0.14 & $2.9 \%$ & 13.20 & 0.16 & $12.5 \%$ \\
\hline mar-13 & 15.64 & 0.11 & $1.8 \%$ & 13.70 & 0.13 & $8.3 \%$ & 15.64 & 0.12 & $2.1 \%$ & 13.70 & 0.14 & $9.4 \%$ & 15.64 & 0.14 & $2.6 \%$ & 13.69 & 0.16 & $11.3 \%$ \\
\hline jun-13 & 14.44 & 0.16 & $3.9 \%$ & 12.16 & 0.20 & $16.9 \%$ & 14.44 & 0.13 & $2.8 \%$ & 12.22 & 0.16 & $12.6 \%$ & 14.44 & 0.13 & $2.6 \%$ & 12.22 & 0.15 & $11.8 \%$ \\
\hline jun-05 & 2.98 & 0.15 & $3.4 \%$ & 2.07 & 0.22 & $16.3 \%$ & 2.98 & 0.15 & $3.5 \%$ & 2.07 & 0.22 & $16.7 \%$ & 2.98 & 0.14 & $2.8 \%$ & 2.07 & 0.20 & $13.9 \%$ \\
\hline set- 05 & 3.31 & 0.16 & $3.5 \%$ & 2.34 & 0.22 & $16.5 \%$ & 3.31 & 0.16 & $3.5 \%$ & 2.34 & 0.22 & $16.4 \%$ & 3.31 & 0.15 & $3.3 \%$ & 2.34 & 0.22 & $15.6 \%$ \\
\hline dez-05 & 4.18 & 0.20 & $5.0 \%$ & 3.11 & 0.28 & $21.7 \%$ & 4.18 & 0.19 & $4.2 \%$ & 3.12 & 0.25 & $18.8 \%$ & 4.18 & 0.18 & $4.0 \%$ & 3.12 & 0.24 & $18.0 \%$ \\
\hline mar-06 & 4.62 & 0.26 & $6.5 \%$ & 3.70 & 0.33 & $25.6 \%$ & 4.62 & 0.25 & $5.8 \%$ & 3.70 & 0.31 & $23.2 \%$ & 4.62 & 0.22 & $4.8 \%$ & 3.71 & 0.28 & $19.9 \%$ \\
\hline jun-06 & 4.27 & 0.22 & $5.0 \%$ & 3.41 & 0.27 & $20.7 \%$ & 4.27 & 0.23 & $5.7 \%$ & 3.40 & 0.30 & $23.3 \%$ & 4.27 & 0.22 & $4.9 \%$ & 3.41 & 0.27 & $20.6 \%$ \\
\hline set-06 & 4.89 & 0.22 & $4.6 \%$ & 4.04 & 0.27 & $19.1 \%$ & 4.89 & 0.23 & $5.0 \%$ & 4.04 & 0.28 & $20.4 \%$ & 4.89 & 0.24 & $5.4 \%$ & 4.03 & 0.29 & $21.9 \%$ \\
\hline dez-06 & 7.34 & 0.21 & $4.7 \%$ & 5.95 & 0.26 & $19.7 \%$ & 7.34 & 0.21 & $4.8 \%$ & 5.95 & 0.26 & $20.0 \%$ & 7.34 & 0.22 & $5.1 \%$ & 5.94 & 0.27 & $21.3 \%$ \\
\hline mar-07 & 7.33 & 0.23 & $5.3 \%$ & 6.13 & 0.28 & $21.5 \%$ & 7.33 & 0.23 & $5.0 \%$ & 6.13 & 0.28 & $20.5 \%$ & 7.33 & 0.23 & $5.1 \%$ & 6.13 & 0.28 & $20.6 \%$ \\
\hline jun-07 & 8.11 & 0.17 & $2.7 \%$ & 6.99 & 0.20 & $11.7 \%$ & 8.11 & 0.21 & $4.1 \%$ & 6.99 & 0.25 & $16.8 \%$ & 8.11 & 0.23 & $4.6 \%$ & 6.98 & 0.26 & $18.5 \%$ \\
\hline set-07 & 9.27 & 0.31 & $7.6 \%$ & 8.07 & 0.36 & $28.5 \%$ & 9.27 & 0.25 & $5.2 \%$ & 8.12 & 0.29 & $20.7 \%$ & 9.27 & 0.25 & $5.2 \%$ & 8.12 & 0.29 & $20.7 \%$ \\
\hline dez-07 & 9.34 & 0.26 & $6.9 \%$ & 7.76 & 0.32 & $27.5 \%$ & 9.34 & 0.26 & $6.9 \%$ & 7.76 & 0.32 & $27.5 \%$ & 9.34 & 0.23 & $5.4 \%$ & 7.81 & 0.28 & $22.0 \%$ \\
\hline mar-08 & 8.56 & 0.30 & $9.6 \%$ & 6.77 & 0.41 & $38.0 \%$ & 8.57 & 0.27 & $8.0 \%$ & 6.87 & 0.36 & $32.5 \%$ & 8.57 & 0.24 & $6.4 \%$ & 6.96 & 0.30 & $26.4 \%$ \\
\hline jun-08 & 7.62 & 0.24 & $7.1 \%$ & 5.89 & 0.33 & $30.4 \%$ & 7.62 & 0.25 & $8.0 \%$ & 5.83 & 0.36 & $33.9 \%$ & 7.62 & 0.24 & $7.1 \%$ & 5.89 & 0.32 & $30.3 \%$ \\
\hline set- 08 & 7.52 & 0.29 & $11.5 \%$ & 4.80 & 0.51 & $52.2 \%$ & 7.55 & 0.24 & $8.7 \%$ & 5.12 & 0.39 & $40.9 \%$ & 7.55 & 0.22 & $7.6 \%$ & 5.23 & 0.35 & $36.2 \%$ \\
\hline
\end{tabular}




\begin{tabular}{|c|c|c|c|c|c|c|c|c|c|c|c|c|c|c|c|c|c|c|}
\hline dez-08 & 7.12 & 0.42 & $22.4 \%$ & 2.99 & 0.95 & $83.5 \%$ & 7.36 & 0.31 & $15.1 \%$ & 3.58 & 0.69 & $70.5 \%$ & 7.47 & 0.23 & $10.1 \%$ & 4.22 & 0.49 & $54.1 \%$ \\
\hline mar-09 & 7.24 & 0.15 & $4.7 \%$ & 5.25 & 0.23 & $23.8 \%$ & 7.12 & 0.30 & $14.1 \%$ & 3.91 & 0.63 & $65.8 \%$ & 7.19 & 0.24 & $10.3 \%$ & 4.44 & 0.47 & $52.3 \%$ \\
\hline jun-09 & 8.14 & 0.17 & $5.2 \%$ & 6.46 & 0.24 & $23.5 \%$ & 8.14 & 0.18 & $5.4 \%$ & 6.44 & 0.25 & $24.4 \%$ & 8.10 & 0.30 & $11.9 \%$ & 5.59 & 0.50 & $52.6 \%$ \\
\hline set-09 & 9.08 & 0.13 & $2.7 \%$ & 7.60 & 0.16 & $12.0 \%$ & 9.08 & 0.17 & $4.3 \%$ & 7.55 & 0.21 & $18.5 \%$ & 9.06 & 0.31 & $11.6 \%$ & 6.81 & 0.47 & $47.8 \%$ \\
\hline dez-09 & 10.97 & 0.20 & $5.3 \%$ & 9.19 & 0.25 & $22.4 \%$ & 10.97 & 0.17 & $4.1 \%$ & 9.25 & 0.21 & $17.4 \%$ & 10.97 & 0.20 & $5.2 \%$ & 9.20 & 0.25 & $21.9 \%$ \\
\hline mar-10 & 9.79 & 0.16 & $3.8 \%$ & 8.20 & 0.20 & $16.5 \%$ & 9.79 & 0.18 & $4.6 \%$ & 8.17 & 0.23 & $19.8 \%$ & 9.79 & 0.18 & $4.6 \%$ & 8.16 & 0.23 & $19.9 \%$ \\
\hline jun-10 & 10.02 & 0.16 & $3.8 \%$ & 8.11 & 0.20 & $16.7 \%$ & 10.02 & 0.16 & $3.7 \%$ & 8.12 & 0.20 & $16.6 \%$ & 10.02 & 0.16 & $3.9 \%$ & 8.11 & 0.20 & $17.2 \%$ \\
\hline set-10 & 11.20 & 0.13 & $2.5 \%$ & 9.15 & 0.16 & $11.4 \%$ & 11.20 & 0.15 & $3.2 \%$ & 9.13 & 0.19 & $14.5 \%$ & 11.20 & 0.17 & $4.0 \%$ & 9.11 & 0.21 & $17.4 \%$ \\
\hline dez-10 & 11.92 & 0.13 & $2.7 \%$ & 9.58 & 0.16 & $12.3 \%$ & 11.92 & 0.13 & $2.5 \%$ & 9.59 & 0.16 & $11.7 \%$ & 11.92 & 0.14 & $3.2 \%$ & 9.57 & 0.18 & $14.3 \%$ \\
\hline mar-11 & 11.22 & 0.14 & $3.1 \%$ & 8.75 & 0.18 & $14.5 \%$ & 11.22 & 0.13 & $2.8 \%$ & 8.76 & 0.17 & $13.2 \%$ & 11.22 & 0.13 & $2.9 \%$ & 8.76 & 0.17 & $13.7 \%$ \\
\hline jun-11 & 12.33 & 0.16 & $3.8 \%$ & 9.62 & 0.21 & $17.4 \%$ & 12.33 & 0.15 & $3.5 \%$ & 9.63 & 0.20 & $16.1 \%$ & 12.33 & 0.14 & $3.1 \%$ & 9.64 & 0.18 & $14.2 \%$ \\
\hline set-11 & 11.33 & 0.22 & $6.6 \%$ & 8.77 & 0.31 & $28.4 \%$ & 11.33 & 0.19 & $5.2 \%$ & 8.87 & 0.26 & $22.8 \%$ & 11.33 & 0.17 & $4.2 \%$ & 8.93 & 0.22 & $18.5 \%$ \\
\hline dez-11 & 12.69 & 0.15 & $3.8 \%$ & 9.96 & 0.20 & $17.5 \%$ & 12.69 & 0.18 & $4.9 \%$ & 9.88 & 0.24 & $22.2 \%$ & 12.69 & 0.16 & $4.1 \%$ & 9.94 & 0.21 & $18.8 \%$ \\
\hline mar-12 & 13.67 & 0.13 & $2.5 \%$ & 11.30 & 0.16 & $11.5 \%$ & 13.67 & 0.15 & $3.4 \%$ & 11.28 & 0.19 & $14.8 \%$ & 13.67 & 0.17 & $4.3 \%$ & 11.23 & 0.22 & $18.7 \%$ \\
\hline jun-12 & 15.48 & 0.20 & $4.9 \%$ & 13.22 & 0.24 & $20.3 \%$ & 15.48 & 0.18 & $3.9 \%$ & 13.27 & 0.21 & $16.5 \%$ & 15.48 & 0.20 & $4.8 \%$ & 13.22 & 0.24 & $20.0 \%$ \\
\hline set-12 & 17.14 & 0.17 & $3.4 \%$ & 15.15 & 0.20 & $14.4 \%$ & 17.14 & 0.20 & $4.3 \%$ & 15.12 & 0.23 & $17.6 \%$ & 17.14 & 0.19 & $4.0 \%$ & 15.13 & 0.22 & $16.6 \%$ \\
\hline dez-12 & 19.98 & 0.13 & $2.2 \%$ & 17.74 & 0.15 & $9.8 \%$ & 19.98 & 0.16 & $3.1 \%$ & 17.73 & 0.18 & $13.1 \%$ & 19.98 & 0.17 & $3.4 \%$ & 17.72 & 0.19 & $14.4 \%$ \\
\hline mar-13 & 19.01 & 0.15 & $2.6 \%$ & 16.86 & 0.17 & $11.4 \%$ & 19.01 & 0.14 & $2.4 \%$ & 16.86 & 0.16 & $10.7 \%$ & 19.01 & 0.17 & $3.4 \%$ & 16.84 & 0.19 & $14.2 \%$ \\
\hline jun-13 & 18.93 & 0.12 & $2.0 \%$ & 16.34 & 0.14 & $9.2 \%$ & 18.93 & 0.13 & $2.2 \%$ & 16.33 & 0.15 & $10.0 \%$ & 18.93 & 0.14 & $2.6 \%$ & 16.33 & 0.16 & $11.5 \%$ \\
\hline jun-05 & 6.46 & 0.06 & $2.8 \%$ & 2.57 & 0.24 & $36.1 \%$ & 6.47 & 0.05 & $2.1 \%$ & 2.85 & 0.17 & $24.8 \%$ & 6.47 & 0.04 & $1.5 \%$ & 3.03 & 0.12 & $16.2 \%$ \\
\hline set- 05 & 5.90 & 0.04 & $1.5 \%$ & 2.68 & 0.12 & $17.9 \%$ & 5.89 & 0.04 & $1.8 \%$ & 2.54 & 0.16 & $24.7 \%$ & 5.90 & 0.03 & $1.3 \%$ & 2.73 & 0.11 & $15.4 \%$ \\
\hline dez-05 & 6.88 & 0.07 & $2.2 \%$ & 3.77 & 0.14 & $16.1 \%$ & 6.88 & 0.08 & $2.8 \%$ & 3.67 & 0.18 & $21.8 \%$ & 6.88 & 0.09 & $3.4 \%$ & 3.56 & 0.22 & $27.0 \%$ \\
\hline mar-06 & 6.66 & 0.13 & $6.2 \%$ & 2.96 & 0.39 & $50.5 \%$ & 6.69 & 0.10 & $4.1 \%$ & 3.46 & 0.26 & $33.1 \%$ & 6.69 & 0.10 & $4.2 \%$ & 3.44 & 0.26 & $34.1 \%$ \\
\hline jun-06 & 6.66 & 0.09 & $3.9 \%$ & 3.61 & 0.24 & $31.1 \%$ & 6.65 & 0.11 & $4.7 \%$ & 3.40 & 0.29 & $38.4 \%$ & 6.67 & 0.09 & $3.7 \%$ & 3.66 & 0.22 & $29.2 \%$ \\
\hline set- 06 & 7.05 & 0.06 & $2.0 \%$ & 4.36 & 0.12 & $13.6 \%$ & 7.05 & 0.08 & $2.9 \%$ & 4.21 & 0.17 & $20.7 \%$ & 7.04 & 0.09 & $3.4 \%$ & 4.09 & 0.20 & $25.9 \%$ \\
\hline dez-06 & 7.73 & 0.07 & $2.0 \%$ & 5.14 & 0.12 & $12.0 \%$ & 7.73 & 0.08 & $2.4 \%$ & 5.11 & 0.14 & $14.4 \%$ & 7.72 & 0.11 & $4.2 \%$ & 4.81 & 0.23 & $27.4 \%$ \\
\hline mar-07 & 7.41 & 0.10 & $3.1 \%$ & 4.99 & 0.17 & $18.0 \%$ & 7.41 & 0.09 & $2.7 \%$ & 5.03 & 0.15 & $15.6 \%$ & 7.41 & 0.12 & $4.2 \%$ & 4.83 & 0.22 & $25.5 \%$ \\
\hline jun-07 & 7.81 & 0.13 & $3.2 \%$ & 5.98 & 0.18 & $15.1 \%$ & 7.81 & 0.15 & $4.1 \%$ & 5.94 & 0.21 & $19.0 \%$ & 7.81 & 0.16 & $4.1 \%$ & 5.94 & 0.21 & $19.3 \%$ \\
\hline set-07 & 8.28 & 0.15 & $4.1 \%$ & 6.31 & 0.21 & $19.5 \%$ & 8.28 & 0.14 & $3.6 \%$ & 6.34 & 0.19 & $17.0 \%$ & 8.28 & 0.15 & $3.9 \%$ & 6.32 & 0.20 & $18.5 \%$ \\
\hline dez-07 & 8.76 & 0.19 & $6.0 \%$ & 6.48 & 0.28 & $28.8 \%$ & 8.76 & 0.17 & $5.1 \%$ & 6.58 & 0.24 & $24.0 \%$ & 8.76 & 0.16 & $4.5 \%$ & 6.63 & 0.22 & $21.2 \%$ \\
\hline mar-08 & 7.86 & 0.15 & $4.8 \%$ & 5.77 & 0.23 & $23.6 \%$ & 7.86 & 0.16 & $5.1 \%$ & 5.73 & 0.24 & $25.4 \%$ & 7.86 & 0.14 & $4.2 \%$ & 5.82 & 0.21 & $20.9 \%$ \\
\hline jun-08 & 7.66 & 0.15 & $4.4 \%$ & 5.63 & 0.22 & $21.3 \%$ & 7.66 & 0.16 & $4.7 \%$ & 5.61 & 0.23 & $22.7 \%$ & 7.66 & 0.16 & $4.7 \%$ & 5.60 & 0.23 & $22.9 \%$ \\
\hline set-08 & 7.92 & 0.17 & $5.2 \%$ & 5.57 & 0.26 & $25.7 \%$ & 7.92 & 0.16 & $4.9 \%$ & 5.60 & 0.25 & $24.2 \%$ & 7.92 & 0.17 & $5.1 \%$ & 5.58 & 0.26 & $25.4 \%$ \\
\hline dez-08 & 8.51 & 0.24 & $9.6 \%$ & 5.25 & 0.45 & $48.5 \%$ & 8.53 & 0.20 & $7.2 \%$ & 5.61 & 0.35 & $37.3 \%$ & 8.54 & 0.17 & $5.9 \%$ & 5.80 & 0.29 & $30.4 \%$ \\
\hline mar-09 & 8.92 & 0.12 & $2.9 \%$ & 6.79 & 0.16 & $13.9 \%$ & 8.92 & 0.19 & $6.7 \%$ & 6.41 & 0.31 & $32.7 \%$ & 8.92 & 0.18 & $5.8 \%$ & 6.54 & 0.27 & $28.1 \%$ \\
\hline jun-09 & 9.28 & 0.11 & $2.2 \%$ & 7.60 & 0.14 & $10.5 \%$ & 9.28 & 0.13 & $2.7 \%$ & 7.59 & 0.16 & $12.6 \%$ & 9.28 & 0.20 & $5.9 \%$ & 7.38 & 0.27 & $26.4 \%$ \\
\hline set-09 & 9.19 & 0.11 & $2.3 \%$ & 7.50 & 0.13 & $10.6 \%$ & 9.19 & 0.11 & $2.2 \%$ & 7.50 & 0.13 & $10.5 \%$ & 9.19 & 0.17 & $4.8 \%$ & 7.35 & 0.22 & $21.9 \%$ \\
\hline dez-09 & 9.59 & 0.09 & $1.6 \%$ & 7.87 & 0.11 & $7.9 \%$ & 9.59 & 0.10 & $2.1 \%$ & 7.86 & 0.13 & $9.7 \%$ & 9.59 & 0.11 & $2.5 \%$ & 7.85 & 0.14 & $11.4 \%$ \\
\hline mar-10 & 9.62 & 0.08 & $1.2 \%$ & 7.89 & 0.09 & $5.9 \%$ & 9.62 & 0.08 & $1.3 \%$ & 7.89 & 0.10 & $6.5 \%$ & 9.62 & 0.10 & $1.9 \%$ & 7.88 & 0.12 & $8.9 \%$ \\
\hline jun-10 & 8.58 & 0.09 & $1.5 \%$ & 6.79 & 0.11 & $7.6 \%$ & 8.58 & 0.08 & $1.3 \%$ & 6.79 & 0.10 & $6.7 \%$ & 8.58 & 0.09 & $1.8 \%$ & 6.79 & 0.12 & $8.6 \%$ \\
\hline
\end{tabular}




\begin{tabular}{|c|c|c|c|c|c|c|c|c|c|c|c|c|c|c|c|c|c|c|}
\hline set-10 & 9.23 & 0.09 & $1.7 \%$ & 7.27 & 0.12 & $8.3 \%$ & 9.23 & 0.09 & $1.6 \%$ & 7.27 & 0.12 & $8.1 \%$ & 9.23 & 0.09 & $1.5 \%$ & 7.27 & 0.11 & $7.4 \%$ \\
\hline dez-10 & 9.83 & 0.10 & $1.6 \%$ & 7.87 & 0.12 & $7.8 \%$ & 9.83 & 0.10 & $1.7 \%$ & 7.87 & 0.13 & $8.4 \%$ & 9.83 & 0.10 & $1.6 \%$ & 7.87 & 0.12 & $7.8 \%$ \\
\hline mar-11 & 10.11 & 0.09 & $1.4 \%$ & .07 & .12 & $6.7 \%$ & 10.11 & 0.10 & $1.5 \%$ & .07 & 0.12 & $4 \%$ & 10.11 & 0.11 & $1.7 \%$ & 8.07 & 0.13 & $3.3 \%$ \\
\hline jun-11 & .82 & 0.10 & $1.6 \%$ & 8.64 & .13 & $7.7 \%$ & 0.82 & 0.10 & $1.5 \%$ & .64 & 0.12 & $7.2 \%$ & 10.82 & 0.11 & $1.7 \%$ & 8.64 & 0.14 & $.3 \%$ \\
\hline set-11 & 0.59 & 0.13 & $2.7 \%$ & 8.21 & 0.17 & $12.9 \%$ & 10.59 & 0.11 & $2.1 \%$ & 3.22 & 0.14 & $10.1 \%$ & 10.59 & 0.10 & $1.8 \%$ & 8.22 & 0.13 & $.7 \%$ \\
\hline dez-11 & 12.19 & 0.13 & $2.7 \%$ & 9.72 & 0.17 & $12.6 \%$ & 12.19 & 0.13 & $2.7 \%$ & 9.72 & 0.17 & $12.7 \%$ & 12.19 & 0.11 & $2.1 \%$ & 9.74 & 0.14 & $9.8 \%$ \\
\hline mar-12 & 1.66 & 0.08 & $1.2 \%$ & 9.46 & 0.10 & $5.9 \%$ & 11.66 & 0.11 & $2.0 \%$ & 9.45 & 0.13 & $9.5 \%$ & 11.66 & 0.11 & $2.0 \%$ & 9.46 & 0.13 & $9.3 \%$ \\
\hline jun-12 & 11.69 & 0.11 & $2.1 \%$ & 9.68 & 0.13 & $9.7 \%$ & 11.69 & 0.09 & $1.6 \%$ & 9.69 & 0.11 & $7.7 \%$ & 11.69 & 0.11 & $2.1 \%$ & 9.68 & 0.13 & $9.8 \%$ \\
\hline set-12 & 12.54 & 0.12 & $2.7 \%$ & 10.44 & 0.14 & $12.3 \%$ & 12.54 & 0.11 & $2.3 \%$ & 10.46 & 0.13 & $10.6 \%$ & 12.54 & 0.10 & $.1 \%$ & 10.47 & 0.12 & $.5 \%$ \\
\hline dez-12 & 12.57 & 10 & $2.1 \%$ & .59 & .12 & $9.6 \%$ & 12.57 & 0.11 & $2.4 \%$ & 0.58 & 0.13 & $10.8 \%$ & 12.57 & 0.10 & $1.9 \%$ & 0.60 & 0.12 & $.0 \%$ \\
\hline mar-13 & 12.11 & 0.12 & $2.9 \%$ & 10.05 & 0.15 & $13.5 \%$ & 12.11 & 0.11 & $2.4 \%$ & 0.08 & 0.13 & $11.3 \%$ & 12.11 & 0.10 & $3 \%$ & 0.09 & .13 & $0.7 \%$ \\
\hline jun-13 & 12.37 & 0.11 & $3.5 \%$ & 9.66 & 0.17 & $18.0 \%$ & 12.37 & 0.10 & $2.9 \%$ & 9.76 & 0.14 & $14.7 \%$ & 12.37 & 0.09 & $2.4 \%$ & 9.84 & 0.12 & $11.8 \%$ \\
\hline jun- 05 & 1.39 & 0.25 & $5.4 \%$ & 1.11 & 0.31 & $21.4 \%$ & 1.39 & 0.24 & $5.3 \%$ & 1.11 & 0.31 & $21.1 \%$ & 1.39 & 0.23 & $4.7 \%$ & 1.11 & 0.29 & $19.2 \%$ \\
\hline set-05 & 1.53 & 0.28 & $5.8 \%$ & 27 & 0.34 & $22.3 \%$ & 1.53 & 0.27 & $5.6 \%$ & 1.27 & 0.33 & $7 \%$ & 1. & 0. & $5.0 \%$ & 1.28 & 31 & $19.5 \%$ \\
\hline dez-05 & 1.94 & 0.21 & $4.0 \%$ & 1.58 & 0.26 & $16.6 \%$ & 1.94 & 0.23 & $4.8 \%$ & 1.57 & 0.29 & $19.5 \%$ & 1.94 & 0.24 & $5.0 \%$ & 1.57 & 0.30 & $20.3 \%$ \\
\hline mar-06 & 8.30 & 0.38 & $4.9 \%$ & 8.07 & 0.40 & $18.3 \%$ & 8.30 & 0.35 & $4.0 \%$ & 8.07 & 0.36 & $15.3 \%$ & 8.30 & 0.36 & $4.3 \%$ & 8.07 & 0.37 & $16.4 \%$ \\
\hline jun-06 & 7.56 & 0.54 & $10.3 \%$ & .27 & 0.56 & $34.3 \%$ & 7.56 & 0.46 & $7.8 \%$ & 7.27 & 0.48 & $27.4 \%$ & 7.56 & 0.40 & $6.0 \%$ & 7.27 & 0.42 & $22.0 \%$ \\
\hline set-06 & 8.88 & 0.36 & $4.6 \%$ & 8.62 & 0.37 & $17.4 \%$ & 8.88 & 0.47 & $7.4 \%$ & 8.62 & 0.48 & $26.4 \%$ & 8.88 & 0.41 & $5.8 \%$ & 8.62 & 0.42 & $21.4 \%$ \\
\hline dez-06 & 10.16 & 0.29 & $3.1 \%$ & 9.83 & 0.30 & $12.5 \%$ & 10.16 & 0.33 & $4.1 \%$ & 9.83 & 0.34 & $16.0 \%$ & 10.16 & 0.40 & $5.9 \%$ & 9.83 & 42 & $22.0 \%$ \\
\hline mar-07 & 8.08 & 0.42 & $6.6 \%$ & 7.79 & 0.43 & $24.1 \%$ & 8.08 & 0.35 & $4.9 \%$ & 7.79 & 0.37 & $18.7 \%$ & 8.08 & 0.41 & $6.5 \%$ & 7.79 & 0.43 & $23.9 \%$ \\
\hline jun-07 & 9.71 & 0.25 & $2.4 \%$ & 9.41 & 0.26 & $10.1 \%$ & 9.71 & 0.35 & $4.5 \%$ & 9. & 0.36 & $17.6 \%$ & 9.71 & 0. & $4.4 \%$ & 9.41 & 35 & $17.0 \%$ \\
\hline set-07 & 7.99 & 0.38 & $6.1 \%$ & 7.68 & 0.40 & $22.7 \%$ & 7.99 & 0.32 & $4.4 \%$ & 7.68 & 0.34 & $17.3 \%$ & 7.99 & 0.34 & $4.8 \%$ & 7.68 & 0.35 & $18.5 \%$ \\
\hline dez-07 & 6.66 & 0.38 & $7.4 \%$ & 6.24 & 0.41 & $26.6 \%$ & 6.66 & 0.37 & $6.9 \%$ & 6.24 & 0.39 & $25.1 \%$ & 6.66 & 0.34 & $6.1 \%$ & 6.24 & 0.37 & $22.6^{c}$ \\
\hline mar-08 & 6.98 & 0.40 & $7.5 \%$ & 6.61 & 0.43 & $27.1 \%$ & 6.98 & 0.40 & $7.5 \%$ & 6.61 & 0.43 & $26.9 \%$ & 6.98 & 0.36 & $6.0 \%$ & 6.62 & 0.38 & 22.5 \\
\hline jun-08 & 6.46 & 0.39 & $7.3 \%$ & 6.09 & 0.42 & $26.2 \%$ & 6.46 & 0.40 & $7.5 \%$ & 6.09 & 0.42 & $26.8 \%$ & 6.46 & 0.39 & $7.0 \%$ & 6.09 & 0.41 & $25.4 \%$ \\
\hline set-08 & 7.33 & 0.44 & $8.7 \%$ & .90 & 0.47 & $30.2 \%$ & 7.33 & 0.42 & $7.8 \%$ & 6.90 & 0.44 & & 7.33 & 0.41 & $7.7 \%$ & 6.90 & 0.44 & $27.4^{\circ}$ \\
\hline dez- 08 & 7.74 & 0.48 & $10.6 \%$ & 7.20 & 0.52 & $35.4 \%$ & 7.74 & 0.46 & $9.7 \%$ & 7.21 & 0.49 & $33.1 \%$ & 7.74 & 0.42 & $8.6 \%$ & 7.21 & 0.46 & $29.9 \%$ \\
\hline mar-09 & 9.24 & 0.35 & $5.4 \%$ & & 0.36 & $20.6 \%$ & 9.24 & 0.43 & $8.1 \%$ & & 0.45 & $28.7 \%$ & 9.24 & 0.43 & $7.9 \%$ & 8.80 & 0.45 & $28.2^{c}$ \\
\hline jun-09 & 10.39 & 0.31 & $4.1 \%$ & .03 & 0.32 & $16.3 \%$ & 10.39 & 0.33 & $4.7 \%$ & 10.03 & 0.34 & $18.6 \%$ & 10.39 & 0.41 & $7.1 \%$ & 10.02 & 0.43 & $26.2^{c}$ \\
\hline set-09 & 12.79 & 0.19 & $1.5 \%$ & 2.44 & 0.19 & $6.4 \%$ & 12.79 & 0.26 & $2.7 \%$ & 12.44 & 0.26 & $11.3 \%$ & 12.79 & 0.36 & $5.2 \%$ & 12.44 & 0.38 & 20.3 \\
\hline dez-09 & 14.64 & 0.22 & $2.0 \%$ & 14.21 & 0.22 & $8.7 \%$ & 14.64 & 0.20 & $1.8 \%$ & 14.21 & 0.21 & $7.6 \%$ & 14.64 & 0.28 & $3.2 \%$ & 14.21 & 0.29 & 13.3 \\
\hline mar-10 & 14.84 & 0.27 & $3.0 \%$ & 14.43 & 0.28 & $12.5 \%$ & 14.84 & 0.25 & $2.5 \%$ & 14.43 & 0.25 & $10.5 \%$ & 14.84 & 0.26 & $2.7 \%$ & 14.43 & 0.26 & $11.2 \%$ \\
\hline jun-10 & 16.37 & 0.24 & $2.3 \%$ & 15.87 & 0.24 & $9.6 \%$ & 16.37 & 0.25 & $2.6 \%$ & 15.87 & 0.26 & $10.9 \%$ & 16.37 & 0.23 & $2.2 \%$ & 15.87 & 0.24 & $9.4 \%$ \\
\hline set-10 & 18.87 & 0.26 & $2.6 \%$ & 18.29 & 0.27 & $10.9 \%$ & 18.87 & 0.25 & $2.4 \%$ & 18.29 & 0.25 & $10.2 \%$ & 18.87 & 0.25 & $2.4 \%$ & 18.29 & 0.25 & $10.2 \mathrm{c}$ \\
\hline dez-10 & 19.80 & 0.26 & $2.7 \%$ & & 0.27 & $11.3 \%$ & 19.80 & 0.26 & $2.6 \%$ & & 0.2 & & 19.80 & 0.26 & $2.6 \%$ & 19.19 & 0.26 & 10.9 \\
\hline mar-11 & 20.16 & 0.24 & $2.6 \%$ & & 0.25 & $10.6 \%$ & & 0.24 & $2.7 \%$ & & 0.26 & $11.0 \%$ & 20.16 & & $2.6 \%$ & 19.29 & 0.25 & 10.7 \\
\hline jun-11 & 17.14 & 0.22 & $2.1 \%$ & 16.36 & 0.23 & $8.9 \%$ & 17.14 & 0.23 & $2.4 \%$ & 16.36 & 0.24 & $9.9 \%$ & 17.14 & 0.24 & $2.6 \%$ & 16.36 & 0.25 & 10.6 \\
\hline set-11 & 14.86 & 0.35 & $5.8 \%$ & 14.00 & 0.37 & $21.9 \%$ & 14.86 & 0.29 & $4.1 \%$ & 14.00 & 0.31 & $16.3 \%$ & 14.86 & 0.26 & $3.5 \%$ & 14.00 & 0.28 & 14.0 \\
\hline dez-11 & 16.55 & 0.24 & $2.8 \%$ & 15.75 & 0.25 & $11.6 \%$ & 16.55 & 0.31 & $4.4 \%$ & 15.75 & 0.32 & $17.3 \%$ & 16.55 & 0.27 & $3.4 \%$ & 15.75 & 0.28 & 13. \\
\hline mar-12 & 18.77 & 0.23 & $2.5 \%$ & 17.92 & 0.24 & $10.6 \%$ & 18.77 & 0.23 & $2.7 \%$ & 17.92 & 0.24 & $11.2 \%$ & 18.77 & 0.26 & $3.4 \%$ & 17.92 & 0.28 & 13.9 \\
\hline
\end{tabular}




\begin{tabular}{|c|c|c|c|c|c|c|c|c|c|c|c|c|c|c|c|c|c|c|}
\hline jun-12 & 21.79 & 0.26 & $3.1 \%$ & 21.01 & 0.27 & $12.7 \%$ & 21.79 & 0.24 & $2.7 \%$ & 21.01 & 0.25 & $11.4 \%$ & 21.79 & 0.28 & $3.6 \%$ & 21.01 & 0.29 & $14.5 \%$ \\
\hline set-12 & 26.33 & 0.24 & $2.8 \%$ & 25.43 & 0.25 & $11.7 \%$ & 26.33 & 0.25 & $2.9 \%$ & 25.43 & 0.26 & $12.3 \%$ & 26.33 & 0.24 & $2.8 \%$ & 25.43 & 0.25 & $11.6 \%$ \\
\hline dez-12 & 27.98 & 0.14 & $1.0 \%$ & 27.06 & 0.15 & $4.6 \%$ & 27.98 & 0.20 & $1.9 \%$ & 27.06 & 0.20 & $8.2 \%$ & 27.98 & 0.22 & $2.3 \%$ & 27.06 & 0.23 & $10.0 \%$ \\
\hline mar-13 & 25.34 & 0.23 & $3.0 \%$ & 24.24 & 0.24 & $12.7 \%$ & 25.34 & 0.19 & $2.0 \%$ & 24.24 & 0.20 & $8.8 \%$ & 25.34 & 0.22 & $2.6 \%$ & 24.24 & 0.23 & $11.1 \%$ \\
\hline jun-13 & 23.94 & 0.23 & $2.7 \%$ & 22.93 & 0.24 & $11.6 \%$ & 23.94 & 0.23 & $2.8 \%$ & 22.93 & 0.24 & $12.0 \%$ & 23.94 & 0.21 & $2.4 \%$ & 22.93 & 0.22 & $10.2 \%$ \\
\hline jun-05 & 2.71 & 0.29 & $9.0 \%$ & 1.97 & 0.42 & $36.1 \%$ & 2.71 & 0.31 & $9.7 \%$ & 1.96 & 0.45 & $38.6 \%$ & 2.71 & 0.29 & $9.0 \%$ & 1.97 & 0.42 & $36.1 \%$ \\
\hline set-05 & 3.77 & 0.35 & $10.4 \%$ & 2.88 & 0.47 & $38.6 \%$ & 3.77 & 0.34 & $10.0 \%$ & 2.88 & 0.46 & $37.6 \%$ & 3.77 & 0.32 & $9.3 \%$ & 2.89 & 0.43 & $35.1 \%$ \\
\hline dez-05 & 3.92 & 0.28 & $6.7 \%$ & 3.18 & 0.35 & $26.0 \%$ & 3.92 & 0.33 & $8.8 \%$ & 3.16 & 0.42 & $32.6 \%$ & 3.92 & 0.35 & $9.7 \%$ & 3.15 & 0.45 & $35.5 \%$ \\
\hline mar-06 & 3.99 & 0.27 & $6.2 \%$ & 3.29 & 0.33 & $24.2 \%$ & 3.99 & 0.28 & $6.5 \%$ & 3.29 & 0.34 & $25.0 \%$ & 3.99 & 0.33 & $8.5 \%$ & 3.28 & 0.40 & $31.4 \%$ \\
\hline jun-06 & 4.17 & 0.31 & $7.5 \%$ & 3.52 & 0.37 & $28.0 \%$ & 4.17 & 0.29 & $6.8 \%$ & 3.53 & 0.35 & $25.9 \%$ & 4.17 & 0.32 & $7.9 \%$ & 3.52 & 0.38 & $29.2 \%$ \\
\hline set-06 & 4.50 & 0.22 & $3.7 \%$ & 3.89 & 0.25 & $15.2 \%$ & 4.50 & 0.27 & $5.6 \%$ & 3.88 & 0.32 & $21.8 \%$ & 4.50 & 0.29 & $6.1 \%$ & 3.88 & 0.33 & $23.5 \%$ \\
\hline dez-06 & 6.08 & 0.25 & $4.3 \%$ & 5.39 & 0.28 & $17.2 \%$ & 6.08 & 0.23 & $4.0 \%$ & 5.39 & 0.26 & $16.0 \%$ & 6.08 & 0.28 & $5.4 \%$ & 5.39 & 0.32 & $21.0 \%$ \\
\hline mar-07 & 6.80 & 0.30 & $5.9 \%$ & 6.12 & 0.34 & $22.4 \%$ & 6.80 & 0.28 & $5.1 \%$ & 6.12 & 0.31 & $19.8 \%$ & 6.80 & 0.30 & $5.7 \%$ & 6.12 & 0.33 & $21.6 \%$ \\
\hline jun-07 & 9.19 & 0.23 & $3.2 \%$ & 8.41 & 0.25 & $13.2 \%$ & 9.19 & 0.27 & $4.6 \%$ & 8.41 & 0.30 & $17.9 \%$ & 9.19 & 0.26 & $4.2 \%$ & 8.41 & 0.29 & $16.8 \%$ \\
\hline set-07 & 8.74 & 0.31 & $6.1 \%$ & 8.00 & 0.34 & $22.9 \%$ & 8.74 & 0.27 & $4.7 \%$ & 8.01 & 0.30 & $18.4 \%$ & 8.74 & 0.28 & $4.9 \%$ & 8.01 & 0.31 & $19.1 \%$ \\
\hline dez-07 & 6.90 & 0.40 & $10.5 \%$ & 6.08 & 0.46 & $36.6 \%$ & 6.90 & 0.34 & $8.2 \%$ & 6.12 & 0.39 & $30.0 \%$ & 6.90 & 0.30 & $6.5 \%$ & 6.14 & 0.34 & $24.6 \%$ \\
\hline mar-08 & 6.28 & 0.41 & $11.7 \%$ & 5.42 & 0.49 & $40.6 \%$ & 6.28 & 0.39 & $10.9 \%$ & 5.44 & 0.47 & $38.4 \%$ & 6.28 & 0.32 & $7.9 \%$ & 5.50 & 0.38 & $29.2 \%$ \\
\hline jun-08 & 6.96 & 0.33 & $8.6 \%$ & 5.99 & 0.40 & $31.7 \%$ & 6.96 & 0.38 & $10.5 \%$ & 5.94 & 0.45 & $37.5 \%$ & 6.96 & 0.34 & $9.0 \%$ & 5.98 & 0.41 & $32.9 \%$ \\
\hline set- 08 & 6.19 & 0.28 & $7.4 \%$ & 5.08 & 0.35 & $28.7 \%$ & 6.19 & 0.29 & $7.7 \%$ & 5.07 & 0.36 & $29.9 \%$ & 6.19 & 0.32 & $9.1 \%$ & 5.03 & 0.41 & $34.6 \%$ \\
\hline dez-08 & 5.93 & 0.49 & $20.0 \%$ & 3.98 & 0.76 & $67.6 \%$ & 5.98 & 0.37 & $13.5 \%$ & 4.34 & 0.55 & $51.4 \%$ & 5.99 & 0.33 & $11.2 \%$ & 4.46 & 0.47 & $44.2 \%$ \\
\hline mar-09 & 6.84 & 0.30 & $8.3 \%$ & 5.68 & 0.37 & $32.1 \%$ & 6.82 & 0.43 & $15.2 \%$ & 5.34 & 0.59 & $53.5 \%$ & 6.83 & 0.36 & $11.5 \%$ & 5.54 & 0.47 & $42.8 \%$ \\
\hline jun-09 & 7.36 & 0.27 & $6.9 \%$ & 6.38 & 0.32 & $26.9 \%$ & 7.36 & 0.29 & $7.7 \%$ & 6.36 & 0.35 & $29.4 \%$ & 7.35 & 0.37 & $11.4 \%$ & 6.19 & 0.46 & $41.7 \%$ \\
\hline set-09 & 7.75 & 0.16 & $2.7 \%$ & 6.86 & 0.19 & $11.7 \%$ & 7.75 & 0.23 & $4.9 \%$ & 6.84 & 0.26 & $19.8 \%$ & 7.74 & 0.36 & $10.7 \%$ & 6.65 & 0.44 & $39.0 \%$ \\
\hline dez-09 & 9.91 & 0.19 & $4.1 \%$ & 8.61 & 0.22 & $17.0 \%$ & 9.91 & 0.17 & $3.4 \%$ & 8.62 & 0.20 & $14.5 \%$ & 9.91 & 0.23 & $5.5 \%$ & 8.57 & 0.27 & $22.1 \%$ \\
\hline mar-10 & 9.66 & 0.17 & $3.2 \%$ & 8.39 & 0.20 & $13.9 \%$ & 9.66 & 0.18 & $3.6 \%$ & 8.39 & 0.21 & $15.1 \%$ & 9.66 & 0.20 & $4.3 \%$ & 8.37 & 0.23 & $17.9 \%$ \\
\hline jun-10 & 8.25 & 0.16 & $3.7 \%$ & 6.77 & 0.20 & $16.2 \%$ & 8.25 & 0.16 & $3.4 \%$ & 6.78 & 0.19 & $15.0 \%$ & 8.25 & 0.15 & $3.2 \%$ & 6.78 & 0.19 & $14.3 \%$ \\
\hline set-10 & 9.37 & 0.17 & $3.4 \%$ & 7.87 & 0.21 & $14.9 \%$ & 9.37 & 0.19 & $3.9 \%$ & 7.86 & 0.22 & $16.8 \%$ & 9.37 & 0.18 & $3.7 \%$ & 7.86 & 0.22 & $15.9 \%$ \\
\hline dez-10 & 9.42 & 0.06 & $0.5 \%$ & 7.94 & 0.07 & $2.4 \%$ & 9.42 & 0.14 & $2.2 \%$ & 7.94 & 0.16 & $9.9 \%$ & 9.42 & 0.16 & $3.0 \%$ & 7.94 & 0.19 & $13.0 \%$ \\
\hline mar-11 & 7.45 & 0.18 & $4.8 \%$ & 5.83 & 0.24 & $21.1 \%$ & 7.45 & 0.14 & $2.9 \%$ & 5.88 & 0.17 & $13.2 \%$ & 7.45 & 0.14 & $3.2 \%$ & 5.88 & 0.18 & $14.5 \%$ \\
\hline jun-11 & 7.74 & 0.10 & $1.5 \%$ & 6.21 & 0.13 & $7.3 \%$ & 7.74 & 0.16 & $3.5 \%$ & 6.20 & 0.21 & $15.7 \%$ & 7.74 & 0.14 & $2.8 \%$ & 6.21 & 0.18 & $12.9 \%$ \\
\hline set-11 & 7.70 & 0.16 & $3.6 \%$ & 6.09 & 0.20 & $16.0 \%$ & 7.70 & 0.13 & $2.5 \%$ & 6.10 & 0.16 & $11.8 \%$ & 7.70 & 0.14 & $2.7 \%$ & 6.10 & 0.17 & $12.7 \%$ \\
\hline dez-11 & 8.53 & 0.16 & $3.3 \%$ & 7.03 & 0.20 & $14.7 \%$ & 8.53 & 0.17 & $3.6 \%$ & 7.03 & 0.21 & $15.6 \%$ & 8.53 & 0.17 & $3.6 \%$ & 7.03 & 0.21 & $15.7 \%$ \\
\hline mar-12 & 10.07 & 0.19 & $3.8 \%$ & 8.75 & 0.22 & $16.0 \%$ & 10.07 & 0.19 & $3.7 \%$ & 8.75 & 0.22 & $15.5 \%$ & 10.07 & 0.18 & $3.3 \%$ & 8.76 & 0.21 & $14.2 \%$ \\
\hline jun-12 & 10.52 & 0.03 & $0.1 \%$ & 9.28 & 0.03 & $0.4 \%$ & 10.52 & 0.14 & $2.2 \%$ & 9.28 & 0.16 & $9.7 \%$ & 10.52 & 0.17 & $3.0 \%$ & 9.27 & 0.19 & $12.9 \%$ \\
\hline set-12 & 10.92 & 0.03 & $0.1 \%$ & 9.69 & 0.03 & $0.5 \%$ & 10.92 & 0.03 & $0.1 \%$ & 9.69 & 0.03 & $0.4 \%$ & 10.92 & 0.13 & $2.0 \%$ & 9.69 & 0.15 & $9.0 \%$ \\
\hline dez-12 & 11.21 & 0.02 & & 10.04 & 0.02 & $0.2 \%$ & 11.21 & 0.03 & $0.1 \%$ & 10.04 & 0.03 & $0.4 \%$ & 11.21 & 0.10 & $1.2 \%$ & 10.04 & 0.11 & $5.5 \%$ \\
\hline mar-13 & 12.02 & 0.04 & $0.2 \%$ & 10.72 & 0.05 & $1.0 \%$ & 12.02 & 0.03 & $0.1 \%$ & 10.72 & 0.04 & $0.7 \%$ & 12.02 & 0.04 & $0.2 \%$ & 10.72 & 0.05 & $1.2 \%$ \\
\hline jun-13 & 13.23 & 0.05 & $0.3 \%$ & 11.66 & 0.06 & $1.6 \%$ & 13.23 & 0.05 & $0.3 \%$ & 11.66 & 0.05 & $1.3 \%$ & 13.23 & 0.04 & $0.2 \%$ & 11.66 & 0.04 & $0.9 \%$ \\
\hline
\end{tabular}




\begin{tabular}{|c|c|c|c|c|c|c|c|c|c|c|c|c|c|c|c|c|c|c|}
\hline jun-05 & 9.35 & 0.07 & $2.4 \%$ & 4.64 & 0.17 & $20.3 \%$ & 9.35 & 0.07 & $2.7 \%$ & 4.57 & 0.18 & $23.2 \%$ & 9.35 & 0.06 & $2.0 \%$ & 4.73 & 0.14 & $16.7 \%$ \\
\hline set-05 & 9.32 & 0.06 & $1.8 \%$ & 4.84 & 0.13 & $14.0 \%$ & 9.32 & 0.06 & $2.2 \%$ & 4.78 & 0.15 & $17.3 \%$ & 9.32 & 0.06 & $2.2 \%$ & 4.78 & 0.15 & $17.3 \%$ \\
\hline dez-05 & 10.55 & 0.05 & $1.6 \%$ & 5.66 & 0.11 & $12.4 \%$ & 10.55 & 0.05 & $1.6 \%$ & 5.66 & 0.11 & $12.4 \%$ & 10.55 & 0.06 & $2.0 \%$ & 5.55 & 0.14 & $16.9 \%$ \\
\hline mar-06 & 9.15 & 0.05 & $1.3 \%$ & 5.31 & 0.09 & $8.8 \%$ & 9.15 & 0.05 & $1.6 \%$ & 5.27 & 0.11 & $11.2 \%$ & 9.15 & 0.06 & $1.9 \%$ & 5.23 & 0.12 & $13.6 \%$ \\
\hline jun-06 & 9.34 & 0.06 & $2.0 \%$ & 5.40 & 0.13 & $15.5 \%$ & 9.34 & 0.05 & $1.6 \%$ & 5.50 & 0.10 & $11.4 \%$ & 9.34 & 0.05 & $1.6 \%$ & 5.50 & 0.10 & $11.5 \%$ \\
\hline set-06 & 9.68 & 0.04 & $1.1 \%$ & 5.90 & 0.07 & $7.2 \%$ & 9.68 & 0.05 & $1.4 \%$ & 5.84 & 0.09 & $10.4 \%$ & 9.68 & 0.04 & $1.3 \%$ & 5.85 & 0.08 & $9.6 \%$ \\
\hline dez-06 & 10.66 & 0.05 & $1.5 \%$ & 6.83 & 0.09 & $9.9 \%$ & 10.66 & 0.05 & $1.5 \%$ & 6.84 & 0.09 & $9.4 \%$ & 10.66 & 0.05 & $1.6 \%$ & 6.81 & 0.10 & $10.6 \%$ \\
\hline mar-07 & 10.48 & 0.05 & $1.5 \%$ & 6.85 & 0.09 & $9.7 \%$ & 10.48 & 0.05 & $1.6 \%$ & 6.85 & 0.09 & $9.8 \%$ & 10.48 & 0.06 & $1.8 \%$ & 6.82 & 0.10 & $11.2 \%$ \\
\hline jun-07 & 10.04 & 0.06 & $1.5 \%$ & 6.98 & 0.09 & $8.5 \%$ & 10.04 & 0.07 & $1.8 \%$ & 6.96 & 0.11 & $10.1 \%$ & 10.04 & 0.07 & $1.9 \%$ & 6.95 & 0.11 & $10.8 \%$ \\
\hline set- 07 & 10.60 & 0.12 & $4.1 \%$ & 7.33 & 0.20 & $23.3 \%$ & 10.60 & 0.10 & $2.9 \%$ & 7.54 & 0.15 & $16.1 \%$ & 10.60 & 0.09 & $2.7 \%$ & 7.58 & 0.14 & $14.4 \%$ \\
\hline dez-07 & 11.60 & 0.10 & $2.9 \%$ & 8.22 & 0.15 & $16.1 \%$ & 11.60 & 0.11 & $3.4 \%$ & 8.12 & 0.18 & $19.4 \%$ & 11.60 & 0.09 & $2.8 \%$ & 8.24 & 0.15 & $15.2 \%$ \\
\hline mar-08 & 11.92 & 0.14 & $5.1 \%$ & 8.07 & 0.25 & $29.0 \%$ & 11.93 & 0.12 & $4.1 \%$ & 8.32 & 0.20 & $22.8 \%$ & 11.93 & 0.11 & $3.6 \%$ & 8.43 & 0.18 & $19.6 \%$ \\
\hline jun-08 & 11.63 & 0.09 & $2.8 \%$ & 8.06 & 0.15 & $15.5 \%$ & 11.63 & 0.12 & $3.9 \%$ & 7.84 & 0.20 & $22.7 \%$ & 11.63 & 0.11 & $3.6 \%$ & 7.90 & 0.19 & $20.8 \%$ \\
\hline set-08 & 11.70 & 0.16 & $6.8 \%$ & 6.45 & 0.37 & $44.9 \%$ & 11.74 & 0.12 & $4.7 \%$ & 7.17 & 0.25 & $30.4 \%$ & 11.74 & 0.11 & $4.1 \%$ & 7.35 & 0.22 & $26.1 \%$ \\
\hline dez-08 & 11.69 & 0.25 & $14.1 \%$ & 4.02 & 0.76 & $78.8 \%$ & 11.95 & 0.18 & $9.3 \%$ & 5.18 & 0.53 & $63.1 \%$ & 12.07 & 0.14 & $6.0 \%$ & 6.43 & 0.34 & $43.6 \%$ \\
\hline mar-09 & 12.35 & 0.08 & $3.0 \%$ & 8.23 & 0.16 & $19.5 \%$ & 12.23 & 0.16 & $7.8 \%$ & 5.89 & 0.44 & $57.1 \%$ & 12.31 & 0.13 & $5.5 \%$ & 7.02 & 0.31 & $41.1 \%$ \\
\hline jun-09 & 12.93 & 0.07 & $2.2 \%$ & 9.43 & 0.11 & $12.9 \%$ & 12.93 & 0.07 & $2.5 \%$ & 9.34 & 0.12 & $15.0 \%$ & 12.88 & 0.12 & $5.3 \%$ & 7.84 & 0.29 & $39.4 \%$ \\
\hline set-09 & 13.75 & 0.06 & $1.2 \%$ & 10.66 & 0.08 & $6.4 \%$ & 13.75 & 0.08 & $2.1 \%$ & 10.59 & 0.11 & $10.8 \%$ & 13.71 & 0.15 & $6.2 \%$ & 9.32 & 0.29 & $36.4 \%$ \\
\hline dez-09 & 14.12 & 0.09 & $2.5 \%$ & 10.89 & 0.13 & $12.8 \%$ & 14.12 & 0.08 & $1.9 \%$ & 10.96 & 0.10 & $9.6 \%$ & 14.12 & 0.10 & $2.8 \%$ & 10.84 & 0.14 & $14.3 \%$ \\
\hline mar-10 & 15.69 & 0.05 & $1.3 \%$ & 11.71 & 0.07 & $7.4 \%$ & 15.69 & 0.05 & $1.5 \%$ & 11.68 & 0.08 & $8.5 \%$ & 15.69 & 0.05 & $1.5 \%$ & 11.67 & 0.08 & $8.7 \%$ \\
\hline jun-10 & 15.80 & 0.05 & $1.3 \%$ & 11.30 & 0.08 & $7.3 \%$ & 15.80 & 0.05 & $1.4 \%$ & 11.28 & 0.08 & $8.0 \%$ & 15.80 & 0.05 & $1.4 \%$ & 11.29 & 0.08 & $7.8 \%$ \\
\hline set-10 & 15.42 & 0.04 & $0.8 \%$ & 10.86 & 0.06 & $4.6 \%$ & 15.42 & 0.04 & $1.0 \%$ & 10.84 & 0.06 & $5.9 \%$ & 15.42 & 0.05 & $1.3 \%$ & 10.81 & 0.07 & $7.3 \%$ \\
\hline dez-10 & 16.55 & 0.05 & $1.1 \%$ & 11.67 & 0.07 & $6.3 \%$ & 16.55 & 0.04 & $1.0 \%$ & 11.68 & 0.06 & $5.6 \%$ & 16.55 & 0.05 & $1.2 \%$ & 11.65 & 0.07 & $7.0 \%$ \\
\hline mar-11 & 16.81 & 0.05 & $1.0 \%$ & 11.69 & 0.07 & $5.9 \%$ & 16.81 & 0.05 & $1.2 \%$ & 11.68 & 0.08 & $6.6 \%$ & 16.81 & 0.05 & $1.2 \%$ & 11.67 & 0.08 & $7.1 \%$ \\
\hline jun-11 & 17.18 & 0.06 & $1.6 \%$ & 11.77 & 0.10 & $9.0 \%$ & 17.18 & 0.06 & $1.3 \%$ & 11.79 & 0.09 & $7.5 \%$ & 17.18 & 0.06 & $1.3 \%$ & 11.80 & 0.08 & $7.3 \%$ \\
\hline set-11 & 18.30 & 0.05 & $1.5 \%$ & 12.13 & 0.09 & $9.3 \%$ & 18.30 & 0.05 & $1.3 \%$ & 12.18 & 0.08 & $8.0 \%$ & 18.30 & 0.04 & $1.1 \%$ & 12.22 & 0.07 & $6.6 \%$ \\
\hline dez-11 & 21.28 & 0.04 & $1.3 \%$ & 14.42 & 0.08 & $8.7 \%$ & 21.28 & 0.04 & $1.3 \%$ & 14.43 & 0.07 & $8.3 \%$ & 21.28 & 0.04 & $1.1 \%$ & 14.52 & 0.06 & $6.6 \%$ \\
\hline mar-12 & 53.41 & 0.01 & $0.4 \%$ & 37.28 & 0.02 & $2.2 \%$ & 53.41 & 0.02 & $0.5 \%$ & 37.18 & 0.03 & $3.2 \%$ & 53.41 & 0.02 & $0.5 \%$ & 37.17 & 0.03 & $3.3 \%$ \\
\hline jun-12 & 56.65 & 0.05 & $1.6 \%$ & 42.00 & 0.08 & $9.2 \%$ & 56.65 & 0.05 & $1.3 \%$ & 42.29 & 0.07 & $7.1 \%$ & 56.65 & 0.05 & $1.4 \%$ & 42.20 & 0.07 & $7.8 \%$ \\
\hline set-12 & 59.36 & 0.05 & $1.6 \%$ & 45.56 & 0.08 & $9.0 \%$ & 59.36 & 0.05 & $1.6 \%$ & 45.57 & 0.08 & $9.0 \%$ & 59.37 & 0.05 & $1.4 \%$ & 45.76 & 0.07 & $7.8 \%$ \\
\hline dez-12 & 61.89 & 0.03 & $0.6 \%$ & 48.85 & 0.04 & $3.3 \%$ & 61.89 & 0.04 & $1.2 \%$ & 48.61 & 0.06 & $6.2 \%$ & 61.89 & 0.04 & $1.2 \%$ & 48.58 & 0.06 & $6.3 \%$ \\
\hline mar-13 & 60.32 & 0.04 & $1.0 \%$ & 46.81 & 0.05 & $5.8 \%$ & 60.32 & 0.03 & $0.8 \%$ & 46.99 & 0.04 & $4.4 \%$ & 60.32 & 0.04 & $1.1 \%$ & 46.80 & 0.05 & $5.9 \%$ \\
\hline jun-13 & 57.16 & 0.05 & $2.0 \%$ & 39.06 & 0.12 & $18.9 \%$ & 57.21 & 0.04 & $1.4 \%$ & 41.62 & 0.07 & $10.3 \%$ & 57.22 & 0.03 & $1.0 \%$ & 42.43 & 0.05 & $6.8 \%$ \\
\hline jun-05 & 7.67 & 0.13 & $3.0 \%$ & 4.98 & 0.20 & $15.8 \%$ & 7.67 & 0.13 & $3.2 \%$ & 4.98 & 0.20 & $16.6 \%$ & 7.67 & 0.12 & $3.0 \%$ & 4.98 & 0.19 & $15.6 \%$ \\
\hline set-05 & 8.68 & 0.10 & $1.7 \%$ & 6.04 & 0.15 & $8.7 \%$ & 8.68 & 0.13 & $2.6 \%$ & 6.03 & 0.19 & $13.1 \%$ & 8.68 & 0.14 & $3.0 \%$ & 6.03 & 0.20 & $14.6 \%$ \\
\hline dez-05 & 9.91 & 0.14 & $2.8 \%$ & 7.17 & 0.19 & $13.3 \%$ & 9.91 & 0.12 & $2.2 \%$ & 7.17 & 0.17 & $11.0 \%$ & 9.91 & 0.15 & $3.1 \%$ & 7.17 & 0.20 & $14.7 \%$ \\
\hline mar-06 & 10.59 & 0.20 & $4.8 \%$ & 8.04 & 0.27 & $20.9 \%$ & 10.59 & 0.18 & $3.9 \%$ & 8.06 & 0.23 & $17.3 \%$ & 10.59 & 0.16 & $3.4 \%$ & 8.06 & 0.22 & $15.4 \%$ \\
\hline jun-06 & 8.97 & 0.16 & $3.6 \%$ & 6.70 & 0.21 & $16.6 \%$ & 8.97 & 0.17 & $4.0 \%$ & 6.69 & 0.23 & $18.4 \%$ & 8.97 & 0.15 & $3.2 \%$ & 6.71 & 0.20 & $15.1 \%$ \\
\hline set-06 & 8.64 & 0.13 & $3.0 \%$ & 6.34 & 0.18 & $14.5 \%$ & 8.64 & 0.13 & $3.1 \%$ & 6.34 & 0.19 & $15.2 \%$ & 8.64 & 0.14 & $3.2 \%$ & 6.34 & 0.19 & $15.5 \%$ \\
\hline dez-06 & 10.38 & 0.16 & $3.8 \%$ & 7.93 & 0.21 & $17.2 \%$ & 10.38 & 0.15 & $3.6 \%$ & 7.94 & 0.20 & $16.6 \%$ & 10.38 & 0.16 & $3.7 \%$ & 7.93 & 0.21 & $17.2 \%$ \\
\hline
\end{tabular}




\begin{tabular}{|c|c|c|c|c|c|c|c|c|c|c|c|c|c|c|c|c|c|c|}
\hline mar-07 & 9.06 & 0.11 & $2.1 \%$ & 6.89 & 0.14 & $10.2 \%$ & 9.06 & 0.13 & $2.9 \%$ & 6.87 & 0.17 & $13.8 \%$ & 9.06 & 0.13 & $3.1 \%$ & 6.87 & 0.18 & $14.5 \%$ \\
\hline dez-07 & 10.92 & 0.14 & $3.7 \%$ & 8.40 & 0.20 & $17.5 \%$ & 10.92 & 0.15 & $4.0 \%$ & 8.38 & 0.20 & $18.5 \%$ & 10.92 & 0.13 & $3.1 \%$ & 8.44 & 0.17 & $14.5 \%$ \\
\hline jun-08 & 11.04 & 0.14 & $3.4 \%$ & 8.44 & 0.19 & $16.0 \%$ & 11.04 & 0.15 & $3.8 \%$ & 8.43 & 0.20 & $17.6 \%$ & 11.04 & 0.15 & $3.9 \%$ & 8.42 & 0.21 & $18.2 \%$ \\
\hline set-08 & 10.71 & 0.18 & $5.3 \%$ & 7.84 & 0.26 & $24.8 \%$ & 10.71 & 0.16 & $4.3 \%$ & 7.91 & 0.23 & $20.3 \%$ & 10.71 & 0.16 & $4.2 \%$ & 7.92 & 0.22 & $19.6 \%$ \\
\hline dez-08 & 10.94 & 0.27 & $10.6 \%$ & 7.03 & 0.47 & $49.5 \%$ & 10.98 & 0.22 & $7.8 \%$ & 7.50 & 0.36 & $37.5 \%$ & 10.99 & 0.18 & $5.7 \%$ & 7.79 & 0.28 & $27.7 \%$ \\
\hline mar-09 & 10.92 & 0.12 & $2.9 \%$ & 8.39 & 0.17 & $14.0 \%$ & 10.91 & 0.21 & $7.1 \%$ & 7.93 & 0.32 & $33.8 \%$ & 10.92 & 0.18 & $5.5 \%$ & 8.17 & 0.26 & $26.1 \%$ \\
\hline dez-09 & 19.38 & 0.14 & $2.8 \%$ & 16.33 & 0.17 & $12.5 \%$ & 19.38 & 0.12 & $2.2 \%$ & 16.35 & 0.15 & $10.2 \%$ & 19.38 & 0.14 & $3.0 \%$ & 16.33 & 0.17 & $13.1 \%$ \\
\hline mar-10 & 19.01 & 0.13 & $2.4 \%$ & 15.92 & 0.15 & $11.1 \%$ & 19.01 & 0.13 & $2.6 \%$ & 15.91 & 0.16 & $11.8 \%$ & 19.01 & 0.13 & $2.6 \%$ & 15.91 & 0.16 & $11.8 \%$ \\
\hline jun-10 & 19.71 & 0.14 & $2.9 \%$ & 16.19 & 0.18 & $13.2 \%$ & 19.71 & 0.14 & $2.7 \%$ & 16.19 & 0.17 & $12.2 \%$ & 19.71 & 0.13 & $2.5 \%$ & 16.20 & 0.16 & $11.5 \%$ \\
\hline set-10 & 19.71 & 0.11 & $2.0 \%$ & 15.91 & 0.14 & $9.7 \%$ & 19.71 & 0.12 & $2.4 \%$ & 15.90 & 0.15 & $11.2 \%$ & 19.71 & 0.13 & $2.5 \%$ & 15.90 & 0.16 & $11.6 \%$ \\
\hline dez-10 & 28.69 & 0.09 & $1.7 \%$ & 22.33 & 0.12 & $8.2 \%$ & 28.69 & 0.09 & $1.7 \%$ & 22.33 & 0.12 & $8.5 \%$ & 28.69 & 0.10 & $2.0 \%$ & 22.32 & 0.13 & $9.8 \%$ \\
\hline mar-11 & 28.56 & 0.09 & $1.7 \%$ & 21.74 & 0.12 & $8.5 \%$ & 28.56 & 0.09 & $1.7 \%$ & 21.74 & 0.12 & $8.3 \%$ & 28.56 & 0.10 & $1.9 \%$ & 21.73 & 0.13 & $9.3 \%$ \\
\hline jun-12 & 34.45 & 0.11 & $2.4 \%$ & 28.25 & 0.14 & $11.2 \%$ & 34.45 & 0.11 & $2.1 \%$ & 28.27 & 0.13 & $10.0 \%$ & 34.45 & 0.12 & $2.7 \%$ & 28.21 & 0.15 & $12.5 \%$ \\
\hline set-12 & 36.96 & 0.09 & $1.5 \%$ & 31.26 & 0.10 & $6.9 \%$ & 36.96 & 0.10 & $2.0 \%$ & 31.23 & 0.12 & $9.2 \%$ & 36.96 & 0.11 & $2.3 \%$ & 31.21 & 0.14 & $10.5 \%$ \\
\hline dez-12 & 37.36 & 0.08 & $1.2 \%$ & 31.88 & 0.09 & $5.8 \%$ & 37.36 & 0.09 & $1.4 \%$ & 31.88 & 0.10 & $6.6 \%$ & 37.36 & 0.10 & $1.8 \%$ & 31.86 & 0.12 & $8.2 \%$ \\
\hline mar-13 & 38.63 & 0.10 & $1.5 \%$ & 33.41 & 0.11 & $7.1 \%$ & 38.63 & 0.09 & $1.4 \%$ & 33.41 & 0.11 & $6.8 \%$ & 38.63 & 0.11 & $1.8 \%$ & 33.40 & 0.13 & $8.4 \%$ \\
\hline jun-13 & 36.68 & 0.12 & $2.2 \%$ & 31.25 & 0.14 & $10.2 \%$ & 36.68 & 0.11 & $1.9 \%$ & 31.26 & 0.13 & $8.7 \%$ & 36.68 & 0.11 & $1.8 \%$ & 31.27 & 0.12 & $8.2 \%$ \\
\hline jun-05 & 82.11 & 0.03 & $0.7 \%$ & 42.14 & 0.06 & $5.3 \%$ & 82.11 & 0.03 & $0.7 \%$ & 42.14 & 0.06 & $5.2 \%$ & 82.11 & 0.03 & $0.6 \%$ & 42.17 & 0.06 & $4.6 \%$ \\
\hline set-05 & 123.03 & 0.10 & $1.9 \%$ & 82.90 & 0.15 & $9.9 \%$ & 123.03 & 0.11 & $2.0 \%$ & 82.89 & 0.16 & $10.6 \%$ & 123.03 & 0.11 & $2.0 \%$ & 82.89 & 0.16 & $10.7 \%$ \\
\hline dez-05 & 133.08 & 0.14 & $3.4 \%$ & 90.61 & 0.21 & $17.1 \%$ & 133.08 & 0.12 & $2.6 \%$ & 90.88 & 0.18 & $13.5 \%$ & 133.08 & 0.11 & $2.3 \%$ & 90.94 & 0.17 & $12.1 \%$ \\
\hline mar-06 & 139.41 & 0.14 & $3.1 \%$ & 100.88 & 0.20 & $14.8 \%$ & 139.41 & 0.15 & $3.4 \%$ & 100.79 & 0.21 & $16.2 \%$ & 139.41 & 0.13 & $2.8 \%$ & 100.95 & 0.18 & $13.4 \%$ \\
\hline jun-06 & 138.42 & 0.15 & $3.3 \%$ & 102.96 & 0.20 & $15.3 \%$ & 138.42 & 0.14 & $3.2 \%$ & 102.97 & 0.20 & $15.0 \%$ & 138.42 & 0.14 & $3.1 \%$ & 103.01 & 0.19 & $14.4 \%$ \\
\hline set-06 & 141.68 & 0.12 & $2.3 \%$ & 105.09 & 0.16 & $11.5 \%$ & 141.68 & 0.13 & $2.7 \%$ & 105.00 & 0.17 & $13.1 \%$ & 141.68 & 0.13 & $3.0 \%$ & 104.91 & 0.18 & $14.3 \%$ \\
\hline dez-06 & 164.24 & 0.10 & $1.6 \%$ & 126.49 & 0.13 & $8.2 \%$ & 164.24 & 0.12 & $2.2 \%$ & 126.45 & 0.15 & $10.4 \%$ & 164.24 & 0.13 & $2.6 \%$ & 126.36 & 0.17 & $12.4 \%$ \\
\hline
\end{tabular}




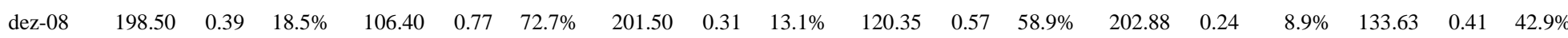
\begin{tabular}{llllllllllllllllllll} 
mar-09 & 230.34 & 0.18 & $5.1 \%$ & 176.20 & 0.25 & $23.4 \%$ & 228.88 & 0.31 & $12.7 \%$ & 151.84 & 0.53 & $54.9 \%$ & 229.88 & 0.26 & $9.3 \%$ & 163.81 & 0.41 & $42.3 \%$ \\
\hline
\end{tabular} $\begin{array}{lllll}9.9 \% & 182.87 & 0.41 & 42.2 \%\end{array}$ \begin{tabular}{lllllllllllllllllll} 
set-09 & 271.35 & 0.10 & $1.7 \%$ & 224.87 & 0.12 & $8.0 \%$ & 271.35 & 0.12 & $2.5 \%$ & 224.58 & 0.15 & $11.3 \%$ & 271.09 & 0.24 & $8.2 \%$ & 211.03 & 0.35 & $36.0 \%$ \\
\hline
\end{tabular} $\begin{array}{lllllllllllllllllll}\text { dez-09 } & 288.03 & 0.11 & 2.2 \% & 238.74 & 0.14 & 10.1 \% & 288.03 & 0.11 & 2.0 \% & 238.82 & 0.13 & 9.2 \% & 288.03 & 0.14 & 3.2 \% & 237.92 & 0.17 & 14.5 \%\end{array}$ 


\begin{tabular}{|c|c|c|c|c|c|c|c|c|c|c|c|c|c|c|c|c|c|c|}
\hline set-10 & 2.49 & 0.07 & $1.3 \%$ & 1.86 & 0.09 & $6.9 \%$ & 2.49 & 0.08 & $1.9 \%$ & 1.86 & 0.11 & $9.7 \%$ & 2.49 & 0.09 & $2.1 \%$ & 1.86 & 0.12 & $10.6 \%$ \\
\hline dez-10 & 2.74 & 0.10 & $2.5 \%$ & 2.09 & 0.14 & $12.2 \%$ & 2.74 & 0.09 & $2.1 \%$ & 2.09 & 0.13 & $10.2 \%$ & 2.74 & 0.10 & $2.5 \%$ & 2.09 & 0.14 & $12.0 \%$ \\
\hline mar-11 & 2.58 & 0.13 & $3.4 \%$ & 1.92 & 0.18 & $16.6 \%$ & 2.58 & 0.12 & $3.0 \%$ & 1.93 & 0.17 & $14.6 \%$ & 2.58 & 0.11 & $2.6 \%$ & 1.93 & 0.15 & $12.9 \%$ \\
\hline jun-11 & 2.79 & 0.09 & $1.9 \%$ & 2.06 & 0.12 & $9.6 \%$ & 2.79 & 0.11 & $2.6 \%$ & 2.05 & 0.15 & $13.0 \%$ & 2.79 & 0.10 & $2.3 \%$ & 2.05 & 0.14 & $11.7 \%$ \\
\hline set-11 & 2.91 & 0.14 & $4.1 \%$ & 2.09 & 0.21 & $21.2 \%$ & 2.91 & 0.11 & $3.0 \%$ & 2.12 & 0.16 & $15.1 \%$ & 2.91 & 0.11 & $2.9 \%$ & 2.13 & 0.16 & $14.5 \%$ \\
\hline dez-11 & 2.92 & 0.10 & $2.3 \%$ & 2.22 & 0.13 & $11.2 \%$ & 2.92 & 0.12 & $3.2 \%$ & 2.20 & 0.17 & $15.9 \%$ & 2.92 & 0.11 & $2.9 \%$ & 2.21 & 0.16 & $14.3 \%$ \\
\hline mar-12 & 3.29 & 0.11 & $2.4 \%$ & 2.64 & 0.14 & $11.2 \%$ & 3.29 & 0.11 & $2.5 \%$ & 2.64 & 0.15 & $11.6 \%$ & 3.29 & 0.13 & $3.0 \%$ & 2.63 & 0.16 & $13.9 \%$ \\
\hline jun-12 & 3.35 & 0.15 & $4.3 \%$ & 2.70 & 0.20 & $19.7 \%$ & 3.35 & 0.13 & $3.3 \%$ & 2.72 & 0.17 & $15.1 \%$ & 3.35 & 0.13 & $3.4 \%$ & 2.72 & 0.17 & $15.6 \%$ \\
\hline set-12 & 3.52 & 0.15 & $3.3 \%$ & 3.02 & 0.18 & $14.3 \%$ & 3.52 & 0.17 & $4.2 \%$ & 3.01 & 0.21 & $17.9 \%$ & 3.52 & 0.15 & $3.5 \%$ & 3.02 & 0.18 & $15.0 \%$ \\
\hline dez-12 & 3.82 & 0.14 & $2.7 \%$ & 3.32 & 0.16 & $12.0 \%$ & 3.82 & 0.15 & $3.3 \%$ & 3.32 & 0.18 & $14.1 \%$ & 3.82 & 0.16 & $3.5 \%$ & 3.31 & 0.18 & $14.9 \%$ \\
\hline mar-13 & 4.52 & 0.13 & $2.5 \%$ & 3.89 & 0.15 & $11.1 \%$ & 4.52 & 0.13 & $2.6 \%$ & 3.89 & 0.15 & $11.5 \%$ & 4.52 & 0.15 & $3.3 \%$ & 3.88 & 0.17 & $14.4 \%$ \\
\hline jun-13 & 4.26 & 0.12 & $2.3 \%$ & 3.59 & 0.14 & $10.6 \%$ & 4.26 & 0.12 & $2.4 \%$ & 3.59 & 0.14 & $10.7 \%$ & 4.26 & 0.13 & $2.8 \%$ & 3.59 & 0.16 & $12.5 \%$ \\
\hline jun-05 & 0.81 & 0.09 & $1.7 \%$ & 0.52 & 0.14 & $9.4 \%$ & 0.81 & 0.08 & $1.5 \%$ & 0.52 & 0.13 & $8.2 \%$ & 0.81 & 0.09 & $1.6 \%$ & 0.52 & 0.14 & $9.2 \%$ \\
\hline set-05 & 0.84 & 0.12 & $2.3 \%$ & 0.57 & 0.17 & $12.0 \%$ & 0.84 & 0.11 & $2.1 \%$ & 0.57 & 0.16 & $11.1 \%$ & 0.84 & 0.10 & $1.9 \%$ & 0.57 & 0.15 & $10.0 \%$ \\
\hline dez-05 & 0.96 & 0.12 & $2.4 \%$ & 0.67 & 0.17 & $12.1 \%$ & 0.96 & 0.12 & $2.4 \%$ & 0.67 & 0.17 & $11.9 \%$ & 0.96 & 0.11 & $2.1 \%$ & 0.67 & 0.16 & $10.5 \%$ \\
\hline mar-06 & 1.06 & 0.13 & $2.6 \%$ & 0.79 & 0.18 & $12.5 \%$ & 1.06 & 0.13 & $2.6 \%$ & 0.79 & 0.18 & $12.6 \%$ & 1.06 & 0.13 & $2.5 \%$ & 0.79 & 0.18 & $12.0 \%$ \\
\hline jun-06 & 0.93 & 0.18 & $4.8 \%$ & 0.69 & 0.26 & $21.6 \%$ & 0.93 & 0.16 & $3.8 \%$ & 0.69 & 0.22 & $17.5 \%$ & 0.93 & 0.15 & $3.1 \%$ & 0.69 & 0.20 & $14.7 \%$ \\
\hline set-06 & 0.96 & 0.12 & $2.3 \%$ & 0.73 & 0.16 & $11.2 \%$ & 0.96 & 0.15 & $3.5 \%$ & 0.73 & 0.21 & $16.4 \%$ & 0.96 & 0.14 & $3.1 \%$ & 0.73 & 0.19 & $14.5 \%$ \\
\hline dez-06 & 1.14 & 0.14 & $2.7 \%$ & 0.91 & 0.18 & $12.6 \%$ & 1.14 & 0.15 & $2.8 \%$ & 0.91 & 0.18 & $12.9 \%$ & 1.14 & 0.16 & $3.4 \%$ & 0.91 & 0.20 & $15.0 \%$ \\
\hline mar-07 & 1.35 & 0.19 & $4.1 \%$ & 1.11 & 0.24 & $17.6 \%$ & 1.35 & 0.18 & $3.5 \%$ & 1.11 & 0.22 & $15.3 \%$ & 1.35 & 0.19 & $3.9 \%$ & 1.11 & 0.23 & $16.6 \%$ \\
\hline jun-07 & 1.80 & 0.15 & $2.6 \%$ & 1.50 & 0.18 & $11.5 \%$ & 1.80 & 0.18 & $3.5 \%$ & 1.50 & 0.22 & $15.2 \%$ & 1.80 & 0.17 & $3.2 \%$ & 1.50 & 0.21 & $14.0 \%$ \\
\hline set-07 & 1.87 & 0.22 & $5.0 \%$ & 1.57 & 0.26 & $20.4 \%$ & 1.87 & 0.19 & $3.8 \%$ & 1.57 & 0.22 & $16.2 \%$ & 1.87 & 0.18 & $3.7 \%$ & 1.57 & 0.22 & $15.7 \%$ \\
\hline dez-07 & 1.86 & 0.22 & $5.0 \%$ & 1.55 & 0.26 & $20.7 \%$ & 1.86 & 0.21 & $4.9 \%$ & 1.55 & 0.26 & $20.4 \%$ & 1.86 & 0.20 & $4.3 \%$ & 1.55 & 0.24 & $18.0 \%$ \\
\hline mar-08 & 1.72 & 0.22 & $6.5 \%$ & 1.35 & 0.30 & $28.0 \%$ & 1.72 & 0.20 & $5.5 \%$ & 1.36 & 0.27 & $23.9 \%$ & 1.72 & 0.18 & $4.6 \%$ & 1.37 & 0.24 & $20.3 \%$ \\
\hline jun- 08 & 1.82 & 0.18 & $4.1 \%$ & 1.49 & 0.23 & $17.6 \%$ & 1.82 & 0.22 & $5.8 \%$ & 1.48 & 0.29 & $23.9 \%$ & 1.82 & 0.21 & $5.3 \%$ & 1.48 & 0.27 & $22.1 \%$ \\
\hline set- 08 & 1.70 & 0.23 & $7.9 \%$ & 1.18 & 0.37 & $37.3 \%$ & 1.70 & 0.19 & $6.0 \%$ & 1.22 & 0.29 & $28.4 \%$ & 1.70 & 0.18 & $5.4 \%$ & 1.23 & 0.27 & $25.7 \%$ \\
\hline dez-08 & 1.35 & 0.28 & $13.1 \%$ & 0.69 & 0.61 & $65.1 \%$ & 1.37 & 0.22 & $9.6 \%$ & 0.78 & 0.46 & $51.8 \%$ & 1.37 & 0.18 & $6.6 \%$ & 0.87 & 0.33 & $37.0 \%$ \\
\hline mar-09 & 1.33 & 0.10 & $2.8 \%$ & 0.96 & 0.15 & $15.0 \%$ & 1.33 & 0.19 & $7.9 \%$ & 0.82 & 0.38 & $45.2 \%$ & 1.33 & 0.16 & $5.9 \%$ & 0.89 & 0.29 & $33.6 \%$ \\
\hline jun-09 & 1.55 & 0.21 & $6.8 \%$ & 1.21 & 0.30 & $30.7 \%$ & 1.55 & 0.19 & $5.6 \%$ & 1.23 & 0.25 & $25.2 \%$ & 1.55 & 0.25 & $9.1 \%$ & 1.16 & 0.39 & $40.9 \%$ \\
\hline set-09 & 2.12 & 0.14 & $3.2 \%$ & 1.74 & 0.17 & $14.3 \%$ & 2.12 & 0.18 & $5.1 \%$ & 1.72 & 0.24 & $22.7 \%$ & 2.11 & 0.24 & $8.4 \%$ & 1.63 & 0.36 & $37.3 \%$ \\
\hline dez-09 & 2.27 & 0.15 & $3.3 \%$ & 1.89 & 0.18 & $14.4 \%$ & 2.27 & 0.15 & $3.3 \%$ & 1.89 & 0.18 & $14.6 \%$ & 2.27 & 0.18 & $4.8 \%$ & 1.88 & 0.23 & $20.5 \%$ \\
\hline mar-10 & 2.28 & 0.10 & $1.8 \%$ & 1.87 & 0.12 & $8.6 \%$ & 2.28 & 0.11 & $2.4 \%$ & 1.87 & 0.14 & $11.1 \%$ & 2.28 & 0.15 & $3.9 \%$ & 1.85 & 0.19 & $17.7 \%$ \\
\hline jun-10 & 2.90 & 0.18 & $3.9 \%$ & 2.43 & 0.22 & $16.6 \%$ & 2.90 & 0.16 & $3.1 \%$ & 2.44 & 0.19 & $13.4 \%$ & 2.90 & 0.17 & $3.4 \%$ & 2.43 & 0.20 & $14.7 \%$ \\
\hline set-10 & 3.49 & 0.13 & $2.3 \%$ & 2.89 & 0.16 & $10.5 \%$ & 3.49 & 0.15 & $3.1 \%$ & 2.89 & 0.19 & $13.6 \%$ & 3.49 & 0.15 & $3.0 \%$ & 2.89 & 0.18 & $13.2 \%$ \\
\hline dez-10 & 3.72 & 0.18 & $4.2 \%$ & 3.05 & 0.22 & $18.0 \%$ & 3.72 & 0.16 & $3.3 \%$ & 3.06 & 0.19 & $14.5 \%$ & 3.72 & 0.15 & $3.1 \%$ & 3.06 & 0.19 & $13.9 \%$ \\
\hline mar-11 & 3.65 & 0.14 & $3.1 \%$ & 2.90 & 0.18 & $13.9 \%$ & 3.65 & 0.15 & $3.5 \%$ & 2.90 & 0.20 & $15.6 \%$ & 3.65 & 0.15 & $3.2 \%$ & 2.90 & 0.19 & $14.5 \%$ \\
\hline jun-11 & 3.72 & 0.14 & $2.4 \%$ & 3.01 & 0.17 & $11.0 \%$ & 3.72 & 0.15 & $2.8 \%$ & 3.01 & 0.18 & $12.8 \%$ & 3.72 & 0.16 & $3.1 \%$ & 3.01 & 0.19 & $13.9 \%$ \\
\hline set-11 & 3.43 & 0.20 & $5.3 \%$ & 2.68 & 0.26 & $23.4 \%$ & 3.43 & 0.16 & $3.8 \%$ & 2.71 & 0.21 & $16.9 \%$ & 3.43 & 0.16 & $3.7 \%$ & 2.71 & 0.20 & $16.5 \%$ \\
\hline dez-11 & 3.25 & 0.15 & $3.6 \%$ & 2.55 & 0.19 & $16.3 \%$ & 3.25 & 0.16 & $4.2 \%$ & 2.54 & 0.22 & $19.3 \%$ & 3.25 & 0.14 & $3.4 \%$ & 2.55 & 0.18 & $15.5 \%$ \\
\hline mar-12 & 3.84 & 0.12 & $2.1 \%$ & 3.20 & 0.15 & $9.6 \%$ & 3.84 & 0.15 & $3.2 \%$ & 3.20 & 0.18 & $14.1 \%$ & 3.84 & 0.16 & $3.6 \%$ & 3.19 & 0.20 & $15.7 \%$ \\
\hline
\end{tabular}




\begin{tabular}{|c|c|c|c|c|c|c|c|c|c|c|c|c|c|c|c|c|c|c|}
\hline jun-12 & 3.62 & 0.13 & $3.0 \%$ & 2.98 & 0.16 & $13.5 \%$ & 3.62 & 0.12 & $2.5 \%$ & 2.99 & 0.15 & $11.6 \%$ & 3.62 & 0.14 & $3.4 \%$ & 2.98 & 0.17 & $15.2 \%$ \\
\hline set-12 & 3.92 & 0.17 & $3.8 \%$ & 3.38 & 0.20 & $16.3 \%$ & 3.92 & 0.16 & $3.7 \%$ & 3.38 & 0.19 & $15.8 \%$ & 3.92 & 0.16 & $3.4 \%$ & 3.38 & 0.19 & $14.8 \%$ \\
\hline dez-12 & 4.30 & 0.16 & $3.7 \%$ & 3.72 & 0.19 & $15.9 \%$ & 4.30 & 0.16 & $3.8 \%$ & 3.72 & 0.19 & $16.1 \%$ & 4.30 & 0.15 & $3.3 \%$ & 3.73 & 0.18 & $14.3 \%$ \\
\hline mar-13 & 4.88 & 0.11 & $2.1 \%$ & 4.17 & 0.13 & $9.6 \%$ & 4.88 & 0.13 & $2.7 \%$ & 4.16 & 0.15 & $12.1 \%$ & 4.88 & 0.13 & $3.0 \%$ & 4.15 & 0.16 & $13.3 \%$ \\
\hline jun-13 & 4.59 & 0.12 & $2.3 \%$ & 3.88 & 0.14 & $10.4 \%$ & 4.59 & 0.11 & $2.2 \%$ & 3.88 & 0.14 & $10.0 \%$ & 4.59 & 0.13 & $2.9 \%$ & 3.87 & 0.16 & $2.7 \%$ \\
\hline jun-05 & 4.32 & 0.11 & $3.4 \%$ & 2.52 & 0.21 & $20.3 \%$ & 4.32 & 0.10 & $2.7 \%$ & 2.55 & 0.17 & $16.0 \%$ & 4.32 & 0.08 & $2.1 \%$ & 2.56 & 0.15 & $2.5 \%$ \\
\hline set- 05 & 4.51 & 0.10 & $2.2 \%$ & 2.85 & 0.16 & $12.5 \%$ & 4.51 & 0.12 & $3.2 \%$ & 2.83 & 0.20 & $17.5 \%$ & 4.51 & 0.11 & $2.7 \%$ & 2.84 & 0.18 & $4.7 \%$ \\
\hline dez-05 & 4.96 & 0.08 & $1.8 \%$ & 3.14 & 0.13 & $10.3 \%$ & 4.96 & 0.08 & $1.9 \%$ & 3.14 & 0.14 & $10.8 \%$ & 4.96 & 0.10 & $2.4 \%$ & 3.13 & 0.16 & $13.7 \%$ \\
\hline mar-06 & 5.34 & 0.11 & $2.6 \%$ & 3.61 & 0.17 & $13.7 \%$ & 5.34 & 0.10 & $2.3 \%$ & 3.62 & 0.15 & $12.3 \%$ & 5.34 & 0.11 & $2.8 \%$ & 3.61 & 0.17 & $4.7 \%$ \\
\hline jun-06 & 5.91 & 0.12 & $3.3 \%$ & 3.96 & 0.19 & $17.7 \%$ & 5.91 & 0.11 & $2.8 \%$ & 3.98 & 0.17 & $15.2 \%$ & 5.91 & 0.10 & $2.4 \%$ & 3.99 & 0.15 & $12.9 \%$ \\
\hline set-06 & 6.84 & 0.09 & $2.1 \%$ & 4.78 & 0.14 & $11.0 \%$ & 6.84 & 0.11 & $2.8 \%$ & 4.76 & 0.16 & $14.6 \%$ & 6.84 & 0.10 & $2.5 \%$ & 4.77 & 0.15 & $12.9 \%$ \\
\hline dez-06 & 8.36 & 0.09 & $1.8 \%$ & 6.15 & 0.13 & $9.0 \%$ & 8.36 & 0.10 & $2.0 \%$ & 6.15 & 0.14 & $10.2 \%$ & 8.36 & 0.12 & $2.7 \%$ & 6.13 & 0.16 & $13.4 \%$ \\
\hline mar-07 & 8.27 & 0.11 & $2.5 \%$ & 6.05 & 0.15 & $12.7 \%$ & 8.27 & 0.10 & $2.2 \%$ & 6.06 & 0.14 & $11.3 \%$ & 8.27 & 0.11 & $2.7 \%$ & 6.04 & 0.16 & $13.4 \%$ \\
\hline jun-07 & 9.43 & 0.11 & $2.3 \%$ & 7.24 & 0.15 & $11.0 \%$ & 9.43 & 0.12 & $2.6 \%$ & 7.24 & 0.16 & $12.5 \%$ & 9.43 & 0.11 & $2.4 \%$ & 7.24 & 0.15 & $11.6 \%$ \\
\hline set-07 & 10.24 & 0.13 & $2.8 \%$ & 8.05 & 0.17 & $13.3 \%$ & 10.24 & 0.12 & $2.6 \%$ & 8.06 & 0.16 & $12.2 \%$ & 10.24 & 0.12 & $2.6 \%$ & 8.05 & 0.16 & $12.3 \%$ \\
\hline dez-07 & 10.47 & 0.13 & $2.9 \%$ & 8.18 & 0.17 & $13.4 \%$ & 10.47 & 0.13 & $2.8 \%$ & 8.18 & 0.17 & $13.3 \%$ & 10.47 & 0.12 & $2.8 \%$ & 8.18 & 0.16 & $12.9 \%$ \\
\hline mar-08 & 10.14 & 0.12 & $2.7 \%$ & 7.83 & 0.16 & $12.7 \%$ & 10.14 & 0.12 & $2.7 \%$ & 7.83 & 0.16 & $12.7 \%$ & 10.14 & 0.12 & $2.6 \%$ & 7.84 & 0.15 & $12.4 \%$ \\
\hline jun-08 & 9.81 & 0.11 & $2.1 \%$ & 7.46 & 0.14 & $10.5 \%$ & 9.81 & 0.11 & $2.4 \%$ & 7.45 & 0.15 & $11.4 \%$ & 9.81 & 0.12 & $2.6 \%$ & 7.45 & 0.16 & $12.4 \%$ \\
\hline set-08 & 9.13 & 0.14 & $4.8 \%$ & 5.92 & 0.25 & $27.7 \%$ & 9.13 & 0.11 & $3.2 \%$ & 6.15 & 0.18 & $17.8 \%$ & 9.13 & 0.10 & $2.6 \%$ & 6.21 & 0.15 & $14.5 \%$ \\
\hline dez-08 & 9.68 & 0.16 & $7.8 \%$ & 4.58 & 0.44 & $55.5 \%$ & 9.73 & 0.13 & $5.5 \%$ & 5.34 & 0.31 & $40.1 \%$ & 9.76 & 0.09 & $3.4 \%$ & 6.00 & 0.19 & $23.3 \%$ \\
\hline mar-09 & 9.59 & 0.09 & $3.3 \%$ & 6.20 & 0.18 & $23.4 \%$ & 9.56 & 0.12 & $5.2 \%$ & 5.46 & 0.29 & $39.6 \%$ & 9.58 & 0.09 & $3.6 \%$ & 6.11 & 0.19 & $5.5 \%$ \\
\hline jun-09 & 9.75 & 0.11 & $3.9 \%$ & 7.10 & 0.19 & $22.0 \%$ & 9.74 & 0.12 & $4.2 \%$ & 7.02 & 0.20 & $24.1 \%$ & 9.73 & 0.14 & $5.5 \%$ & 6.65 & 0.26 & $2.9 \%$ \\
\hline set-09 & 10.12 & 0.09 & $2.1 \%$ & 7.91 & 0.12 & $10.5 \%$ & 10.12 & 0.11 & $3.3 \%$ & 7.79 & 0.16 & $16.5 \%$ & 10.10 & 0.16 & $5.7 \%$ & 7.29 & 0.26 & $1.1 \%$ \\
\hline dez-09 & 10.72 & 0.13 & $3.9 \%$ & 8.27 & 0.18 & $19.4 \%$ & 10.72 & 0.11 & $3.1 \%$ & 8.38 & 0.15 & $15.0 \%$ & 10.72 & 0.13 & $4.2 \%$ & 8.22 & 0.20 & $21.1 \%$ \\
\hline mar-10 & 12.47 & 0.12 & $3.6 \%$ & 9.69 & 0.17 & $17.7 \%$ & 12.47 & 0.12 & $3.7 \%$ & 9.67 & 0.18 & $18.4 \%$ & 12.47 & 0.12 & $3.7 \%$ & 9.67 & 0.18 & $18.3 \%$ \\
\hline jun-10 & 12.03 & 0.15 & $5.1 \%$ & 8.75 & 0.24 & $26.3 \%$ & 12.03 & 0.14 & $4.3 \%$ & 8.90 & 0.21 & $22.2 \%$ & 12.04 & 0.13 & $3.8 \%$ & 8.99 & 0.19 & $19.1 \%$ \\
\hline set-10 & 13.18 & 0.09 & $2.1 \%$ & 9.88 & 0.12 & $10.6 \%$ & 13.18 & 0.12 & $3.6 \%$ & 9.71 & 0.18 & $18.3 \%$ & 13.18 & 0.12 & $3.6 \%$ & 9.71 & 0.18 & $18.6 \%$ \\
\hline dez-10 & 12.92 & 0.08 & $1.5 \%$ & 9.71 & 0.10 & $7.9 \%$ & 12.92 & 0.08 & $1.9 \%$ & 9.70 & 0.11 & $9.5 \%$ & 12.92 & 0.11 & $3.2 \%$ & 9.58 & 0.17 & $16.3 \%$ \\
\hline mar-11 & 12.76 & 0.07 & $1.4 \%$ & 9.39 & 0.10 & $7.5 \%$ & 12.76 & 0.07 & $1.4 \%$ & 9.39 & 0.10 & $7.5 \%$ & 12.76 & 0.10 & $2.6 \%$ & 9.33 & 0.15 & $13.5 \%$ \\
\hline jun-11 & 11.97 & 0.08 & $1.8 \%$ & 8.41 & 0.11 & $10.0 \%$ & 11.97 & 0.07 & $1.5 \%$ & 8.43 & 0.10 & $8.4 \%$ & 11.97 & 0.07 & $1.6 \%$ & 8.43 & 0.10 & $8.9 \%$ \\
\hline set-11 & 12.20 & 0.08 & $2.9 \%$ & 8.03 & 0.16 & $18.5 \%$ & 12.20 & 0.07 & $2.1 \%$ & 8.23 & 0.12 & $12.6 \%$ & 12.20 & 0.06 & $1.5 \%$ & 8.32 & 0.09 & $9.0 \%$ \\
\hline dez-11 & 12.50 & 0.06 & $1.7 \%$ & 8.57 & 0.09 & $10.5 \%$ & 12.50 & 0.06 & $2.0 \%$ & 8.48 & 0.11 & $13.0 \%$ & 12.50 & 0.05 & $1.5 \%$ & 8.61 & 0.08 & $9.1 \%$ \\
\hline mar-12 & 13.31 & 0.06 & $1.6 \%$ & 9.63 & 0.09 & $9.4 \%$ & 13.31 & 0.06 & $1.7 \%$ & 9.60 & 0.09 & $10.2 \%$ & 13.31 & 0.06 & $1.8 \%$ & 9.58 & 0.10 & $10.7 \%$ \\
\hline jun-12 & 13.62 & 0.07 & $2.3 \%$ & 9.95 & 0.12 & $14.4 \%$ & 13.62 & 0.06 & $2.0 \%$ & 10.06 & 0.10 & $12.1 \%$ & 13.62 & 0.06 & $2.0 \%$ & 10.05 & 0.10 & $12.2 \%$ \\
\hline set-12 & 15.87 & 0.10 & $2.7 \%$ & 12.61 & 0.13 & $13.7 \%$ & 15.87 & 0.11 & $3.4 \%$ & 12.44 & 0.16 & $17.7 \%$ & 15.87 & 0.10 & $3.0 \%$ & 12.54 & 0.14 & $15.4 \%$ \\
\hline dez-12 & 18.41 & 0.11 & $2.9 \%$ & 14.97 & 0.14 & $14.2 \%$ & 18.41 & 0.11 & $3.3 \%$ & 14.89 & 0.16 & $16.2 \%$ & 18.41 & 0.11 & $3.4 \%$ & 14.87 & 0.16 & $16.4 \%$ \\
\hline mar-13 & 19.21 & 0.11 & $2.8 \%$ & 15.69 & 0.14 & $13.5 \%$ & 19.21 & 0.11 & $3.0 \%$ & 15.66 & 0.14 & $14.1 \%$ & 19.21 & 0.12 & $3.4 \%$ & 15.56 & 0.16 & \\
\hline
\end{tabular}




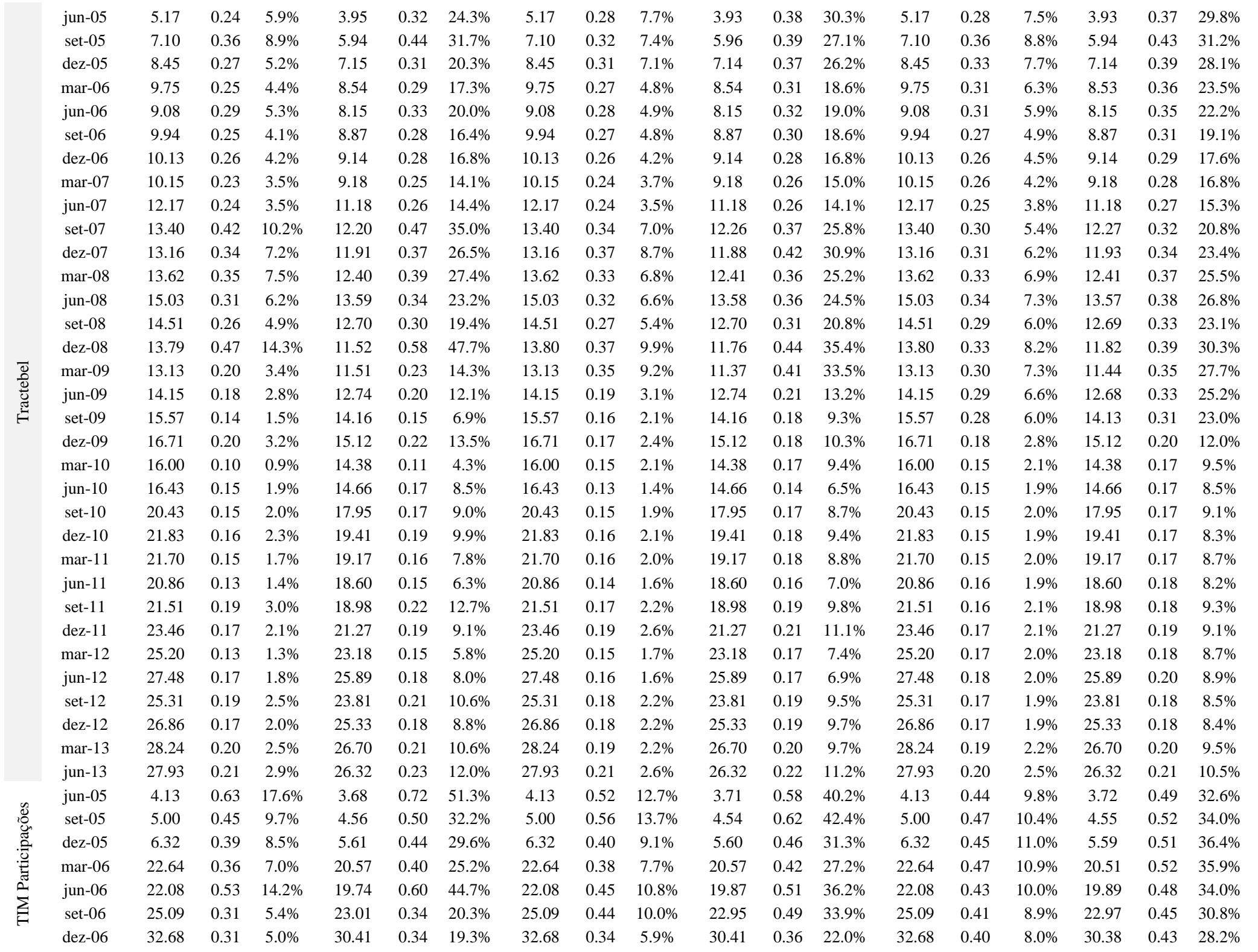




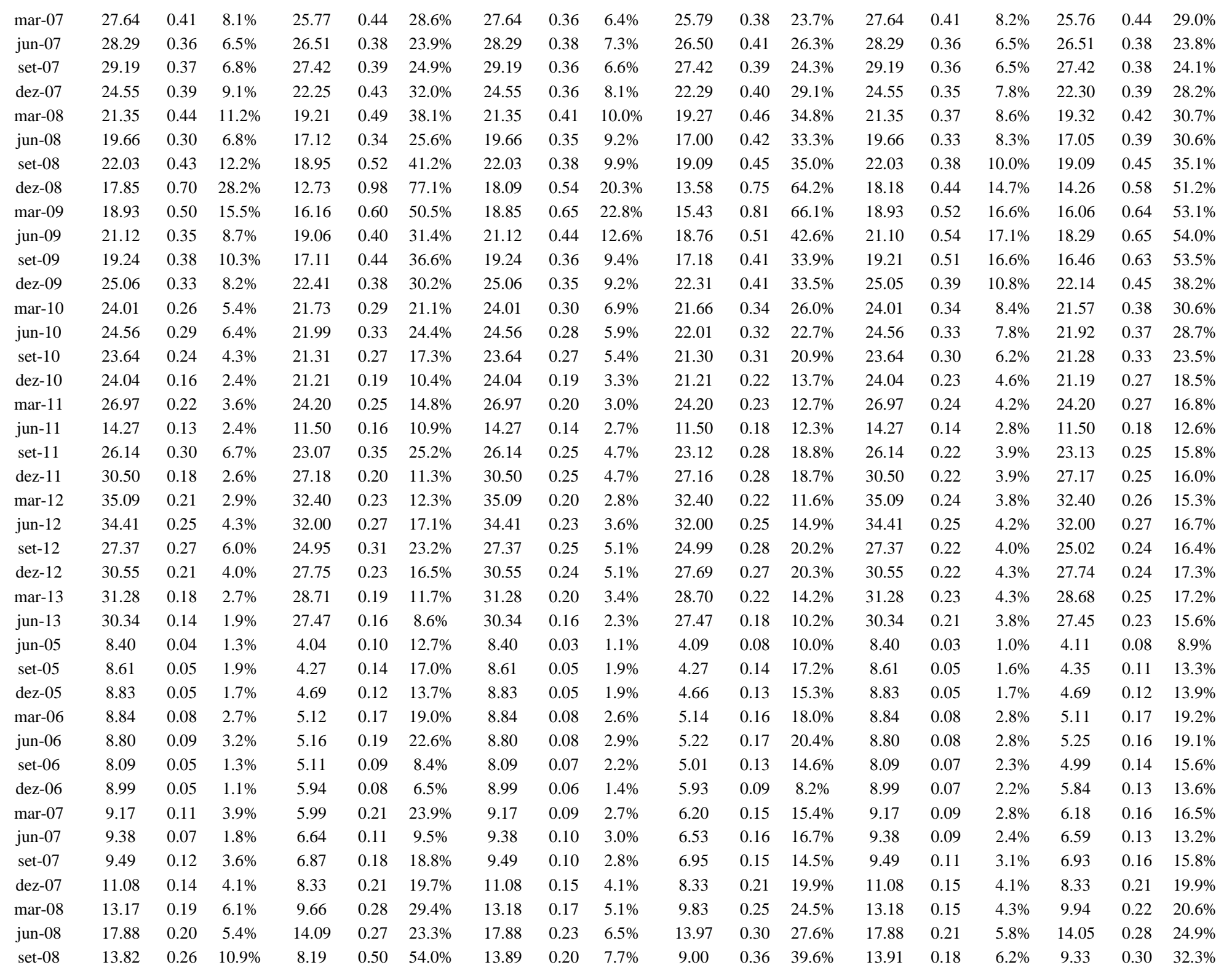




\begin{tabular}{|c|c|c|c|c|c|c|c|c|c|c|c|c|c|c|c|c|c|c|}
\hline dez-08 & 13.47 & 0.26 & $13.8 \%$ & 5.52 & 0.70 & $73.8 \%$ & 13.64 & 0.22 & $10.8 \%$ & 6.30 & 0.56 & $64.0 \%$ & 13.78 & 0.16 & $7.1 \%$ & 7.60 & 0.38 & $45.8 \%$ \\
\hline mar-09 & 14.21 & 0.15 & $5.6 \%$ & 9.33 & 0.28 & $33.2 \%$ & 14.06 & 0.23 & $10.6 \%$ & 7.38 & 0.52 & $60.4 \%$ & 14.16 & 0.18 & $7.9 \%$ & 8.40 & 0.39 & $47.3 \%$ \\
\hline jun-09 & 14.05 & 0.17 & $5.3 \%$ & 10.84 & 0.24 & $25.3 \%$ & 14.04 & 0.19 & $6.3 \%$ & 10.60 & 0.28 & $30.6 \%$ & 13.97 & 0.26 & $10.6 \%$ & 9.42 & 0.46 & $50.4 \%$ \\
\hline set-09 & 14.61 & 0.13 & $3.2 \%$ & 11.84 & 0.17 & $14.7 \%$ & 14.61 & 0.15 & $4.3 \%$ & 11.72 & 0.20 & $19.6 \%$ & 14.56 & 0.25 & $9.5 \%$ & 10.55 & 0.41 & $44.0 \%$ \\
\hline dez-09 & 14.63 & 0.13 & $3.0 \%$ & 12.01 & 0.16 & $13.4 \%$ & 14.63 & 0.14 & $3.3 \%$ & 11.99 & 0.17 & $14.8 \%$ & 14.63 & 0.18 & $5.3 \%$ & 11.77 & 0.24 & $23.7 \%$ \\
\hline mar-10 & 16.40 & 0.14 & $3.0 \%$ & 13.66 & 0.17 & $13.3 \%$ & 16.40 & 0.14 & $3.1 \%$ & 13.65 & 0.17 & $13.7 \%$ & 16.40 & 0.17 & $4.3 \%$ & 13.57 & 0.21 & $18.7 \%$ \\
\hline jun-10 & 16.42 & 0.14 & $3.8 \%$ & 12.66 & 0.19 & $17.9 \%$ & 16.42 & 0.12 & $3.2 \%$ & 12.73 & 0.17 & $15.2 \%$ & 16.42 & 0.12 & $3.1 \%$ & 12.73 & 0.17 & $14.9 \%$ \\
\hline set-10 & 22.58 & 0.14 & $2.8 \%$ & 18.42 & 0.17 & $12.8 \%$ & 22.58 & 0.17 & $3.8 \%$ & 18.37 & 0.21 & $16.9 \%$ & 22.58 & 0.16 & $3.6 \%$ & 18.39 & 0.20 & $15.8 \%$ \\
\hline dez-10 & 20.65 & 0.15 & $3.3 \%$ & 16.62 & 0.19 & $14.9 \%$ & 20.65 & 0.14 & $3.1 \%$ & 16.63 & 0.18 & $13.9 \%$ & 20.65 & 0.15 & $3.5 \%$ & 16.61 & 0.19 & $15.6 \%$ \\
\hline mar-11 & 20.86 & 0.18 & $4.4 \%$ & 16.51 & 0.23 & $19.4 \%$ & 20.86 & 0.16 & $3.9 \%$ & 16.55 & 0.21 & $17.2 \%$ & 20.86 & 0.16 & $3.9 \%$ & 16.55 & 0.21 & $17.2 \%$ \\
\hline jun-11 & 18.21 & 0.11 & $2.3 \%$ & 13.71 & 0.14 & $11.3 \%$ & 18.21 & 0.13 & $3.1 \%$ & 13.67 & 0.17 & $14.9 \%$ & 18.21 & 0.12 & $2.8 \%$ & 13.68 & 0.16 & $13.8 \%$ \\
\hline set-11 & 17.40 & 0.16 & $5.7 \%$ & 11.94 & 0.28 & $30.5 \%$ & 17.41 & 0.13 & $3.9 \%$ & 12.44 & 0.20 & $20.3 \%$ & 17.41 & 0.12 & $3.3 \%$ & 12.55 & 0.18 & $17.2 \%$ \\
\hline dez-11 & 17.75 & 0.12 & $3.4 \%$ & 12.96 & 0.17 & $17.8 \%$ & 17.75 & 0.14 & $4.4 \%$ & 12.70 & 0.22 & $23.5 \%$ & 17.75 & 0.12 & $3.5 \%$ & 12.95 & 0.18 & $18.0 \%$ \\
\hline mar-12 & 18.58 & 0.11 & $2.6 \%$ & 14.46 & 0.14 & $12.5 \%$ & 18.58 & 0.12 & $3.2 \%$ & 14.38 & 0.16 & $15.6 \%$ & 18.58 & 0.13 & $3.7 \%$ & 14.29 & 0.18 & $18.0 \%$ \\
\hline jun-12 & 16.60 & 0.07 & $2.1 \%$ & 12.56 & 0.11 & $11.5 \%$ & 16.61 & 0.07 & $2.0 \%$ & 12.59 & 0.10 & $10.8 \%$ & 16.60 & 0.08 & $2.6 \%$ & 12.42 & 0.13 & $14.6 \%$ \\
\hline set-12 & 18.48 & 0.21 & $9.1 \%$ & 11.98 & 0.41 & $49.8 \%$ & 18.56 & 0.17 & $6.3 \%$ & 13.53 & 0.28 & $34.2 \%$ & 18.59 & 0.14 & $4.6 \%$ & 14.36 & 0.21 & $23.8 \%$ \\
\hline dez-12 & 19.52 & 0.16 & $5.3 \%$ & 15.60 & 0.23 & $25.3 \%$ & 19.49 & 0.21 & $7.8 \%$ & 14.56 & 0.33 & $38.4 \%$ & 19.52 & 0.17 & $5.5 \%$ & 15.50 & 0.24 & $26.7 \%$ \\
\hline mar-13 & 17.79 & 0.12 & $3.5 \%$ & 14.45 & 0.17 & $16.9 \%$ & 17.79 & 0.14 & $4.3 \%$ & 14.26 & 0.19 & $20.8 \%$ & 17.78 & 0.16 & $5.5 \%$ & 13.84 & 0.24 & $27.7 \%$ \\
\hline jun-13 & 16.34 & 0.12 & $4.1 \%$ & 12.20 & 0.19 & $23.4 \%$ & 16.35 & 0.10 & $3.4 \%$ & 12.48 & 0.16 & $18.8 \%$ & 16.33 & 0.13 & $4.7 \%$ & 11.91 & 0.22 & $27.6 \%$ \\
\hline jun-05 & 12.86 & 0.17 & $3.8 \%$ & 9.34 & 0.24 & $17.5 \%$ & 12.86 & 0.18 & $4.2 \%$ & 9.33 & 0.26 & $19.0 \%$ & 12.86 & 0.17 & $3.5 \%$ & 9.34 & 0.23 & $16.2 \%$ \\
\hline set-05 & 14.51 & 0.14 & $3.1 \%$ & 10.04 & 0.20 & $15.1 \%$ & 14.51 & 0.15 & $3.3 \%$ & 10.04 & 0.21 & $16.0 \%$ & 14.51 & 0.14 & $3.1 \%$ & 10.04 & 0.21 & $15.4 \%$ \\
\hline dez-05 & 14.13 & 0.12 & $2.1 \%$ & 10.43 & 0.16 & $10.0 \%$ & 14.13 & 0.14 & $2.8 \%$ & 10.43 & 0.19 & $13.0 \%$ & 14.13 & 0.16 & $3.5 \%$ & 10.42 & 0.22 & $16.0 \%$ \\
\hline mar-06 & 14.43 & 0.16 & $2.9 \%$ & 11.26 & 0.20 & $13.0 \%$ & 14.43 & 0.15 & $2.5 \%$ & 11.26 & 0.19 & $11.6 \%$ & 14.43 & 0.17 & $3.2 \%$ & 11.25 & 0.21 & $14.2 \%$ \\
\hline jun-06 & 13.87 & 0.19 & $4.2 \%$ & 10.83 & 0.24 & $18.1 \%$ & 13.87 & 0.17 & $3.5 \%$ & 10.84 & 0.22 & $15.5 \%$ & 13.87 & 0.16 & $3.1 \%$ & 10.85 & 0.21 & $14.2 \%$ \\
\hline set-06 & 14.70 & 0.15 & $2.8 \%$ & 11.70 & 0.19 & $12.8 \%$ & 14.70 & 0.17 & $3.5 \%$ & 11.69 & 0.22 & $15.4 \%$ & 14.70 & 0.16 & $3.0 \%$ & 11.70 & 0.20 & $13.7 \%$ \\
\hline dez-06 & 16.07 & 0.13 & $1.7 \%$ & 13.37 & 0.15 & $8.0 \%$ & 16.07 & 0.15 & $2.4 \%$ & 13.37 & 0.18 & $10.8 \%$ & 16.07 & 0.17 & $3.0 \%$ & 13.36 & 0.21 & $13.2 \%$ \\
\hline mar-07 & 15.86 & 0.16 & $2.7 \%$ & 13.15 & 0.19 & $11.9 \%$ & 15.86 & 0.14 & $2.2 \%$ & 13.15 & 0.17 & $9.9 \%$ & 15.86 & 0.17 & $3.1 \%$ & 13.15 & 0.20 & $13.4 \%$ \\
\hline jun-07 & 17.25 & 0.17 & $2.5 \%$ & 14.99 & 0.19 & $10.8 \%$ & 17.25 & 0.17 & $2.7 \%$ & 14.98 & 0.20 & $11.5 \%$ & 17.25 & 0.17 & $2.6 \%$ & 14.99 & 0.20 & $11.1 \%$ \\
\hline set-07 & 17.05 & 0.27 & $6.5 \%$ & 14.70 & 0.32 & $25.1 \%$ & 17.05 & 0.22 & $4.6 \%$ & 14.76 & 0.26 & $18.5 \%$ & 17.05 & 0.19 & $3.4 \%$ & 14.78 & 0.22 & $14.4 \%$ \\
\hline dez-07 & 16.74 & 0.17 & $3.4 \%$ & 13.83 & 0.20 & $14.9 \%$ & 16.74 & 0.20 & $4.6 \%$ & 13.78 & 0.24 & $19.6 \%$ & 16.74 & 0.17 & $3.6 \%$ & 13.82 & 0.21 & $15.5 \%$ \\
\hline mar-08 & 16.14 & 0.21 & $4.8 \%$ & 13.43 & 0.25 & $19.9 \%$ & 16.14 & 0.19 & $4.1 \%$ & 13.46 & 0.23 & $17.5 \%$ & 16.14 & 0.19 & $4.2 \%$ & 13.45 & 0.24 & $17.9 \%$ \\
\hline jun-08 & 15.96 & 0.18 & $3.5 \%$ & 13.32 & 0.22 & $15.0 \%$ & 15.96 & 0.20 & $4.2 \%$ & 13.31 & 0.24 & $17.6 \%$ & 15.96 & 0.21 & $4.5 \%$ & 13.30 & 0.25 & $18.8 \%$ \\
\hline set-08 & 16.12 & 0.24 & $5.8 \%$ & 13.09 & 0.30 & $23.6 \%$ & 16.12 & 0.21 & $4.5 \%$ & 13.13 & 0.26 & $19.0 \%$ & 16.12 & 0.20 & $4.4 \%$ & 13.13 & 0.25 & $18.7 \%$ \\
\hline dez-08 & 18.40 & 0.29 & $8.5 \%$ & 14.39 & 0.38 & $34.0 \%$ & 18.40 & 0.25 & $6.7 \%$ & 14.57 & 0.32 & $27.6 \%$ & 18.40 & 0.22 & $5.4 \%$ & 14.66 & 0.28 & $22.7 \%$ \\
\hline mar-09 & 18.95 & 0.16 & $3.0 \%$ & 15.96 & 0.20 & $13.2 \%$ & 18.95 & 0.25 & $6.3 \%$ & 15.83 & 0.30 & $25.2 \%$ & 18.95 & 0.22 & $5.2 \%$ & 15.90 & 0.27 & $21.2 \%$ \\
\hline jun-09 & 17.46 & 0.12 & $1.7 \%$ & 15.18 & 0.14 & $7.9 \%$ & 17.46 & 0.15 & $2.4 \%$ & 15.17 & 0.17 & $10.6 \%$ & 17.46 & 0.21 & $4.8 \%$ & 15.12 & 0.25 & $19.6 \%$ \\
\hline
\end{tabular}




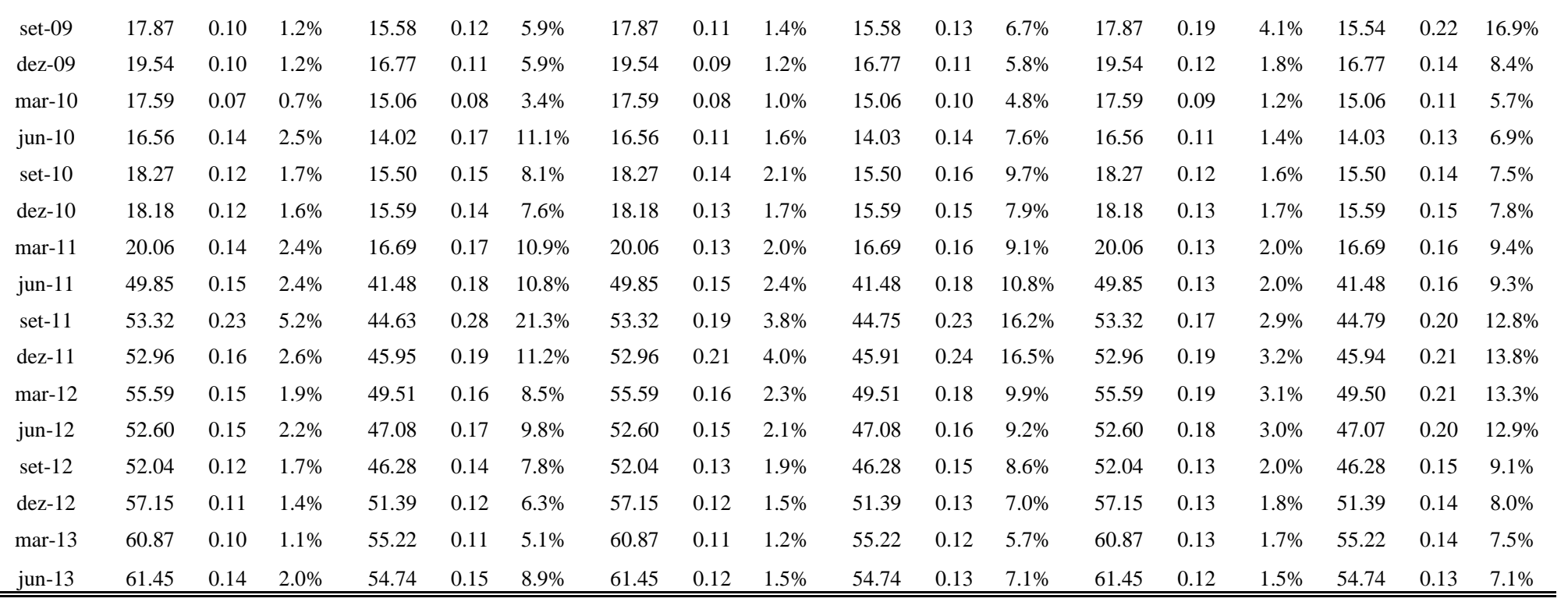

